\title{
FIRE RISK ANALYSIS OF COMBUSTIBLE AND NON-COMBUSTIBLE MID-RISE \\ RESIDENTIAL BUILDINGS USING CURISK
}

\author{
A thesis submitted to \\ the Faculty of Graduate and Postdoctoral Affairs \\ in Partial Fulfillment of the requirements for the degree \\ Master of Applied Science in Civil Engineering \\ by
}

Ping Rao
Department of Civil and Environmental Engineering Carleton University

Ottawa-Carleton Institute of Civil and Environmental Engineering

May, 2014

(C)2014 Ping Rao 


\begin{abstract}
Life safety and property protection are the two main objectives of a performance-based design. At Carleton University in Canada, a quantitative fire risk analysis computer model CUrisk is being developed to evaluate the fire risk levels in mid-rise buildings. By using this model, this thesis evaluated the fire safety in multi-storey buildings with different building construction materials, heights and floor areas.
\end{abstract}

The CUrisk Evacuation submodel is compared with other methods including the Pathfinder models and the Society of Fire Protection Engineers (SFPE) analytical calculations. Case studies were performed by applying these models to different building design conditions and the results were compared. The comparisons showed that the CUrisk Evacuation submodel produce results comparable to those of the other models.

CUrisk was applied to evaluate the fire risk level in buildings of non-combustible frame and combustible frame. Fire development in concrete, unprotected CLT, protected CLT and light-frame timber were compared and the performance of different fire protection systems was evaluated. Finally, the fire risks in buildings with higher building height or larger building area were compared. The results of this study show that CUrisk is an effective model to assess fire risks in multi-storey buildings. 


\section{Acknowledgements}

I would like take this opportunity to thank a number of people who have been supporting and giving me invaluable guidance throughout this research project, without which I would not have completed the thesis.

Foremost, I would like to express my deepest gratitude to my supervisor Professor George Hadjisophocleous for giving me the opportunity of joining his research group and for his encouragement, guidance and support throughout the writing of my thesis.

I also deeply appreciate Dr. Xia Zhang and Ph.D. candidate Xiao Li for their valuable help on my thesis. Their kindly guidance helped me better understand and use the CUrisk model.

I wish to thank Prof. Jim Mehaffey and Prof. Ehab Zalok for their lectures and advice throughout their courses.

I am also grateful to my colleagues for their wonderful support and assistance throughout the two years.

Finally, and most importantly, I have to thank my parents, my sister and all my family members. They constantly provide me with encouragement and motivation for my work. I love them forever. 


\section{Table of Contents}

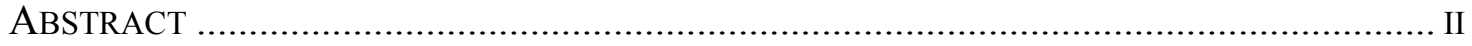

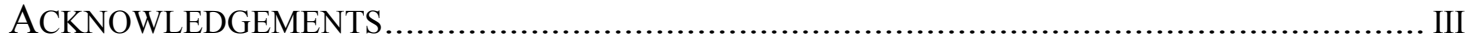

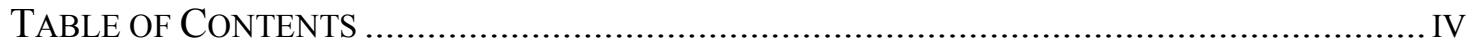

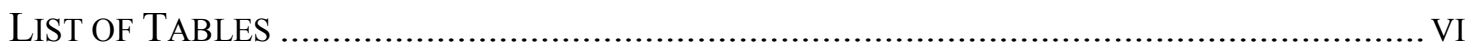

LIST OF FIGURES ..................................................................................... VIII

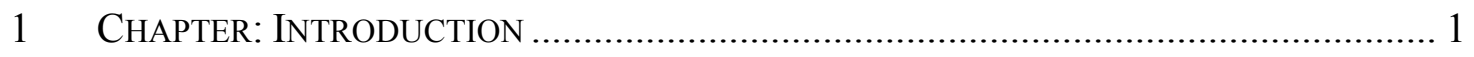

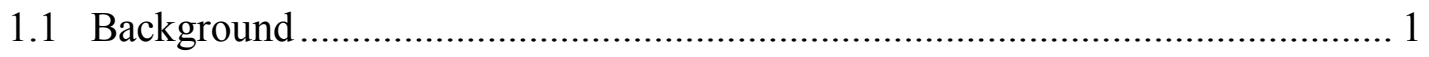

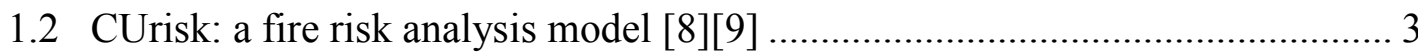

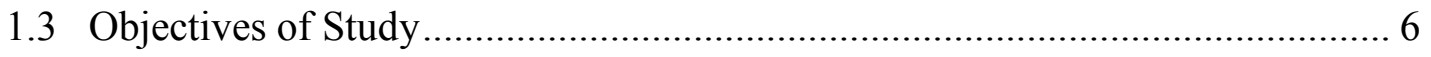

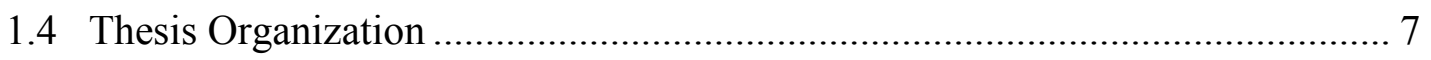

2 CHAPTER: LiTERATURE REVIEW ................................................................. 9

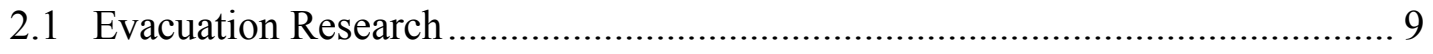

2.2 Building Design in Mid-Rise Building .................................................... 35

2.3 Fire Safety in Timber Construction .......................................................... 54

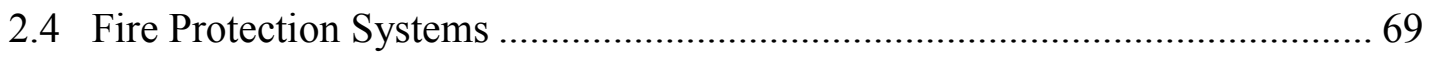

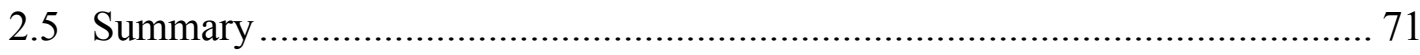

3 Chapter: Comparisons of CURisk Evacuation Model Results .................. 73

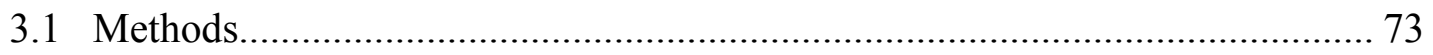

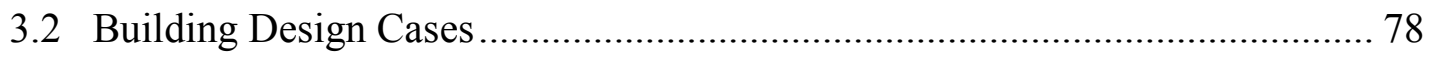




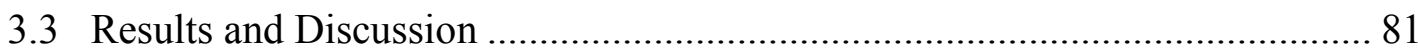

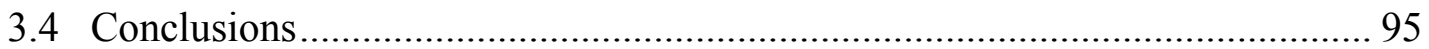

4 ChAPTER: Fire Risk ANALYSiS FOR MUlti-StOREy APARTMENT BUILDINGS..... 97

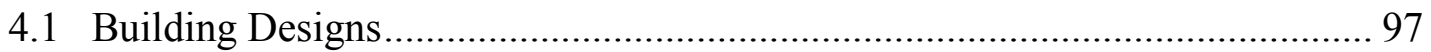

4.2 Events in the Fire Event Tree...................................................................... 99

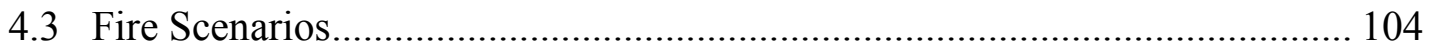

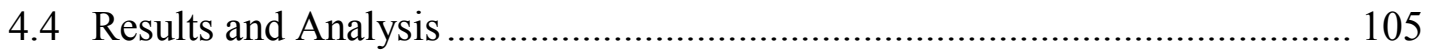

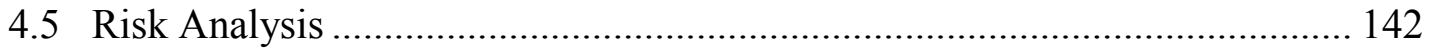

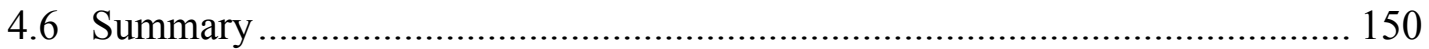

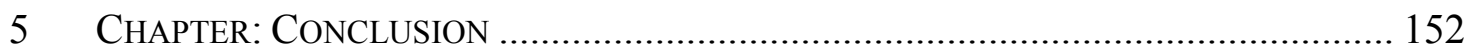

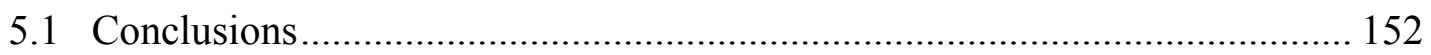

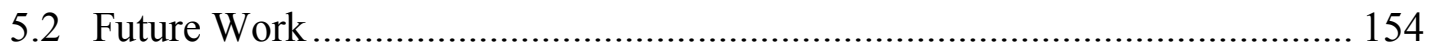

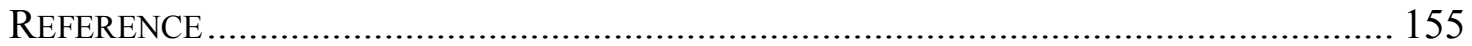




\section{List of Tables}

Table 2.1 Walking speed according to influencing factors[18] ................................ 11

Table 2.2 Walking speed for disabled occupants[18] ........................................... 12

Table 2.3 Walking speeds on stairs in terms of stair characteristics [18] ................ 12

Table 2.4 Walking speeds on stair according to occupant [18] ................................ 13

Table 2.5 Estimated delay time to start evacuation in minutes [22] ....................... 27

Table 2.6 Maximum number of storeys for multi-storey wood-frame buildings under building codes in selected countries [65].................................................... 38

Table 2.7 Maximum allowable heights [68] .......................................................... 42

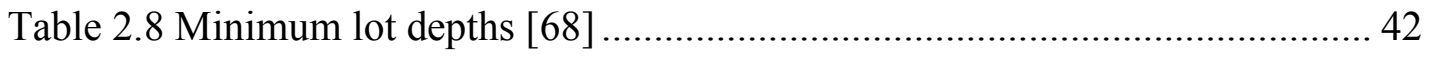

Table 2.9 Allowable building height, number of stories and proportionate floor areas

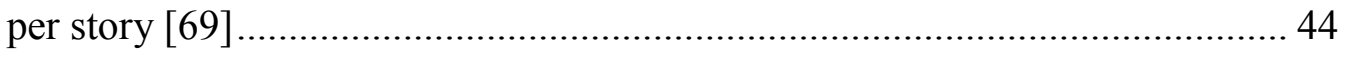

Table 2.10 Maximum building area, up to 6 storeys non-combustible construction

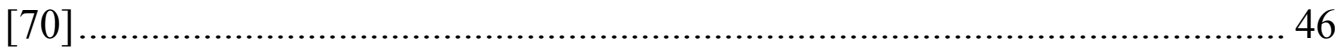

Table 2.11 Maximum building area, up to 3 storeys [70]...................................... 47

Table 2.12 Building requirement for residential buildings [70] .............................. 48

Table 2.13 Building requirement of mercantile buildings [70] .............................. 49

Table 2.14 Occupant load in Canada Building Code [70] ....................................... 50

Table 2.15 Overview of the full-scale tests performed under natural fire conditions

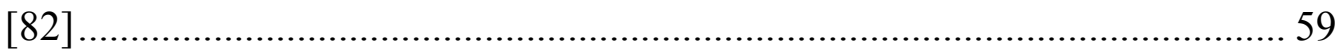




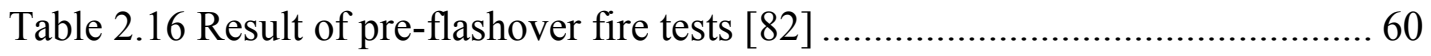

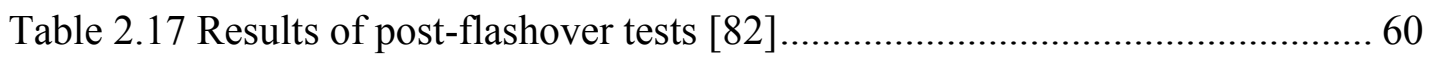

Table 2.18 Minimum requirements for fire resistance rating in residential and

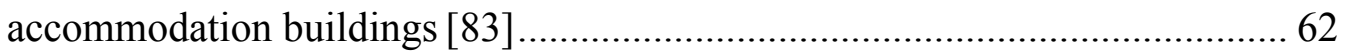

Table 2.19 Summary of light timber and heavy timber frame construction [85] ..... 64

Table 2.20 Design charring rates $\beta_{0}$ and $\beta_{\mathrm{n}}$ of timber, LVL, wood paneling and

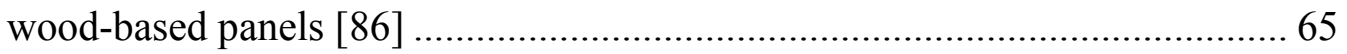

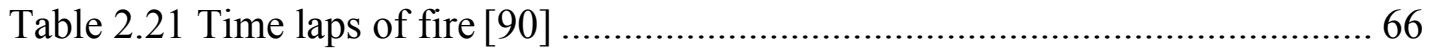

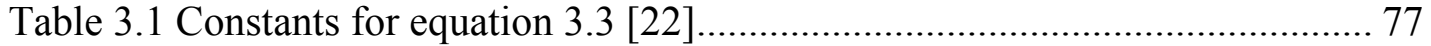

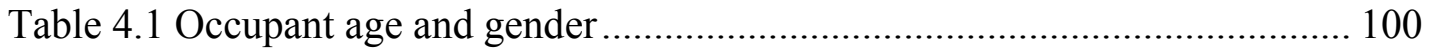

Table 4.2 Thresholds of injury and death ................................................... 101

Table 4.3 The reliabilities of fire protection systems in this study...................... 103

Table 4.4 Fire department response option....................................................... 104

Table 4.5 Design parameters of five scenarios ..................................................... 106

Table 4.6 Values of ERL in different design options (person/year) ..................... 147

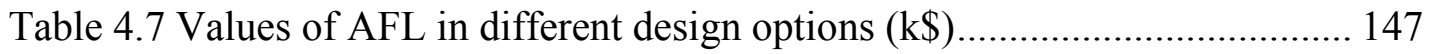




\section{List of Figures}

Figure 1.1 Number of fires and injuries between 2008 and 2012 [1] ...................... 2

Figure 1.2 A schematic of the fire risk analysis model CUrisk [8] ......................... 6

Figure 2.1 Uni-directional walking speed as a function of density, redrawn from Ando [21] 15

Figure 2.2 Relation between speed and density on stairs in uncontrolled total evacuations (Dashed line from Fruin) [22] 16

Figure 2.3 Relation between flow and density on stairs in uncontrolled total evacuations [22] 17

Figure 2.4 Clogging near a bottleneck [35] 19

Figure 2.5 Pedestrian flow experiment through a bottleneck under normal conditions 20

Figure 2.6 Lane formation in a street [35] 21

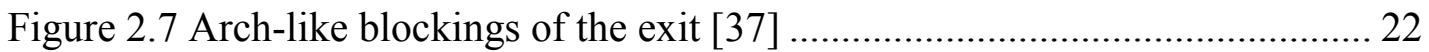

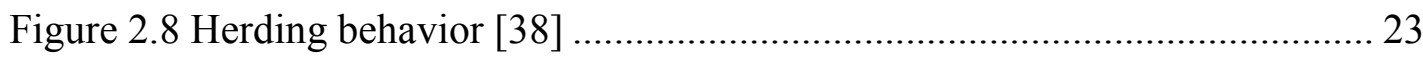

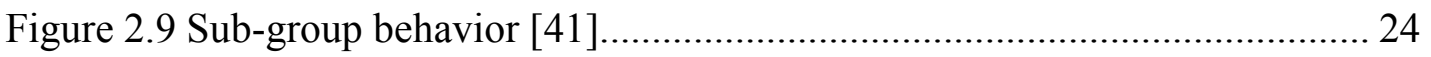

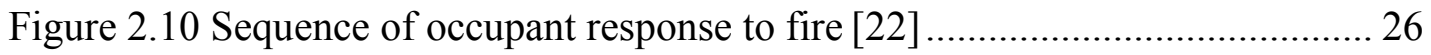

Figure 2.11 Measurement of effective stair width in relation to walls and handrails 30

Figure 2.12 The four main interacting aspects to be considered in the optical design 
Figure 2.13 Eollis Building, in BC during construction [64] .............................. 37

Figure 2.14 Building area required in $\mathrm{BC}$ code [67] ......................................... 45

Figure 2.15 Building area comparison [67] ..................................................... 46

Figure 2.16 Two main fire stages that are relevant for the fire safety in buildings [76]

Figure 2.17 Six-storey timber frame building and the floor plan [81].... 58

Figure 2.18 Fire development 7 mins after fire ignition; left: lower module wit combustible linings (fire test BÜ bb), right: lower module with non-combustible linings (fire test BÜ nbb) [82] 61

Figure 2.19 Fire development after about 32 minutes (left) and after 40 minutes (right) after fire ignition [91] 69

Figure 3.1 Plans of the second floor of the three layouts..................................... 80

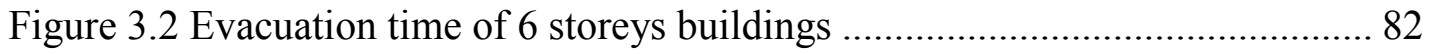

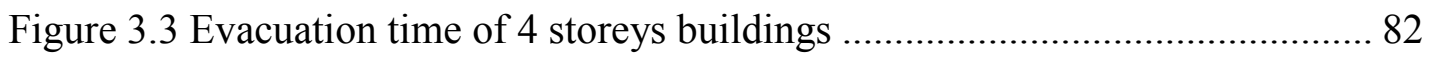

Figure 3.4 The probability density distributions of the total evacuation times in different layouts 85

Figure 3.5 Cumulative probability curves in 6 and 4 storeys building evacuation... 88

Figure 3.6 Evacuation time at different building heights 90

Figure 3.7 Remaining percentages in different building heights 92 
Figure 3.8 The effect of building layout on evacuation time

Figure 4.1 Different design alternatives for mid-rise apartment buildings................ 98

Figure 4.2 The floor plan of the first floor.......................................................... 99

Figure 4.3 The floor plan of the second floor ....................................................... 99

Figure 4.4 The scenario structure for each building design proposal ..................... 105

Figure 4.5 HRR vs. time in the fire room of scenarios No.12, No.14 and No.16... 107

Figure 4.6 Upper layer temperatures vs. time in the fire room of scenarios No.12, No.14 and No.16. 108

Figure 4.7 Upper layer $\mathrm{O}_{2}$ concentrations vs. time in the fire room of scenarios No.12, No.14 and No.16 109

Figure 4.8 Upper layer of $\mathrm{CO}_{2}$ concentration vs. time in the fire room of scenarios No.12, No.14 and No.16 111

Figure 4.9 Upper layer $\mathrm{CO}$ concentrations vs. time in the fire room of scenarios No.12, No.14 and No.16 112

Figure 4.10 Upper layer smoke soot concentrations vs. time in the fire room of scenarios No.12, No.14 and No.16 112

Figure 4.11 Smoke layer interface heights vs. time in the fire room of scenarios No.12, No.14 and No.16 113

Figure 4.12 Probability of evacuation initiation in scenario No.15 and No.16 in the six-storey buildings . 115 
Figure 4.13 Average remaining percentages in scenario No.15 and No.16 in

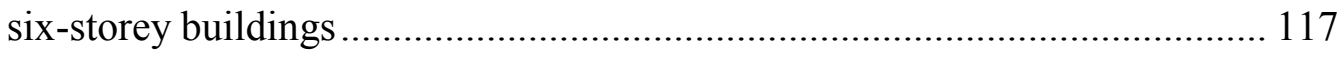

Figure 4.14 Upper layer temperature and radiation vs. time of scenarios No.16 in the corridor of the first floor 117

Figure 4.15 Damages to each compartment of the protected CLT building of scenario No.16

Figure 4.16 Direct damages to the four different buildings of four scenarios (No.9, No.12, No.14 and No.16) 120

Figure 4.17 Deaths and injuries of four different buildings of four scenarios (No.9, No.12, No.14 and No.16) 122

Figure 4.18 Probabilities of death and fire spread of scenario No.16 in the unprotected CLT building 123

Figure 4.19 Probability distribution of deaths produced by Mont Carlo simulation for scenario No.16. 124

Figure 4.20 Probability distribution of injuries produced by Mont Carlo simulation of scenario No.12 125

Figure 4.21 Upper layer temperatures in stair shafts of second and fourth floors vs. time of scenario No.16 in light-frame timber buildings 127

Figure 4.22 Smoke CO concentrations in stair shafts of second and fourth floors vs. time of scenario No.16 in light-frame timber buildings 128 
Figure 4.23 Probability of evacuation of scenario No.16 in light-frame buildings 129

Figure 4.24 The direct damage to each compartment of the 4-storey light-frame building for scenario No.16. 130

Figure 4.25 The direct damage to each compartment of the 12-storey light-frame building for scenario No.16 131

Figure 4.27 Fire losses of buildings with different heights 132

Figure 4.28 The number of deaths and injuries for four scenarios 133

Figure 4.28 Upper layer temperatures in the $1^{\text {st }}$ corridor vs. time of scenarios No.16 in buildings with different floor areas and construction materials 136

Figure 4.29 Upper CO concentrations in the $1^{\text {st }}$ corridor vs. time of scenarios No.16 in buildings with different floor areas and construction materials 137

Figure 4.30 Probability of evacuation in large unprotected CLT buildings for scenarios No.15 and No.16 138

Figure 4.31 Remaining percentage in unprotected buildings for scenario No.15 and No.16 139

Figure 4.32 The number of deaths and injuries for the large 6-storey building in four scenarios 140

Figure 4.33 Probability of death and evacuation route for occupants 142

Figure 4.34 Expected fire losses in buildings with different heights and construction materials 143 
Figure 4.35 Expected fire losses in buildings with different floor sizes and

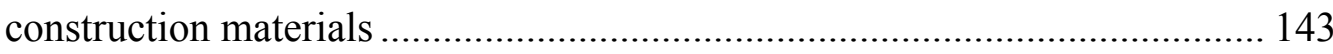

Figure 4.36 Expected number of deaths in buildings with different heights and construction materials 144

Figure 4.37 Expected number of deaths in buildings with different floor areas and construction materials 145

Figure 4.38 Expected number of injuries in buildings with different floor areas and construction materials 145

Figure 4.39 Relative FCE of sixteen building design options 148

Figure 4.40 Relative ERL of sixteen building design options 


\section{Chapter: Introduction}

\subsection{Background}

Building fires threaten public safety and cause great losses to all nations. The two main objectives of building codes or of performance-based designs are: 1) to ensure safe evacuation of occupants; 2) to prevent damages to property, contents and operations. Generally, occupant evacuation relies on fire detection systems (smoke and heat detectors and alarms), fire suppression systems (sprinklers and the fire department) and fire-rated assemblies that limit fire spread. In a performance-based design, life safety can be achieved when the available safe egress time (ASET) is greater than the required safe egress time (RSET). Fire loss is related to the construction type, the spread of fire and smoke and fire resistance rating of the building components.

Each year, fires in buildings cause huge economic losses to property and large numbers of deaths and injuries. According to the data offered by Fire Marshal and Emergency Management office (OFMEM), in Ontario from 2008 to 2012, there were 61,742 fires

with losses [1]. $46 \%$ of these fires occurred in residential occupancies. Figure 1.1 shows residential fire statistics. Civilian fire injures varied slightly during these four years. Residential fires decreased from 5,837 to 5,441 and civilian fire injuries were 339 persons in 2008, and 512 in 2012 [1]. A recent tragic fire at a Quebec seniors' home in January 23, 2014 caused 32 deaths [2]. This three storey seniors house was made of combustible material (wood), equipped with fire alarms smoke detectors, but was only 
partially sprinklered.

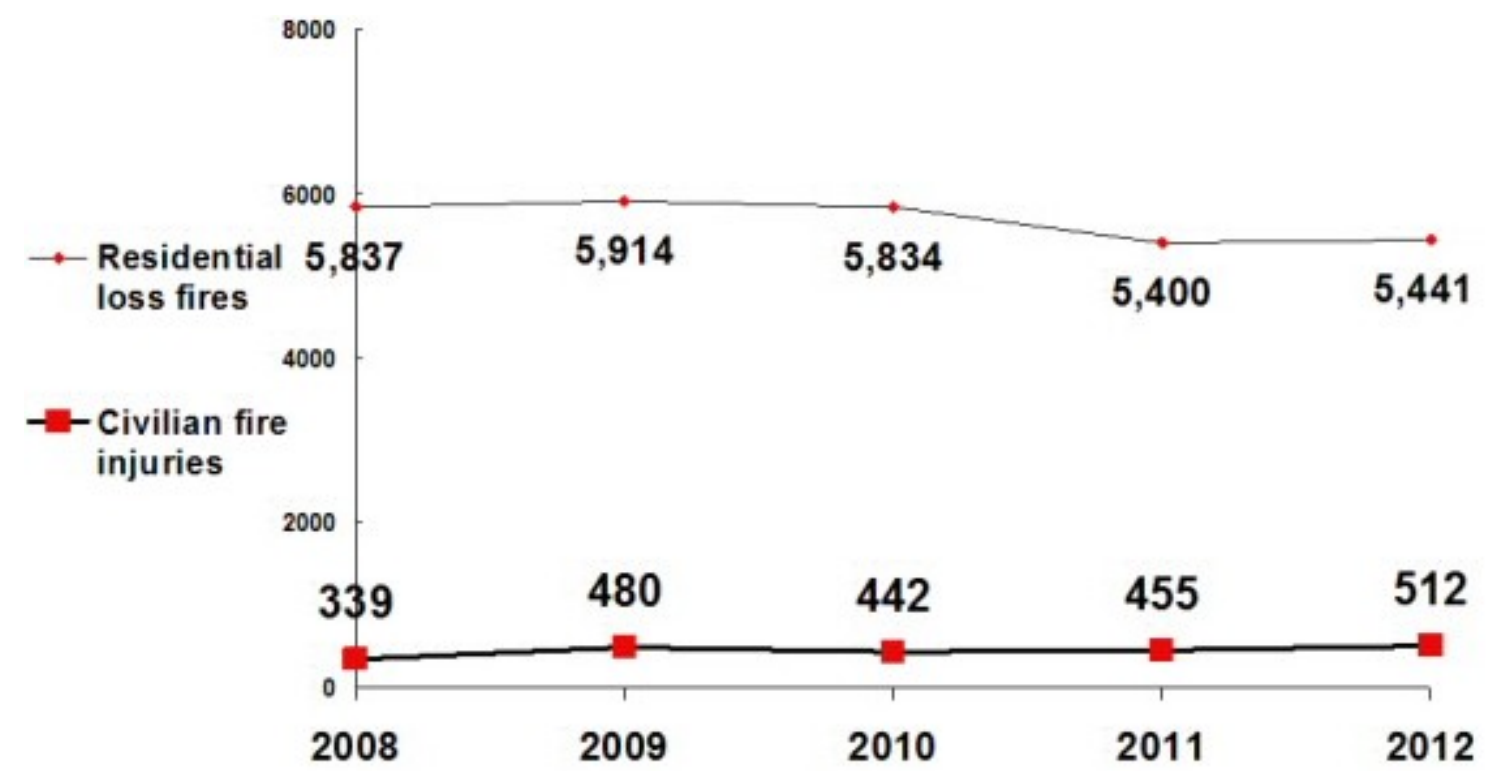

Figure 1.1 Number of fires and injuries between 2008 and 2012 [1]

Performance-based building fire safety design provides the possibility of a wider use of wood as a building material. But wood is a combustible material thus more attention should be given to ensure that the building environment is safe. Statistics [3] suggest that there is a slightly higher rate of injuries for buildings constructed of combustible material, and sprinklers have a major impact on reducing the injuries. Therefore, in order to reduce the casualties and losses of the fire, there is a need to reasonably evaluate the fire safety of the buildings. fire risk assessment is based on a number of factors such as the building fire protection systems to be used, building layout and size, the height of the building, the number of occupants, internal compartmentation, the building cost and so on [4].

In recent years, some fire risk analysis models have been developed to quantify the risk to the occupants and the building including CESARE-Risk [5], FiRECAM and 
FIERAsystem (Fire Evaluation and Risk Assessment system) [6], CRISP (Computation of Risk Indices by Simulation Procedures) [7]. Following the approaches used in FiRECAM and FIERAsystem, a new fire risk analysis model called CUrisk has been developed at Carleton University in Canada. This model could be used to determine the fire risk of timber-framed buildings as well as hybrid construction.

\subsection{CUrisk: a fire risk analysis model [8][9]}

CUrisk model is composed of a system model and sixteen interacting submodels that deal with different aspects of a fire. This model can calculate the expected risk to life as well as the expected fire cost for a building during its lifetime.

As shown in Figure 1.2, CUrisk starts with the generation of fire scenarios. In this model, an event tree method is applied to construct scenario structures. These fire events are linked together by the success or failure probabilities of certain actions or fire protection systems. A fire occurrence is related to many factors including room of fire origin, fire growth, fire load and fuel type, ventilation, fire protection systems, boundary failure and so on. The outputs of the Fire Scenario submodel are used by the Expected Risk to Life, and Fire Cost Expectation submodels.

For each scenario, the fire risk assessment begins from the selection of the design fire. The Design Fire submodel is intended to provide the Fire Growth submodel a nominal description of the design fire including the fire growth rate in t-square fire, the 
composition of the fuel, the heat of combustion of the fuel, ratios of species production and consumption rates, and the nominal maximum heat release rate. Then, the Fire Growth submodel and Smoke Movement submodel calculate the hazardous conditions in the compartment of fire origin and compartments away from the fire origin. The predicted results consist of the heat release rate, the smoke temperature, concentration and optical density, smoke interface height, radiant heat flux, and time to flashover. The Boundary Failure and Fire Spread submodels are used to calculate the probability of fire spread from fire origin to other compartments at different simulation time, and this probability depends on the fire severity and the fire resistance rating of the assemblies. Then, the information of hazardous conditions is used in the Fire Department, Detection, Response and Evacuation submodels. The Fire Department submodel determines the time that firefighters respond to the fire, and it's related on the characteristics of fire department, the location of the fire origin compartment, and the building properties. The Response submodel computes the evacuation probability by calculating the probabilities of occupants perceiving fire signals, receiving fire alarms and taking action. The Evacuation submodel is based on the Monte Carlo method, and can generate distributions of evacuation times. The travel speed is affected by personal characteristics (gender, age, and location), occupant density, and hazard level of the environment (as smoke level factor). 
After that, the Life Hazard submodel is used to calculate the number of injuries and deaths in each fire scenario. The probability of death depends on the degree to which occupants are exposed to toxic gases, hot gases, radiant fluxes and fire spread. The Building Cost submodel includes the capital investment of building components and construction, active and passive fire protection systems, and annual maintenance and inspection costs of the active fire protection systems.

At last, the final two decision-making parameters, the Fire Cost Expectation (FCE) and the Expected Risk to Life (ERL) are obtained. 


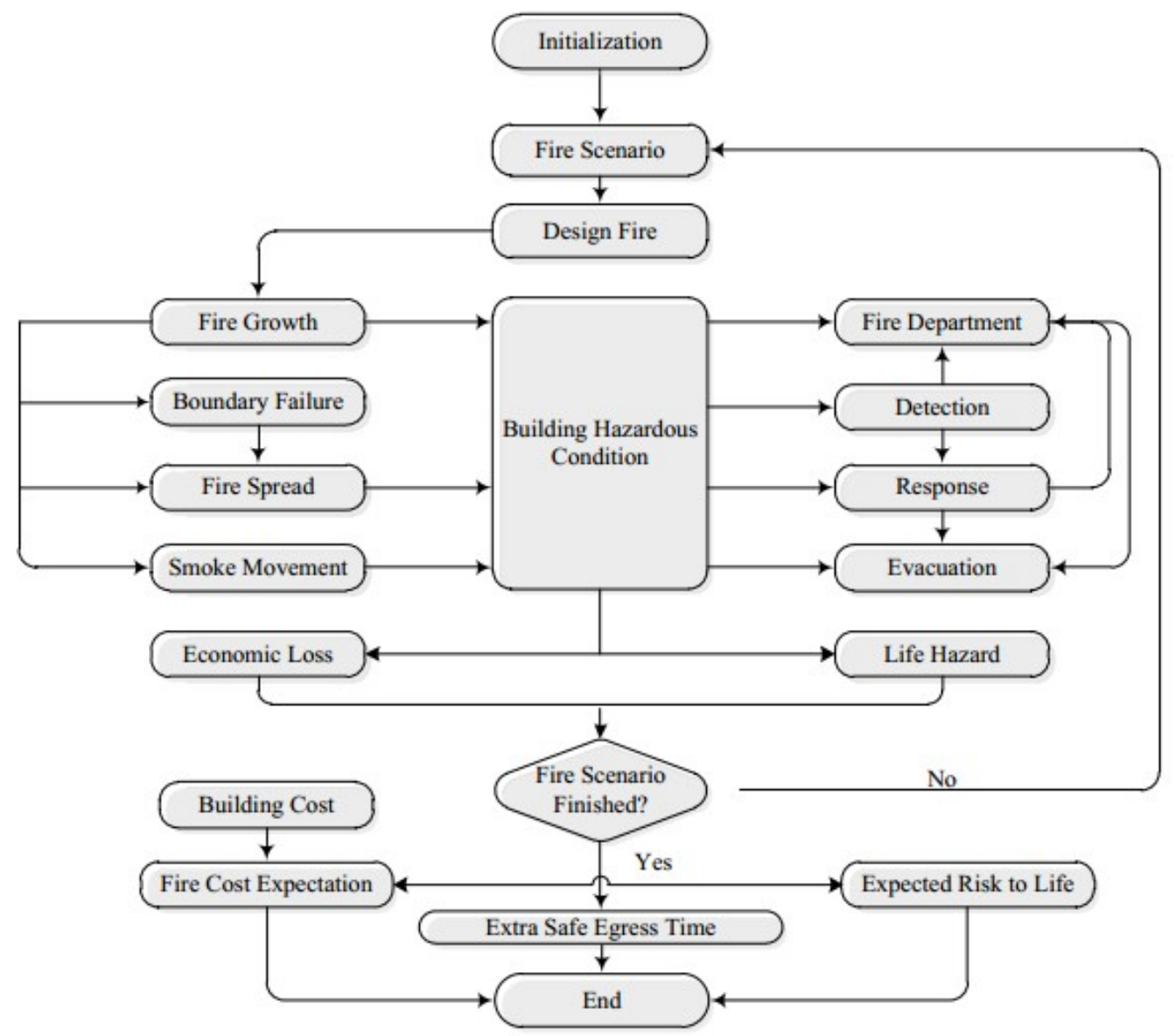

Figure 1.2 A schematic of the fire risk analysis model CUrisk [8]

\subsection{Objectives of Study}

From a fire safety perspective, building codes establish the minimum requirements for the fire safe design of buildings. For combustible buildings, there are limitations to the maximum floor area, maximum heights and number of storeys in different building codes in different countries around the world. This project aims to evaluate and compare the fire safety of mid-rise buildings under different construction types.

The objectives of this research project are as follows:

1. To compare the results generated by CUrisk Evacuation submodel and other 
evacuation models.

2. To investigate how building design conditions affect evacuation efficiency in a fire emergency.

3. To perform a fire risk analysis in a non-combustible building and a comparable combustible building using CUrisk.

4. To evaluate whether building height and building area have an impact on the fire risk.

\subsection{Thesis Organization}

This thesis consists of several chapters and appendices. The main contents of each chapter are listed below:

Chapter 1- "Introduction": this chapter gives a description of the research background, research methodology, research objective, and thesis structure.

Chapter 2- "Literature Review": this review is made from three aspects including human evacuation, timber building construction and fire protection systems.

Chapter 3- "Comparisons of CUrisk Evacuation Submodel and Application to Mid-Rise Building": this chapter compares the Occupant Evacuation submodel with the Pathfinder software and the SFPE analytical calculation. The predicted evacuation times are compared and discussed. The effect of building design (different building heights, floor areas and occupants loads) on evacuation is analyzed.

Chapter 4- "Fire Risk Analysis for Multi-Storey Apartment Building": this chapter 
compares the fire behavior of different construction materials including non-combustible, exposed CLT, protected CLT and light-frame timber. The risk to life and property damages in mid-rise apartment buildings is calculated by CUrisk. The effectiveness of different active fire protection systems in reducing fire risk is evaluated. And the risks in different heights and building area are compared.

Chapter 5- "Conclusion": this chapter presents the conclusions and suggestions for future work. 


\section{Chapter: Literature Review}

The main fire safety objectives in buildings are to provide life safety and property protection. The first objective is to ensure safe and orderly evacuation of the building in the event of fire. Generally, the efficiency of occupant evacuation is affected by factors such as occupant characteristics, environmental conditions, and building types. The latter objective is to reduce fire losses caused by fire. The design of timber-frame buildings should ensure that the fire objectives are achieved and that building design, construction types, fire behavior of different materials and protection systems are considered. As this thesis deals with fire safety of wood buildings, the literature review of this chapter is conducted from three aspects including human evacuation, timber building construction and fire protection systems.

\subsection{Evacuation Research}

The study area of and evacuation is started in the early $20^{\text {th }}$ century in the United States, especially focusing on human behavior in fires [10]. In 1972, Wood made a study on the behavior of people in fires using interview and questionnaire techniques administered by Fire Brigade Offices at the scenes of fires, and the data was collected from nearly1000 fire incidents and more than 2000 people who were involved in them [11]. The results were published as a report "The Behavior of People in Fires". Then, some other scholars such as Sime [12], Breaux [13] in England, Fruin [14] in U.S and Proulx [15] from NRC (National Research Council Canada) performed research on the theory and field 
observation. John Fruin is a prominent researcher and his well-known book "Pedestrian Planning and Design" [14] is a comprehensive reference book on crowd movement which is still cited. The observations in Canada concentrated on people's movement in large assembly occupancy buildings. Generally speaking, the evacuation research is characterized by research focused on the human behavior under emergency situation such as fire, earthquake, evacuation strategy under different building layout, and computer models for evacuation. There are over 30 models developed to study evacuation [16] [17].

\subsubsection{Basic Parameters of Evacuation Dynamics}

\subsubsection{Occupant Density}

Density is defined as the number of occupants per unit area (persons $/ \mathrm{m}^{2}$ ) or the average area per person $\left(\mathrm{m}^{2} /\right.$ person). Generally speaking, occupant density affects the total evacuation time as it defines the number of people, the movement speed and the effective width of exits. When the density reaches $0.28 \mathrm{~m}^{2} /$ person, accidents may occur due to crowded conditions. When the density reaches $0.25 \mathrm{~m}^{2} /$ person, stampede may occur because of overcrowding. So, occupant density shall not less than $0.28 \mathrm{~m}^{2} /$ person in order to ensure safe evacuation.

\subsubsection{Movement Speed}

Movement speed is defined as the travelling distance per time step and the unit is generally $\mathrm{m} / \mathrm{s}$. Movement speed is an important parameter used in evacuation models and 
varies with many factors, such as walking types, walking conditions, occupant types and place types. Shi [18] has done a lot of research on this subject. The following tables about movement speed considering different factors come from Shi's research.

Table 2.1 Walking speed according to influencing factors[18]

\begin{tabular}{|c|c|c|c|c|}
\hline Influencing factors & & $\begin{array}{l}\text { Speed } \\
(\mathrm{m} / \mathrm{s})\end{array}$ & $\begin{array}{l}\text { Range } \\
(\mathrm{m} / \mathrm{s})\end{array}$ & References \\
\hline \multirow[t]{2}{*}{$\overline{\text { Walking type }}$} & Free move & & $1.2-1.8$ & [17] \\
\hline & Exit move & & $0.8-1.5$ & \\
\hline \multirow{4}{*}{$\begin{array}{l}\text { Walking conditions for } \\
\text { corridors, doorway on ship }\end{array}$} & Low & 1.4 & & {$[6]$} \\
\hline & Optimum & 0.70 & & \\
\hline & Moderate & 0.39 & & \\
\hline & crush & 0.10 & & \\
\hline \multirow[t]{3}{*}{ Place type } & Public place & & $0.51-1.27$ & [19] \\
\hline & $\begin{array}{l}\text { High-rise } \\
\text { apartment }\end{array}$ & 1.05 & $0.57-1.20$ & \\
\hline & & 0.95 & $0.56-1.12$ & \\
\hline \multirow[t]{7}{*}{ Occupant type ${ }^{a}$} & Children & 1.08 & & {$[18]$} \\
\hline & Female elderly & 1.04 & & \\
\hline & Male elderly & 1.05 & & \\
\hline & Elderly & 1.04 & & \\
\hline & Female adult & 1.24 & & \\
\hline & Male adult & 1.30 & & \\
\hline & Adult & 1.27 & & \\
\hline
\end{tabular}

a The walking speeds according to occupant type are average data. All of these data were take when pedestrian density was less than 0.43 person $/ \mathrm{m}^{2}$. 
Table 2.2 Walking speed for disabled occupants[18]

\begin{tabular}{clll}
\hline Factors & & $\begin{array}{l}\text { Speed } \\
(\mathrm{m} / \mathrm{s})\end{array}$ & $\begin{array}{l}\text { Range } \\
(\mathrm{m} / \mathrm{s})\end{array}$ \\
\hline Wheelchair & Man & 1.06 & \\
& Woman & 1.06 & \\
& & & \\
High-rise & Electric wheelchair & 0.89 & \\
building & Manual wheelchair & 0.69 & \\
& Crutches & 0.94 & \\
& Walking stick & 0.81 & \\
& No disability & 1.24 & \\
Disabled & All disabled subjects & & \\
subjects & With locomotion & 1.00 & $0.10-1.77$ \\
& No aid & 0.80 & $0.10-1.68$ \\
& Crutches & 0.95 & $0.24-1.68$ \\
& Cane & 0.94 & $0.63-1.35$ \\
& Walker/Rollator & 0.81 & $0.26-1.60$ \\
& Without locomotion disability & 0.57 & $0.10-1.02$ \\
& Unassisted wheelchair & 0.89 & $0.82-1.77$ \\
& Assisted ambulant & 0.78 & $0.21-1.40$ \\
& Assisted wheelchair & 1.30 & $0.84-1.98$ \\
\hline
\end{tabular}

Table 2.3 Walking speeds on stairs in terms of stair characteristics [18]

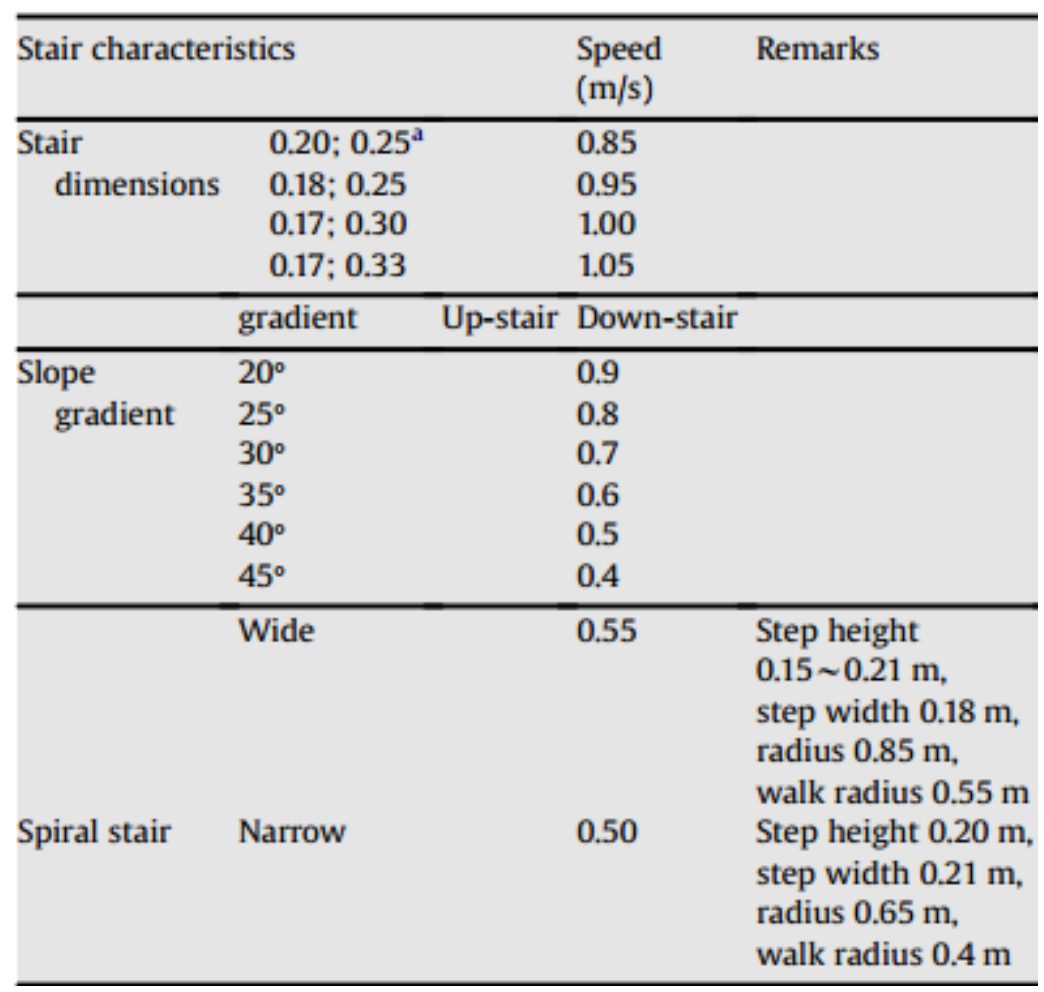


Table 2.4 Walking speeds on stair according to occupant [18]

\begin{tabular}{|c|c|c|c|c|}
\hline \multirow[t]{2}{*}{ Influencing factors } & & & \multicolumn{2}{|c|}{ Speed $(\mathrm{m} / \mathrm{s})$} \\
\hline & & & Up-stairs & Down-stair \\
\hline $\begin{array}{l}\text { Occupant density } \\
\text { (persons } / \mathrm{m}^{-2} \text { ) }\end{array}$ & & $\begin{array}{l}\text { One by one } \\
2.5 \\
2.4 \\
2.2 \\
1.5 \\
1.5 \\
2.0 \\
\text { One by one }\end{array}$ & $\begin{array}{l}0.57 \\
0.76 \\
0.72 \\
0.8\end{array}$ & $\begin{array}{l}1.0 \\
0.88 \\
0.82 \\
0.91\end{array}$ \\
\hline $\begin{array}{l}\text { Conditions for } \\
\text { traveling on ships }\end{array}$ & & $\begin{array}{l}\text { Low } \\
\text { Optimum } \\
\text { Moderate } \\
\text { Crush }\end{array}$ & $\begin{array}{l}0.80 \\
0.40 \\
0.22 \\
0.10\end{array}$ & $\begin{array}{l}1.00 \\
0.50 \\
0.28 \\
0.13\end{array}$ \\
\hline Occupant age & $\begin{array}{l}\text { Male } \\
\text { Female }\end{array}$ & $\begin{array}{l}<30 \\
30-50 \\
>50 \\
<30 \\
30-50 \\
>50\end{array}$ & $\begin{array}{l}0.67 \\
0.63 \\
0.51 \\
0.635 \\
0.59 \\
0.485\end{array}$ & $\begin{array}{l}1.01 \\
0.86 \\
0.67 \\
0.755 \\
0.655 \\
0.595\end{array}$ \\
\hline Occupant type ${ }^{\mathrm{a}}$ & $\begin{array}{l}\text { Children } \\
\text { Female elderly } \\
\text { Male elderly } \\
\text { Elderly } \\
\text { Female adult } \\
\text { Male adult } \\
\text { Adult }\end{array}$ & & $\begin{array}{l}0.29 \\
0.27 \\
0.29 \\
0.28 \\
0.30 \\
0.32 \\
0.31\end{array}$ & $\begin{array}{l}0.31 \\
0.26 \\
0.29 \\
0.28 \\
0.36 \\
0.42 \\
0.38\end{array}$ \\
\hline
\end{tabular}

\subsubsection{Specific Flow}

Specific flow, Fs, is defined as the flow of evacuating persons past a point in the exit route per unit of time per unit of effective width. Specific flow is expressed in persons $/ \mathrm{s} / \mathrm{m}$. In most cases, when the specific flow is larger than 1 persons $/ \mathrm{s} / \mathrm{m}$, people can move freely which is stable flow. In Fruin's 'Pedestrian Planning Design' [14], the most reasonable specific flow ranges are $0.55-1.38$ persons $/(\mathrm{m} . \mathrm{s})$ in horizontal movement, 
0.33-0.87 persons $/(\mathrm{m} . \mathrm{s})$ in upstairs movement and $0.44-0.98$ persons $/(\mathrm{m} . \mathrm{s})$ in downstairs movement.

\subsubsection{Empirical Data}

A number of researchers have examined the affect of occupant density on movement speed such as Predtechenskii and Milinskii [19], Fruin in the U.S [14], Smith in England [20], Ando [21] in Japan and Pauls in Canada [22]. Predtechenskii and Milinskii have conducted influential work concerning merging flows. They developed the following empirical formulas for movement speed based on occupant density:

$V=112 D^{4}-380 D^{3}+434 D^{2}-217 D+57 \quad(\mathrm{~m} / \mathrm{min}) 0<D \leq 0.92$

Upstairs movement:

$V \uparrow=V m \uparrow \quad(\mathrm{m} / \mathrm{min})$

$m \uparrow=0.785+0.09 e^{3.45 D \uparrow} \sin 15.7 D \uparrow 0<D<0.6$

$m \uparrow=0.785-0.10 \sin (7.85 D \uparrow+1.57) 0.6 \leq D \leq 0.92$

Downstairs movement:

$V \downarrow=V m \downarrow \quad(\mathrm{m} / \mathrm{min})$

$m \downarrow=0.775+0.44 e^{-0.39 D \downarrow} \sin (5.61 D \downarrow-0.224)$

Ando [21] carried out a series of field observation research concerned with crowd movement in densely populated railway stations. He obtained a lot of data on the movement in horizontal level and stairs. Figure 2.1 presents data on the relationship 
between walking speed and crowd density. He termed the situation at the density of about 4 person $/ \mathrm{m}^{2}$, 'stagnation'. But some slow forward movement is still possible even at the density of 7.4 persons $/ \mathrm{m}^{2}$.

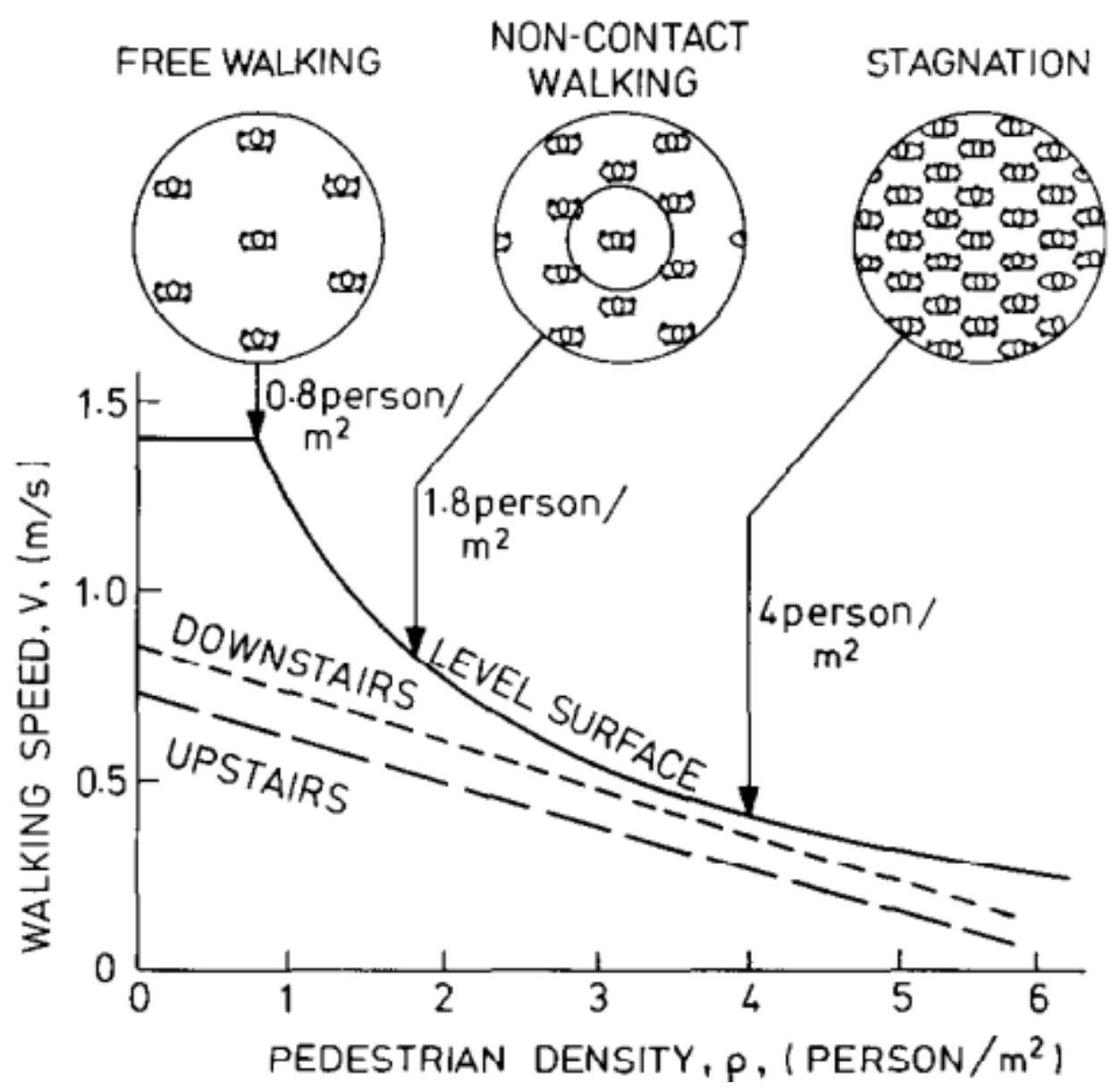

Figure 2.1 Uni-directional walking speed as a function of density, redrawn from Ando [21]

Pauls [22] did comparative observations and detailed analysis of many evacuation drills in Canada, and basic characteristics and relationships developed are often described in publications on pedestrian movement. The relationship between density and speed from a study in uncontrolled total evacuations of tall office buildings is shown in Figure 2.2. The dash curve is a similar finding from Fruin's study. From this figure, it is found that 
movement speed declines with the increasing of density, and the curve is linear: $S=1.08-0.29 \mathrm{~d}$

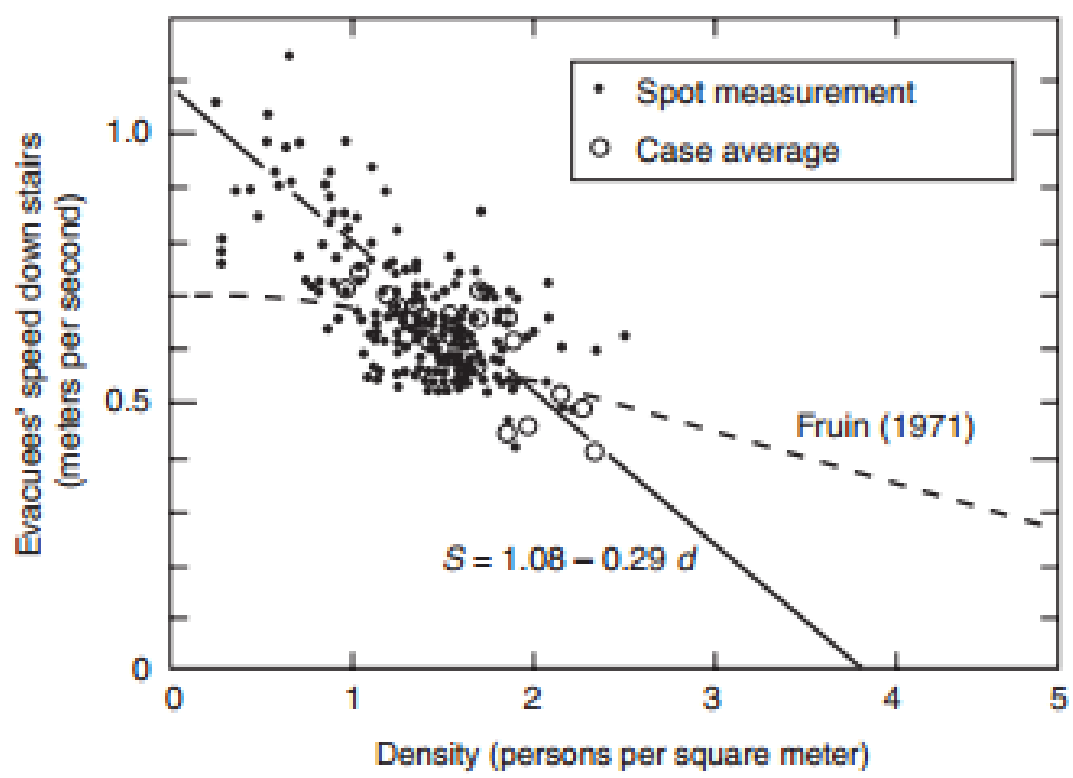

Figure 2.2 Relation between speed and density on stairs in uncontrolled total evacuations (Dashed line

from Fruin) [22]

Figure 2.3 presents the relationship between flow and density. It shows that the values of flow are small at both low and high densities, but they reach a peak value at an intermediate density around 2.0 persons $/ \mathrm{m}^{2}$. The flow-density relation obtained for stairs from the study by Pauls [22] in total evacuations of tall office buildings follows the equation:

flow $=1.2($ density $)-[0.33(\text { density })]^{2}$

The flow and density relationship is also described in publication on pedestrian and movement by Fruin [14]. Little difference is found between the curves at the high density 
end. Note that Fruin's data were not derived from observations of evacuations in buildings but from measurements in a pedestrian street environment.

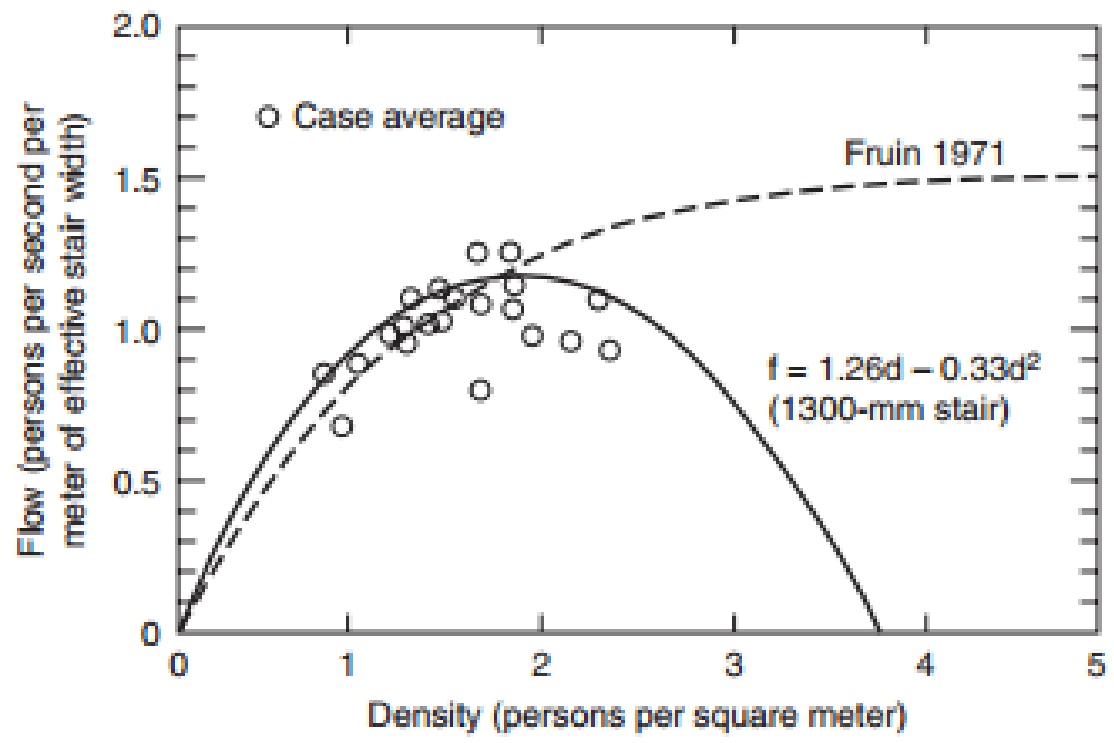

Figure 2.3 Relation between flow and density on stairs in uncontrolled total evacuations [22]

\subsubsection{Human Behavior in Evacuations}

\subsubsection{Research Method}

Due to the complexity of human behavior, a series of approaches are used in this field including investigation, field observation, evacuation experiments and experiments based on animals.

Methods of investigation include questionnaire survey, interview, data analysis, etc. For example, Wood [11] used interview and questionnaire techniques to investigate human behavior in nearly 1000 fire incidents. After 9.11, Proulx from the National Research of Council of Canada and Fahy from National Fire Protection Association worked together 
to study the crowd behavior in fire [23].

Field observation is mainly used to study the characteristics of pedestrians' movement. In Qi's research [24], passenger alighting and boarding behavior were observed in three metro stations in Beijing and the effects of different group sizes on these behaviors were studied. Cheung [25] investigated the behavior of pedestrians in choosing between escalators and stairways in Hong Kong Mass Transit Railway (MTR) stations.

Evacuation experiment is a very important method to investigate human behavior. Well designed experiments can be done to obtain more reliable data such as density, velocity, flow and the relationship among them. The results from experiments can be used to develop and validate computer models. So far, a number of studies on human behavior based on controlled experiments have been reported as merging behavior [26-28] and movement without visibility condition [29-30] in corridors [31-32] and in classrooms [33].

It is not easy to conduct experiments with humans considering large scale scenario due to the cost and concerns about the safety of participants. Some studies have found that there are similar behavioral traits [34] between humans and animals. So, experiments based on animals are an effective way to obtain results that can be applied to human evacuation.

\subsubsection{Typical Human Behavior}

Human evacuation behavior in emergency is affected by many kinds of factors including 
the incident dangers, human characteristics such as familiarity, physical characteristics, locations, responsibility, environmental condition and the human reaction. In the event of an emergency, some special psychological reactions are emerged as panic, fear, impulsion, fluke heart, loneliness, group psychology and so on. And these psychological reactions can cause irrational behavior in evacuation. Typical human behaviors observed provide important information for modelling methods.

1) Jamming [35]
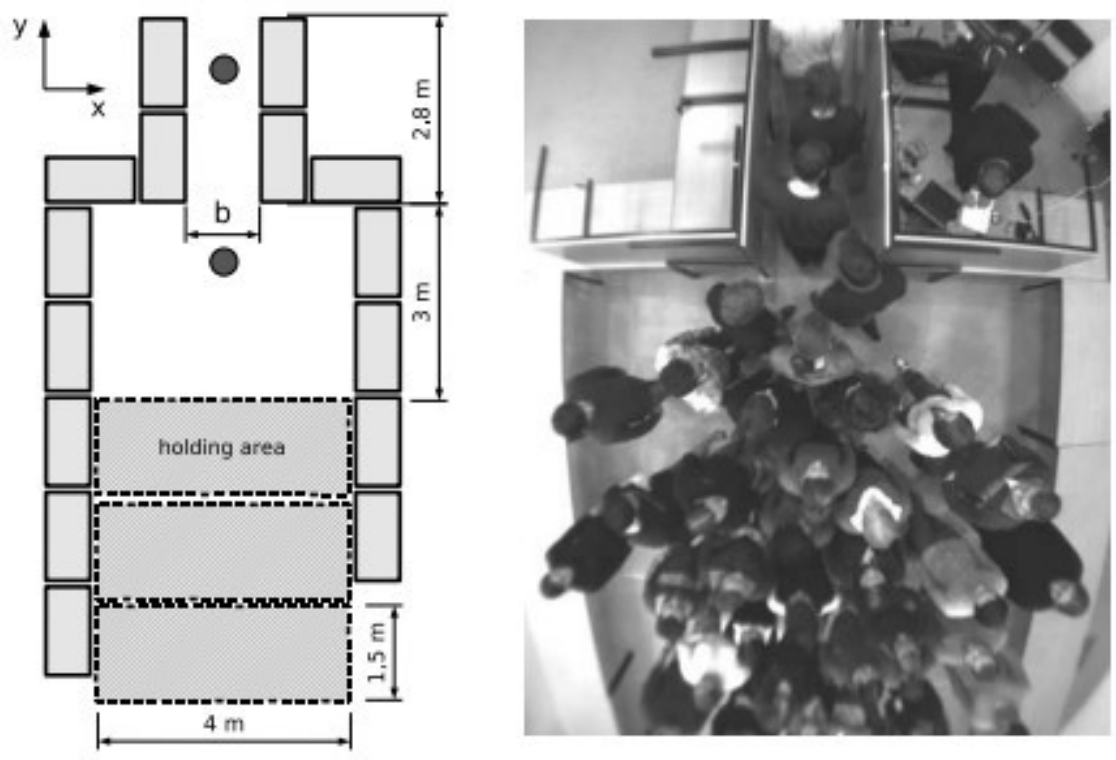

Figure 2.4 Clogging near a bottleneck [35]

In high density areas the inflow may exceed the building capacity causing jamming. Locations that reduce capacity are called bottlenecks. Figure 2.4 shows a typical jamming phenomenon near a bottleneck. Seyfried [35] studied the unidirectional pedestrian flow through bottlenecks under different widths. For every width, they performed three runs with the pedestrian numbers of 20, 40 and 60 in front of the bottleneck. The purpose of 
his study was to analyze the densities, the individual velocity development with the time in bottlenecks of different widths. The results show that the flow increases linearly with the width and a jam occurs even if the incoming flow does not exceed the maximum capacity.

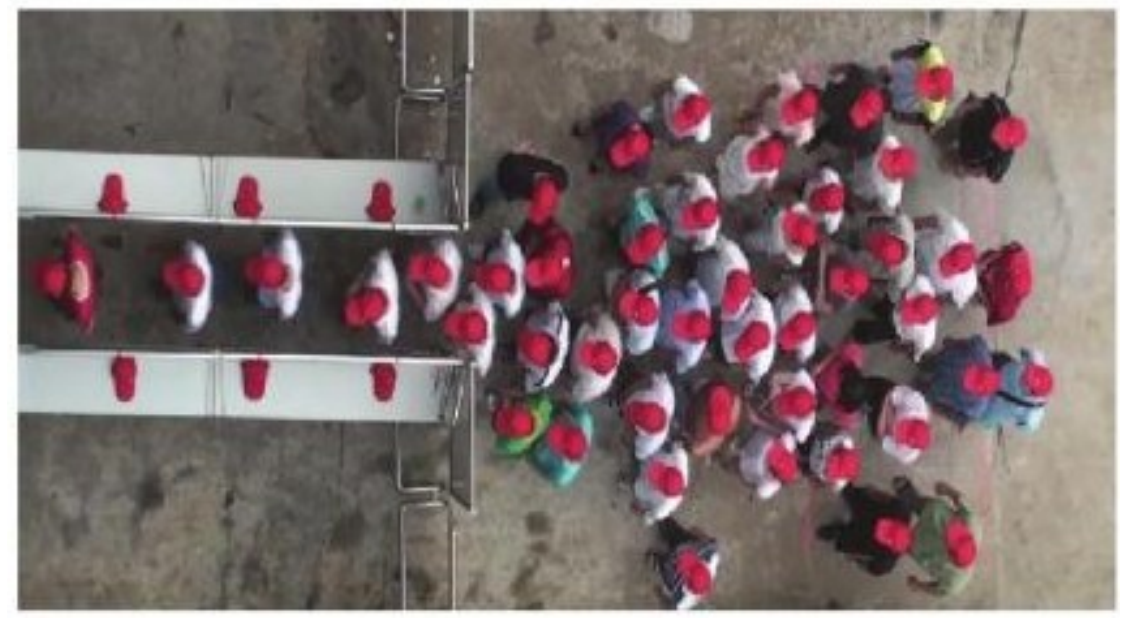

Figure 2.5 Pedestrian flow experiment through a bottleneck under normal conditions [36]

Song [36] conducted an experiment in China in which the width of the bottleneck was increased from the minimal value of $0.5 \mathrm{~m}$ in steps of 0.1 to a maximum value of $1.4 \mathrm{~m}$. The shape of the jam in front of the bottleneck was studied, and the relationship between the flow rate through the bottleneck and the width was studied and compared with other researchers' results. 


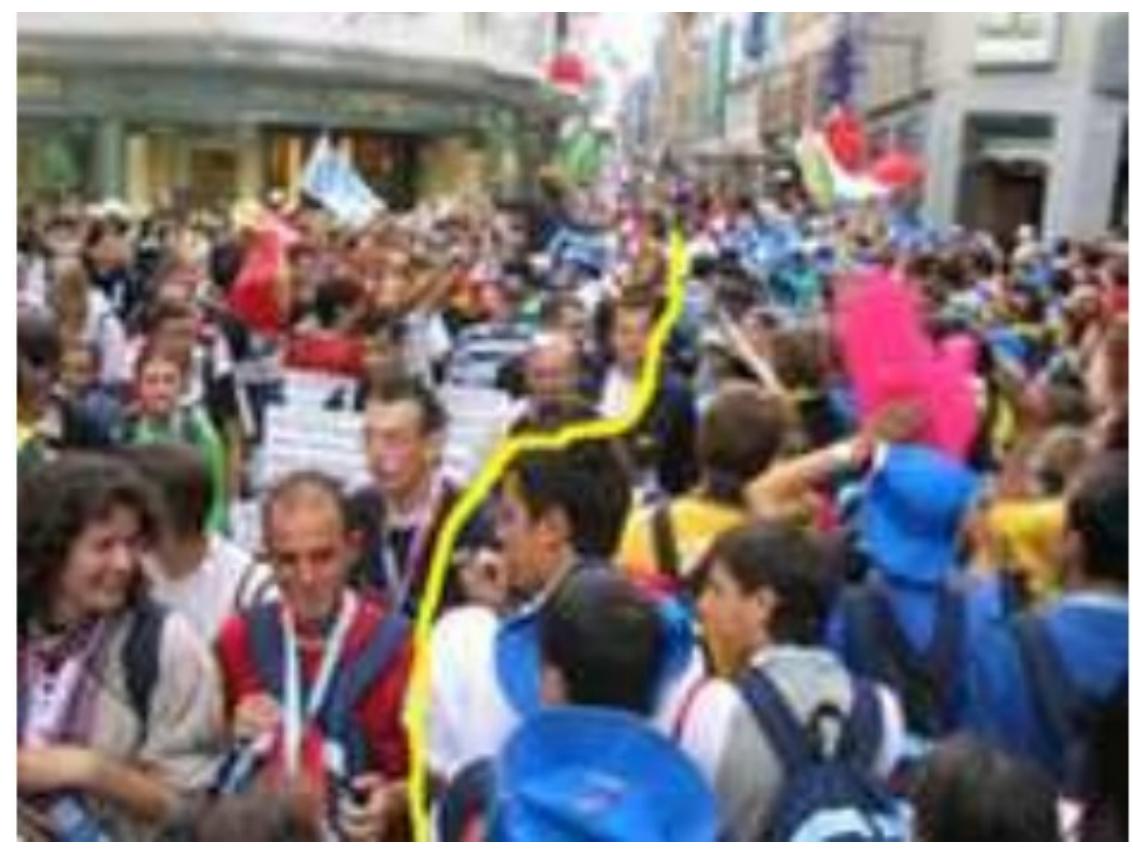

Figure 2.6 Lane formation in a street [35]

Jamming also occurs in counterflow. That means when two groups of people move in opposite directions, two lanes are formed where people move in one direction. This phenomenon is called lane formation. In this situation, the interaction between occupants is reduced and it's difficult to turn around or go back in high density or flow rate. Figure 2.6 shows two comparatively large lanes in a street in the city center of Cologne during the World Youth Day in Cologne (August 2005) [35].

2) Panic [35]

In panic situations, human behavior is totally different. People are more nervous, try to move faster than normal and some individuals start pushing. Jamming occurs in front of the exits, escape slows down, and people may fall or get injured during evacuation. Some studies [37-39] of panic behavior are presented in the following sections: 


\section{Fast-is-slower effect [37]}

In an emergency such as fire, earthquake, occupants are impatience to escape. They try to move faster which can cause a smaller average movement speed of leaving. Consequently, more and more people accumulate near the exit and the total evacuation time is delayed.

\section{Transition to incoordination [37]}

Helbing simulated the evacuation from a well-coordinated regular room. He found an irregular succession of arch-like blockings of the exit when the velocities exceed $1.5 \mathrm{~m} / \mathrm{s}$ as shown in Figure 2.7. This phenomenon has been observed for small enough openings that cannot meet the discharge capacity.

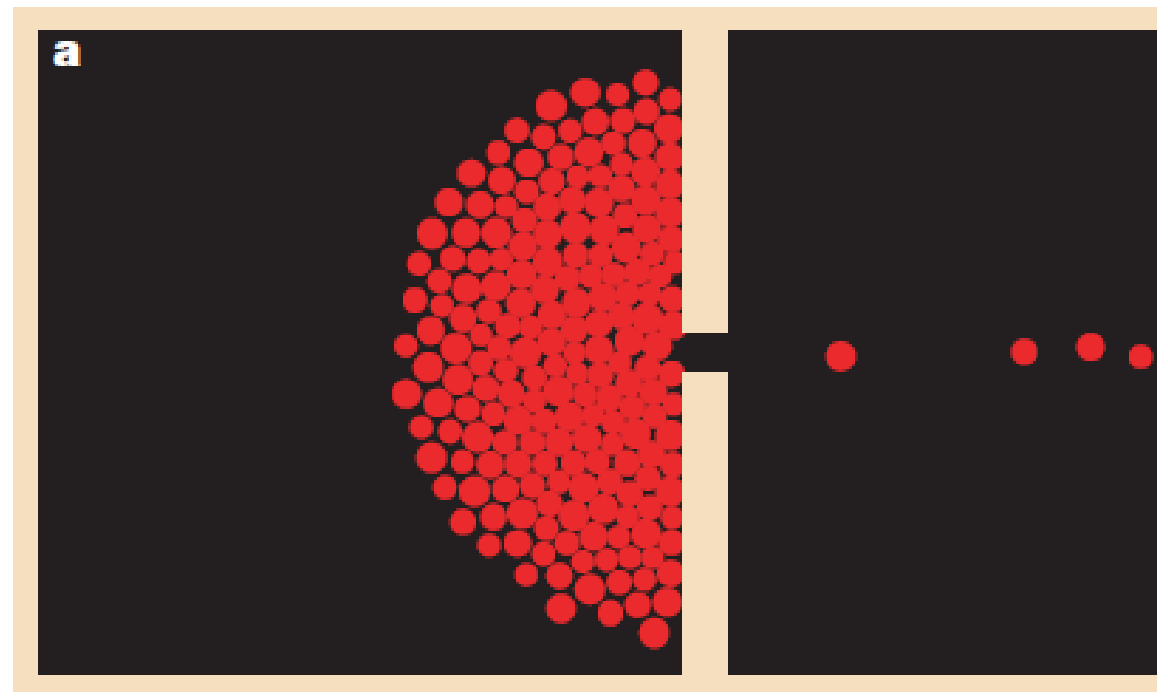

Figure 2.7 Arch-like blockings of the exit [37]

$>$ Herding behavior [35, 38-39]

In a smoke-filled room, it is difficult to determine the correct route for occupants due to 
the blocked visibility. In this situation, people follow the crowd blindly. As shown in Figure 2.8, herding behavior cause uneven distribution of occupants in the two exits which few people using the right exit. Zhao [39] divided the psychology of going with the crowd (the abbreviation is GWC) into two types including directional GWC (DGWC) and spatial GWC (SGWC). The former means that occupants try to follow the people around but do not try to keep a consistent movement direction with them. The latter means that occupants try to keep the same movement direction but they do not try to gather together.

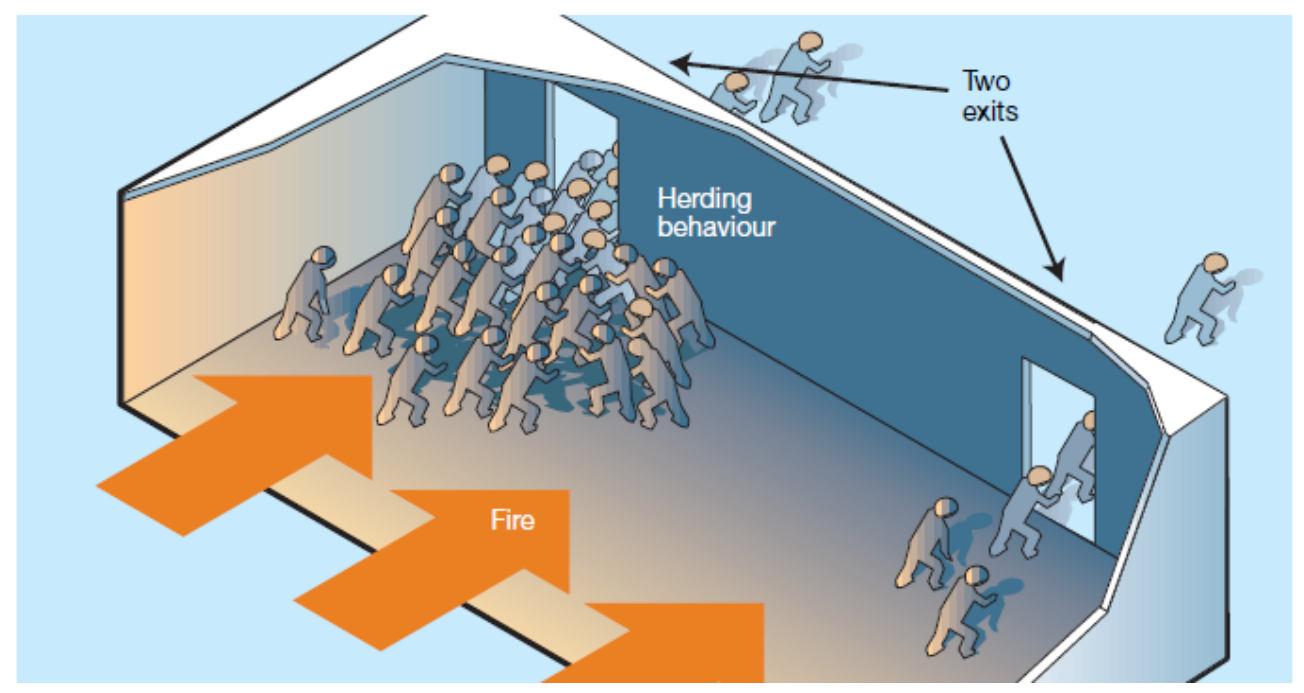

Figure 2.8 Herding behavior [38]

$>$ Interactions in the jammed crowd [37]

The pressure in a jammed crowd can reach as high as 4,450 Newton per meter due to the physical interactions, which can bend steel barriers or tear down brick walls.

3) Kin behavior

Kin behavior is a common behavior in evacuation. This phenomenon consists of the 
following behavior: Occupants in fires or emergency conditions are willing to be close with their familiar people and they tend to evacuate in groups; some occupants may backtrack and enter the fire room if their family members are lost in fire; some occupants may wait their group members near the exit at the beginning of evacuation. Zhao's simulation results [40] show that all these behavior will bring negative influence and be harmful to other occupants in emergency evacuation. Ping [41] did some observation on this behavior in emergency staircase evacuation as shown in Figure 2.9.
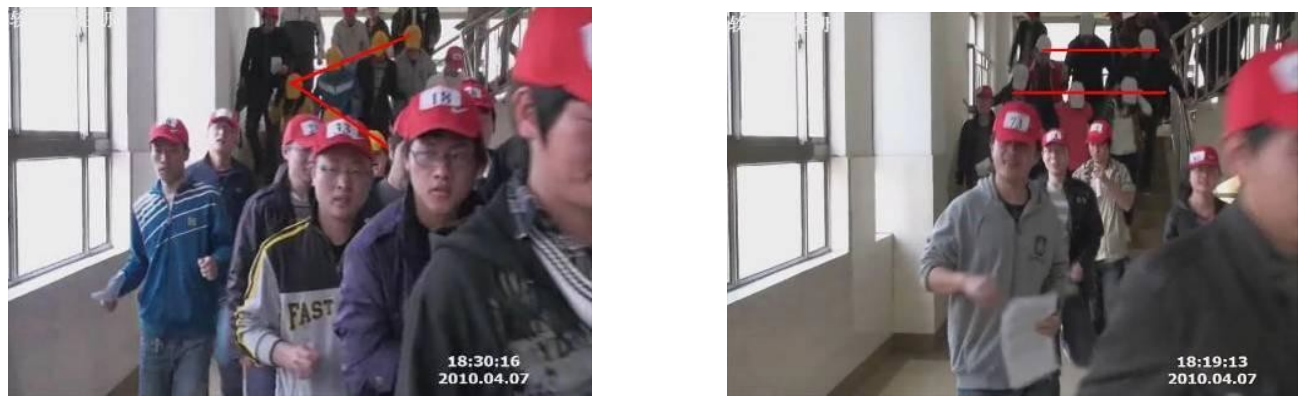

Figure 2.9 Sub-group behavior [41]

\section{4) Gender difference}

The difference in evacuation behavior between male and female is obvious in emergencies. As early as 1971, Henderson [42] did some research on the sexual difference in crowd motion. Velocity was collected for more than 2000 people including university students, pedestrians on a zebra crossing and 6-8 years old children. The results show that the velocity is in good agreement with Maxwell-Bolzmann theory which is based on the Kinetic Theory of Gases, gives the distribution of speeds for a gas under a certain set of conditions. The distribution curves of the velocity between male 
and female are different and females are much more easily perturbed in their motion compared to males. Byran [43] examined the differences of the first behavior response actions between male and female. He found that males were predominant in fire fighting acitvites. Males were more inclined to "search for fire" and "get extinguishers" while females acted like "call fire department" and "get the family". Zhao [44] did a post-fire survey for a multi-storey office building fire and he found that females differed significanlty from the males in the behavioral reactions and pre-evacuation times. Females had lower pre-evacuation times due to a higher urgency to escape at once if they perceived the fire cues. Thus it can be seen that evacuation behavior of males and females can have a big influence on the evacuation process and evacuation time. Gender difference is an important factor in evacuation research.

\subsubsection{Evacuation Time}

It's very important to predict occupant evacuation time. A timeline assessment designated as ASET (Available Safe Egress Time) and RSET (Required Safe Egress Time) shown in Figure 2.10 illustrates the different components of time available. ASET and RSET have been accepted as the basis of life safety assessment. RSET contains four stages: the detection time, the alarm time, the occupant pre-movement time and occupant movement time. Fire detection and alarm time is affected by the characteristics of fire detection and alarm system. If RSET $<$ ASET, occupants can evacuate safely. 


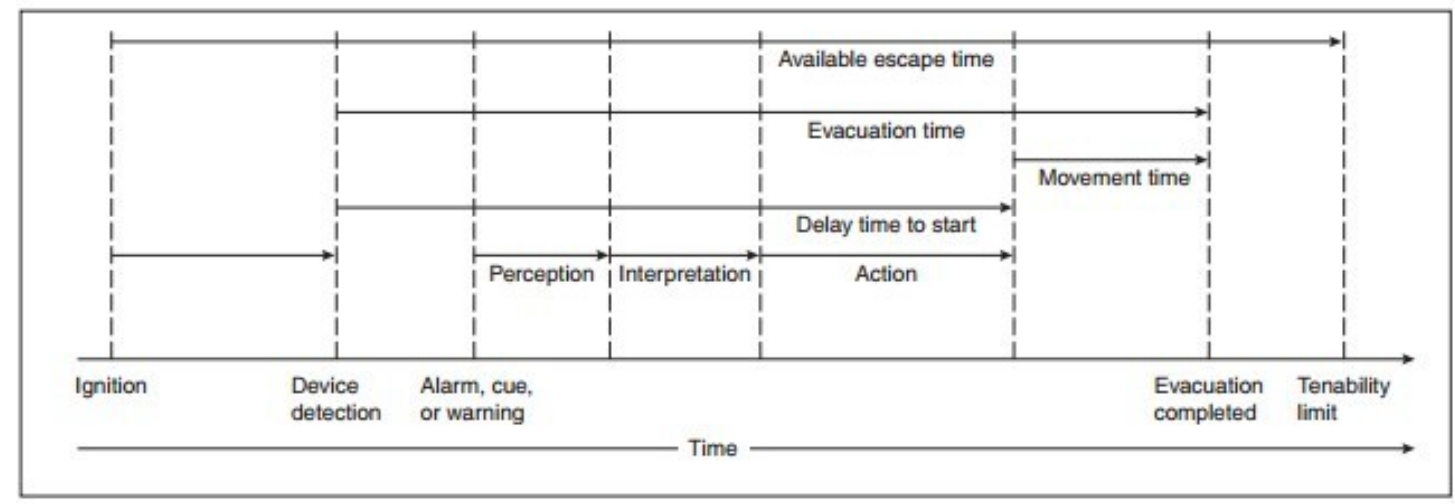

Figure 2.10 Sequence of occupant response to fire [22]

\subsubsection{Pre-Evacuation Time}

Per-evacuation time is defined as the time after an alarm is activated, but before the occupants begin to move towards an exit. This stage is also called delay time. Table 2.5 shows some per-evacuation times for different occupancies according to different warning systems provided in the buildings [22]. Some research [45] has revealed that pre-evacuation is not an explicit value, but a random variable which follows some distribution. 
Table 2.5 Estimated delay time to start evacuation in minutes [22]

\begin{tabular}{|c|c|c|c|}
\hline Occupancy Type & $\begin{array}{l}\text { W1 } \\
\text { (min) }\end{array}$ & $\begin{array}{l}\text { W2 } \\
\text { (min) }\end{array}$ & $\begin{array}{l}\text { W3 } \\
\text { (min) }\end{array}$ \\
\hline $\begin{array}{l}\text { Offices, commercial and Industrial buildings, } \\
\text { schools, colleges and universities } \\
\text { (Occupants awake and familiar with the } \\
\text { building, the alarm system, and evacuation } \\
\text { procedure.) }\end{array}$ & $<1$ & 3 & $>4$ \\
\hline $\begin{array}{l}\text { Shops, museums, leisure-sport centers, and } \\
\text { other assembly buildings (Occupants awake } \\
\text { but may be unfamiliar with building, alarm } \\
\text { system, and evacuation procedure.) }\end{array}$ & $<2$ & 3 & $>6$ \\
\hline $\begin{array}{l}\text { Dormitories, residential mid-rise and high- } \\
\text { rise (Occupants may be asleep but are } \\
\text { predominantly familiar with the building, } \\
\text { alarm system, and evacuation procedure.) }\end{array}$ & $<2$ & 4 & $>5$ \\
\hline $\begin{array}{l}\text { Hotels and boarding houses (Occupants may } \\
\text { be asleep and unfamiliar with the building, } \\
\text { alarm system, and evacuation procedure.) }\end{array}$ & $<2$ & 4 & $>6$ \\
\hline $\begin{array}{l}\text { Hospitals, nursing homes, and other } \\
\text { institutional establishment (A significant } \\
\text { number of occupants may require } \\
\text { assistance.) }\end{array}$ & $<3$ & 5 & $>8$ \\
\hline
\end{tabular}

W1: live directives using a voice communication system from a control room with closed-circuit television facility, or live directives in conjunction with well-trained, uniformed staff that can be seen and heard by all occupants in the space.

W2: nondirective voice messages (prerecorded) and/or informative warning visual display with trained staff.

W3: warning system using fire alarm signal and staff with no relevant training.

\subsubsection{Movement Time Calculation}

Several empirical equations are used to calculate the evacuation time. Key factors that affect movement time are movement speed and occupant flow rate. The following section 
presents hand calculation methods.

1) Togawa equation [46]

Kikuji Togawa developed a simplified equation for calculation of the evacuation time.

This method uses the hydraulic model that means the interactions between occupants and interactions between occupants and the environment are not considered.

$T_{e}=\frac{N_{a}}{B N}+\frac{K_{s}}{V}$

Where: $T_{e}$ : time required for escape (s)

$N_{a}$ : total number of the escaping people (persons)

B: breadth of the most limiting passageway $(\mathrm{m})$

$\mathrm{N}$ : unit flow capacity of the most limiting passageway (persons $/ \mathrm{m} / \mathrm{s}$ )

$K_{s}$ : the distance from the point of the first person in the crowd to the destination where the evacuation is completed $(\mathrm{m})$

$\mathrm{V}$ : walking speed of the crowd $(\mathrm{m} / \mathrm{s})$

In this equation, the first term represents the flow time and the second term is the travel time of the first person to the safety place. This equation is mainly used to calculate the escape time in a public place with high density.

2) Melinek and Booth equation [46]

Melinek and Booth proposed a method to calculate the minimum evacuation time of multi-storeys buildings. They assumed that all people are waiting at the exit of stairs at the beginning of the evacuation and the evacuated people do not decrease the flow rate 
from the upper floors.

$t_{m o v e-r}=\frac{\sum_{i=r}^{n} N_{i}}{w_{r} C}+r t_{s}$

Where: $t_{\text {move }-r}$ : minimum time for the population from floor $\mathrm{r}$ to floor $\mathrm{n}$

\author{
$N_{i}$ : population of floor $\mathrm{i}$ \\ $w_{r}$ : staircase width between floor $\mathrm{r}-1$ and $\mathrm{r}$ \\ C: flow rate of people per unit width down the stairs \\ $t_{s}$ : time for a member of an unimpeded crowd to descend one story,
}

typically about 16 seconds.

3) Pauls' empirical equation [47]

Pauls developed an effective width model to calculate the flow rate and movement speed in a staircase based on observations of many evacuation drills in tall office buildings. This effective width model indicated that the width used by occupants should consider the effect of edge. For example, the corridor width should be reduced by $150 \mathrm{~mm}$ for a wall boundary and $90 \mathrm{~mm}$ for a handrail centerline (see Figure 2.11). 


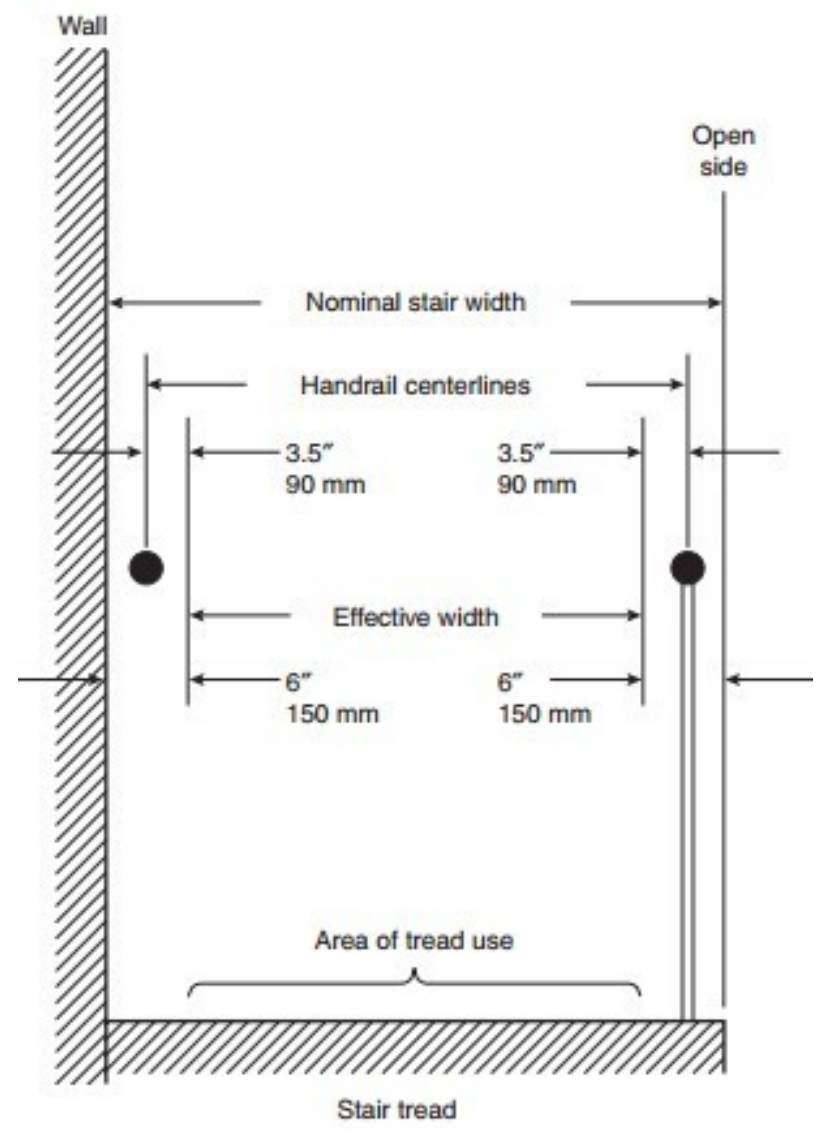

Figure 2.11 Measurement of effective stair width in relation to walls and handrails [47]

Pauls established the following equation:

$f=0.206 p^{0.27}$

Where: $\mathrm{f}$ is the mean evacuation flow (persons per second per meter of effective stair width); $p$ is the evacuation population (person per meter of effective stair width).

The relation between effective stair width and actual total population is listed as:

$\frac{W}{P}=\frac{8.04}{t^{1.37}}$

Where: $\mathrm{W}$ is the effective stair width $(\mathrm{mm})$; $\mathrm{P}$ is the actual total population (persons) and $t$ is the expected flow time $(\mathrm{sec})$. 
The total evacuation time equations were provided:

$T=0.68+0.081 p^{0.73} p \leq 800$

$T=0.70+0.0133 P \quad P>800$

Where: $\mathrm{T}$ is the minimum time to complete an uncontrolled total evacuation using stairs (mins); $\mathrm{p}$ is the actual evacuation population per meter of effective stair width, measured just above the discharge level of the exit. (Note the upper limit of 800 persons per meter of effective stair width.)

4) Nelson equation [22]

Based on the research above, Nelson improved the method to calculate evacuation time. More details can be found in chapter three.

$T_{p}=\frac{P}{S D W_{e}}$

Where: $T_{p}$ is time for passage (min); $\mathrm{P}$ is population in persons; $\mathrm{S}$ is the speed of movement $(\mathrm{m} / \mathrm{s}) ; \mathrm{D}$ is density (persons $\left./ \mathrm{m}^{2}\right)$ and $W_{e}$ is effective width $(\mathrm{mm})$.

\subsubsection{Evacuation Model}

Evacuation drills is an effective approach to estimate evacuation time, but it also poses considerable ethical, practical and financial problems. On the practical point, a single test does not provide sufficient information for the optimal evacuation efficiency. Even repeated experiments are performed with the same people under the same experimental conditions, the result will not be identical. This demonstrates that it's unwise to make definitive statements on the evacuation time. To achieve a more realistic evacuation 
method, engineers have been looking to evacuation computer model to assess a building's life safety. Gwynne [17] pointed out 'in order to fully assess the potential evacuation efficiency of an enclosure it is essential to address the configurational environmental behavioral and procedural aspects of the evacuation process' (see Figure

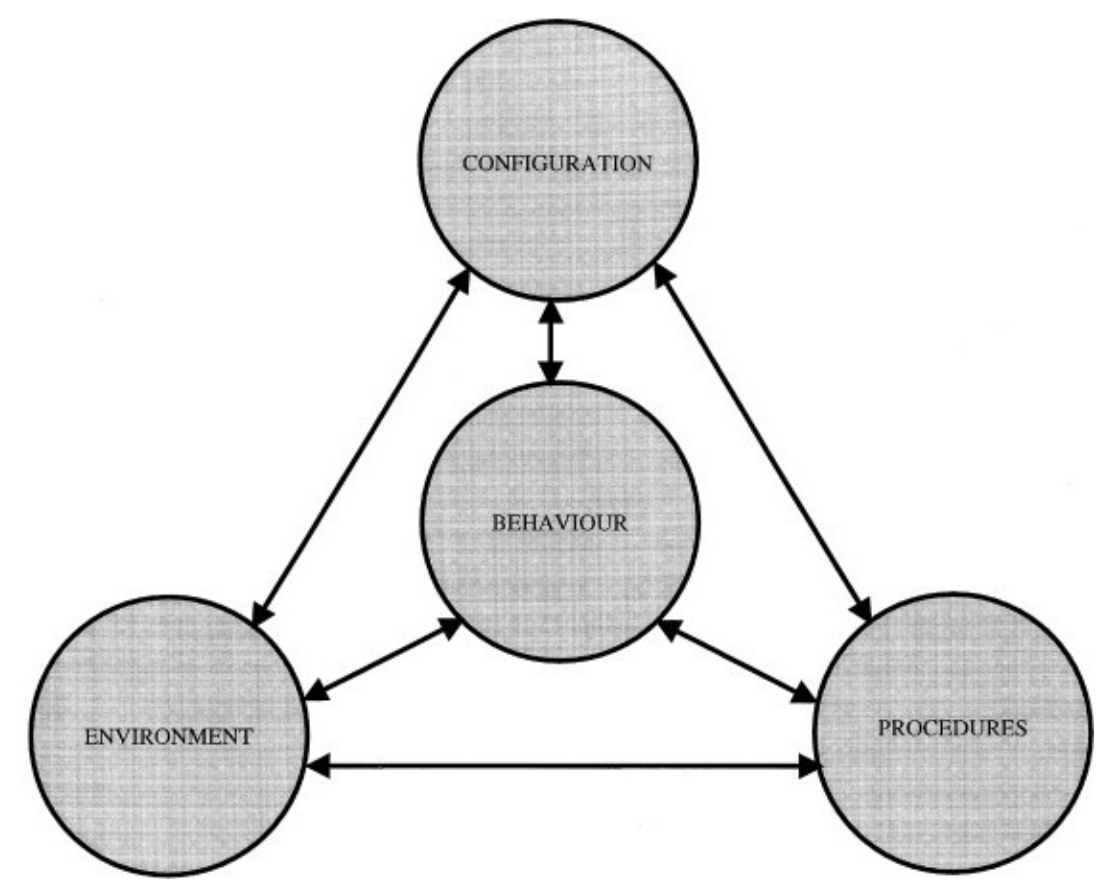

Figure 2.12 The four main interacting aspects to be considered in the optical design of an enclosure for evacuation [17]

According to Gwynne [17] and Erica [16] research, evacuation models are divided into the following categories:

$>$ Categories based on building representation

1) Coarse networks

In the coarse network approach, the spatial layout of a building is represented by nodes 
which are connected by arcs representing the travel path between two nodes. Each node may represent a room, corridor or stair. Nodes are specified in terms of the length and width. Occupants can move from one node to another, for example, they can only move from one room to another room, instead of from one position to another position. Models currently available: EVACNET 4 [48], WAYOUT [49], EESCAPE [50].

\section{2) Fine networks}

In the fine network approach, the entire floor space of the building is usually divided into a series of fine nodes, and the size and shape of a node can vary from model to model. For instance, SIMULEX [51] uses $0.25 \mathrm{~m}$ by $0.25 \mathrm{~m}$ square; BuildingExodus [52] uses $0.5 \mathrm{~m}$ by $0.5 \mathrm{~m}$ typically. In this method, it is possible to represent the building geometry, internal obstacles and each occupant's location at any time. There is no doubt that fine network models give a more accurate prediction of the evacuation time compared with the coarse network models. However, for tall buildings which comprise many compartments, thousands of nodes will be needed to represent the whole geometry. It demands a large quantity of computational time and causes a low speed of computation. Models currently available: Simulex, GridFlow [53], Exodus [52], STEPS [54], PedGo [55], SGEM [56].

$>$ Categories based on population perspectives

1) Individual perspective

Models that have an individual view of the occupants can track the movement of 
individuals and give information about their position throughout the evacuation. A challenge for these models is that the information sources available are limited for individual occupants. Individual occupants decide their route based on information from the floor and personal experience. Models currently available: EGRESS [57], Legion $[58]$.

2) Global perspective

Models that have a global view of the occupants, consider occupants as a homogeneous group without different identities moving to the exits. Occupants seem to have an "all knowing" view of the building. Models currently available: ALLSAFE [17], PED-PAX [17].

$>$ Categories based on behavior perspectives

1) No behavior: occupant evacuation is only determined by physical influences such as occupant density, building geometry. Models currently available: FPETool [59], EVACENT4 [48].

2) Functional analogy behavior: an equation or set of equations are applied to determine occupant movement and behavior. And all individuals are affected in the same way by this equation. Models currently available: Magnetic [60], Social Force [61].

3) Implicit behavior: secondary data is applied to these models to pre-define occupant behavior characteristics such as pre-evacuation, gender difference, physical difference. Models currently available: Simulex [51], GridFlow [53]. 
4) Rule based behavioral system: occupant evacuation is based on pre-defined rules. For example, occupants choose the nearest available exit if they are in a smoke filled room. Models currently available: Exodus [52].

5) Artificial intelligence based behavioral system: Each individual in this model is designed to mimic human intelligence. Occupants are able to make decision according to their own condition. Models currently available: EGRESS [57], VEGAS [62].

\subsection{Building Design in Mid-Rise Building}

Over the last few years there is an increased demand for mid-rise timber buildings in North American. They may be a single use like an office or residential apartment or of mix use which may consist of office, residential, retail, and community service all in the same building. Timber has been used widely as a building material, however, there are safety concerns because wood is combustible. Therefore, the capability to predict the fire risk of mid-rise timber building is becoming increasingly important. What is the design requirement for mid-rise wood building? What is the fire behavior of timber? What is the difference between passive and active fire protection? These questions will be discussed in the following sections.

\subsubsection{Definition of Mid-Rise Building}

CUI (Canadian Urban Institute) Workshop investigated the avenues and mid-rise buildings in Toronto in 2009. They pointed out that mid-rise buildings generally range in 
height from 4 to 12 storeys up to, but no taller than the width of the street right-of-way (R.O.W). A street right-of-way is the land occupied by the road and dedicated to public use. It is municipal property and wider than the actual street. Mid-rise buildings support a comfortable pedestrian environment, and animate the street by lining the sidewalk with doors and windows with active uses including stores, restaurants, services, grade related apartments, and community uses [63].

In the early 20th century, numerous mid-rise building projects have primarily been built of wood all around the world. In recent years, there has been an increase in the construction of mid-rise wood-based buildings in Europe and North America. Mid-rise buildings present a unique opportunity to apply new timber technologies. One example in British Columbia is the Ellis Street building in Kelowna (Figure 2.13) [64], a six-storey multi-family wood-frame residential building which was built before the government of British Columbia amended its provincial building code in 2009. It was designed and constructed in accordance with what the provincial code required and allowed at that time. 


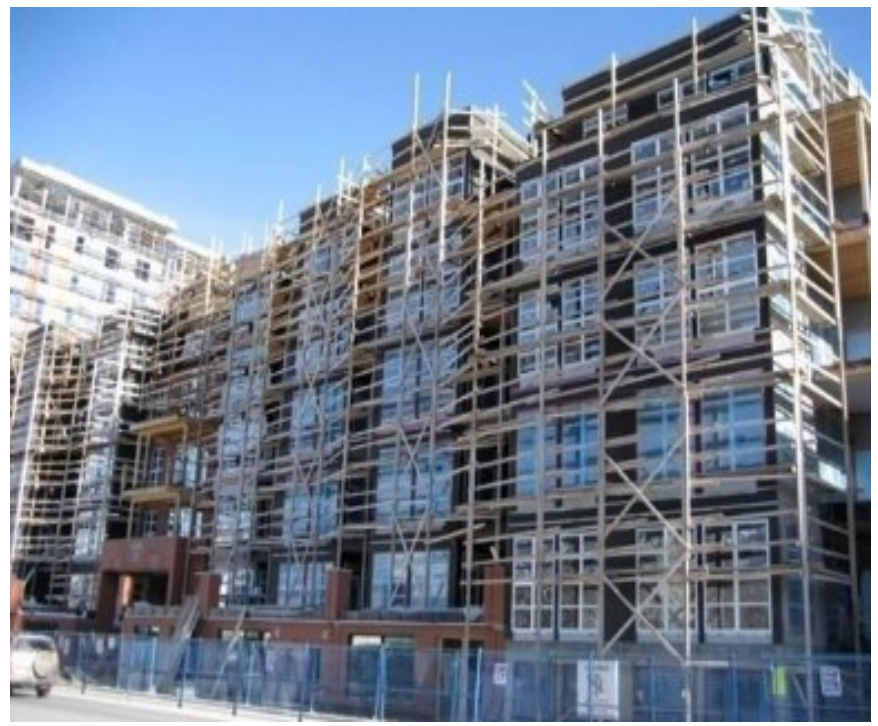

Figure 2.13 Eollis Building, in BC during construction [64]

Wood-frame buildings have many advantages over the traditional concrete buildings.

Wood as a construction material is abundant, relatively simple to shape and has high ratios of stiffness and strength to weight. Wood buildings are lighter so there are less loads on their supports. Wood is also easy to fasten with nails, glue, and other connectors, and easy to paint or treat with preservatives. In addition, massive wood performs well in fire situations. When exposed to fire, pyrolysis occurs producing combustible gases, and then a char surface is formed. This charring layer acts as an insulation barrier to protect the interior of the timber section against heat due to its low thermal conductivity. When designing a wood-frame building, features like fire safety, load bearing capacity and integrity should be considered.

\subsubsection{Building Height}

From a fire safety perspective, building codes imposed limitations on the maximum 
height of buildings made of combustible materials. But regulations and restrictions in different building codes at different countries around the world have wide variation and limitation on the maximum heights and number of storeys of wood-frame constructions.

Some countries set a maximum of two storeys for wood-frame buildings, as in the case of Romania, Latvia and Turkey, while others have no set maximum, as in Germany, Norway and Sweden. Further, other countries, such as Denmark and Finland have a limit of a maximum of four storeys for wood-frame buildings. Table 2.6 [65] provides an overview of the maximum number of storeys permitted for wood-frame buildings under building codes in different countries around the world.

Table 2.6 Maximum number of storeys for multi-storey wood-frame buildings under building codes in selected countries [65]

\begin{tabular}{|c|l|l|}
\hline Country & \multicolumn{1}{|c|}{$\begin{array}{c}\text { Maximum number of } \\
\text { storeys }\end{array}$} & \multicolumn{1}{c|}{ Description/details } \\
\hline Croatia & No limits. & Buildings must meet prescribed characteristics. \\
\hline $\begin{array}{c}\text { Czech } \\
\text { Republic }\end{array}$ & $\begin{array}{l}\text { No regulations on the } \\
\text { construction } \\
\text { multi-storey wood-frame } \\
\text { buildings. }\end{array}$ & $\begin{array}{l}\text { There are limiting factors: fire safety, elevator } \\
\text { locations, acoustic issues, etc. }\end{array}$ \\
\hline Denmark & Maximum 4 storeys. & $\begin{array}{l}\text { It is possible to apply for a variance to build } \\
\text { higher. }\end{array}$ \\
\hline Estonia & Maximum 4 storeys. & $\begin{array}{l}\text { A combination of various factors usually limits } \\
\text { the number of storeys to one or two. }\end{array}$ \\
\hline Finland & Maximum 4 storeys. & $\begin{array}{l}\text { However, regulation 1.3.2 of Finland's building } \\
\text { Code permits more than 4 storeys for } \\
\text { wood-frame buildings. The tallest wood-frame } \\
\text { building in Finland is currently 4 storeys high. }\end{array}$ \\
\hline Germany & No set maximum. & The country has fire specifications. \\
\hline Greece & No limits. & --- \\
\hline
\end{tabular}




\begin{tabular}{|c|c|c|}
\hline Hungary & No regulations. & No regulations for wood-frame buildings. \\
\hline Latvia & Maximum 2 storeys. & Regulation no. 866. \\
\hline Norway & $\begin{array}{l}\text { No restrictions or } \\
\text { regulations on the number } \\
\text { of wood-frame storeys. }\end{array}$ & $\begin{array}{l}\text { Regulatory technical standards under the } \\
\text { Planning and Building Act 1997. Buildings } \\
\text { more than nine meters high (regardless of } \\
\text { material used) must be constructed in an area } \\
\text { zoned for tall buildings. Project involving a } \\
\text { 20-storey wood-frame building (tallest in the } \\
\text { world). The use of wood in government } \\
\text { buildings is encouraged, but there is no public } \\
\text { policy to that end. }\end{array}$ \\
\hline Poland & $\begin{array}{l}\text { No regulations on the } \\
\text { maximum number of } \\
\text { storeys. }\end{array}$ & --- \\
\hline Portugal & $\begin{array}{l}\text { No specific legal } \\
\text { references on the subject. }\end{array}$ & $\begin{array}{l}\text { Wood-frame buildings must comply with law } \\
\text { no. } 235 / 83 \text { and law no. } 220 / 2008 \text {. }\end{array}$ \\
\hline Romania & $\begin{array}{l}\text { No more than } 2 \text { storeys } \\
\text { (ground \& second floors). }\end{array}$ & $\begin{array}{l}\text { If the ground floor is built of masonry, the } \\
\text { regulations permit two wood-frame storeys. }\end{array}$ \\
\hline Russia & $\begin{array}{l}\text { No provisions in the } \\
\text { legislation regulating the } \\
\text { matter. }\end{array}$ & --- \\
\hline $\begin{array}{c}\text { Slovak } \\
\text { Republic }\end{array}$ & No restrictions. & $\begin{array}{l}\text { Restrictions do not depend on the type of } \\
\text { material. All types of construction must meet } \\
\text { the same six criteria. }\end{array}$ \\
\hline Sweden & $\begin{array}{l}\text { No regulations on the } \\
\text { number of storeys for } \\
\text { wood-frame buildings. }\end{array}$ & $\begin{array}{l}\text { Sweden's national codes are } \\
\text { performance-based. If the codes are complied } \\
\text { with, there are no limits on the use of wood } \\
\text { frames. }\end{array}$ \\
\hline Turkey & $\begin{array}{l}\text { Maximum } 2 \text { storeys to a } \\
\text { maximum height of } 6.5 \\
\text { metres. }\end{array}$ & --- \\
\hline $\begin{array}{l}\text { United } \\
\text { Kingdom }\end{array}$ & Maximum 7 storeys. & $\begin{array}{l}\text { However, British construction regulations } \\
\text { discourage the use of combustible materials in } \\
\text { buildings more than } 18 \text { meters high. On the } \\
\text { other hand, it is possible to build higher if } \\
\text { adequate fire prevention measures are put in } \\
\text { place. }\end{array}$ \\
\hline
\end{tabular}




\begin{tabular}{|c|l|l|l|} 
United & $\begin{array}{l}\text { Maximum 5 storeys if the } \\
\text { building is not equipped } \\
\text { with automatic sprinklers. }\end{array}$ & $\begin{array}{l}\text { The International Building Code acts as a } \\
\text { model Code in the United States. It is amended }\end{array}$ \\
$\begin{array}{l}\text { States } \\
\text { Maximum 6 storeys if the } \\
\text { building is equipped with } \\
\text { automatic sprinklers. }\end{array}$ & $\begin{array}{l}\text { on wood buildings related to floor area and } \\
\text { occupant load and type. }\end{array}$ \\
\hline
\end{tabular}

In Canada, the National Building Code of Canada (NBCC) is a model code and can be adopted by the provinces as is, or with some modifications. For this reason, the building height limitation fluctuates slightly. The first National Building Code was published in 1941. For combustible constructions, the maximum permitted building height was 4 storeys although building height was also limited [66]. In 2005, an objectives-based format of the NBCC was published that provides the construction industry professionals to more flexibility in design. Multi-storey wood-frame buildings of more than four storeys can be considered provided it can be shown that they satisfy the code objectives.

Several provinces in Canada have launched their own initiatives to increase the height of combustible construction. The province of British Columbia modified and subsequently amended its provincial building code (BCBC) on April 6, 2009 to encourage the use of wood [67].

- Builders are able to construct up to six storeys out of wood for residential buildings. The height of individual storeys is not regulated but mid-rise residential wood-frame buildings must be less than 18 meters to the top floor.

- The total permissible building area for each floor of a five and six-storey wood-frame 
building is $1440 \mathrm{~m}^{2}$ for 5 -storey building and $1200 \mathrm{~m}^{2}$ for 6-storey building which leads to total floor area of $7200 \mathrm{~m}^{2}$.

A study done by the city of Toronto on mid-rise buildings recommends that height of mid-rise buildings should depend on street width. On the narrower 20 metres wide streets in the downtown, a mid-rise building of 5 or 6 stories high maybe permitted. On the wider arterial streets outside of the downtown, a mid-rise building could reach a maximum of 11 storeys on the widest avenues. Table 2.7 and Table 2.8 which are based on the recommendations of this report identify the maximum allowable heights and minimum lot depths based on street right-of-way (R.O.W) width [68]. Performance Standards are on the base of best principles (Official Plan policies) and best practices (urban design criteria and guidelines). It has an important implication for guiding the design of mid-rise buildings. The followings give the range of mid-rise building height by Performance Standards [68] .

- Maximum Allowable Height: The maximum allowable height of buildings on the avenues will be no taller than the width of the avenue right-of-way, up to a maximum mid-rise height of 11 storeys (36 metres).

- Minimum Building Height: All new buildings on the avenues must have a minimum height of 10.5 metres (up to 3 storeys) at the street frontage. 
Table 2.7 Maximum allowable heights [68]

\begin{tabular}{|c|c|c|c|c|}
\hline R.O.W. Width $^{1}$ & \multicolumn{2}{c|}{ Mixed-Use } & \multicolumn{2}{c|}{ Commercial } \\
\hline \multirow{4}{*}{$20 \mathrm{~m}$} & storeys & height $(\mathrm{m})^{2}$ & storeys & height $(\mathrm{m})^{3}$ \\
\cline { 2 - 5 } & 6 & 19.5 & 5 & 18.9 \\
\cline { 2 - 5 } $27 \mathrm{~m}$ & 8 & 25.5 & 7 & 26.1 \\
\cline { 2 - 5 } $30 \mathrm{~m}$ & 9 & 28.5 & 8 & 29.7 \\
$36 \mathrm{~m}$ & 11 & 34.5 & 9 & 33.3 \\
\cline { 2 - 5 } & & &
\end{tabular}

Table 2.8 Minimum lot depths [68]

\begin{tabular}{|c|c|}
\hline R.O.W. Width & Lot Depth \\
\hline & Ideal Minimum \\
\hline $20 \mathrm{~m}$ & $32.6 \mathrm{~m}$ \\
\hline $27 \mathrm{~m}$ & $41.0 \mathrm{~m}$ \\
\hline $30 \mathrm{~m}$ & $44.6 \mathrm{~m}$ \\
\hline $36 \mathrm{~m}$ & $51.8 \mathrm{~m}$ \\
\hline
\end{tabular}

\subsubsection{Floor Area}

Floor area (FA) is a building, architecture, and real estate term referring to the area (measured as square feet or square meters) taken up by a building or part of it. Two ways of floor area are defined when determining requirements for occupancy load and egress including gross floor area (GFA) and net floor area (NFT) depending on what factors of the building should be included like internal and external walls, corridors, lift, stairs, etc. GFA is often used in real estate referring to the floor area within the inside perimeter of the exterior walls. The gross floor area should not include shafts with no opening or interior courts. NFA is the actual occupied area which shall not include unoccupied accessory areas like corridors, stairs, washrooms, mechanical rooms and closets.

In the International Building Code [69], allowable gross floor area per floor is included in 
Table 2.9 for five construction types. The examples are chosen to highlight the differences among different construction types as from Type I fire-protected building to Type V nonrated building. For Type I A construction and any group occupancy, there is no limitation on the allowable floor area for each storey. However, for Type IV construction and group R-2 occupancy, the floor area limit is 1904 square meter and building height limit is 19.8 meter with 4 storeys. 
Table 2.9 Allowable building height, number of stories and proportionate floor areas per story [69]

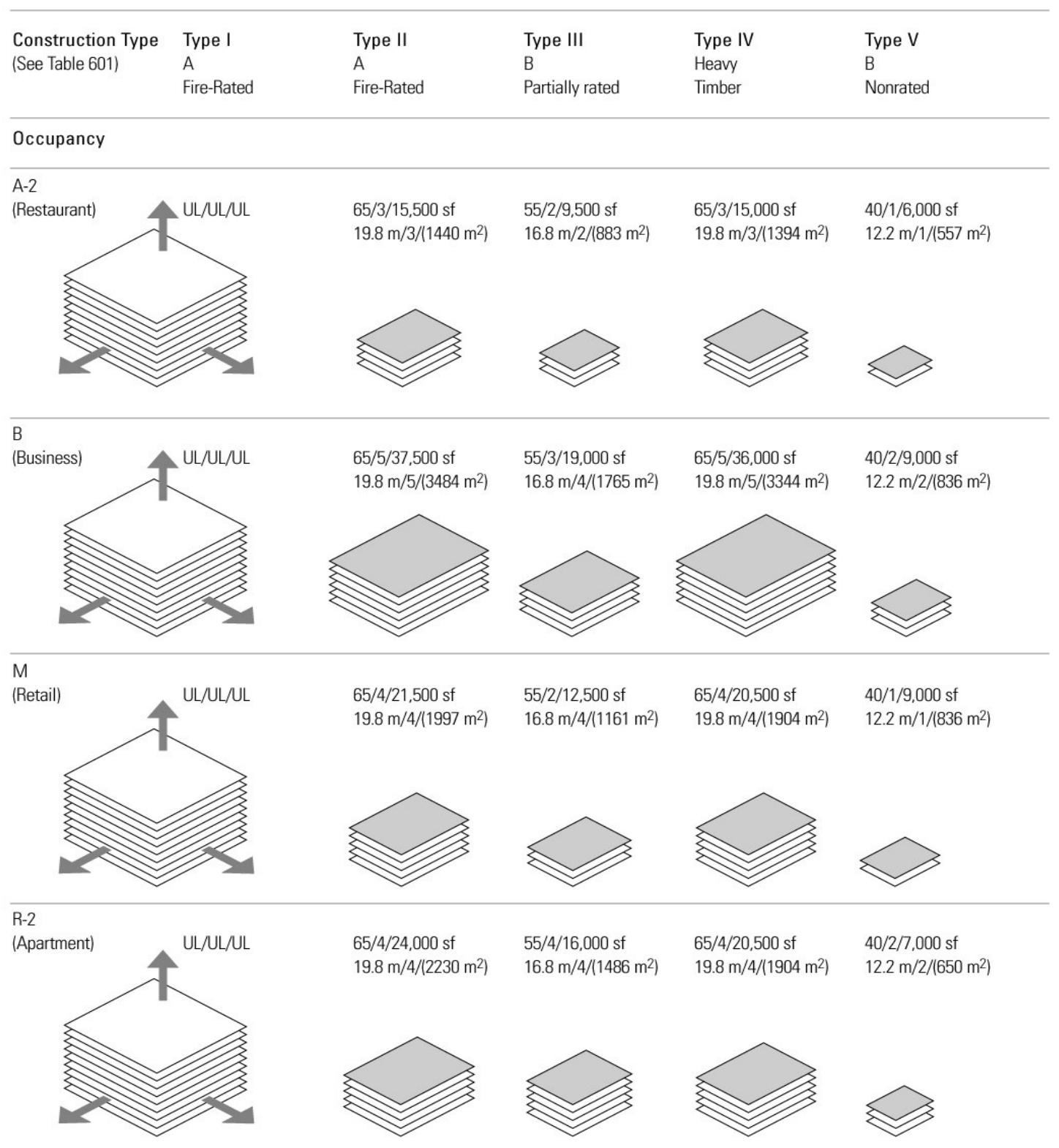

In the BC Building Code, the gross floor area per floor is limited to $1,200 \mathrm{~m}^{2}$ for mid-rise residential wood-frame building (see Figure 2.14). This value is $80 \%$ lower than the non-combustible residential building which a maximum gross floor area of $6,000 \mathrm{~m}^{2}$ per floor. The floor plate becomes smaller with each additional storey [67]. 


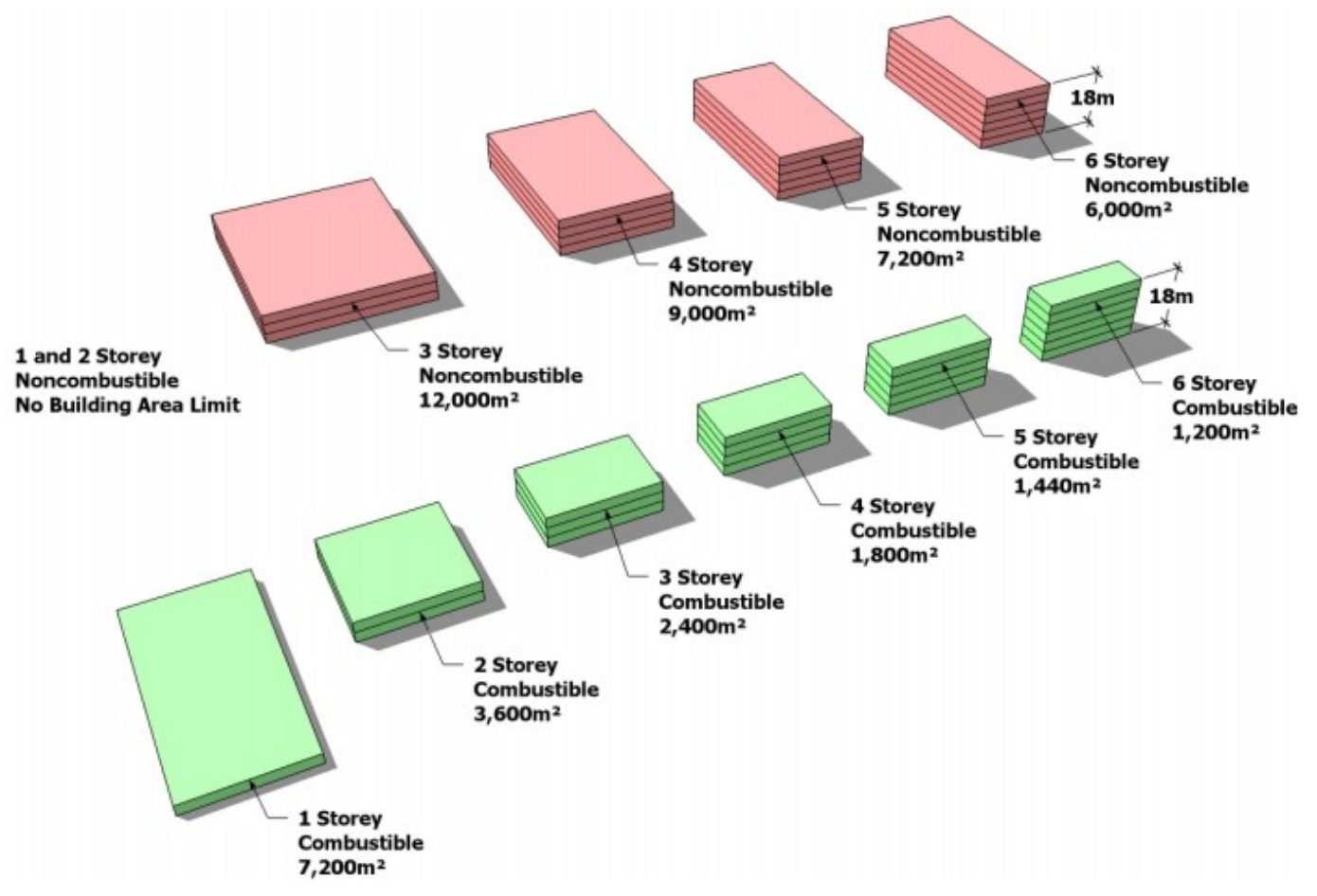

Figure 2.14 Building area required in $\mathrm{BC}$ code [67]

In the $\mathrm{BC}$ Building code, firewalls can be used to separate mid-rise residential wood-frame buildings within one larger structure [67]. As see in Figure 2.15, two firewalls are used to prevent the spread of fire through a combustible building. The maximum gross floor area per floor can reach $3,600 \mathrm{~m}^{2}$ which is $40 \%$ smaller than a non-combustible residential building. 


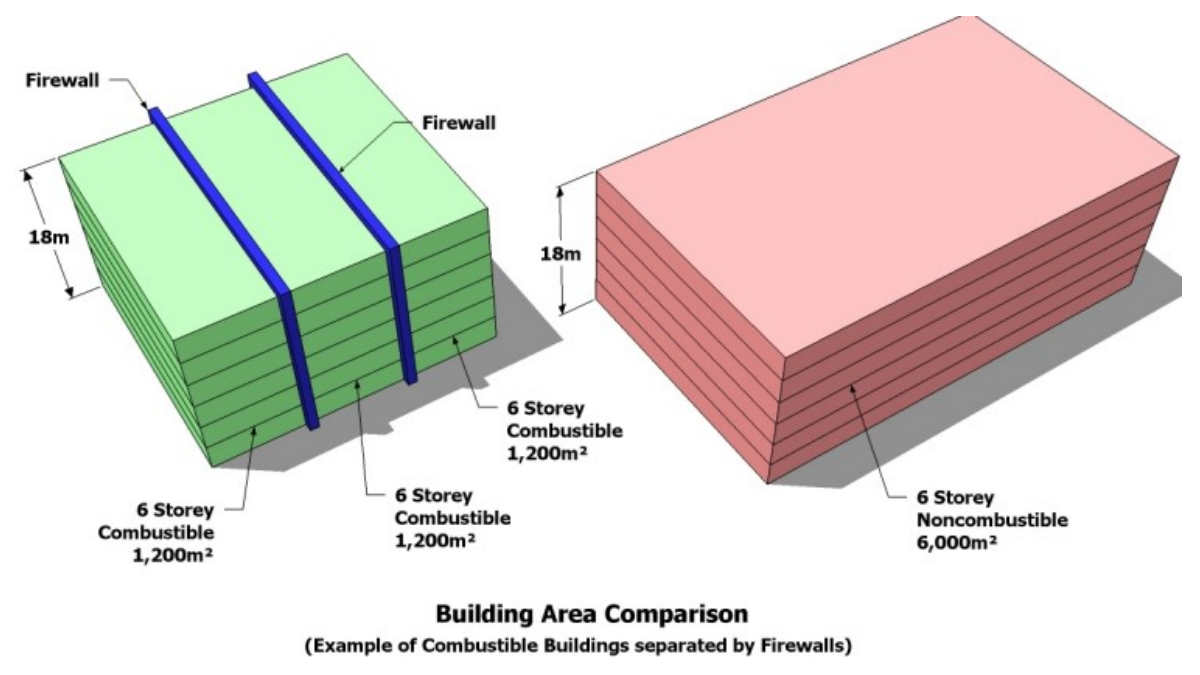

Figure 2.15 Building area comparison [67]

In the Ontario Building Code, the applicable building area is based on the division of occupancy [70]. For example, if the building is classified as business occupancy, residential occupancy and mercantile occupancy, the building areas shall conform to the following requirements.

Business type:

1) If the building is up to 6 storeys, the maximum building area shall conform to Table 2.10 .

Table 2.10 Maximum building area, up to 6 storeys non-combustible construction [70]

\begin{tabular}{|r|c|c|c|c|}
\hline Item & Column 1 & Column 2 & Column 3 & Column 4 \\
\hline & No. of storeys & $\begin{array}{c}\text { Maximum } \\
\text { area }\left(\mathrm{m}^{2}\right)\end{array}$ & & \\
\hline & & Facing 1 & Facing 2 & Facing 3 \\
& & street & streets & streets \\
\hline 1. & & Not limited & Not limited & Not limited \\
\hline
\end{tabular}




\begin{tabular}{|r|r|r|r|r|}
\hline 2. & 2 & 7200 & Not limited & Not limited \\
\hline 3. & 3 & 4800 & 6000 & 7200 \\
\hline 4. & 4 & 3600 & 4500 & 5400 \\
\hline 5. & 5 & 2800 & 3600 & 4320 \\
\hline 6. & 6 & 2400 & 3000 & 3600 \\
\hline
\end{tabular}

2) The building is up to 6 storeys with sprinklers. If the building height is not more than 2 storeys, the building area is not limited. If 3 storeys in building height, the building area shall not be more than $14400 \mathrm{~m}^{2}$. If 5 storeys in building height, the building area shall not be more than $8640 \mathrm{~m}^{2}$. If 6 storeys in building height, the building area shall not be more than $7200 \mathrm{~m}^{2}$.

As noted the building shall be of non-combustible construction, and the floor assemblies should have a fire resistance rating not less than $1 \mathrm{~h}$.

3) If the building is up to 3 storeys, the maximum building area shall conform to Table 2.11

Table 2.11 Maximum building area, up to 3 storeys [70]

\begin{tabular}{|l|l|l|l|l|}
\hline Item & Column 1 & Column 2 & Column 3 & Column 4 \\
\hline & $\begin{array}{l}\text { No. of } \\
\text { storeys }\end{array}$ & $\begin{array}{l}\text { Maximum area } \\
\left(\mathrm{m}^{2}\right)\end{array}$ & \\
\hline & & Facing 1 street & Facing 2 streets & Facing 3 streets \\
\hline 1. & 1 & 4800 & 6000 & 7200 \\
\hline 2. & 2 & 2400 & 3000 & 3600 \\
\hline 3. & 3 & 1600 & 2000 & 2400 \\
\hline
\end{tabular}


4) The building is up to 3 storeys with sprinklers. If 1 storey in building height, the building area shall be limited to $14400 \mathrm{~m}^{2}$. If 2 storeys in building height, the building area shall be limited to $7200 \mathrm{~m}^{2}$. If 3 storeys in building height, the building area shall be limited to $4800 \mathrm{~m}^{2}$.

The building shall be of non-combustible construction or combustible construction or in combination. The floor assemblies shall have a fire resistance rating not less than $45 \mathrm{mins}$ for combustible buildings.

Residential type:

Table 2.12 Building requirement for residential buildings [70]

\begin{tabular}{|c|c|c|c|c|}
\hline $\begin{array}{l}\text { Number } \\
\text { of storey }\end{array}$ & $\begin{array}{l}\text { Construction } \\
\text { type }\end{array}$ & Maximum area & Fire resistance & sprinkler \\
\hline $\begin{array}{l}\text { Any } \\
\text { height }\end{array}$ & Non-combustible & Any area & $\begin{array}{l}\text { Floor assemblies: } \\
2 \mathrm{~h} \text {; } \\
\text { Mezzanines: } 1 \mathrm{~h}\end{array}$ & Required \\
\hline $\begin{array}{l}\text { Up to six } \\
\text { storeys }\end{array}$ & Non-combustible & $\begin{array}{l}\text { Unlimited for } 2 \text { storeys; } \\
9000 \mathrm{~m}^{2} \text { for } 4 \text { storeys; } \\
7200 \mathrm{~m}^{2} \text { for } 5 \text { storeys; } \\
6000 \mathrm{~m}^{2} \text { for } 6 \text { storeys }\end{array}$ & $\begin{array}{l}\text { Floor assemblies: } \\
\text { 1h; } \\
\text { Mezzanines: } 1 \mathrm{~h}\end{array}$ & Required \\
\hline $\begin{array}{l}\text { Up to four } \\
\text { storeys }\end{array}$ & $\begin{array}{l}\text { Non-combustible } \\
\text { or combustible or } \\
\text { a combination }\end{array}$ & $\begin{array}{l}7200 \mathrm{~m}^{2} \text { for } 1 \text { storeys; } \\
3600 \mathrm{~m}^{2} \text { for } 2 \text { storeys; } \\
2400 \mathrm{~m}^{2} \text { for } 3 \text { storeys; } \\
1800 \mathrm{~m}^{2} \text { for } 4 \text { storeys }\end{array}$ & $\begin{array}{l}\text { Floor assemblies: } \\
\text { 1h; } \\
\text { Mezzanines: } 1 \mathrm{~h}\end{array}$ & Required \\
\hline
\end{tabular}


Mercantile type:

Table 2.13 Building requirement of mercantile buildings [70]

\begin{tabular}{|c|c|c|c|c|}
\hline $\begin{array}{l}\text { Number } \\
\text { of storey }\end{array}$ & $\begin{array}{l}\text { Construction } \\
\text { type }\end{array}$ & Maximum area & Fire resistance & sprinkler \\
\hline $\begin{array}{l}\text { Any } \\
\text { height }\end{array}$ & Non-combustible & Any area & $\begin{array}{l}\text { Floor assemblies: } \\
2 \mathrm{~h} \text {; } \\
\text { Mezzanines: } 1 \mathrm{~h}\end{array}$ & Required \\
\hline $\begin{array}{l}\text { Up to four } \\
\text { storeys }\end{array}$ & $\begin{array}{l}\text { Non-combustible } \\
\text { or combustible or } \\
\text { a combination }\end{array}$ & $1800 \mathrm{~m}^{2}$ & $\begin{array}{l}\text { Floor assemblies: } \\
\text { 1h; } \\
\text { Mezzanines: } 1 \mathrm{~h}\end{array}$ & Required \\
\hline
\end{tabular}

\subsubsection{Occupant Load}

The occupant load of a building is defined as the total number of persons that may occupy a building or portion thereof at any one time, and the occupant load factor refers to the floor area occupied by each person in the Life Safety Code [71]. Occupant load requirements of building codes vary based on the type of occupancy. Four basic types of occupancies are defined by Georgia Institute of Technology including assembly, business, laboratories and residential [72].

- Assembly: 1) concentrated use without fixed seating like dance floors or auditoriums which is calculated at one person per 7 square feet of NFA (net floor area). 2) unconcentrated use without fixed seating like dining rooms, exhibit rooms, conference rooms which are calculated at one person per 15 square feet of NFA (net

floor area). 3) With fixed seating, the occupant load shall be determined by the 
number of fixed seats. For areas without dividing arms, the occupant loads shall not be less than the number of seats calculated at one person per 18 inches. 4) Reading rooms are calculated at one person per 50 square feet of NFA and stack areas are 100 square feet of GFA (gross floor area).

- Business occupancies: occupant load is calculated at one person per 100 square feet of GFA.

- Laboratory occupancies: occupant load is calculated at one person per 100 square feet of GFA.

- Residential occupancies: occupant load is calculated at one person per 200 square feet of GFA.

The National Building Code of Canada gives more detail design criteria of occupant loads per area (see Table 2.14). To calculate the occupancy load for a specific building, first the area of the building is calculated by determining the length and width and multiplying them together. Then, the area is multiplied by criteria value to get the total occupancy load.

Table 2.14 Occupant load in Canada Building Code [70]

\begin{tabular}{|l|l|l|}
\hline Item & $\begin{array}{l}\text { Type of Use of Building or Floor Area or Part of Floor } \\
\text { Area }\end{array}$ & Area per person, $\mathrm{m}^{2}$ \\
\hline $\mathbf{1 .}$ & Assembly uses & See (a) \\
\hline & Space with fixed seats & 0.75 \\
\hline & Space with non-fixed seats & \\
\hline
\end{tabular}




\begin{tabular}{|c|c|c|}
\hline & Stages for theatrical performances & 0.75 \\
\hline & Space with non-fixed seats and tables & 0.95 \\
\hline & Standing space & 0.40 \\
\hline & Stadia and grandstands & 0.60 \\
\hline & Bowling alleys, pool and billiard rooms & 9.30 \\
\hline & Classrooms & 1.85 \\
\hline & School shops and vocational room & 9.30 \\
\hline & Reading or writing rooms or lounges & 1.85 \\
\hline & Dining, alcoholic beverage and cafeteria space & 1.10 \\
\hline & Laboratories in schools & 4.60 \\
\hline & Exhibition halls other than those classified in Group E & 2.80 \\
\hline \multirow[t]{4}{*}{2.} & Care or detention uses & \\
\hline & B-1: detention quarters & 11.60 \\
\hline & B-2: treatment and sleeping room areas & 10.00 \\
\hline & B-3: sleeping room areas & 10.00 \\
\hline \multirow[t]{3}{*}{3.} & Residential uses & \\
\hline & Dwelling units & See (b) \\
\hline & Dormitories & 4.60 \\
\hline \multirow[t]{3}{*}{4.} & Business and personal services uses & \\
\hline & Personal service shops & 4.60 \\
\hline & offices & 9.30 \\
\hline \multirow[t]{3}{*}{5.} & Mercantile uses & \\
\hline & Basements and first storeys & 3.70 \\
\hline & $\begin{array}{l}\text { Second storeys having a principal entrance from a } \\
\text { pedestrian }\end{array}$ & 3.70 \\
\hline
\end{tabular}




\begin{tabular}{|l|l|l|}
\hline & Thoroughfare or a parking area & \\
\hline & Dining alcoholic beverage and cafeteria space & 1.10 \\
\hline 6. & Other storeys & 5.60 \\
\hline & Industrial uses & \\
\hline & Manufacturing or process rooms & 4.60 \\
\hline & Storage garages & 46.00 \\
\hline & Aircraft hangars & 28.00 \\
\hline 7. & Other uses & 46.00 \\
\hline & Cleaning and repair of goods & \\
\hline & Kitchens & 4.60 \\
\hline & Storage & 9.30 \\
\hline & $\begin{array}{l}\text { Public corridors intended for occupancies in addition } \\
\text { to Pedestrian travel }\end{array}$ & 3.70 \\
\hline
\end{tabular}

(a) The number of seats in an assembly occupancy having fixed seats; (b) two people per sleeping room or sleeping area in a dwelling unit or suite

Because of changes in the building layouts from compartmented rooms to open plan rooms, some researchers have questioned this occupant load factor as too conservative. One of them is James A.Milke from Maryland College Park [73], who did a survey of occupant load factors in 23 office buildings including federal government, county government, and private sector buildings located in the Washington, DC area. Based on the building walk-through and telephone survey, the mean occupant load factor for all buildings is $248 \mathrm{ft}^{2} /$ person with a standard deviation of $67.3 \mathrm{ft}^{2} /$ person. This value is 
much higher than that in the Life Safety Code and the Canada National Building Code. This research is significant to assess the occupant load factor as it reflects an average loads in office buildings.

In Hong Kong, Wong [74] studied the occupant load factors for an old high-rise residential building by an interview survey. Based on the interview survey conducted in daytime and evening, the average maximum occupancy load factor for apartment buildings was found to be 0.1 person $/ \mathrm{m}^{2}$ with a standard deviation of 0.041 person $/ \mathrm{m}^{2}$. During daytime, the occupant load was $50 \%-80 \%$ of the maximum value. The result may be representative of other similar buildings in Hong Kong, which raises the question whether the specified occupant load factor in the code is appropriate, given the actual occupant loads measured.

And the National Research Council of Canada, Pauls and Johnson [75] found the occupant load factor to be $278 \mathrm{ft}^{2} /$ person by assessing the videotape records of evacuation drills in Canadian office buildings. Similarly, videotape records of occupant movement during a three-day period in a 21 -storey office building were used to obtain the occupant load at any time. The maximum occupant load was 1400 persons from the video, and the estimation of occupant load using the load factor cited in the code was 3400 persons. Based on the survey, an average occupant load factor of $243 \mathrm{ft}^{2} /$ person for this building was found. 


\subsection{Fire Safety in Timber Construction}

The combustibility of timber is one of the main reasons for many building regulations and standards to strongly restrict the use of timber in building construction and particularly of the number of storeys of timber buildings. Fire safety is an important criterion for the use of timber for buildings. The main objectives of fire safety are to provide life safety and property protection. The first objective ensures the safe egress of occupants and the safety of the rescue team. The objective aims to minimize fire losses to the building including the structure damages, fire protection system damages and damages of building contents.

\subsubsection{Growth of Fire}

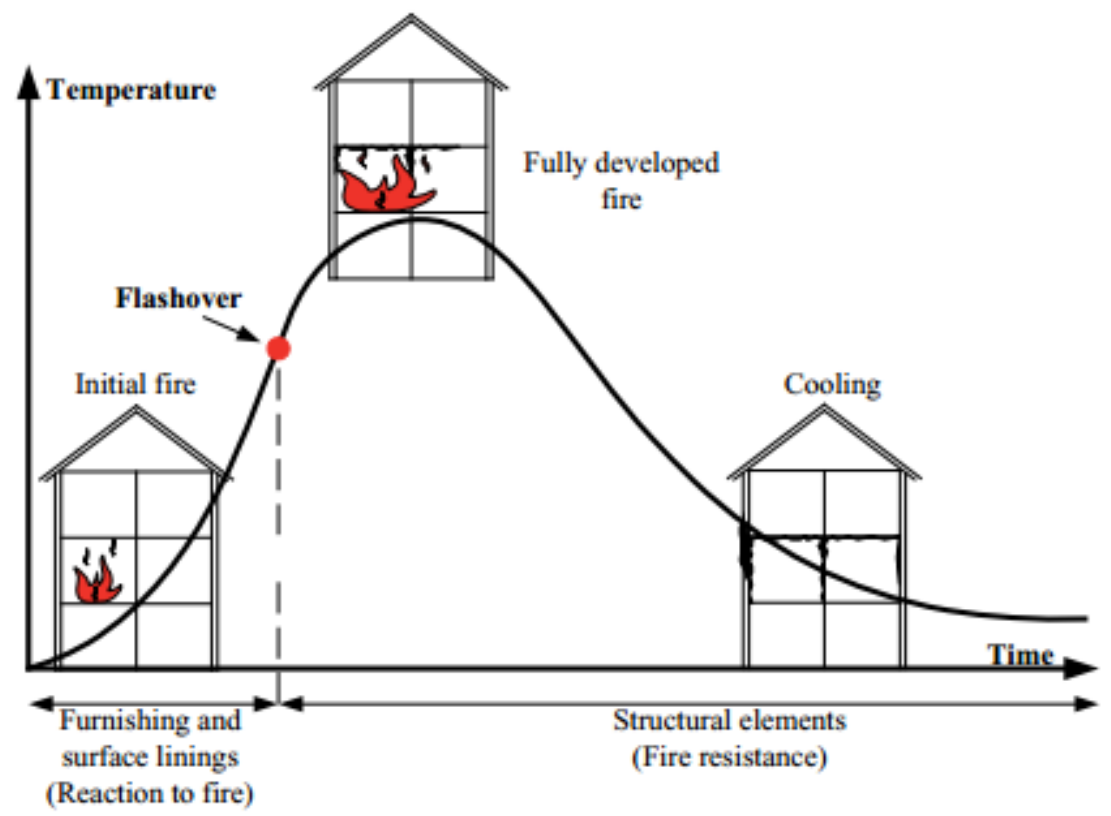

Figure 2.16 Two main fire stages that are relevant for the fire safety in buildings [76]

There are two different stages of fire development to be considered in the fire safety 
design of a building in relation to construction materials and structures [76]. As seen in Figure 2.16, the first stage is initial fire or pre-flashover fire. In this stage, the pre-flashover fire depends on the fire loads like the building contents and furnishing in the room and combustible building surface linings. The surface linings can contribute to rapid fire spread and the production of large quantities of combustion products. Building contents are not subject to building regulations, but surface linings are. Detecting fire in this stage is important as it will allow occupants to escape before untenable conditions develop. When flashover occurs, all unprotected combustible materials burn. The time to flashover is only a few minutes, but can trap, injure or kill occupants and firefighters. There are a lot of studies related small-scale room fire tests. For example, Mark [77] conducted twelve room fire tests with gypsum board ceiling and various wall lining materials to assess the reaction to fire of materials. A propane ignition burner located in one of the rear corners, and the test samples on walls only. The results showed that with a burner increase from $100 \mathrm{~kW}$ to $300 \mathrm{~kW}$, the time to flashover of unprotected plywood was less than 10 minutes, while that of fire retardant polyurethane foam was greater than 10 minutes. The test with rooms lined with gypsum boards did not flashover.

Following flashover, all combustible materials ignite, and the fire is considered fully developed. In this stage, the performance of load bearing and separating structures is important to limit the fire spread. The ability to contain the fire is called the fire resistance of the building structure [78]. Usually, fire resistance is assessed through 
full-scale fire resistance tests. The time-temperature curve used in tests is called the standard fire. Common standards for fire-resistance testing are ISO 834 (international standard used by many countries), ASTM E119 (US standard), ULC-S 101(Canadian standard similar to ASTM E119) and BS 476 Parts 20-23 (British Standard) [78]. There are three failure criterions for fire resistance testing including insulation, stability and integrity [79]. The first criterion insulation is to prevent the development of excessive temperature on the unexposed surface of the building element. The integrity criterion is to maintain the separating function in preventing spread of flame and smoke. And the stability criterion is the ability for load-bearing structural elements to support the load under fire.

\subsubsection{Fire Behavior of Timber}

Timber is widely used in building construction, but differs from other commonly used structural building materials as it is combustible. When the outer layer temperature reaches about $300{ }^{\circ} \mathrm{C}$, the wood ignites. A charred layer is formed which is a good insulator preventing excessive temperature rise in the core. There are three wood-based building systems in the building construction. 1) light-frame system which is used mostly in North America; 2) heavy timber post and beam system which was used a lot in the past; 3) cross-laminated timber (CLT) which is a new, cost-competitive building system. Understanding the fire behavior of different timber systems is becoming important in building design. 


\subsubsection{Light-Frame Systems}

Lightweight wood-framed assemblies are widely used in one-to-four storey residential buildings duo to their light weight and low construction cost. Walls and partitions are usually constructed with sawn timber studs. And floors consist of plywood or particle board sheeting with joists which may be sawn timber or engineered wood products. In most wall construction, these assemblies are required to provide adequate fire resistance in order to reduce fire risk level. Typically, timber-frame timber walls and floors are lined with gypsum plasterboards which are excellent insulators. Standard 1/2" gypsum plasterboards can achieve a fire resistance rating at least 15 mins in an ISO standard test $[80]$.

Full-scale fire tests in real buildings have shown that light timber fame construction can be designed with good fire resistance. At the Building Research Establishment facility (BRE) in Cardington U.K, a large-scale compartment fire test has been carried out to evaluate the fire resistance of a medium six storey timber frame building in 2000 [81]. The building and floor plan are shown in Figure 2.17. The fire took place in a single flat on level 3 and the fire load was provided by timber cribs spread over the floor area. The fire was ignited in the living area. Peak temperatures in the fire room reached around $1000{ }^{\circ} \mathrm{C}$ and remained at this level until the test was stopped by firefighter at 64 mins. The maximum heat release rate reached was approximately $6 \mathrm{MW}$. During this test, there was no evidence that the fire spread out of the fire room, and the temperatures in the 
adjacent flat, the flat above and flat below did not exceed $50^{\circ} \mathrm{C}$. Results also showed that fire conditions in the test were approximately $10 \%$ more severe than the standard 60 minute fire resistance test. This timber building performance in fire was able to meet the functional safety standards of the Building Regulation.
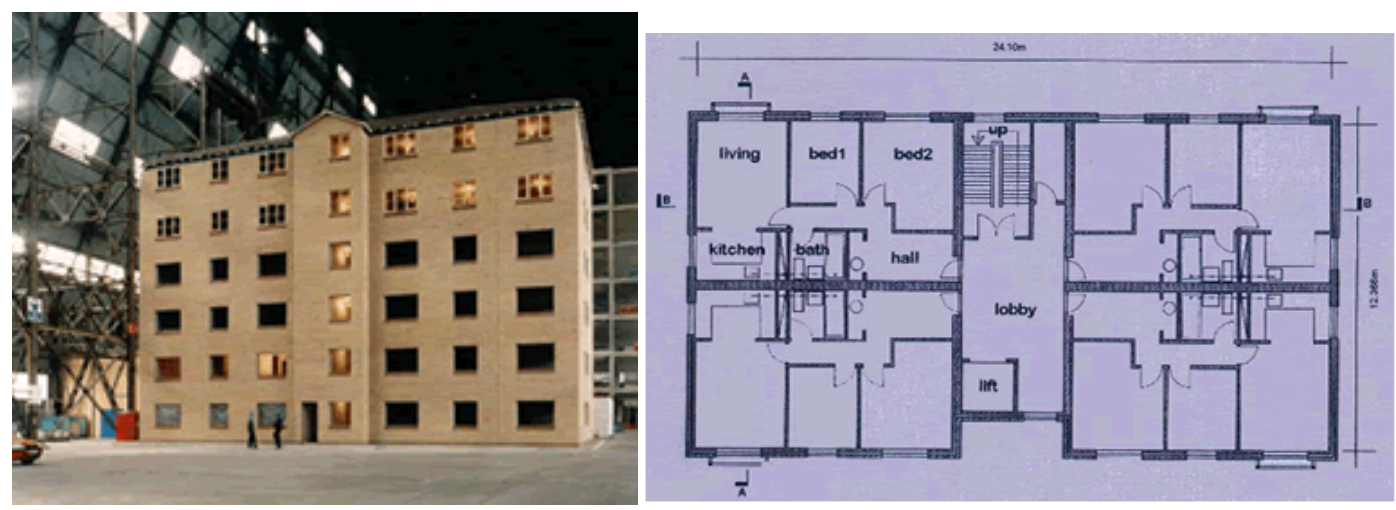

Figure 2.17 Six-storey timber frame building and the floor plan [81]

In Switzerland, six full scale tests on wooden modular hotels were performed under natural fire conditions (see Table 2.15) [82]. Four hotel modules (H1, H2, G1 and G2) were manufactured in shops as light timber frame construction with dimension of $6.6 \mathrm{x}$ $3.1 \times 2.8 \mathrm{~m}$. They had different interior room linings of walls and ceiling. For H1 and H2, combustible wood panels (OSB) were used. For G1 and G2, the linings consisted of one or two layers of non-combustible gypsum plasterboards. All modules were equipped with an automatic fire detection system: one was attached on the ceiling; the other was attached on the wall. The mattress was ignited and the total fire load included the room content and 11 wooden pallets. The total fire load density for the modules ranged from 363 to $855 \mathrm{MJ} / \mathrm{m}^{2}$. 
Table 2.15 Overview of the full-scale tests performed under natural fire conditions [82]

\begin{tabular}{|l|c|c|c|c|c|}
\hline \multicolumn{1}{|c|}{ Fire test } & $\begin{array}{c}\text { Safety } \\
\text { concept }\end{array}$ & Fire type & Modules & $\begin{array}{c}\text { Window } \\
\text { opening }\end{array}$ & Room linings \\
\hline BE bb g & $\begin{array}{c}\text { technical } \\
\text { (sprinkler) }\end{array}$ & $\begin{array}{c}\text { pre-flashover } \\
\text { fire }\end{array}$ & H1 & closed & combustible \\
\hline BE bb o I & $\begin{array}{c}\text { technical } \\
\text { (sprinkler) }\end{array}$ & $\begin{array}{c}\text { pre-flashover } \\
\text { fire }\end{array}$ & H1 & opened & combustible \\
\hline BE bb o II & $\begin{array}{c}\text { technical } \\
\text { (sprinkler) }\end{array}$ & $\begin{array}{c}\text { pre-flashover } \\
\text { fire }\end{array}$ & H1 & opened & combustible \\
\hline BÜ nbb & structural & $\begin{array}{c}\text { post-flashover } \\
\text { fire }\end{array}$ & $\begin{array}{c}\text { lower: G1 } \\
\text { upper: H2 }\end{array}$ & $\begin{array}{c}\text { opened } \\
\text { closed }\end{array}$ & $\begin{array}{c}\text { non combustible } \\
\text { combustible }\end{array}$ \\
\hline BÜ bb & structural & $\begin{array}{c}\text { post-flashover } \\
\text { fire }\end{array}$ & $\begin{array}{c}\text { lower: H1 } \\
\text { upper: H2 }\end{array}$ & $\begin{array}{c}\text { opened } \\
\text { closed }\end{array}$ & $\begin{array}{c}\text { combustible } \\
\text { combustible }\end{array}$ \\
\hline BÜ nbb demo & structural & $\begin{array}{c}\text { post-flashover } \\
\text { fire }\end{array}$ & $\begin{array}{c}\text { lower: G2 } \\
\text { upper: H2 }\end{array}$ & $\begin{array}{c}\text { opened } \\
\text { closed }\end{array}$ & $\begin{array}{c}\text { non combustible } \\
\text { combustible }\end{array}$ \\
\hline
\end{tabular}

The sprinkler systems were activated after 2-3 mins (see Table 2.16). No significant difference was observed between ceiling and wall sprinkler systems. Tests also showed that ventilation conditions did not influence the activation of the sprinkler. The automatic fire detection system (FDS) had four different four detection algorithms with different sensitivity, and detected the fire within two minutes. Table 2.17 shows the results of post-flashover tests. After ignition, fire grew very rapidly and the temperatures increased within few minutes to flashover. After flashover, the external burning out of the window was much more severe for the module which was constructed with combustible linings (see Figure 2.18). Except for the comparison of fire behavior between combustible and non-combustible constructions, the tests demonstrated that with fast response sprinkler systems the influence of combustible construction on fire growth and spread can be minimized. This study suggests that sprinkler protection can satisfy life safety objectives for any type of construction, including timber buildings with or without gypsum board 
protection.

Table 2.16 Result of pre-flashover fire tests [82]

\begin{tabular}{|c|c|c|c|c|c|c|c|}
\hline \multirow[t]{2}{*}{ Fire test } & \multirow{2}{*}{$\begin{array}{c}\text { Time of } \\
\text { mattress } \\
\text { ignition } \\
\text { [min] }\end{array}$} & \multirow{2}{*}{$\begin{array}{c}\text { Sprinkler on } \\
\text { the ceiling } \\
\Theta_{\mathrm{a}}\left[^{\circ} \mathrm{C}\right]^{\mathrm{a}} \\
\mathbf{t}_{\mathrm{a}}[\mathrm{min}]^{\mathrm{b}}\end{array}$} & \multirow{2}{*}{$\begin{array}{c}\text { Sprinkler on } \\
\text { the wall } \\
\Theta_{\mathrm{a}}\left[^{\circ} \mathrm{C}\right]^{\mathrm{a}} \\
\mathbf{t}_{\mathrm{a}}[\mathrm{min}]^{\mathrm{b}}\end{array}$} & \multicolumn{4}{|c|}{$\begin{array}{c}\text { Fire detection systems (FDS) Measured } \\
\text { detecting time [min] }\end{array}$} \\
\hline & & & & FDS 1 & FDS 2 & FDS 3 & FDS 4 \\
\hline BE bb g & ca. 01 '50" & $\begin{array}{l}57^{\circ} \mathrm{C} \\
2^{\prime} 45^{\prime \prime}\end{array}$ & $68^{\circ} \mathrm{C}$ (air) & $00 ’ 21 "$ & 00 '33" & 01'02" & 01 '27"' \\
\hline BE bb o I & ca. 02'00" & $\begin{array}{c}68^{\circ} \mathrm{C} \\
03^{\prime} 03^{\prime \prime}\end{array}$ & $68^{\circ} \mathrm{C}$ (air) & $00^{\prime} 30^{\prime \prime}$ & 00 '33" & 01'15" & $01^{\prime} 46^{\prime \prime}$ \\
\hline BE bb o II & ca. 01'20" & $\begin{array}{l}57^{\circ} \mathrm{C} \text { (air) } \\
02^{\prime} 01^{\prime \prime}\end{array}$ & $\begin{array}{l}68^{\circ} \mathrm{C} \\
02^{\prime} 15^{\prime \prime}\end{array}$ & $00 ' 33$ " & $00^{\prime} 36^{\prime \prime}$ & 00 '50" & 01'19" \\
\hline
\end{tabular}

Table 2.17 Results of post-flashover tests [82]

\begin{tabular}{|c|c|c|c|c|c|c|c|}
\hline \multirow{2}{*}{\multicolumn{2}{|c|}{$\begin{array}{l}\text { Fire test } \\
\text { Modules }\end{array}$}} & \multicolumn{2}{|c|}{ BÜ nbb } & \multicolumn{2}{|c|}{ Bü bb } & \multicolumn{2}{|c|}{ BÜ demo } \\
\hline & & lower: G1 & upper: $\mathrm{H} 2$ & lower: $\mathrm{H} 1$ & upper: $\mathrm{H} 2$ & lower: G2 & upper: H2 \\
\hline \multicolumn{2}{|c|}{ Window } & opened & closed & opened & closed & opened & closed \\
\hline \multicolumn{2}{|c|}{ Ignition time of mattress } & ca.01'30" & - & ca.01'40" & - & ca.01'40" & - \\
\hline \multicolumn{2}{|c|}{ Flashover } & ca.06’00" & - & $04 ' 27$ ' & - & $06{ }^{\prime} 58^{\prime \prime}$ & - \\
\hline \multicolumn{2}{|c|}{$\begin{array}{l}\text { Failure time of exterior window } \\
\text { glass of upper module }\end{array}$} & n.u. & $13^{\prime} 57^{\prime \prime}$ & n.u. & $06^{\prime} 09^{\prime \prime}$ & n.u. & $14 ’ 25 "$ \\
\hline \multicolumn{2}{|c|}{$\begin{array}{c}\text { Failure time of interior window } \\
\text { glass of upper module }\end{array}$} & n.u. & $42 ' 35^{\prime \prime}$ & n.u. & $07 ' 28$ "' & n.u. & $40 ' 16 "$ \\
\hline \multirow{2}{*}{$\begin{array}{l}\text { Sprinkler on the } \\
\text { ceiling }\end{array}$} & $\Theta_{\mathrm{a}}$ & $68^{\circ} \mathrm{C}$ (air) & $68^{\circ} \mathrm{C}$ & $68^{\circ} \mathrm{C}$ (air) & $68^{\circ} \mathrm{C}$ & $68^{\circ} \mathrm{C}$ (air) & $68^{\circ} \mathrm{C}$ (air) \\
\hline & $t_{a}$ & $02 ' 15 "$ & $42^{\prime} 40^{\prime \prime}$ & 03'20"' & - & $02 ' 35$ " & $42^{\prime} 30^{\prime \prime}$ \\
\hline \multirow{2}{*}{$\begin{array}{l}\text { Sprinkler on the } \\
\text { wall }\end{array}$} & $\Theta_{\mathrm{a}}$ & $68^{\circ} \mathrm{C}$ (air) & $68^{\circ} \mathrm{C}$ & $68^{\circ} \mathrm{C}$ (air) & $68^{\circ} \mathrm{C}$ & $68^{\circ} \mathrm{C}$ (air) & $68^{\circ} \mathrm{C}$ (air) \\
\hline & $\mathrm{t}_{\mathrm{a}}$ & $02{ }^{\prime} 20 "$ & $42^{\prime} 41^{\prime \prime}$ & 03 '27'” & $07 ' 30 "$ & 02 ' $44^{\prime \prime}$ & $41 ' 21 "$ \\
\hline \multirow{4}{*}{$\begin{array}{l}\text { Fire detection } \\
\text { systems (FDS) }\end{array}$} & FDS 1 & $00^{\prime} 25^{\prime \prime}$ & $15^{\prime} 10^{\prime \prime}$ & 01 '10" & 06 '54" & \multirow{4}{*}{$\begin{array}{l}\vec{J} \\
\mathscr{0} \\
\Xi \\
0\end{array}$} & $18^{\prime} 37^{\prime \prime}$ \\
\hline & FDS 2 & $00 ' 29 "$ & $15^{\prime} 31^{\prime \prime}$ & 01 '10" & 07 ’00" & & $19 ' 26 "$ \\
\hline & FDS 3 & $00 ' 59 "$ & $19^{\prime} 54^{\prime \prime}$ & 01 '17" & $07 ' 16 "$ & & 20'33" \\
\hline & FDS 4 & $01 ' 26 "$ & $31 ' 27$ ' & $01 ' 50$ '" & 07'30" & & $28^{\prime} 48^{\prime \prime}$ \\
\hline
\end{tabular}

${ }^{\mathrm{a}} \Theta_{\mathrm{a}}$ : activating temperature of sprinkler

${ }^{b} t_{\mathrm{a}}$ : measured activating time of sprinkler

cn.u.: window not used in the lower module 

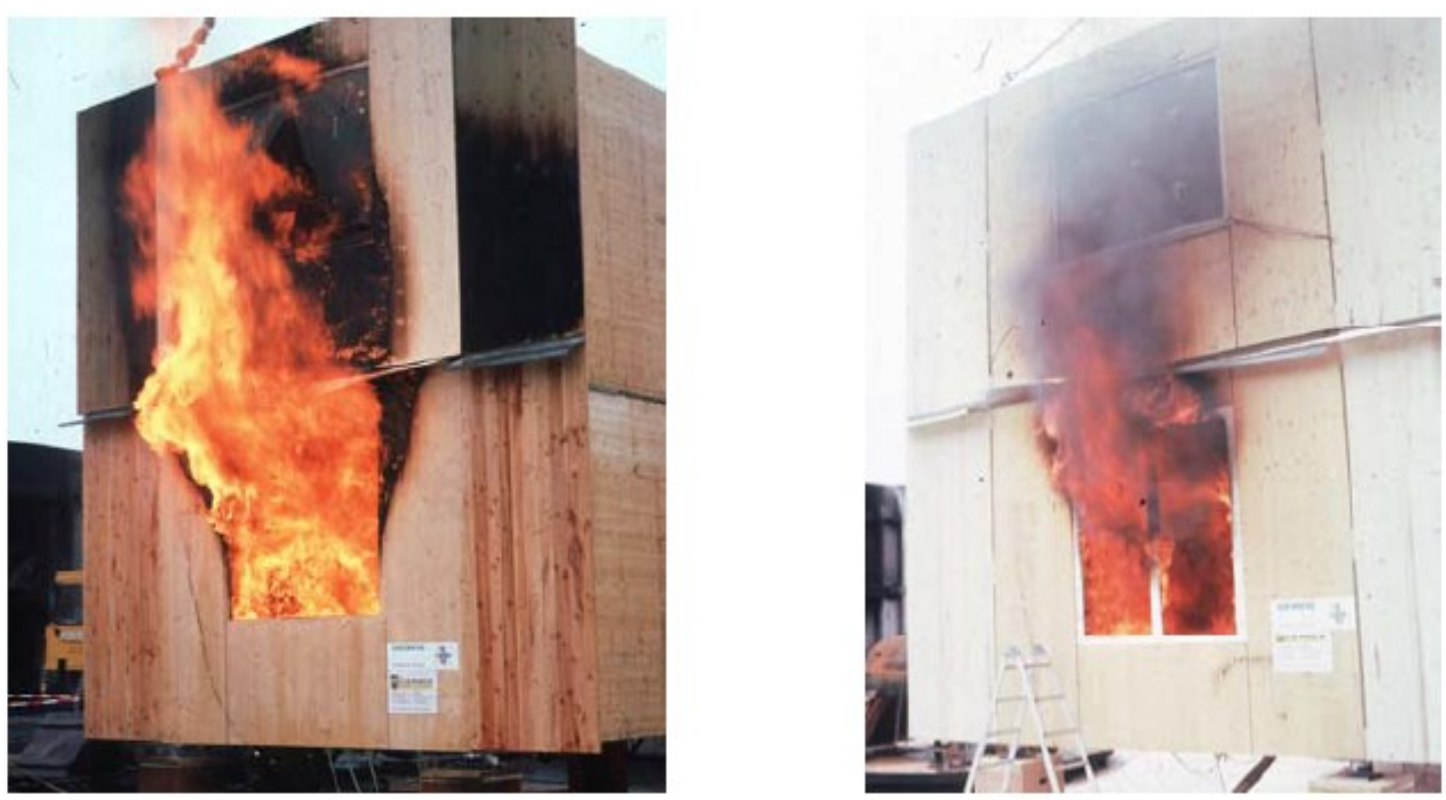

Figure 2.18 Fire development 7 mins after fire ignition; left: lower module wit combustible linings (fire test BÜ bb), right: lower module with non-combustible linings (fire test BÜ nbb) [82]

At the University of Canterbury of New Zealand, Thomas proposed three requirements of the fire resistance rating for different types multi-storey light timber fame buildings [83]. As shown in Table 2.18, the first requirement (F rating) is aimed at occupant escape, fire fighters rescue and fire-fighting operations. The second requirement (S rating) is aimed at structure integrity. If the sprinklers are installed, $\mathrm{S}$ rating can be halved. The figures in this table are typical for residential and accommodation buildings. The third requirement is aimed at residential units or suites that are fire separated from each other. The proposed minimum fire resistance rating for these buildings is 30 mins. 
Table 2.18 Minimum requirements for fire resistance rating in residential and accommodation

buildings [83]

\begin{tabular}{|c|c|c|c|c|}
\cline { 2 - 5 } \multicolumn{1}{c|}{} & \multicolumn{2}{c|}{$\begin{array}{c}\text { Fire Rating for Escape } \\
\text { (F Rating) }\end{array}$} & \multicolumn{2}{c|}{$\begin{array}{c}\text { Fire Rating for } \\
\text { Boundary Walls } \\
\text { (S Rating) }\end{array}$} \\
\hline Escape Height & $\begin{array}{c}\text { Without } \\
\text { Sprinklers }\end{array}$ & $\begin{array}{c}\text { With } \\
\text { Sprinklers }\end{array}$ & $\begin{array}{c}\text { Without } \\
\text { Sprinklers }\end{array}$ & $\begin{array}{c}\text { With } \\
\text { Sprinklers }\end{array}$ \\
\hline$\leq 25$ & 45 & 30 & $30-50$ & $15-25$ \\
\hline $25-34$ & not permitted & 30 & $30-50$ & $15-25$ \\
\hline$>34$ & not permitted & 45 & $30-50$ & $15-25$ \\
\hline
\end{tabular}

At the National Research Council of Canada (NRC) of Canada, Benichou and Sultan [84] made a literature review on the fire resistance of lightweight wood-framed assemblies. The conclusions obtained from this work are the following [84]:

1) Standard fire tests cannot represent real fire scenarios. Some models have been developed to predict real time-temperature curves in a building compartment, but they are not international approved. So, developing recognized models is needed in the future. 2) Experimental studies of fire behavior of light frame assemblies have been conducted by many countries. Generally speaking, the greater the thickness or the number of layers of gypsum board the higher the fire resistance rating of light timber assemblies. 3) Existing fire resistance models: a finite element model developed by the University of California to predict the failure of light frame assemblies exposed to the ASTM E119 fire curve; a two-dimensional heat transfer model TASEF developed at the Swedish National Testing Institute; WALL2D model developed at Forintek Canada Corp. to predict the fire 
behavior of light frame wood-stud walls exposed to the CAN/ULC-S101-M89 fire curve; SAWFT model developed at the University of Wisconsin to predict the fire endurance of assemblies with protections; model developed by Building Research Association of New Zealand to predict the thermal response of small cavity structural walls exposed to standard and real fires. Most of the models have limitations and refinement for practical use is required.

\subsubsection{Heavy Timber Systems}

Heavy timber consists of columns, beams, decks, and trusses made from sawn or laminated timber. The main difference between light and heavy timber construction is the section size of the timber members used in construction. This has an important impact on the fire performance and method of fire protection [85]. Heavy timber construction with long floor spans is suited to office buildings and multiple use buildings. Heavy timber elements have good fire resistance. A comparison between light timber and heavy timber construction is presented in the Table 2.19. A new, engineered wood product known as Cross Laminated Timber (CLT) is used in heavy timber construction. It is a flexible building system, suitable for use in all assembly types (e.g., walls, floors and roofs). CLT panels consist of several layers that are adhered perpendicularly to each other to attain strength in multiple directions. 
Table 2.19 Summary of light timber and heavy timber frame construction [85]

\begin{tabular}{|c|c|c|c|c|c|}
\hline $\begin{array}{c}\text { Framing } \\
\text { Type }\end{array}$ & $\begin{array}{c}\text { Average } \\
\text { Max } \\
\text { Height }\end{array}$ & $\begin{array}{c}\text { Typical } \\
\text { Timber } \\
\text { Elements }\end{array}$ & $\begin{array}{l}\text { Typical Nominal } \\
\text { Member Size }\end{array}$ & $\begin{array}{c}\text { Typical } \\
\text { Building } \\
\text { Function }\end{array}$ & $\begin{array}{l}\text { Protected vs. } \\
\text { Unprotected }\end{array}$ \\
\hline $\begin{array}{l}\text { Light } \\
\text { Timber } \\
\text { Frame }\end{array}$ & $\begin{array}{l}\text { Up to 5- } \\
6 \text { Stories }\end{array}$ & $\begin{array}{l}\text { Studs and } \\
\text { joists }\end{array}$ & $\begin{array}{l}2 " \mathrm{x} 4 "[50 \mathrm{~mm} \mathrm{x} \\
100 \mathrm{~mm}] \text { to } \\
2 " \mathrm{x} 12 "[50 \mathrm{~mm} \times \\
300 \mathrm{~mm}] \text { or similar }\end{array}$ & Residential & $\begin{array}{l}\text { Gypsum board } \\
\text { protection }\end{array}$ \\
\hline $\begin{array}{l}\text { Heavy } \\
\text { Timber } \\
\text { Frame }\end{array}$ & $\begin{array}{l}\text { Up to } 8+ \\
\text { Stories }\end{array}$ & $\begin{array}{l}\text { Columns, } \\
\text { posts and } \\
\text { beams }\end{array}$ & $\begin{array}{l}\text { Greater than 6"x } \\
6 "[150 \mathrm{~mm} x \\
150 \mathrm{~mm}\end{array}$ & $\begin{array}{l}\text { Residential / } \\
\text { Commercial }\end{array}$ & $\begin{array}{l}\text { *Unprotected } \\
\text { beams and posts } \\
\text { and / or gypsum } \\
\text { board protection }\end{array}$ \\
\hline
\end{tabular}

*Application of gypsum board protection is dependent on approval authority requirements

When timber members are exposed to fire, a process of pyrolysis occurs producing combustible gases, accompanied by a loss in mass and cross-section. A surface char layer is then formed which protects the interior of the timber cross-section against heat because of its low conductivity. With the increasing of char layer depth, the amount of heat transferred by surface burning to the unburnt part decrease. But, cracks in the char layer facilitate the passage of heat into the pryolysis zone. The charring rate of timber is the main parameter to describe the fire behavior of timber. Most design codes specify a constant char rate for the calculation of fire resistance rating. The Eurocode 5 for timber design gives two types of charring rate depending on whether corner rounding is included. As shown in Table 2.20, a slightly larger value is used if the effects of corner rounding and fissures are considered [86]. In the Swiss Federal Institute of Technology, the charring rate was studied using ISO-fire tests [87]. For different types of timber specimens, the measured charring rates were similar, and the mean values varied from 0.67 and $0.70 \mathrm{~mm} / \mathrm{min}$. In the New Zealand code, the specified charring rate for 
softwoods is $0.65 \mathrm{~mm} / \mathrm{min}$ obtained from tests on radiate pine glulam beams [88].

Table 2.20 Design charring rates $\beta_{0}$ and $\beta_{n}$ of timber, LVL, wood paneling and wood-based panels [86]

\begin{tabular}{|c|c|c|}
\hline & $\begin{array}{l}\boldsymbol{\beta}_{0} \\
\mathrm{~mm} / \mathrm{min}\end{array}$ & $\begin{array}{l}\boldsymbol{\beta}_{\mathrm{h}} \\
\mathrm{mm} / \mathrm{min}\end{array}$ \\
\hline $\begin{array}{l}\text { a) Softwood and beech } \\
\text { Glued laminated timber with a characteristic } \\
\text { density of } \geq 290 \mathrm{~kg} / \mathrm{m}^{3} \\
\text { Solid timber with a characteristic density of } \geq \\
290 \mathrm{~kg} / \mathrm{m}^{3}\end{array}$ & $\begin{array}{l}0,65 \\
0,65\end{array}$ & $\begin{array}{l}0,7 \\
0,8\end{array}$ \\
\hline $\begin{array}{l}\text { b) Hardwood } \\
\text { Solid or glued laminated hardwood with a } \\
\text { characteristic density of } 290 \mathrm{~kg} / \mathrm{m}^{3} \\
\text { Solid or glued laminated hardwood with a } \\
\text { characteristic density of } \geq 450 \mathrm{~kg} / \mathrm{m}^{3}\end{array}$ & $\begin{array}{l}0,65 \\
0,50\end{array}$ & $\begin{array}{l}0,7 \\
0,55\end{array}$ \\
\hline $\begin{array}{l}\text { c) LVL } \\
\text { with a characteristic density of } \geq 480 \mathrm{~kg} / \mathrm{m}^{3}\end{array}$ & 0,65 & 0,7 \\
\hline $\begin{array}{l}\text { d) Panels } \\
\text { Wood panelling } \\
\text { Plywood } \\
\text { Wood-based panels other than plywood }\end{array}$ & $\begin{array}{l}0,9^{\mathrm{a}} \\
1,0^{\mathrm{a}} \\
0,9^{\mathrm{a}}\end{array}$ & $\bar{z}$ \\
\hline
\end{tabular}

( $\beta_{0}$ is the one-dimensional design charring rate under standard fire exposure; $\beta_{\mathrm{n}}$ means the notional design charring rate, the magnitude of which includes for the effect of corner roundings and fissures)

With the recent interest in CLT construction, there has been some research in the fire testing of CLT panel assemblies. Frangi and Fargiacoome [89] performed separate fire testing of CLT members, and the results were compared with homogeneous timber panels. The result of the analysis indicates that the fire behavior of CLT panels can be strongly influenced by the thickness and the number of layers. If the charred layers or the fire protection fall off, an increased charring rate should be taken into account. The horizontal fire test showed that the charring rate of 3-layered timber panels is higher than that of 
homogeneous timber panels due to the fall-off of the charred layers. The three-layer timber panel with $3 \times 9 \mathrm{~mm}$ thickness has a higher charring rate than the three-layer timber panel with $3 \times 18 \mathrm{~mm}$ thickness. The vertical fire test showed a better fire behavior in comparison to horizontal timber panel tests because of a less pronounced falling of the charred layer.

Full-scale fire testing of heavy timber frame construction has been conducted by some researchers to demonstrate the effects of different fire protection systems, such as sprinklers and gypsum board protection. In Waseda University of Japan, a series of tests were conducted to investigate a large-scale glue-laminated timber gymnasium fire that happened in October 2000 in Hiroshima [90]. Table 2.21 shows the time lapse from the occurrence of the fire to the extinction based on the information obtained from hearings held at the site of the fire and in the municipal office as well as from newspaper articles about the fire [90]. The fire reached flashover very quickly within 9 minutes, and the post flashover fire lasted for 20 to 30 minutes. Almost all combustible objects and building components except for the heavy timber frames were lost in this fire.

Table 2.21 Time laps of fire [90]

\begin{tabular}{|l|l|}
\hline Time & Event \\
\hline & A teacher found pupils gathering in the gear supply storage and \\
$12: 30$ & picked up several cigarette ends from the gap between a urethane \\
\hline
\end{tabular}




\begin{tabular}{|l|l|}
\hline $12: 49$ & $\begin{array}{l}\text { Though teachers who noticed fire outbreak by fire detector, tried to } \\
\text { suppress the fire, the fire already had reached the ceiling and was too } \\
\text { large for them to extinguish. (Newspaper article) }\end{array}$ \\
\hline $12: 51$ & $\begin{array}{l}\text { The windows broke and the flame was ejected from the stage side to } \\
\text { opposite side of the gymnasium one after another in not so long time. } \\
\text { (Newspaper article) }\end{array}$ \\
\hline $12: 58$ & Fire brigade arrived and began to hose. (Fire department) \\
\hline $13: 10$ & Fire was suppressed. (Fire department) \\
\hline
\end{tabular}

The tests were conducted using combustible items suspected as the source of the fire including urethane mattress, tatami mat and a timber-frame partition wall to verify why the fire spread so quickly. The partition wall was covered by a layer of $5.5 \mathrm{~mm}$ plywood on the storage side and wood fiber reinforced cement board on the arena side. By comparing the total heat release rate of the respective specimens with a minimum calculated energy to cause flashover, the direct cause of flashover was estimated to be attributed to the burning of the partition wall which was probably ignited by the burning mattress. These tests also give some counter-measures to reduce the hazard of fires anticipated in such buildings: using non-combustible partition wall for the storage; installing sprinklers in the stage and the storage; and reducing the combustibility of 
urethane mattress.

In 2008, a natural full-scale fire test was performed in a 3 story cross-laminated (XLam) solid timber building with an area of about $7 \times 7 \mathrm{~m}$ and a height of about $10 \mathrm{~m}$ to check the timber structure performance in fire [91]. The fire room $(3.34 \times 3.34 \times 2.95 \mathrm{~m})$ was located on the first floor with two window openings $(1.0 \times 1.0 \mathrm{~m})$ and a door $(0.9 \times 2.1$ $\mathrm{m})$. The floor and roof consisted of 142-mm CLT panels with one layer of 12-mm gypsum board, and the fire room included 85-mm CLT wall panels with two layers of 12-mm gypsum. The total fire load density is calculated for the fire room was about 790 $\mathrm{MJ} / \mathrm{m}^{2}$. As seen in Figure 2.19, flashover occurred after a long time around 40 minutes because the window was opened only at one quarter of the width at the beginning. After the gypsum board failed, the temperatures at the interface of the different layers of the wall grew very fast. No smoke was observed and no elevated temperatures were measured in the upper level room. The findings indicate that with the protection of the non-combustible gypsum board, it is possible to limit the fire spread into the upper level room and the damage to the CLT building can be minimized. 


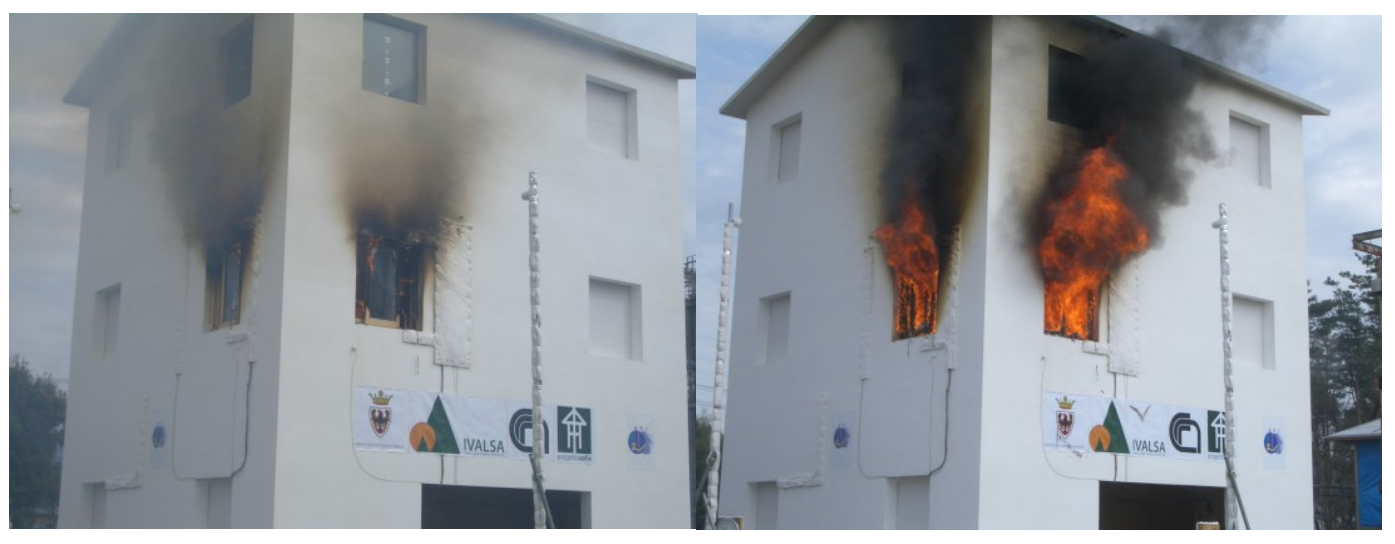

Figure 2.19 Fire development after about 32 minutes (left) and after 40 minutes (right) after fire

ignition [91]

\subsection{Fire Protection Systems}

There are essentially two kinds of fire protection systems, active fire protection (AFP) and passive fire protection system (PFP). AFP refers to systems activated either mechanically or electronically in a fire. PFP can provide an effective alternative to active systems for protecting the building structural collapse, and preventing the spread of fire.

\subsubsection{Passive Fire Protection System}

The objective of passive fire protection systems is to contain fires or slow fire spread within a building. This is achieved by using fire-resistance walls, floors and doors, limiting the fire compartment size, installing passive smoke collection and venting systems, providing protected escape routes such as emergency exits and staircases.

Fire usually spreads through common concealed spaces in walls, floors or ceilings, broken windows and fire door opening. Therefore, it is very important that these concealed spaces be protected to resist fire spread. Fire door openings should be in the 
right direction and closing to protect the passages, compartment walls and holding areas [92]. Having smaller fire compartments may prevent the spread of heat, smoke and gases from the room of origin to other building spaces. This minimizes the building damage and gives more time to the building occupants and firefighters for emergency escape and rescue.

In timber structures, there are currently two principal ways that wood can be directly modified to improve its fire performance [93]. The first method is fire retardant treated wood (FRTW) which is widely recognized in North American building codes. The aim is to delay ignition and reduce the amount of heat released during combustion by using a chemical treatment. Most FRTW is manufactured using the "full-cell pressure method" where the excess surface chemicals are removed by vacuum and overpressure. The other method of increasing the fire performance of the structure is through the application of a coating. The coating can be fire retardant coating, fire resistance coating or a combination of both.

\subsubsection{Active Fire Protection}

Active fire protection (AFP) is an integral part of any fire safety strategy. It includes fire detection, smoke and heat extraction systems, fire suppression and sprinkler systems.

Fire is detected by smoke and heat detectors and warnings are provided by the alarm systems. Alarm systems play a key role in life safety. They initiate emergency evacuation and alert the local fire department. They can be activated by a number of devices 
including smoke and heat detectors, sprinklers and by occupant pulling a pull-bar. Where a detection system is implemented, it can be programmed to carry out other actions like automatic closing fire doors and opening servo-actuated vents in stairways.

Smoke and heat venting and exhaust control systems are often used in large buildings due to the difficulties to ventilate smoke through natural openings. The aim is to extend the occupant escape time and facilitate escape and rescue.

Fire can be extinguished by firefighting or extinguishers. Sprinkler systems are found in many building types. It helps save lives by quickly reducing the heat, flame and smoke produced in a fire.

\subsection{Summary}

Since life safety closely relies on an efficient evacuation in fire conditions, a review of research on human behavior and evacuation dynamics under emergency conditions was performed. Basic evacuation parameters, human behavior, evacuation time calculations and evacuation models were reviewed. It was found that there are limited studies on emergency evacuation in mid-rise buildings in North American. In this context, a new network evacuation model CUrisk evacuation model developed at Carleton University was developed to study occupant evacuation in mid-rise buildings. This model can consider the effects of smoke on movement speed and exit choices. To provide an environment for the occupants inside or near a building that is safe from fire, the 
requirements of timber building construction as building heights, floor areas and occupant loads, the fire behavior of wood and means of improving the fire performance of timber were discussed. 


\section{Chapter: Comparisons of CUrisk Evacuation Model Results}

Emergency evacuation of a building becomes necessary in case of an accident such as fire. At Carleton University in Canada, a network evacuation model has been developed to investigate occupant evacuation in building fire emergencies. The aim of this chapter is to compare the predictions of this model with other methods and analyze how building design conditions affect evacuation efficiency in a fire emergency.

The study of this chapter is divided into two parts:

1) A comparison of three different methods including CUrisk evacuation model, Pathfinder software and SFPE analytical calculations.

2) A comparison of the evacuation time by considering different design conditions.

\subsection{Methods}

This chapter introduces the methodology of the CUrisk evacuation model and the other egress models selected to compare with CUrisk evacuation model. Two ways are used to compare with the CUrisk result: software and hand calculation. For the evacuation software, Pathfinder is selected as it contains two different modeling approaches which are a continuous behavior model and SFPE model based on flow model. For the hand calculation, SFPE analytical calculations are used.

\subsubsection{CUrisk Evacuation Model}

The CUrisk evacuation model is a sub-model of the fire risk analysis model CUrisk. It is 
a probabilistic occupant evacuation model based on Monte Carlo methods that can generate distributions of evacuation times collected from the repeated runs of each simulation [94]. Random variables include the pre-evacuation times, occupant properties such as age, gender, type, speed and initial location, exit selection and distance to be traveled to the exit from a compartment. During a Monte Carlo simulation, a time step and overall time length are specified and the number of runs is controlled by the minimum and maximum run number and a tolerable relative change. In each time step, a random number is generated for each occupant to determine movement state. For example, if the evacuation probability of the occupant is higher than the random number, this person will start to evacuate. Otherwise, he will stay in his current compartment and wait for the next time step. The distribution for the random number is assumed to be a uniform distribution. Under Monte Carlo running, the model can calculate the relative changes of the evacuation time distributions, the average evacuation time, and the most probable evacuation time.

The CUrisk evacuation model uses a coarse network approach to define the building geometry, including compartments, corridors, stairs, doors and building exits, as well as the initial positions of occupants. In this model, the spatial layout of a building is represented by nodes which are connected by arcs representing travel path between two nodes. Each node may represent a room, corridor or stair. Nodes are specified in terms of length and width and doors are defined in terms of width and boundary layer width. In 
narrow structures such as a long corridor, a multi nodes approach is used. That means, the long, narrow building components are divided into a series of small nodes which more accurately reflect human evacuation route. So, when modeling evacuation in a complex building such as a mid-rise building, this method will save computer running time so that repeated simulations can be completed in a reasonable timeframe.

In this model, occupants move from one node to another instead of from one position inside the compartment to another. The travel speed is affected by occupant density, hazard level of the environment (as smoke level factor) and evacuee's base travel speed which is decided by personal characteristics (gender, age, location.). The movement speed can be expressed by the following formula.

$$
\begin{aligned}
& S=f_{s} f_{d} S_{0} \\
& f_{d}= \begin{cases}1 & d \leq 0.55 \text { people } / \mathrm{m}^{2} \\
\frac{(1-0.266 d)}{0.8537} & d>0.55 \text { people } / \mathrm{m}^{2}\end{cases}
\end{aligned}
$$

Where, $\mathrm{d}$ is the denstiy, $f_{s}$ is the smoke level factor, $f_{d}$ is the density factor and $s_{0}$ is the base speed. $f_{s}$ is given by a series of experiment data ranging from 1 to 0.5 [22]. $f_{d}$ is derived from Nelson's research in SFPE handbook which follows equation 3.2 [22]. $s_{0}$ is the base speed with a uniform distribution.

Occupant travel distance is calculated by multiplying the adjusted speed of the occupant by the increment of time considered in the simulation. This value is then subtracted from the remaining distance the occupant needs to travel to exit the component. If the new 
value is 0 or negative, the model will check if the person can pass the door. If it's true, the occupant will enter to the next node, if not, he will remain in the front of the door and queues. In this model, the maximum flow rate 1.3 people $/ \mathrm{s} / \mathrm{m}$ [94] is used. If in one time step, the number of occupant pass from the door is smaller than maximum capacity and the density in next node is less than 4 people $/ \mathrm{m}^{2}$, this occupant will pass.

\subsubsection{Pathfinder}

Pathfinder is an agent based egress and human movement simulator developed by Thunderhead Engineering Consultants, Inc [95]. It supports two ways to model the evacuation process: a steering model and an SFPE model. The first one is a continuous model based on the idea of inverse steering behaviors. Pathfinder's steering model uses a combination of path planning, steering mechanisms and collision handing to control occupant movement and allows each occupant to interact with other occupants and the environment. The SFPE model is a flow model implementing the concepts in the SFPE Handbook of Fire Protection Engineering [95]. The moving speed is determined by occupant density and flow through doors which is controlled by the door width. The initial occupant load is obtained by specifying the density in certain areas or by giving a discrete number of occupants. The output files include the number of people that have used an exit, the times that the first and last occupant exits from a given room, and the total evacuation time.

\subsubsection{SFPE Analytical Calculations}


This method is defined by Nelson in the SFPE Handbook. Hand calculations follow a series of expressions given in the Emergency Movement Chapter. The evacuation time is estimated using these equations that relate data acquired from tests and observations to a hydraulic approximation of human flow [22]. Some assumptions are made in this method: all occupants start to evacuate at the same time without a response time; the prime controlling factor will be either the stair or the door widths; the occupants will use all facilities in the optimum balance. The solution as follows: The first step is to estimate the flow capability of a stair and door using the effective width and maximum specific flow. Then, determine the speed of movement for the estimated stairway flow. This step is done by the following empirical equation.

$$
S=k-k \alpha D
$$

S: Speed along the line of travel; D: Density (persons per area); k: constant value as in the Table 3.1 (for $\mathrm{k}_{1}, \alpha$ is 2.86 for speed in $\mathrm{ft} / \mathrm{min}$ and density in persons $/ \mathrm{ft}^{2}$; for $\mathrm{k}_{2}, \alpha$ is 0.266 for speed in $\mathrm{m} / \mathrm{s}$ and density in persons $/ \mathrm{m}^{2}$ ).

Table 3.1 Constants for equation 3.3 [22]

\begin{tabular}{llcc}
\hline \multicolumn{2}{c}{ Exit Route Element } & $k_{1}$ & $k_{2}$ \\
\hline $\begin{array}{l}\text { Corridor, Aisle, } \\
\quad \text { Ramp, Doorway }\end{array}$ & & 275 & 1.40 \\
Stairs & & \\
Riser (in.) & Tread (in.) & & \\
7.5 & 10 & 196 & 1.00 \\
7.0 & 11 & 212 & 1.08 \\
6.5 & 12 & 229 & 1.16 \\
6.5 & 13 & 242 & 1.23 \\
\hline 1
\end{tabular}

$1 \mathrm{in} .=25.4 \mathrm{~mm}$.

Calculating the total travelling distance, a convenient multiplier is used to convert the 
vertical distance between floors to a horizontal distance. The travel time of one person moving between two floors with the maximum flow can be obtained. In the last step, the total evacuation time in the building can be estimated. This model only provides quantitative results about evacuation time and does not give information about queuing and bottlenecks.

\subsection{Building Design Cases}

In order to justify the application and usefulness of the present CUrisk evacuation model, and quantify the affect of the design conditions on occupant evacuation in mid-rise buildings, three different building layouts have been selected. Figure 3.1 shows the plans of the second floor of each building. The other storeys have the same plan as the second floor except for the first floor whose lobby hall replaces the small compartments and are connected with exits in b) and c). Stairwells are connected with exits directly in a). The dimensions and total areas of the three buildings are listed as follows.

Layout a: small-sized design, 8 office rooms $(12 \mathrm{~m} \times 7.5 \mathrm{~m})$ on each floor with 2 stairways $(1.2 \mathrm{~m} \times 5.5 \mathrm{~m})$; total floor area is $907.5 \mathrm{~m}^{2}\left(9768 \mathrm{ft}^{2}\right)$.

Layout b: medium-sized design, 18 office rooms on each floor (sixteen $12 \mathrm{~m} \times 7.5 \mathrm{~m}$ and two $7 \mathrm{~m} \times 7.5 \mathrm{~m})$ with 2 stairways $(1.2 \mathrm{~m} \times 5.5 \mathrm{~m})$; total floor area is $1815 \mathrm{~m}^{2}(19536$ $\left.\mathrm{ft}^{2}\right)$.

Layout c: large-sized design, 26 office rooms (twenty-four $12 \mathrm{~m} \times 7.5 \mathrm{~m}$ and two $7 \mathrm{~m} \times$ 
$7.5 \mathrm{~m})$ in each floor with 4 stairways $(1.2 \mathrm{~m} \times 5.5 \mathrm{~m})$; total floor area is $2607 \mathrm{~m}^{2}(28062$ $\left.\mathrm{ft}^{2}\right)$.

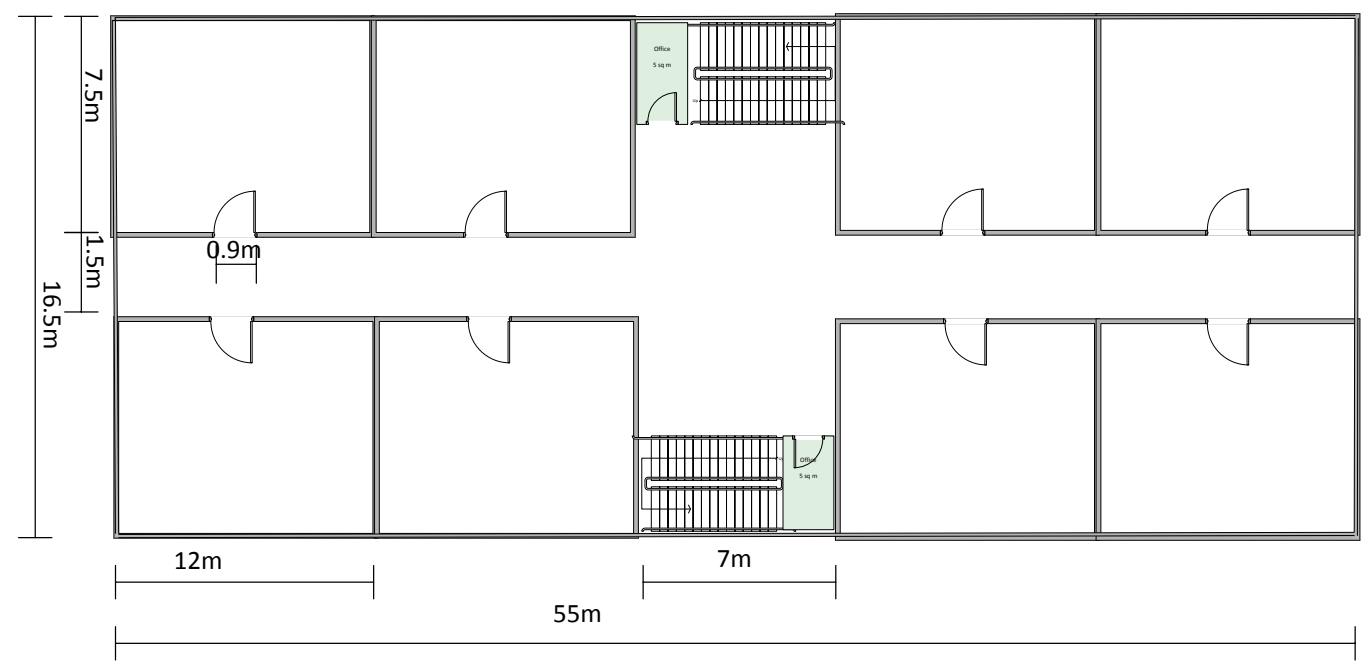

Layout a

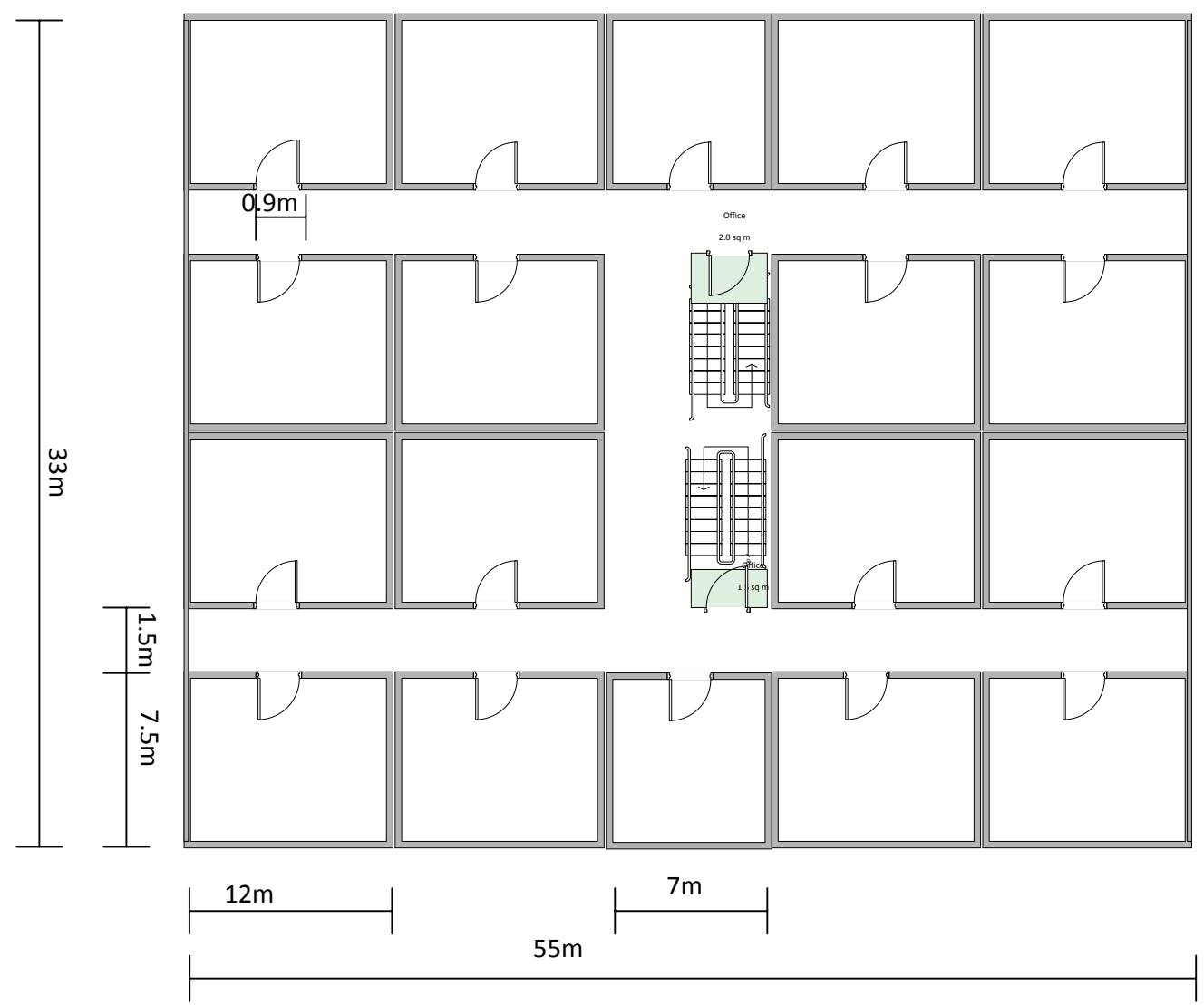

Layout $b$ 


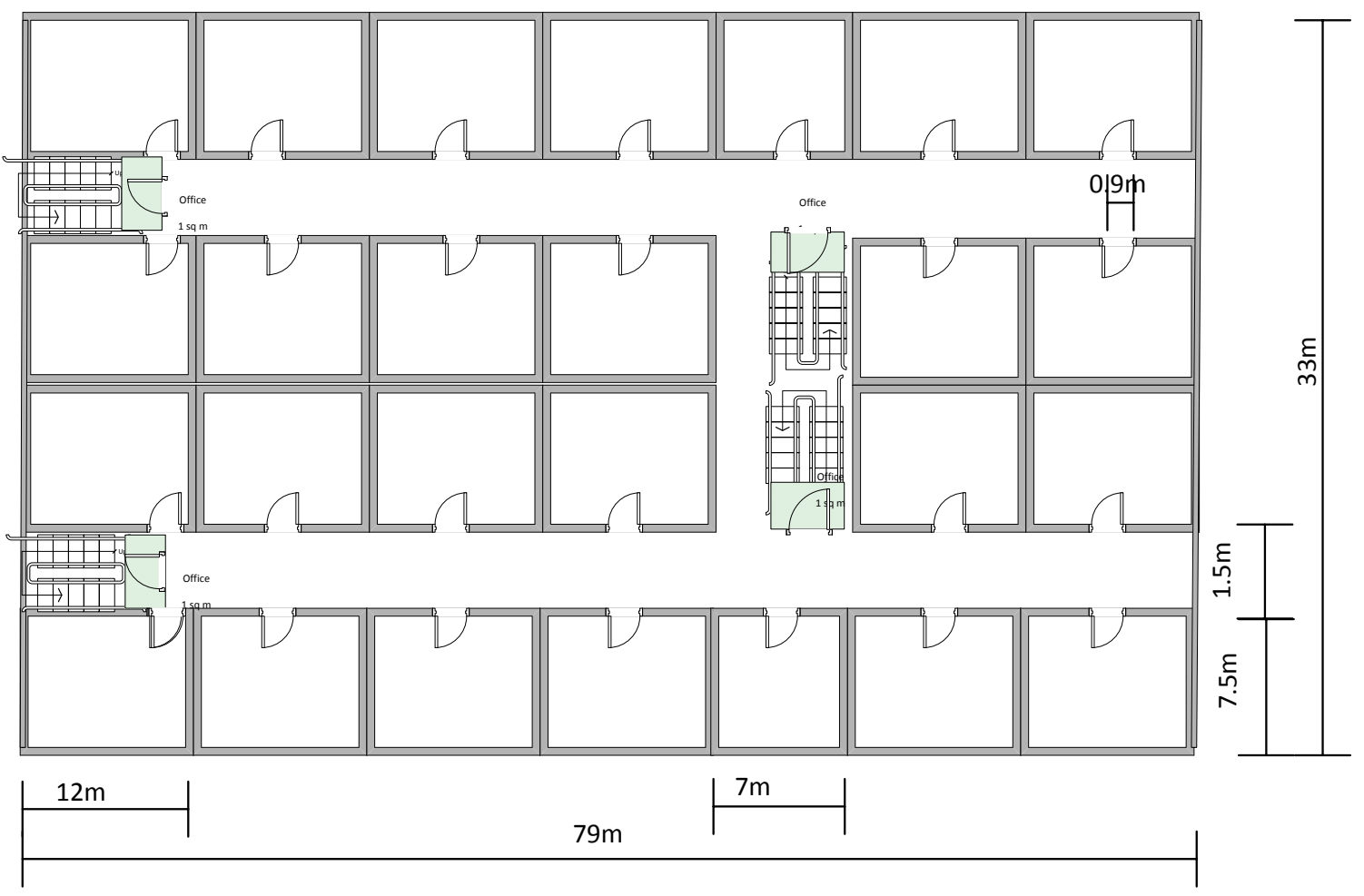

Layout c

Figure 3.1 Plans of the second floor of the three layouts

According to the National Building Code of Canada [70], for business office, the occupant load should not be less than 100 square feet per person. So the maximum occupant loads in layouts a, b and c are 98, 195, 280 persons per floor respectively. Simulations were done for each layout from 2 storeys to 6 storeys. The evacuation cases conducted in this study correspond to the following 18 scenarios:

Scenario 1-3: using the maximum occupant load of 98 persons per floor in layout a, three heights of buildings are considered: 2 storeys, 4 storeys and 6 storeys buildings.

Scenario 4-9: using the occupant load of 98 persons and 195 persons per floor in layout $b$, three heights of buildings are considered: 2 storeys, 4 storeys and 6 storeys. 
Scenario 10-18: using the occupant load of 98 persons, 195 persons and 280 persons per floor in layout c, three heights of buildings are considered: 2 storeys, 4 storeys and 6 storeys.

It is assumed that all the evacuation scenarios are in fire drill mode which assumes no occupant response time. The initial walking speeds are in the range of $0.8-1.8 \mathrm{~m} / \mathrm{s}$. The evacuation is modeled considering different building heights, floor sizes, stairway number and occupant loads.

\subsection{Results and Discussion}

\subsubsection{Comparison of Evacuation Results of the Different Models}

This section presents comparison results for 6 and 4 storeys building with layout a, layout $\mathrm{b}$ and layout $\mathrm{c}$. The maximum occupant loads were set in each layout to ensure the same occupant density. The total building evacuation was simulated so that all occupants started the evacuation at the same time. Figure 3.2 and Figure 3.3 shows the results of the CUrisk evacuation model, Pathfinder software and the SFPE analytical calculations. 


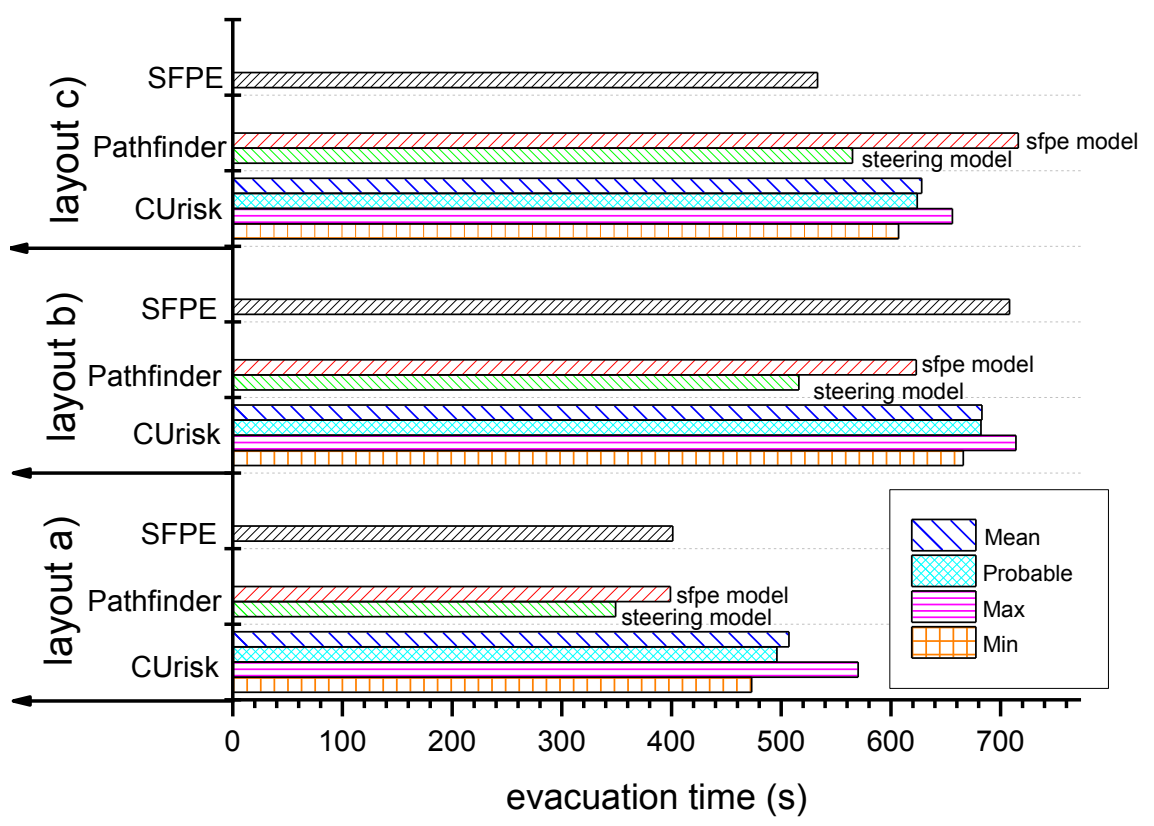

Figure 3.2 Evacuation time of 6 storeys buildings

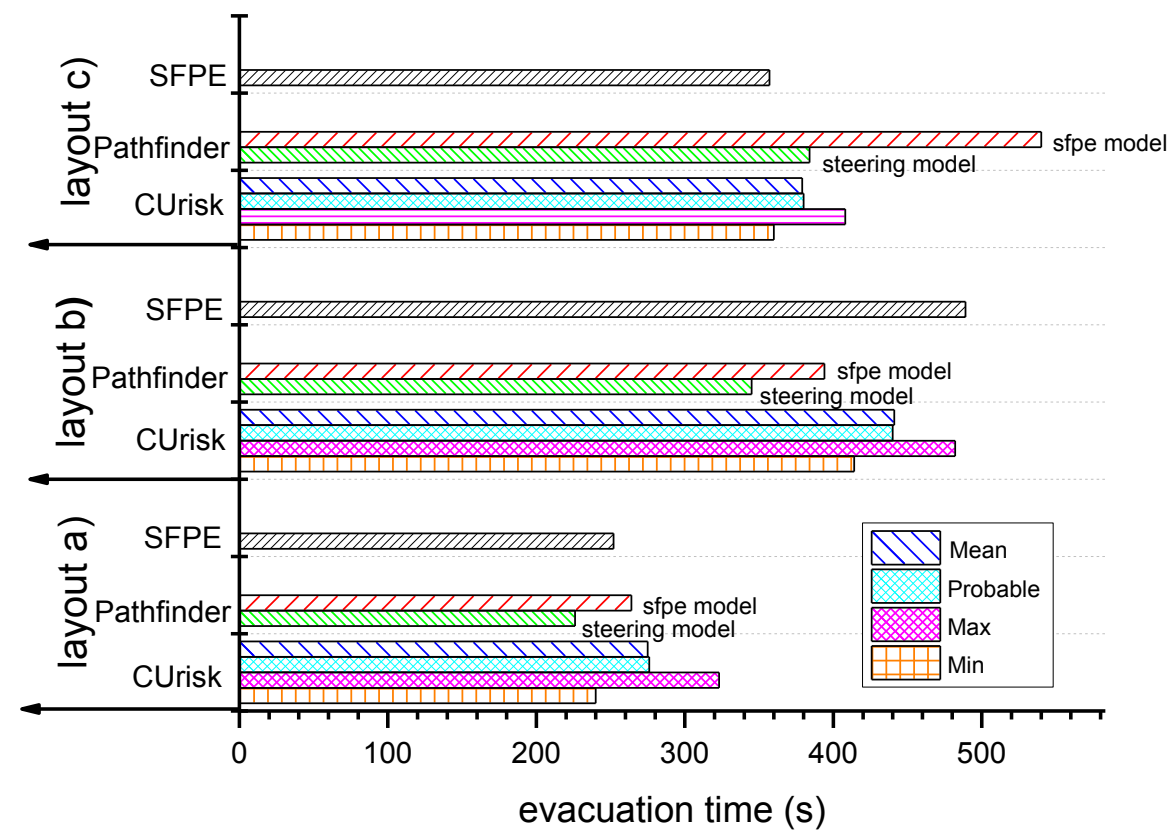

Figure 3.3 Evacuation time of 4 storeys buildings 
The results show that the total evacuation times produced by the CUrisk model and the SFPE analytical calculations are close. For example, in 4 storeys buildings, the data produced by CUrisk in layout a, b, and $\mathrm{c}$ are $9 \%$ higher, $10 \%$ lower and $6 \%$ higher respectively than those of the SFPE analytical calculations; and in 6 storeys building, the difference are $19 \%,-4 \%$ and $15 \%$ respectively. In addition, the CUrisk evacuation model provides four different categories of evacuation times that collected from the repeated runs of each simulation. They are the mean value, the most probable value and the maximum and minimum values when the last person evacuates the building. During a Monte Carlo simulation, statistical information for evacuation times is calculated. The mean evacuation time is the average value of the evacuation time of all runs, the most probable evacuation time is the evacuation time with highest probability. These calculations are possible because the CUrisk is a probabilistic occupant evacuation model that can produce probability distributions of evacuation times. Figure 3.4 presents the probability density distributions of the total evacuation time in 4 and 6 storeys buildings. It can be seen that the total evacuation times generated from the CUrisk model are close to a normal distribution with standard deviations of 13.0 and 17.6 for layout a, 10.7 and 7.9 for layout $\mathrm{b}$ and 7.5 and 9.7 for layout $\mathrm{c}$. 


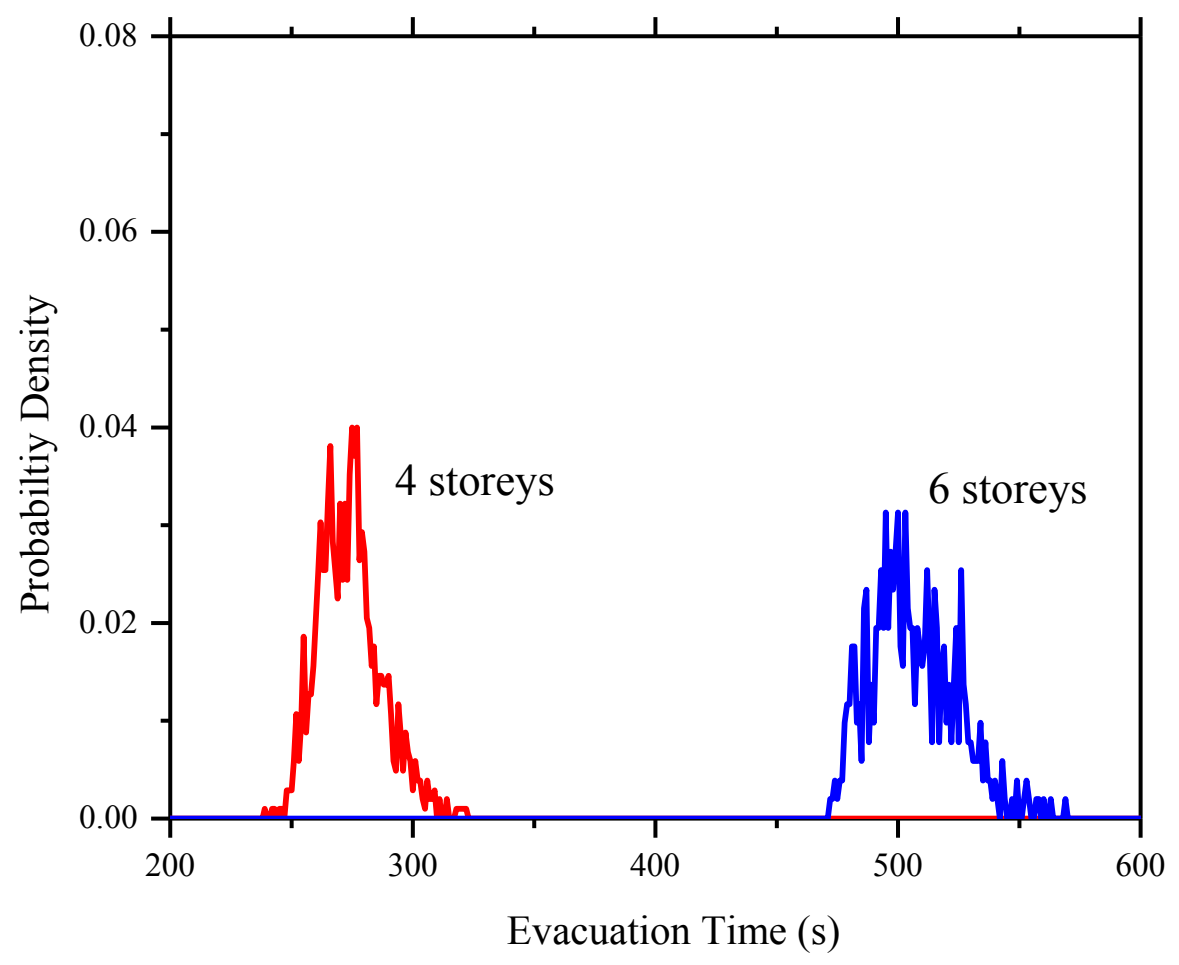

Layout a

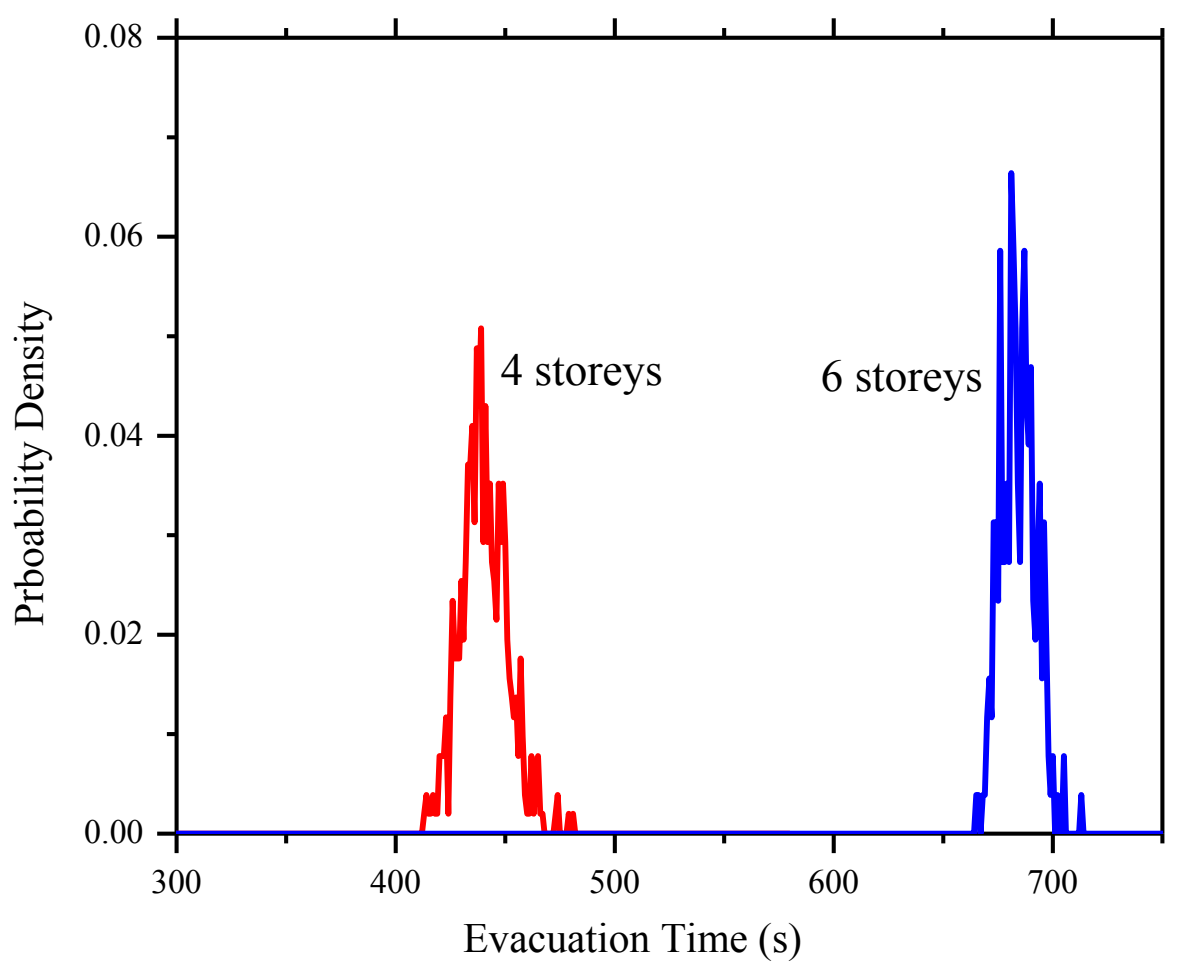

Layout b 


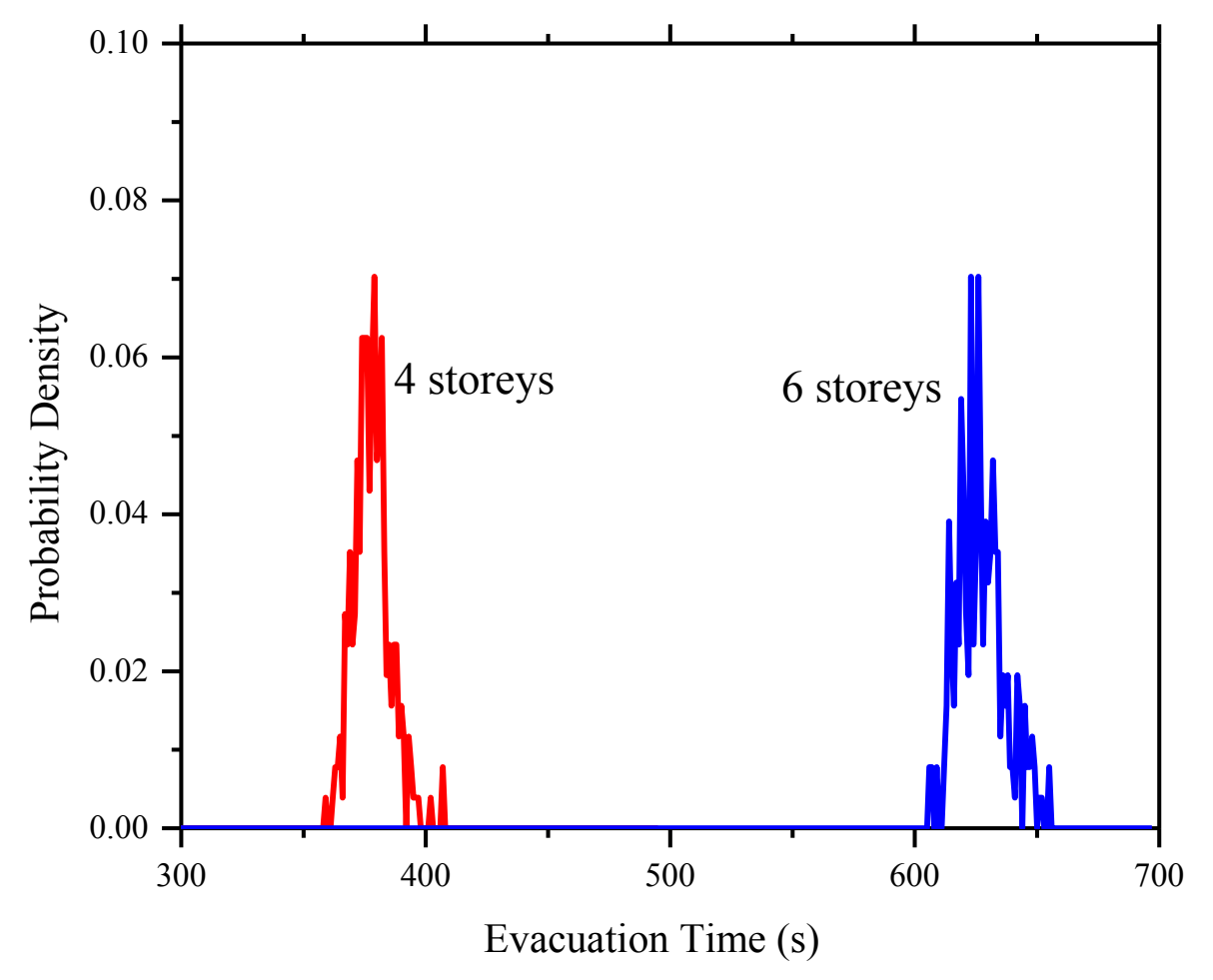

Layout c

Figure 3.4 The probability density distributions of the total evacuation times in different layouts

The reasons for the small difference between the results of the CUrisk model and hand calculations are the following: 1) The empirical equation used in the SFPE analytical calculations is an average result which comes from data fitting of total evacuations under different conditions in office buildings. The prime controlling factor of evacuation time is either the stair or the door widths, and it does not consider the effect of density on movement speed. 2) The CUrisk model uses the coarse network approach that simplifies the representation of the building space and occupants' characteristics. Although it considers the effective width model in which a specific flow rate of 1.3 people $/ \mathrm{s} / \mathrm{m}$ is defined as in the SFPE handbook, the CUrisk model takes into account the effect of 
density on movement speed. What's more, with over 2000 times of Monte Carlo repeated running, more rational results can be obtained. Thus, using the effective width model, CUrisk is able to produce reasonable evacuation times which do not differ greatly from the calculated results of the SPFE correlation.

When comparing the total building evacuation times with the Pathfinder software, it can be seen that most of the evacuation times obtained from CUrisk are a bit higher. The results obtained from the steering and SFPE models of Pathfinder show obvious differences. Specifically, the SFPE model in Pathfinder produces lower total evacuation times as shown in Figure 3.3 and Figure 3.4. The differences between the CUrisk and the Pathfinder models range from $-18 \% \sim-4 \%$ (layout a), $-21 \% \sim-10 \%$ (layout $b$ ), 1\% 42\% (layout c) in 4 storeys buildings, and -29\% - 20\% (layout a), -24\% -9\% (layout b), $-10 \% \sim 33 \%$ (layout c) in 6 storeys buildings.

Besides the total evacuation times, the cumulative probability of the number of evacuated occupants can be an indicator to show the changes of the flow during the evacuation. According to Figure 3.5, it is apparent that the Pathfinder simulations give perfectly linear trends in both the steering and SFPE model. In CUrisk simulations, the slopes of the cumulative probabilities significantly decrease in the later evacuation process. This is due to queuing: people from different storeys will be evacuated through the limited exits, so the number of people will increase and queue in the front of exits which causes a heavy congestion and slower movement speed. Along with the increasing number of 
occupants on each floor, queuing appears earlier. For example, in layout a, flow rate changes after about $100 \mathrm{~s}$ while in layout $\mathrm{b}$ after about $70 \mathrm{~s}$.
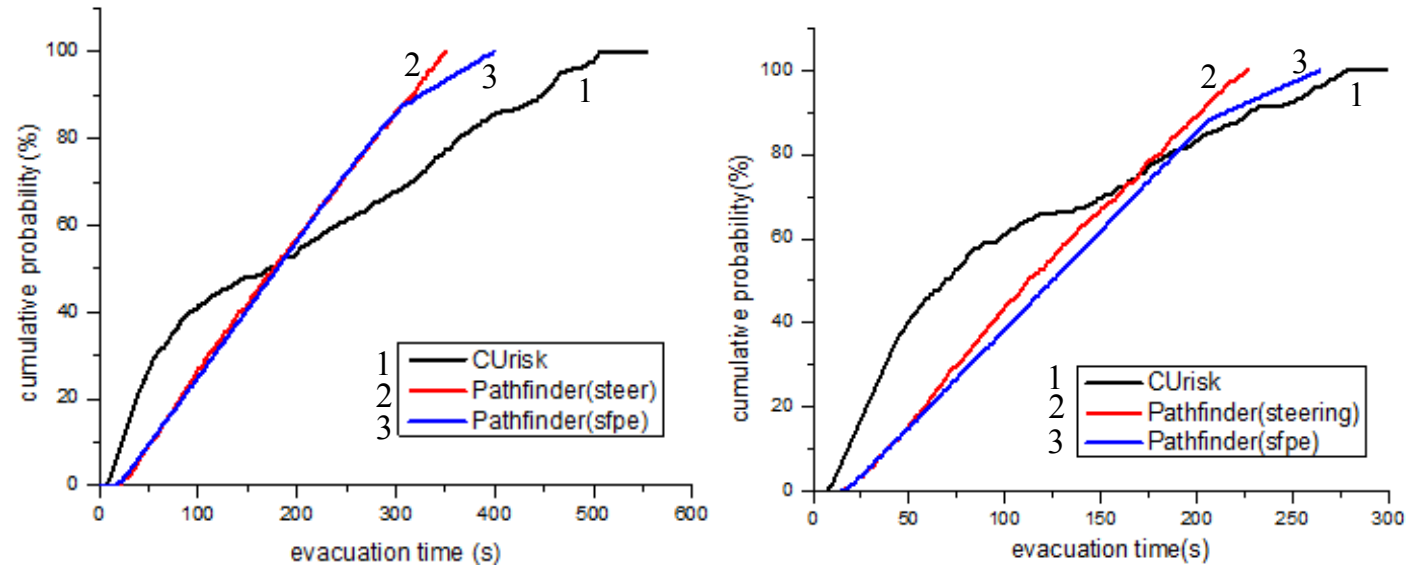

Layout a (6 storeys and 4 storeys)
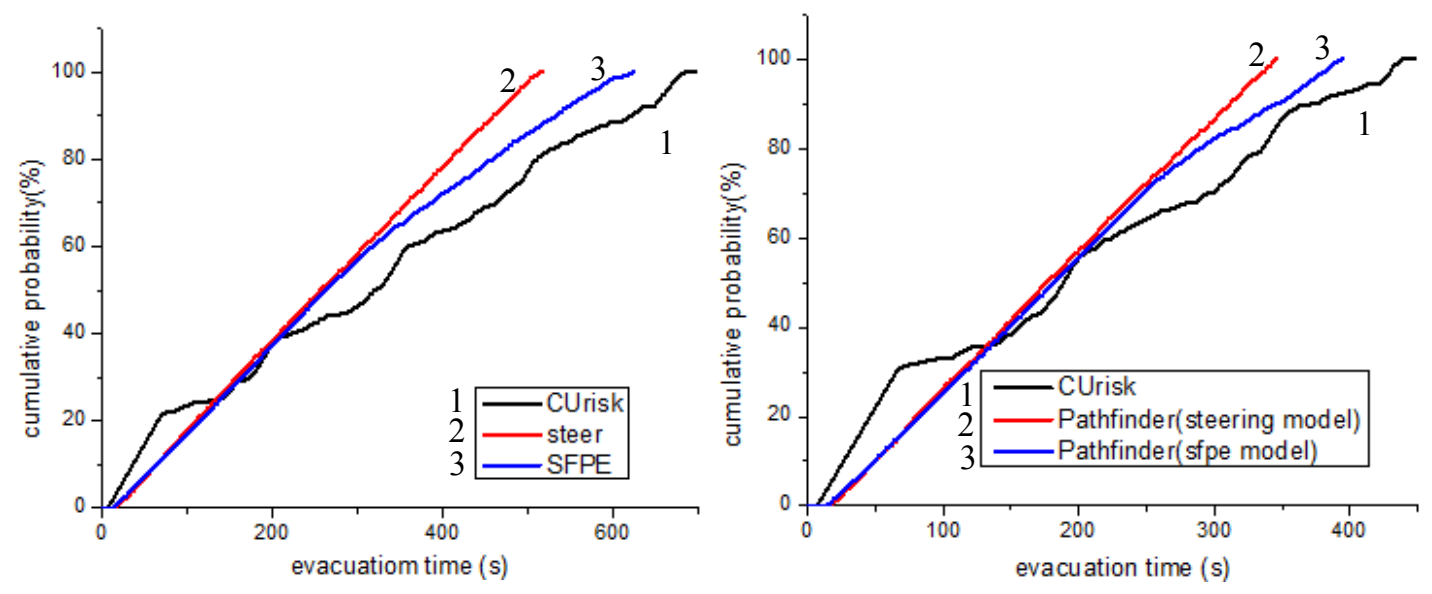

Layout b (6 storeys and 4 storeys) 

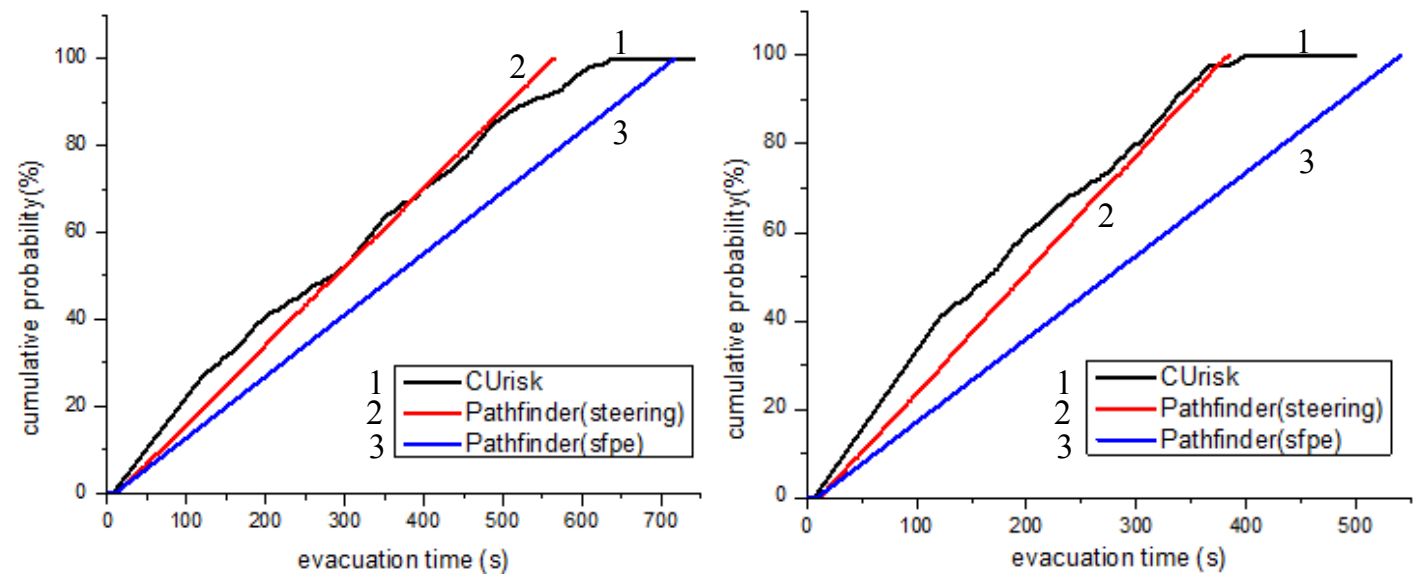

Layout c (6 storeys and 4 storeys)

Figure 3.5 Cumulative probability curves in 6 and 4 storeys building evacuation

One of the factors affecting the difference between CUrisk and Pathfinder is the use of different modeling approaches, i.e., Pathfinder steering model is a continuous model while CUrisk is a network model. The movement method employed in CUrisk is based on a maximum admitted flow rather than the steering behaviors (seek, avoid walls and avoid other occupants) adopted by Pathfinder. Although the SFPE model in Pathfinder use the effective width model as CUrisk, the differences between evacuation times should not be ignored. This difference is probably based on the number of running and parameter settings. In the Pathfinder model, occupants stay in the same place which produces the same results in repeated simulations. But in CUrisk, Monte Carlo method randomizes occupant locations, gender, age and initial speed, and specifies tolerable relative changing criteria to control the number of runs in a simulation. Another factor is the slope of stairways that is considered in SFPE model of Pathfinder by defining the 
stair riser and trend. This factor has an influence on the movement in stairways.

Comparing the results between the Pathfinder SFPE model and the SFPE analytical calculations of evacuation times, the difference for the same scenario for layout a $<$ layout $\mathrm{b}<$ layout $\mathrm{c}$ are $-5 \%,-12 \%, 51 \%$ for the 4 -storey building, and $0,-19 \%, 34 \%$ for the 6-storey buildings respectively. Although the occupant flow rate through the door is specified by the SFPE guidelines, the difference is a bit obvious in the building with large

floor area. The reasons are as follows: 1) the desired velocity is updated each time in Pathfinder which is similar to CUrisk, while SFPE uses a constant average speed; 2) the SFPE analytical calculation is a coarse estimation and the occupants are considered to move together as a whole. That's why in a single simulation, the bigger the floor size is, the bigger the error.

\subsubsection{Comparison with Different Design Conditions}

The CUrisk and Pathfinder modeling results for three different heights with floor layouts a, b and c with occupant loads per floor of 98 in layout a, 195 in layout b and 280 occupants in layout c are compared. Layouts a and b have only two stairways, but layout c has four stairways and maximum floor area. Simulation results are shown in Figure 3.6. 


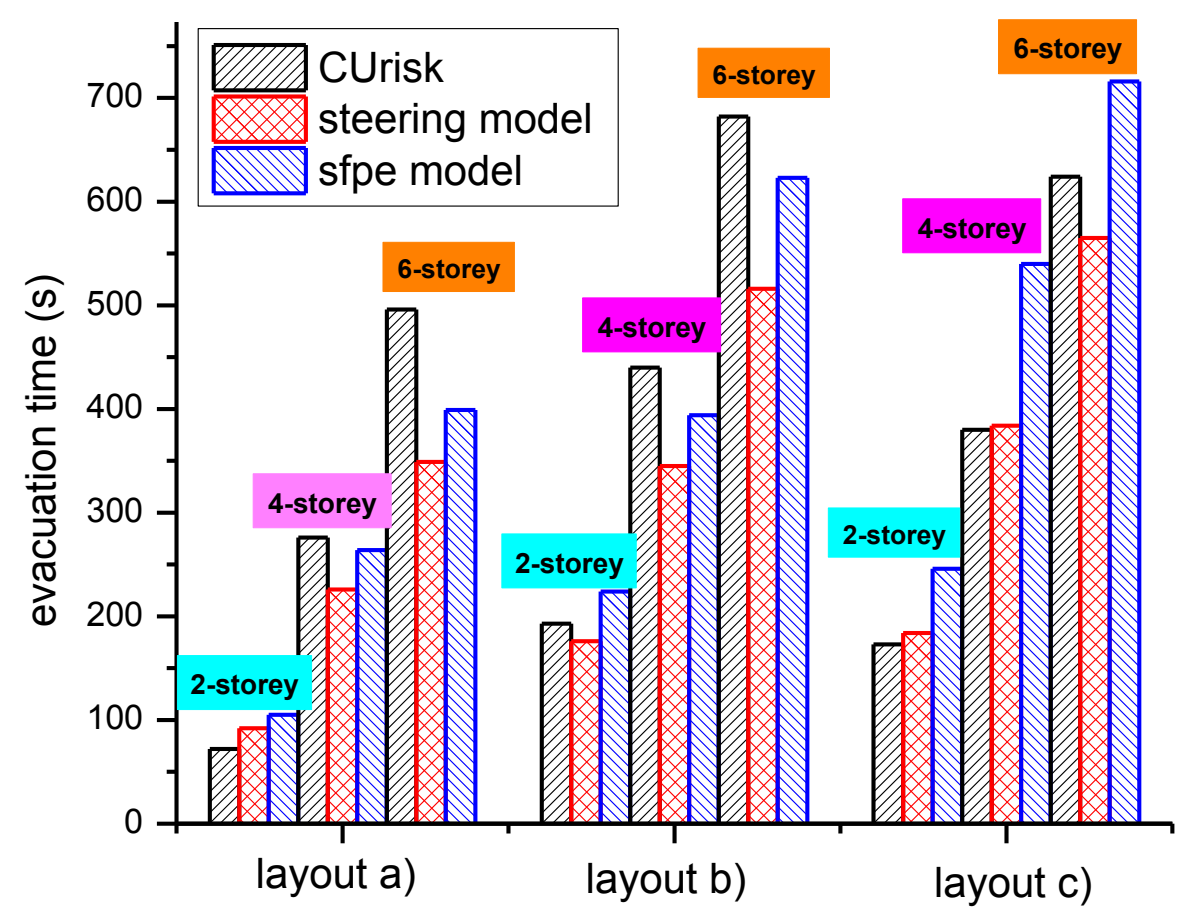

Figure 3.6 Evacuation time at different building heights

The results of CUrisk model show that when the building height increases from 2 storeys to 4 storeys building, the evacuation time increases by a factor of approximately $280 \%$, $130 \%$ and $120 \%$ in layouts a, b and c respectively. The high increase of evacuation time in layout a when the building height increases from 2 to 4 storeys is due the fact that the occupant load in the building doubles but the stairshaft area is the same. An increase from 4 storeys to 6 storeys buildings results in an increase of the evacuation time by about $80 \%$, $60 \%$ and $60 \%$ for the three layouts respectively. The Pathfinder results show similar trend. For instance, from 2 storeys to 4 storeys the time increases by nearly $150 \%$ in layout a and $100 \%$ in layouts $\mathrm{b}$ and $\mathrm{c}$. The evacuation time of 4 storeys and 6 storeys buildings is 
very close to CUrisk values that increased by around $50 \%$. The evacuation time difference is found to decrease with the increasing height of the building.

Layout a has the larger increase of evacuation time with increasing building height. This would be reasonable based on the fact that less queuing occurs due to the minimum occupant load per floor of 98 . The evacuation time of CUrisk for the 2 storey building is about 6 times lower than that of the 6 storey building, while the evacuation times of Pathfinder are 5 times lower. The difference between layout $\mathrm{b}$ and layout $\mathrm{c}$, is around 3 times in CUrisk and 2 times in Pathfinder. Overall, CUrisk evacuation times have the similar trend as Pathfinder.

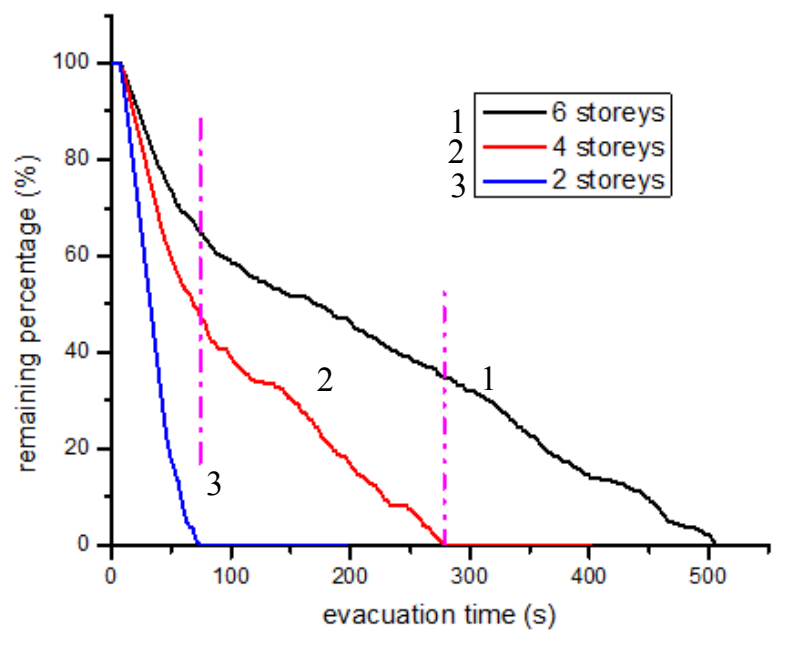

(Layout a) 


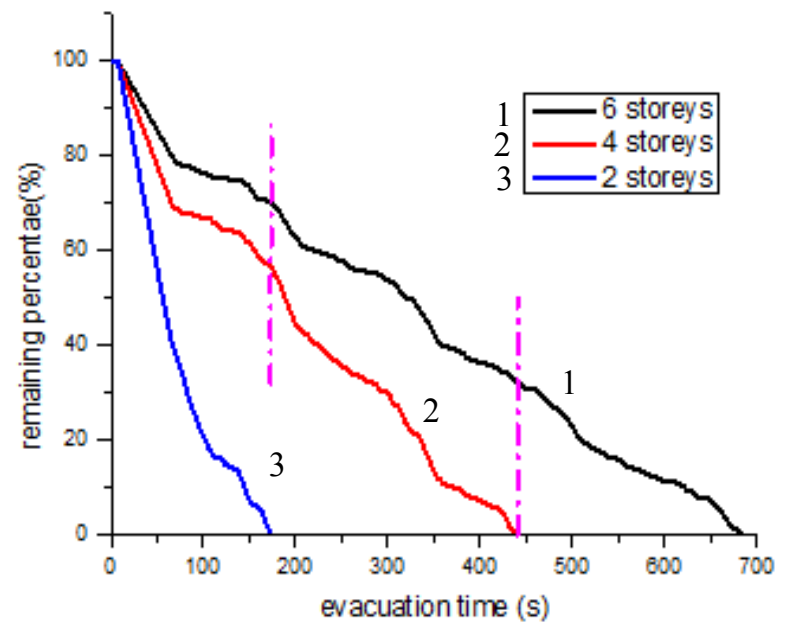

(Layout b)

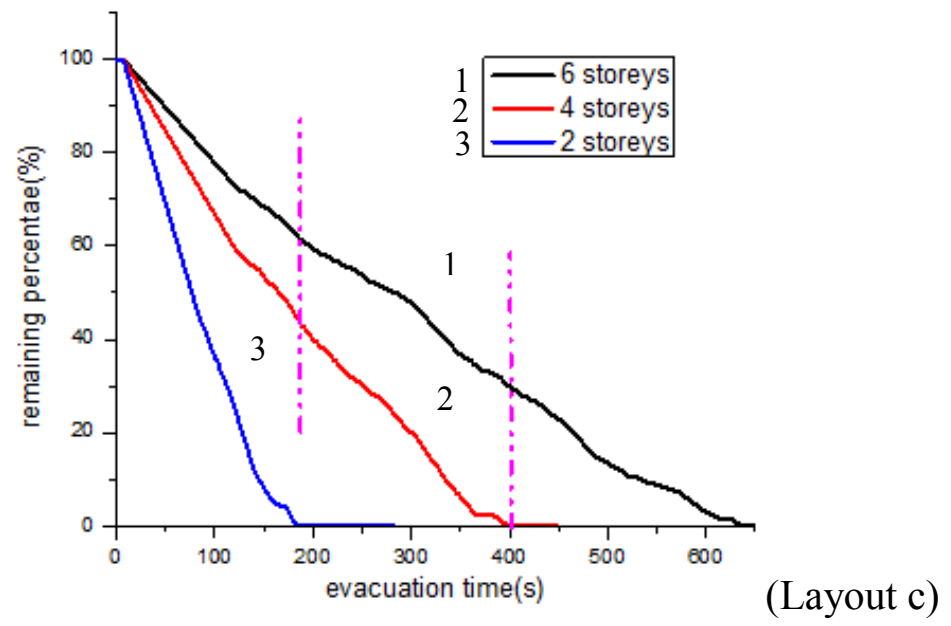

Figure 3.7 Remaining percentages in different building heights

Figure 3.7 presents the remaining percentage of occupant with time in 2, 4 and 6 storeys obtained from CUrisk. Under the maximum occupant loads in each layout which means the densities are same, it is found that, although floor sizes are different among the three layouts, the remaining percentage trends among the three storey buildings are similar. From the nine scenarios of evacuation in the three layouts, it can be observed that at the time when the evacuation is complete in 2 the storeys building, there are still around $50 \%$ remaining occupants in the 4-storey building and 70\% occupants in the 6-storey in both 
layout a and layout $\mathrm{b}$. The values in layout $\mathrm{c}$ are about $40 \%$ and $60 \%$ due to the presence of more stairways. Furthermore, when all the people have evacuated from the 4-storey building, about $40 \%$ occupants remain in the 6-storey building in all layouts. This demonstrates that under the same density, when the evacuation is done in lower building the percentage of remaining occupants for the higher buildings doesn't change too much with different floor areas.

\subsubsection{Building Layout and Occupant Loads}

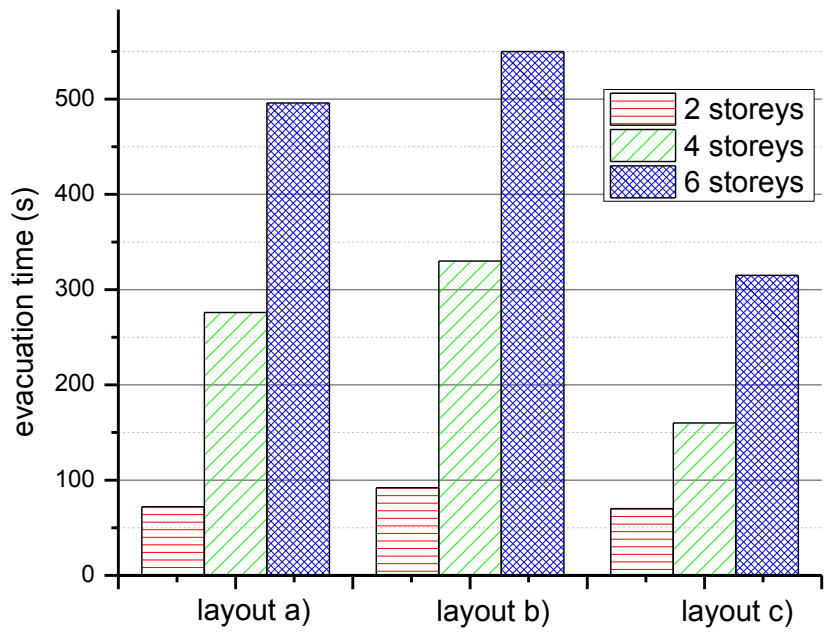

a) 98 persons per floor 


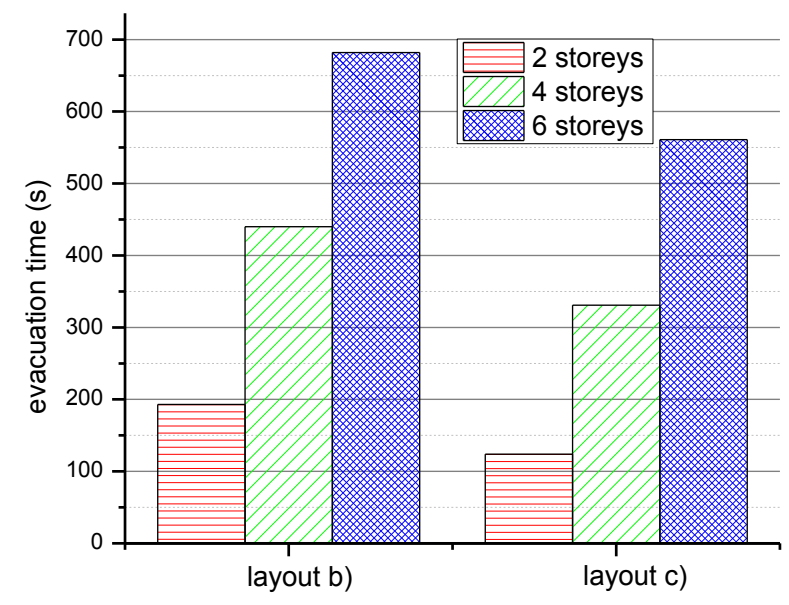

b) 195 persons per floor

Figure 3.8 The effect of building layout on evacuation time

This section focuses on how building layouts and occupant loads impact on evacuation time. In Figure 3.8, when the occupant load is 98 occupants per floor, the largest evacuation time appears in layout $b$ which is the medium-sized design. The smallest evacuation time is obtained from layout $\mathrm{c}$ with the largest floor area and number of stairwells. For example, the evacuation times of layout $\mathrm{b}$ are about $28 \%, 23 \%$ and $11 \%$ higher than the times of layout a for the 2, 4 and 6 storeys buildings respectively. However, the evacuation times of layout $\mathrm{c}$ are $3 \%, 42 \%$ and $36 \%$ lower than the times of layout a which is the small-sized design. Similar observations are made when the occupant load is 195 persons per floor that the evacuation time is lower in the large-sized building with more stairwells than in the medium-sized building regardless of building height. 
The results suggest that under the same occupant load the number of stairways plays a more important role in evacuation efficiency compared with floor size. Layouts a and b have only two stairways, but layout $\mathrm{c}$ has four stairways. When applying the same occupant load in the different layouts, the total evacuation time is controlled by the exit width and movement time for one floor. The exits of buildings with different sizes have the same width which controls the occupant flow. But the movement times for one floor are different due to the different floor size and stairways number. Floor size determines the movement time from the initial position to the entrance of the stairway and the stairway number controls the total flow capability of stairways. It's easy to conclude that the larger floor size and the fewer stairways, the longer the evacuation time for one floor. But when considering both factors, it is found that the stairways number plays a leading role. That's why the smallest total evacuation time is for layout $\mathrm{c}$ buildings.

Comparing the evacuation times with two occupant loads, it can be found that when the occupant loads increase from 98 to 195 persons per floor, the evacuation time for 2, 4 and 6 storey buildings increases by $100 \%, 33 \%, 24 \%$ for layout b, respectively. High occupant loads result in queuing in the front of exits which increase the total evacuation time.

\subsection{Conclusions}

This chapter presented results of a coarse network evacuation model CUrisk Evacuation 
submodel using the Monte Carlo approach. This model is used to simulate evacuation in a multi-storey mid-rise office building. The results of CUrisk were compared to the results of Pathfinder and the SFPE handbook correlations for different building design conditions. The following conclusions were drawn:

1) Comparing with other models, the results of the CUrisk evacuation model are close to those of SFPE analytical calculation and a bit higher than those of the Pathfinder software. The flow trends obtained by CUrisk model are more reasonable reflecting occupants queuing at exits.

2) With the same density, the evacuation time is longer with increasing building height. The relative time difference was found to decrease with increasing building height. CUrisk and Pathfinder produced similar results: the relative time difference for different heights is larger in the building of layout a with small floor area. The occupants remaining percentages trends are similar in different layouts.

3) The number of stairways plays a more important role in evacuation than floor areas. Although the floor area in large-sized building was about 3 times the small-sized building, the evacuation time is lower due to the presence of more stairways. It was found that increasing occupant loads increase evacuation times.

Overall, it can be concluded that the CUrisk evacuation model is an effective model to reasonably simulate evacuation in mid-rise buildings. 


\section{Chapter: Fire Risk Analysis for Multi-Storey Apartment}

\section{Buildings}

This chapter discusses the fire risk analysis case studies using the CUrisk model. The purpose is to show general differences between buildings made of non-combustible and combustible materials. Apart from construction materials, the risk analysis considered the effect of building heights and floor areas. Event trees have been used to construct scenario structures for each design proposal of multi-storey apartment buildings.

\subsection{Building Designs}

Performance-based building regulations have lead to the wider use of timber buildings. Buildings of different construction materials such as concrete, heavy timber (CLT), and light timber might have different fire behaviour, which will have an effect on fire risk. In this chapter, different types of multi-storey apartment buildings are investigated. The following figure describes three main comparisons that will be considered in building design. 

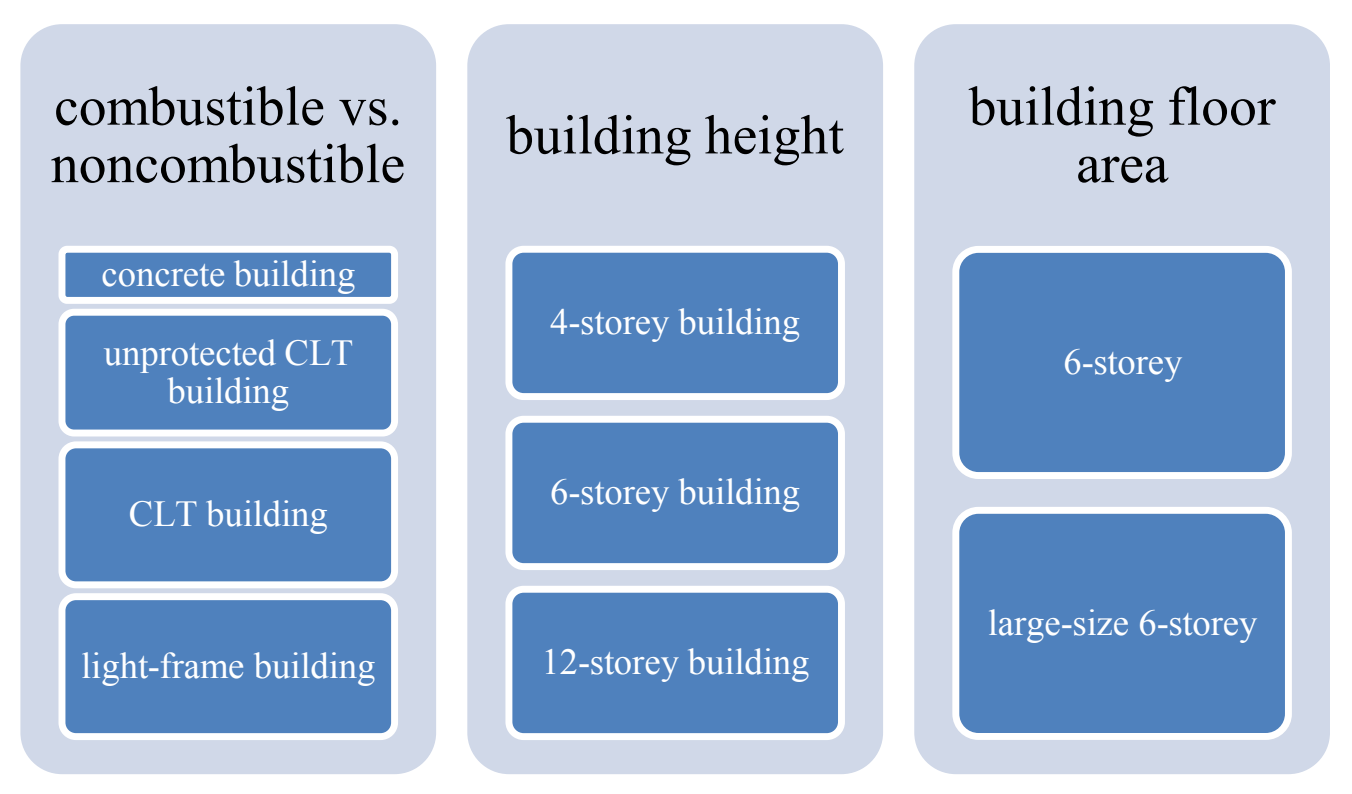

Figure 4.1 Different design alternatives for mid-rise apartment buildings

Buildings to be considered are multi-storey residential buildings. Take a 6 -story building for example. Based on the existing floor area requirement of the National Building Code of Canada [70], the total area of the building shall be $918 \mathrm{~m}^{2}$, with a ceiling height of $3 \mathrm{~m}$. The conceptual layouts of floors are shown in Figure 4.2 and Figure 4.3. The plan of each floor is identical and contains 12 apartments (ten $6 \mathrm{~m} \times 10 \mathrm{~m}$ and two $6 \mathrm{~m} \times 12 \mathrm{~m}$ ), two corridors $(1.5 \mathrm{~m} \times 30 \mathrm{~m}$ ), three stair shafts (one in the middle with a size of $4 \mathrm{~m} \times 5 \mathrm{~m}$ and two on the sides with a size of $2 \mathrm{~m} \times 5 \mathrm{~m})$, one elevator shaft $(2 \mathrm{~m} \times 2 \mathrm{~m})$ and a lobby near the elevator. There is an exit close to the elevator $(1.5 \mathrm{~m})$ and two exits on each side of the first floor $(0.9 \mathrm{~m})$. Each apartment in the building is assumed to have only one compartment and one window for simplicity. Therefore, each floor has 18 compartments. 


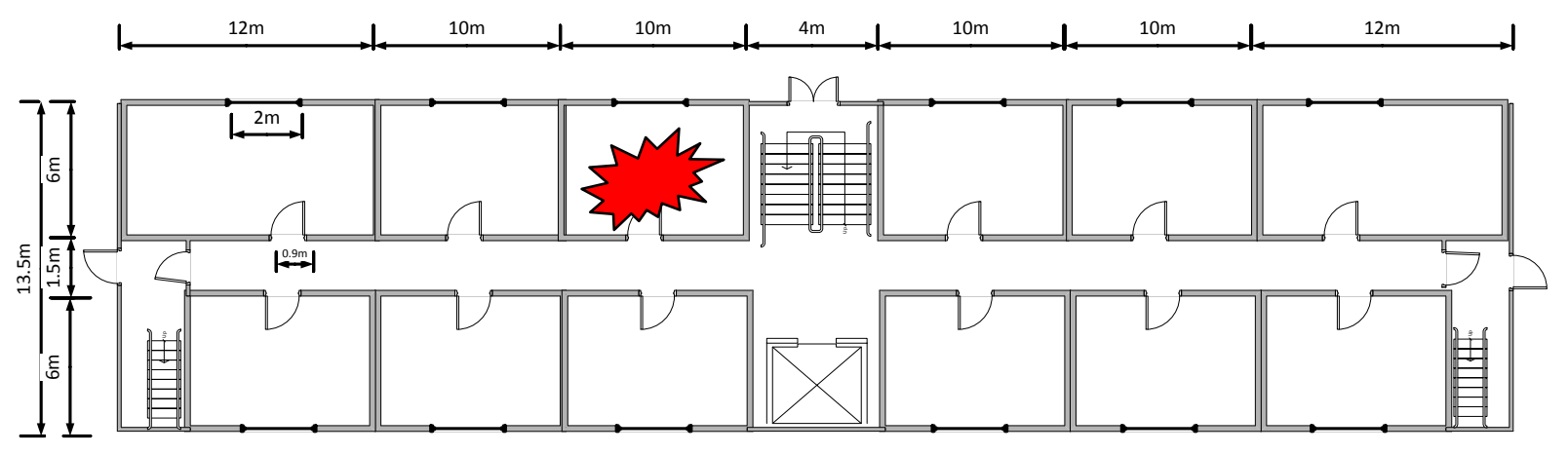

Figure 4.2 The floor plan of the first floor

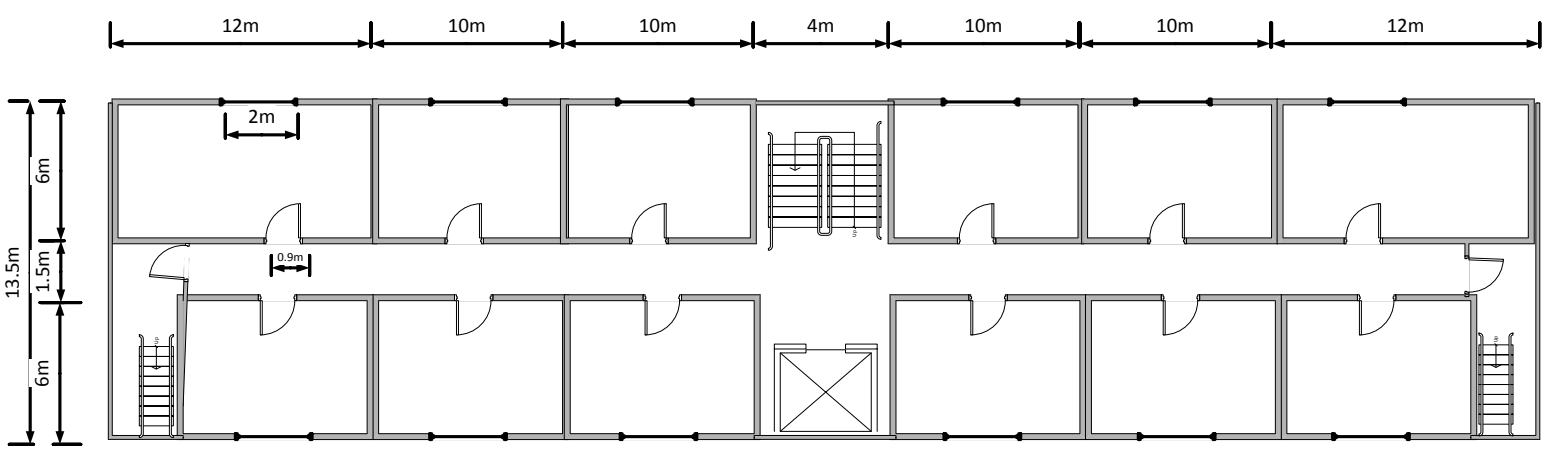

Figure 4.3 The floor plan of the second floor

\subsection{Events in the Fire Event Tree}

The event tree can group all of the possible fires into a manageable number of scenario subsets. Fire events are linked together by the success or failure probabilities of the fire protection systems [96]. Fire characteristics depend on many factors such as building size and type, fire location, fire load and fuel type, ignition source, lining materials of wall and ceiling, ventilation and so on [97]. In the fire risk analysis, the factors listed in the 
following sections will make up the event tree for different building designs.

\subsubsection{Occupant Characteristics}

Since the building is an apartment building, the occupant type is categorized to be a residential occupancy according to NBCC [70]. The number of occupants is assumed to be 4 persons per unit, producing a total occupant load on each floor of 48 persons. Occupant characteristics are listed in Table 4.1.

Table 4.1 Occupant age and gender

\begin{tabular}{|l|l|}
\hline Male percentage of population ratio & $50 \%$ \\
\hline Younger percentage of population ratio & $50 \%$ \\
\hline
\end{tabular}

Due to the fire hazardous conditions like hot gases, toxic smoke, high radiant fluxes and fire spread, occupants may get injured or die when they are exposed to a fire. The numbers of injuries and deaths in each scenario are calculated by the CUrisk Life Hazard submodel. The fractional effective dosage FED is used to determine the life safety state of occupants. FED is calculated based on the dosage of toxic gases an occupant breaths and his exposure to hot gases and heat fluxes. FED thresholds values for injury and death are shown in Table 4.2. When the FED of an occupant exceeds the thresholds, the occupant in the compartment will be assumed injured or dead. If a fire reaches flashover, the occupants in that compartment are considered dead. 
Table 4.2 Thresholds of injury and death

\begin{tabular}{|l|l|}
\hline Threshold of injury & $0.3[98]$ \\
\hline Threshold of death & $1.0[98]$ \\
\hline
\end{tabular}

\subsubsection{Initial Fire Location}

The probability of fire occurrence on each floor is assumed to be the same. This analysis is limited to only studying the effects of fires on the first floor since the consequences for this scenario are the worst. The fire is located in the compartment near the main staircase on the first floor. The fire room is assumed to be $5 \mathrm{~m} \times 6 \mathrm{~m}$ with a window of $2 \mathrm{~m} \times 1.5$ m.

\subsubsection{Opening}

The door of the fire compartment is set to $50 \%$ open during the whole fire development process. Exits and stair shaft doors are set to 50\% open. All other interior doors of the apartments are set to be $20 \%$ open and all windows are set to break at $300{ }^{\circ} \mathrm{C}$.

\subsubsection{Design Fire}

The compartment fire is assumed to be a $t^{2}$ fire in the middle at the apartment. The parameters used to characterize a design fire consist of the fire growth rate, maximum heat release rate (HRR) and fire load which governs the duration of the fire. It was also assumed that non-apartment compartments such as elevator shafts, stair shafts, corridors and public zones do not have enough fire load to support fire growth and fire spread. The maximum HRR of the fire can be estimated by the following equation 


$$
Q_{\text {max }}=1518 A_{v} \sqrt{H_{v}}
$$

where, $A_{v}$ is the area of the vent $\left(\mathrm{m}^{2}\right)$ and $H_{v}$ is the height of the vent (m).

Two kinds of fire types are considered, a medium growth (living room fires) and a fast growth (kitchen fires), and the designed maximum heat release rates is $6 \mathrm{MW}$ based on equation 4.1.

\subsubsection{Fire Load}

Fire load is an important factor governing the severity and duration of a fire. Fire load is designed as the energy contained in the fuel per unit floor area, often in $\mathrm{MJ} / \mathrm{m}^{2}$ and it is calculated from the heat of combustion of all the combustibles present in the compartment. The released energy may be from the building contents or the structural elements. Usually, building elements are protected with cladding. Hence, the main source of fire load is the energy of the contents of a building. According to published fire load densities for residential buildings in different countries, the values range from $450 \mathrm{MJ} / \mathrm{m}^{2}$ to $1200 \mathrm{MJ} / \mathrm{m}^{2}$ [99]. Based on statistical data of Canada, the fire load is taken as 550 $\mathrm{MJ} / \mathrm{m}^{2}[99]$.

\subsubsection{Fire Protection Systems}

Fire protection systems play an important role in the building fire safety level and the impact of fires on occupants and property damage. CUrisk model includes two groups of fire protection systems: passive fire protection and active fire protection systems.

Passive fire protection systems in the building include: compartment fire boundaries, 
protection of openings, and egress routes. In this study, for buildings below 6-storey, a one-hour fire resistance rating is specified for the wall and floor assemblies. For buildings above 6-storey, a two hour fire resistance rating is specified for the wall and floor assemblies according to NBCC 2005 [70]. 15 minutes fire resistance rating is specified for doors and windows. Standard 1/2" gypsum plasterboard systems on walls and ceilings typically are capable of achieving a fire resistance rating (FRR) of at least 15 minutes [80]. Three exit doors are located in the middle, north and south side of the building and each floor is served by three stair shafts and one elevator shaft.

Active fire protection systems in the building include: sprinklers, fire alarms and smoke/heat detectors. Active fire protection systems are used to increase the fire safety level as a compliment to passive fire protection. The reliabilities of different systems used in the model are shown in the Table 4.3. The reliability is expressed as the operational reliability which indicates the probability of a fire protection system operating as expected.

Table 4.3 The reliabilities of fire protection systems in this study

\begin{tabular}{|l|l|}
\hline System & Reliability \\
\hline Sprinkler & $0.95[100]$ \\
\hline Detector system & $0.9[100]$ \\
\hline Fire department & $0.8[101]$ \\
\hline
\end{tabular}

\subsubsection{Fire Department Response}


CUrisk is able to include the performance of fire department action in fighting fire and rescuing people in the fire risk analysis. The fire department response is based on the notification time, response time and setup time. Two options are used in the model as shown in Table 4.4. Option 1 represents the case fire fighters reach the building in $510 \mathrm{~s}$; option 2 means no fire fighter arrive at the scene.

Table 4.4 Fire department response option

\begin{tabular}{|c|c|c|c|}
\hline Option No. & Notification & Response time & Setup time \\
Time (s) & $(\mathrm{s})$ & $(\mathrm{s})$ \\
\hline 1 & 30 & 360 & 120 \\
\hline 2 & disabled & disabled & disabled \\
\hline
\end{tabular}

\subsection{Fire Scenarios}

In total, sixteen different buildings have been used in the analysis: 4-storey, 6-storey, 12-storey and large 6-storey buildings made of non-combustible (concrete) and combustible materials (unprotected CLT, protected CLT and light-frame timber) respectively. For each building, sprinklers, fire department, and detector systems and alarms are chosen as active fire protection options. The event tree illustrated in Figure 4.4 applies to all buildings. The reliabilities values used are from Table 4.3. The probability of each branch is obtained by multiplying the properties of all the events in that branch. 


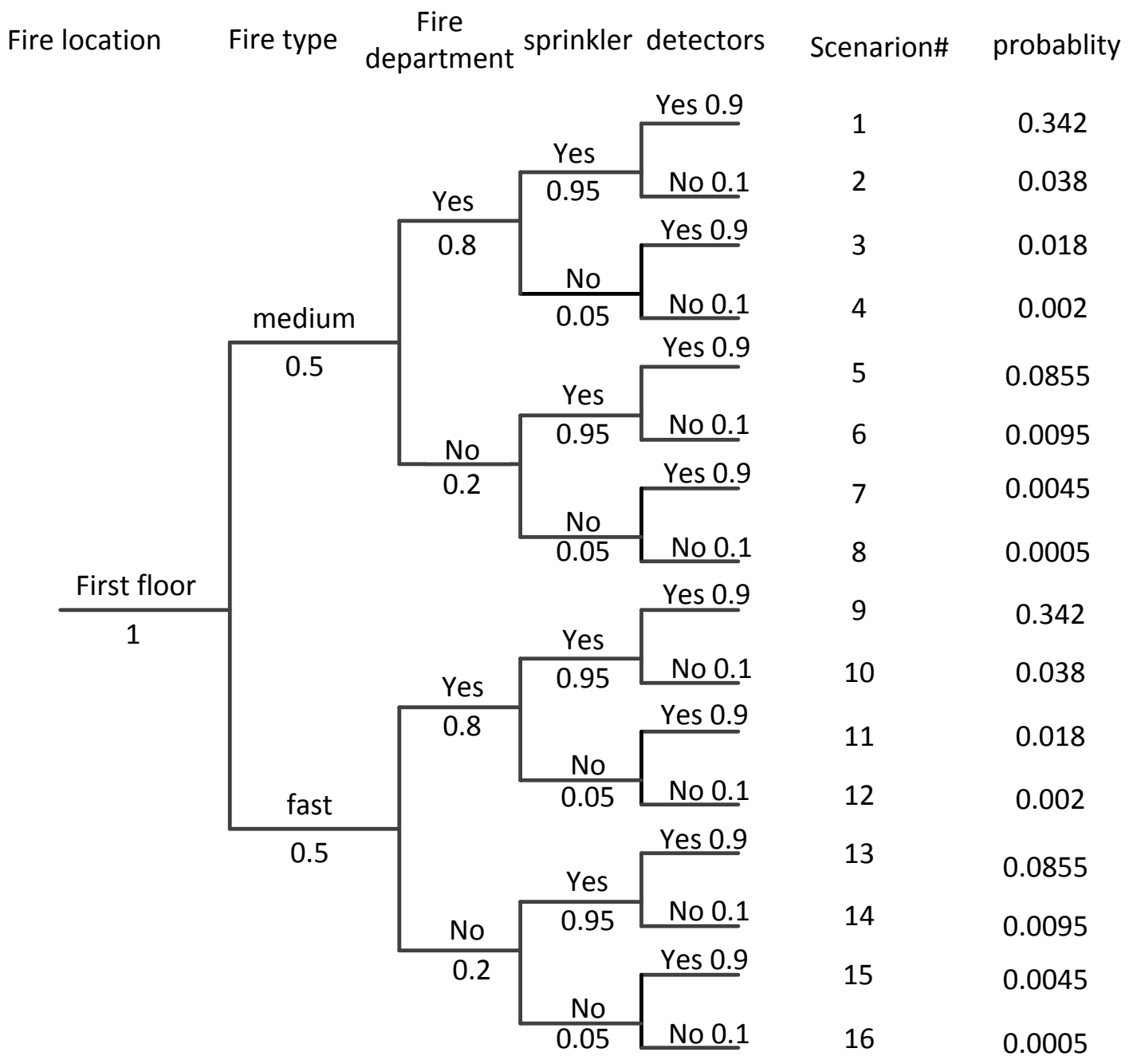

Figure 4.4 The scenario structure for each building design proposal

\subsection{Results and Analysis}

The results obtained by running CUrisk for the different buildings are presented in this section. The analysis is carried out from three aspects: fire development and smoke spread in the building, occupant response and evacuation and property losses and casualties. The simulation time for each scenario was set to $2400 \mathrm{~s}$ with a time step $2 \mathrm{~s}$. It was assumed that by this time the fire department would arrive on the scene and control 
the fire.

\subsubsection{Combustible vs. Non-combustible Buildings}

To better understand the fire risk difference among different construction materials, five scenarios are chosen for detailed analysis. For example, in scenario No.12, only the fire department arrives at the fire scene; in scenario No.14, only the sprinkler is activated; and in scenario No.15, only detector systems work (see Table 4.5). For comparison four building types are used:

Design Option 1: 6-storey non-combustible building (concrete);

Design Option 2: 6-storey CLT building without gypsum board protection;

Design Option 3: 6-storey CLT building protected with one layer of gypsum board (15 minutes fire resistance rating);

Design Option 4: 6-storey light-frame building protected with one layer of gypsum board (15 minutes fire resistance rating).

Table 4.5 Design parameters of five scenarios

\begin{tabular}{|c|c|c|c|c|}
\hline Scenario & Fire type & Fire & sprinkler & Detector and \\
department & alarm \\
\hline No.9 & fast & Yes & Yes & Yes \\
\hline No.12 & fast & Yes & No & No \\
\hline No.14 & fast & No & Yes & No \\
\hline No.15 & fast & No & No & Yes \\
\hline No.16 & fast & No & No & No \\
\hline
\end{tabular}




\subsubsection{Fire Development and Smoke Spread}

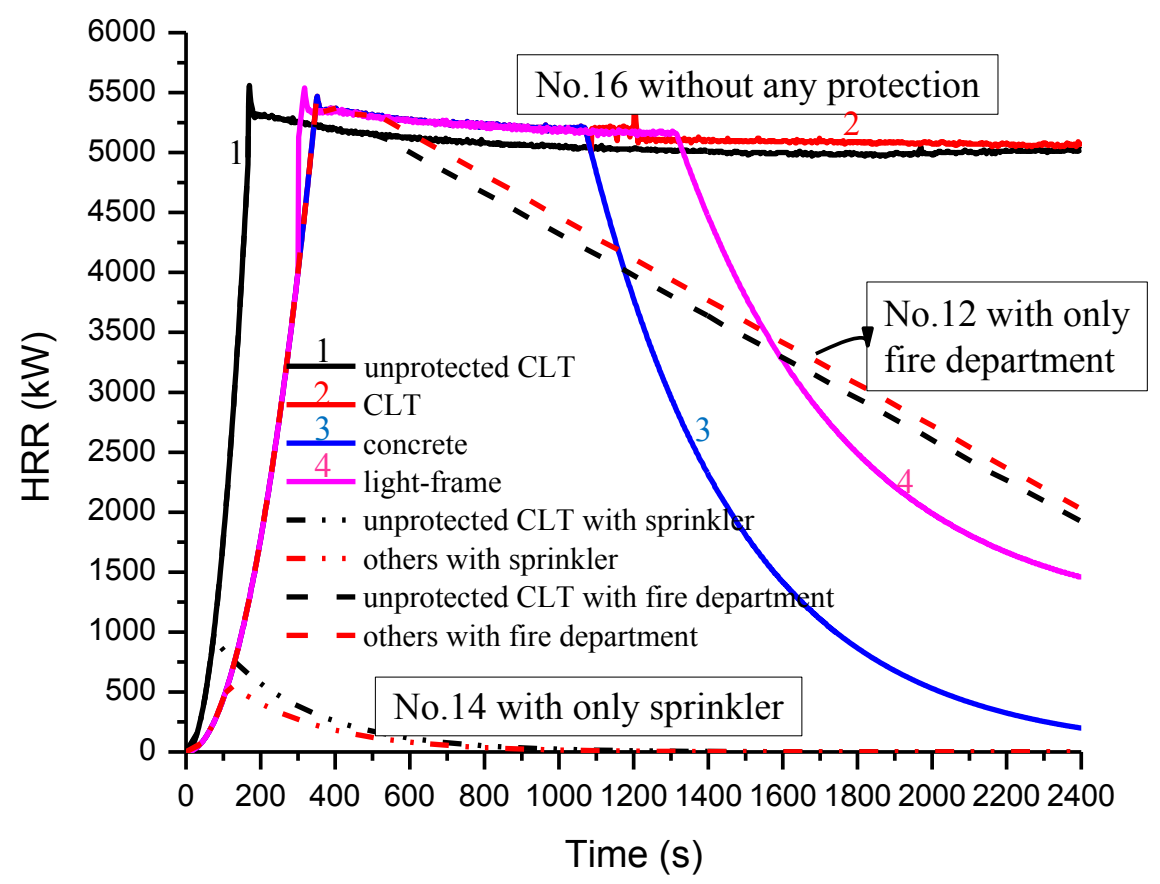

Figure 4.5 HRR vs. time in the fire room of scenarios No.12, No.14 and No.16

Figure 4.5 illustrates heat release rate curves of the fire origin room predicted by the

CUrisk Smoke Movement submodel considering the effects of sprinklers and the fire department action. The fire starts on the first floor close to the middle staircase. As shown in this graph, in scenario No.16, the heat release rate of design option 2 (unprotected CLT buildings) climbs up dramatically at an ultrafast growth rate 0.188 $\mathrm{KW} / \mathrm{s}^{2}$ before it reaches the peak heat release rate of $5.5 \mathrm{MW}$ at $170 \mathrm{~s}$. The ultrafast growth is due to the effect of unprotected CLT, which accelerate the growth rate of the fire. After that, the values remain stable at around 5.3 MW until the end of simulation.

However, for the other three design options, the HRR has a fast growth rate of 0.047 
$\mathrm{KW} / \mathrm{s}^{2}$ until the peak of about $5.5 \mathrm{MW}$ at $352 \mathrm{~s}$. The important point to be noted here is the decay phase. In options 2 and 3, there is no decay phase due to CLT's contribution to the room fire after the gypsum board failure. In option 1 and option 4, the heat release rates start to decline at the time of about $1100 \mathrm{~s}$ and $1300 \mathrm{~s}$. The light-frame structure has a small contribution to the room fire because of the small mass of timber members. In scenario No.14, the sprinklers activate at $73 \mathrm{~s}$ in option 2 and at $114 \mathrm{~s}$ in options 1, 3 and 4. After activation, the heat release rates drop quickly to almost 0 at $1000 \mathrm{~s}$. In scenario No.12 with only the fire department, there is almost no HRR difference among different construction materials. Fire department action time is much longer than the sprinkler operation time, and it takes effect after $510 \mathrm{~s}$.

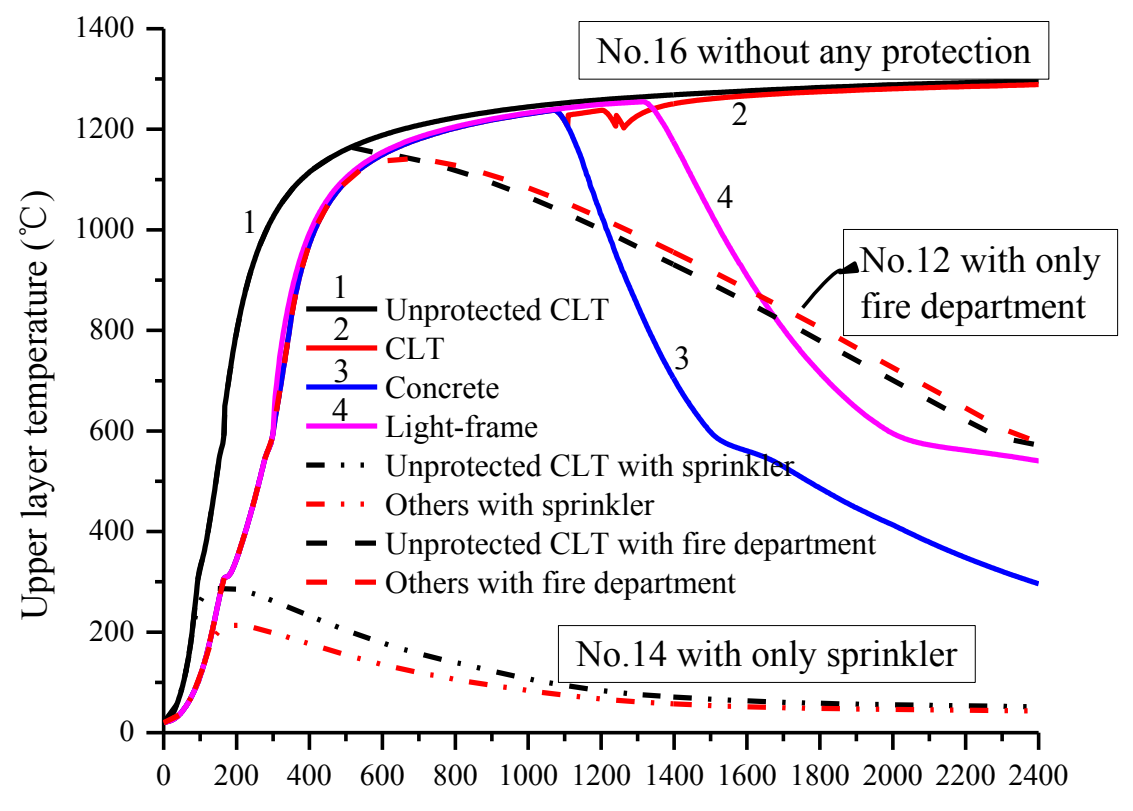

Time (s)

Figure 4.6 Upper layer temperatures vs. time in the fire room of scenarios No.12, No.14 and No.16 
Figure 4.6 shows the temperature of the upper layer in the compartment of fire. It demonstrates similar trends seen in Figure 4.5. It can be observed that, without sprinklers the upper layer temperature reaches more than $1200{ }^{\circ} \mathrm{C}$ in the fire origin room in all design options. In options 2 and 3 the temperatures stabilize at around $1300{ }^{\circ} \mathrm{C}$ until the end of the simulation. In option 1 and 4, the upper layer temperatures start to go down after $1100 \mathrm{~s}$ and $1300 \mathrm{~s}$ respectively, and in scenario No.14 with sprinklers, the maximum smoke temperature only reach about $300{ }^{\circ} \mathrm{C}$ in the unprotected CLT building and $210{ }^{\circ} \mathrm{C}$ in the other three buildings. Furthermore, the widows break at $94 \mathrm{~s}$ in option 2 and $162 \mathrm{~s}$ in other options. If only the fire department takes action, the smoke temperature starts to drop after $510 \mathrm{~s}$ and it decreases to below $650{ }^{\circ} \mathrm{C}$ after 40 minutes.

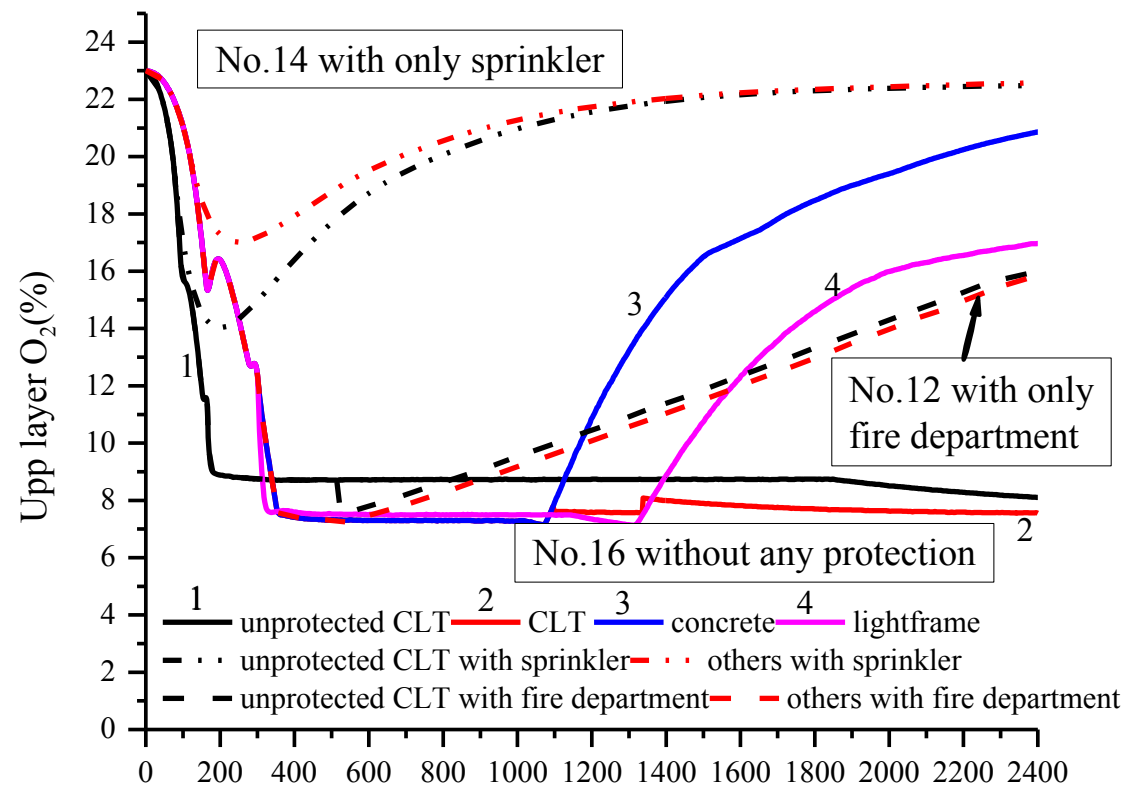

Time (s)

Figure 4.7 Upper layer $\mathrm{O}_{2}$ concentrations vs. time in the fire room of scenarios No.12, No.14 and No.16

Figure 4.7 shows the oxygen concentration in the upper layer as a function of time in 
these four design options. As it can be seen from the graph, after fire starts, there is a rapid drop of the concentration of $\mathrm{O}_{2}$ in the fire room from $23 \%$ to around $8 \%$ in scenario No.16. After the fuels burn out, the sprinklers are activated or the fire department arrives, the $\mathrm{O}_{2}$ concentration starts to recover. In scenario No.16, $\mathrm{O}_{2}$ concentration remains at a low value until the end of the simulation because of the contribution of CLT as part of the fire load. Whereas, in scenario No.12 and No.14, the quick increase of $\mathrm{O}_{2}$ concentration occurs because of lowered oxygen consumption due to activation of the sprinklers or the arrival of the fire department. 


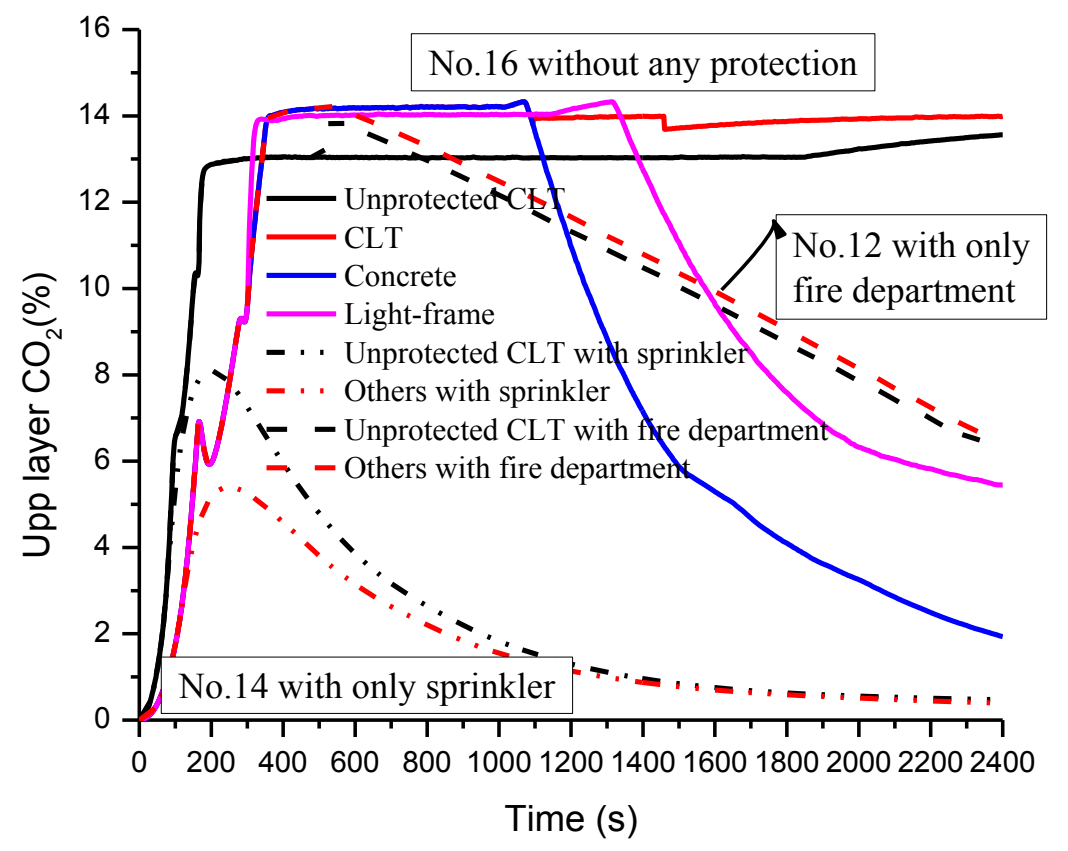

Figure 4.8 Upper layer of $\mathrm{CO}_{2}$ concentration vs. time in the fire room of scenarios No.12, No.14 and

No.16

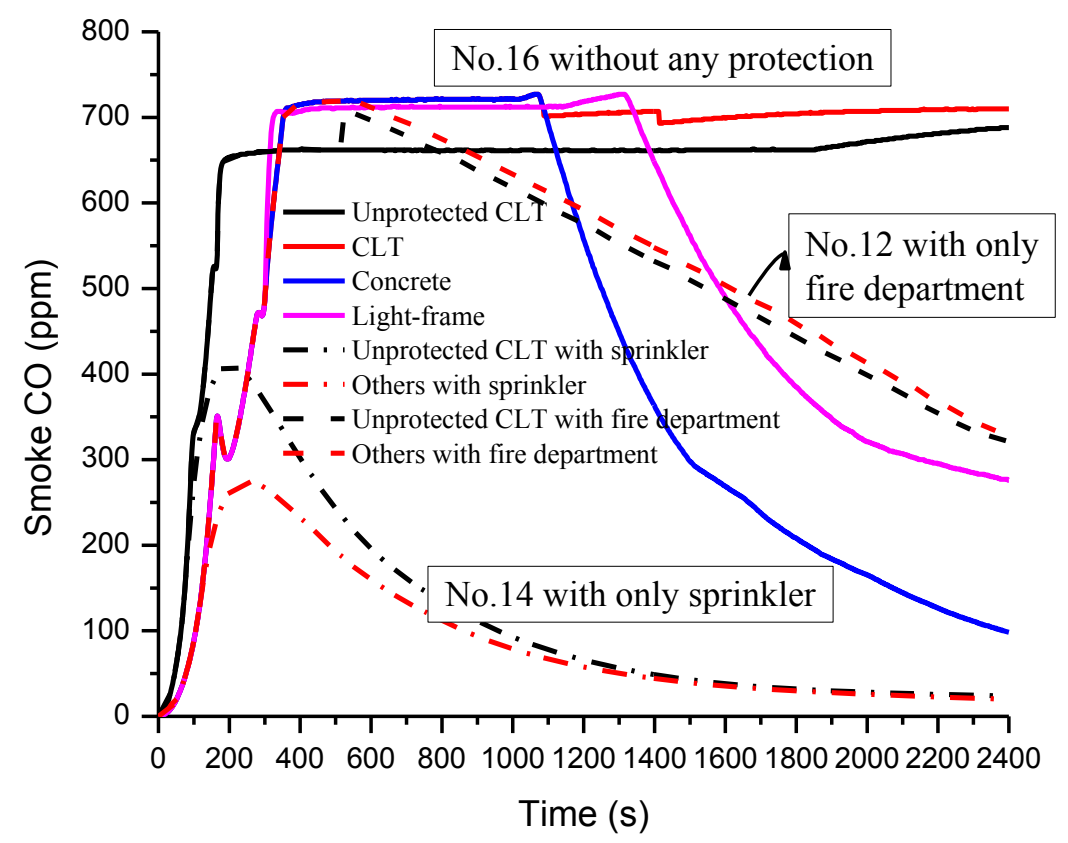


Figure 4.9 Upper layer $\mathrm{CO}$ concentrations vs. time in the fire room of scenarios No.12, No.14 and

No.16

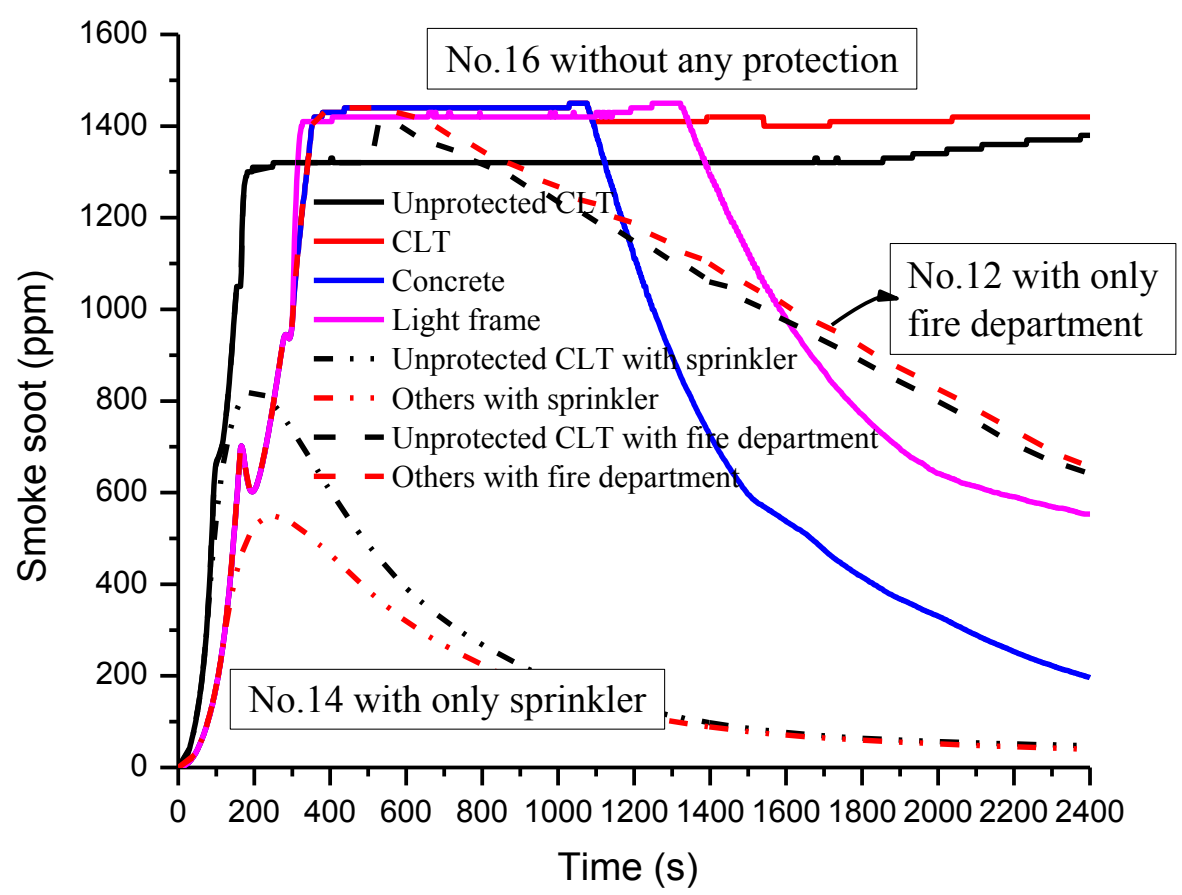

Figure 4.10 Upper layer smoke soot concentrations vs. time in the fire room of scenarios No.12, No.14 and No.16

Figure 4.8 to Figure 4.10 illustrate the concentrations of the combustion products $\mathrm{CO}_{2}$, $\mathrm{CO}$ and soot, all of which show similar curves. After flashover in scenario No.16, the products concentrations remain stable for a while due to the steady burning. The maximum concentrations in the fire room reach $13 \% \sim 14 \%$ for $\mathrm{CO}_{2}, 660 \sim 730 \mathrm{ppm}$ for $\mathrm{CO}$ and 13000 14200 ppm for smoke soot. It can also be seen that, the smoke level in the unprotected CLT building increases rapidly to the peak in a very short period. Contrary to 
light-frame and non-combustible structures, CLT structure contributes to the fire duration and the production of large quantities of combustion products.

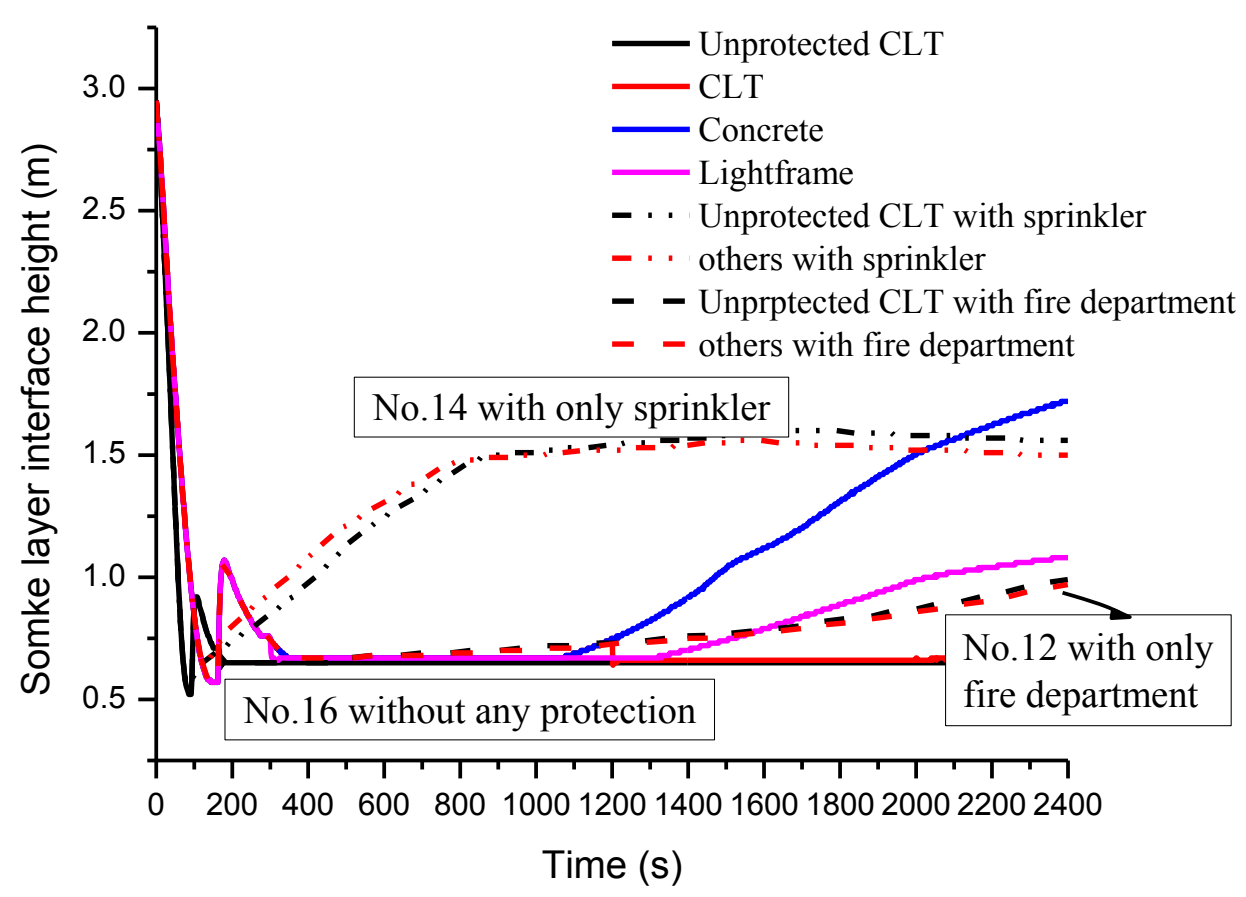

Figure 4.11 Smoke layer interface heights vs. time in the fire room of scenarios No.12, No.14 and No.16

Figure 4.11 provides a comparison of the smoke layer interface heights in buildings with different construction materials. As it can be seen from this graph, after the fire starts, the interface height drops from the ceiling height of $3 \mathrm{~m}$ to $0.7 \mathrm{~m}$ above the floor in a very short time. The graph shows that there is a short fluctuation period due to window breaking. At the end of the simulation period, the smoke layer interface height recovers to $1.7 \mathrm{~m}$ in the concrete building and $1.1 \mathrm{~m}$ in the light-frame building in scenario No.16. If the sprinkler is activated, the smoke layer interface heights of all the buildings ascend to 
about $1.6 \mathrm{~m}$ and stay there. If only the fire department arrives at the fire scene, the smoke layer interface rises slowly, reaching $1 \mathrm{~m}$ by the end of the simulation.

\subsubsection{Occupants Response and Evacuation}

The CUrisk Occupant Response submodel predicts the response of occupants to the various warning signals. It takes input data from the Hazardous Conditions, Fire Department and Detection submodels, and produces the evacuation probabilities, which are used by the Occupant Evacuation submodel. Occupants located at different compartments will perform different actions after realizing there is a fire in the building. To reflect the difference of the evacuation probabilities of occupants in different locations, the mean, minimum and maximum evacuation probabilities are calculated. Generally speaking, occupants in the fire room have the maximum evacuation probability as they can receive the most strong fire cues and occupants located in the farthest compartments from the fire compartment have the minimum evacuation probability.

The Occupant Evacuation submodel is based on the Monte Carlo method, and can generate distributions of evacuation times and predict the evacuation route for each occupant. 


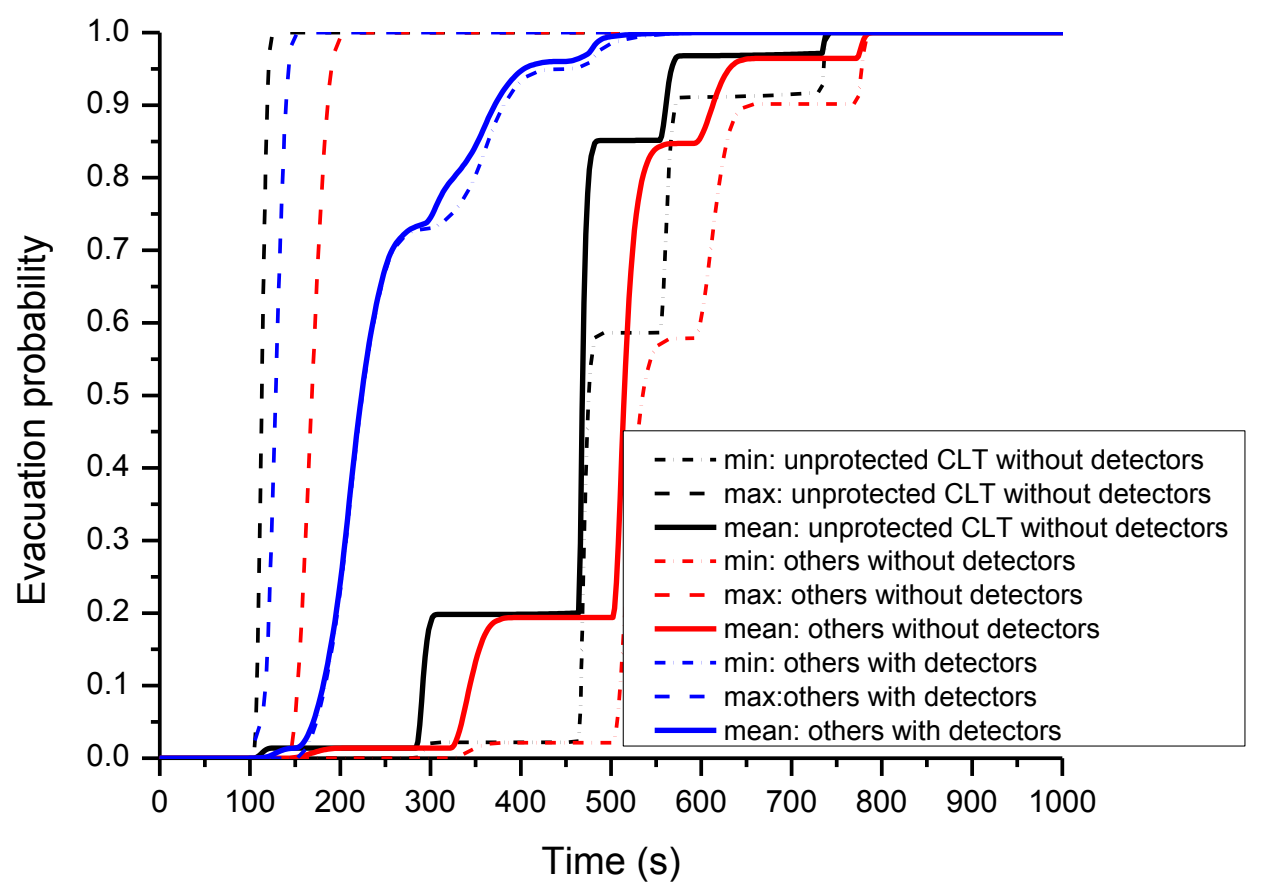

Figure 4.12 Probability of evacuation initiation in scenario No.15 and No.16 in the six-storey buildings

Considering fire scenarios with only the detector systems, without any other fire protection systems, the evacuation probabilities for the different buildings are plotted in Figure 4.12. The figure shows that scenario No.15 with detector systems has a much higher evacuation probability. The reason is that occupants in the building can quickly receive fire alarms and take action when smoke and heat detectors are connected to alarms. Detector systems can significantly shorten occupant response times. When detector systems are not available, occupants in the unprotected CLT building have a higher evacuation probabilities compared to other buildings. This is because the fire in the unprotected CLT grows faster and hence the fire cues to the occupants occur at earlier time than the other buildings. For example, the mean evacuation probability curve starts 
to increase at $100 \mathrm{~s}$ and reaches 0.99 at $720 \mathrm{~s}$ in the unprotected CLT building while the values are $140 \mathrm{~s}$ and $760 \mathrm{~s}$ respectively in the others buildings. Stable stages correspond to the interpretation processes that occupants will need time to judge the information after receiving warnings of the fire. In the scenarios without fire protection systems, occupants receive warnings only from the fire cues and other occupants. In the Occupant Response submodel, it is assumed that the related delay time for direct perception of fire cues and warning from the voice alarm is 90 seconds, and the related delay time for warnings from other occupants is 180 seconds. 


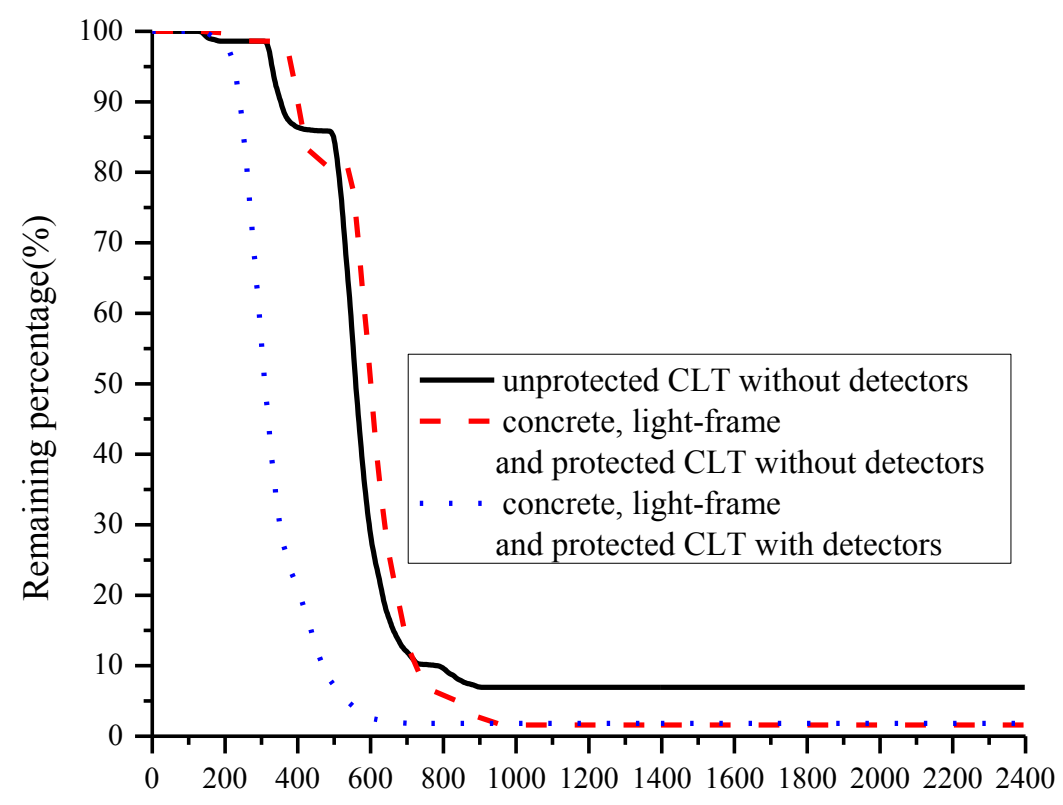

Time (s)

Figure 4.13 Average remaining percentages in scenario No.15 and No.16 in six-storey buildings

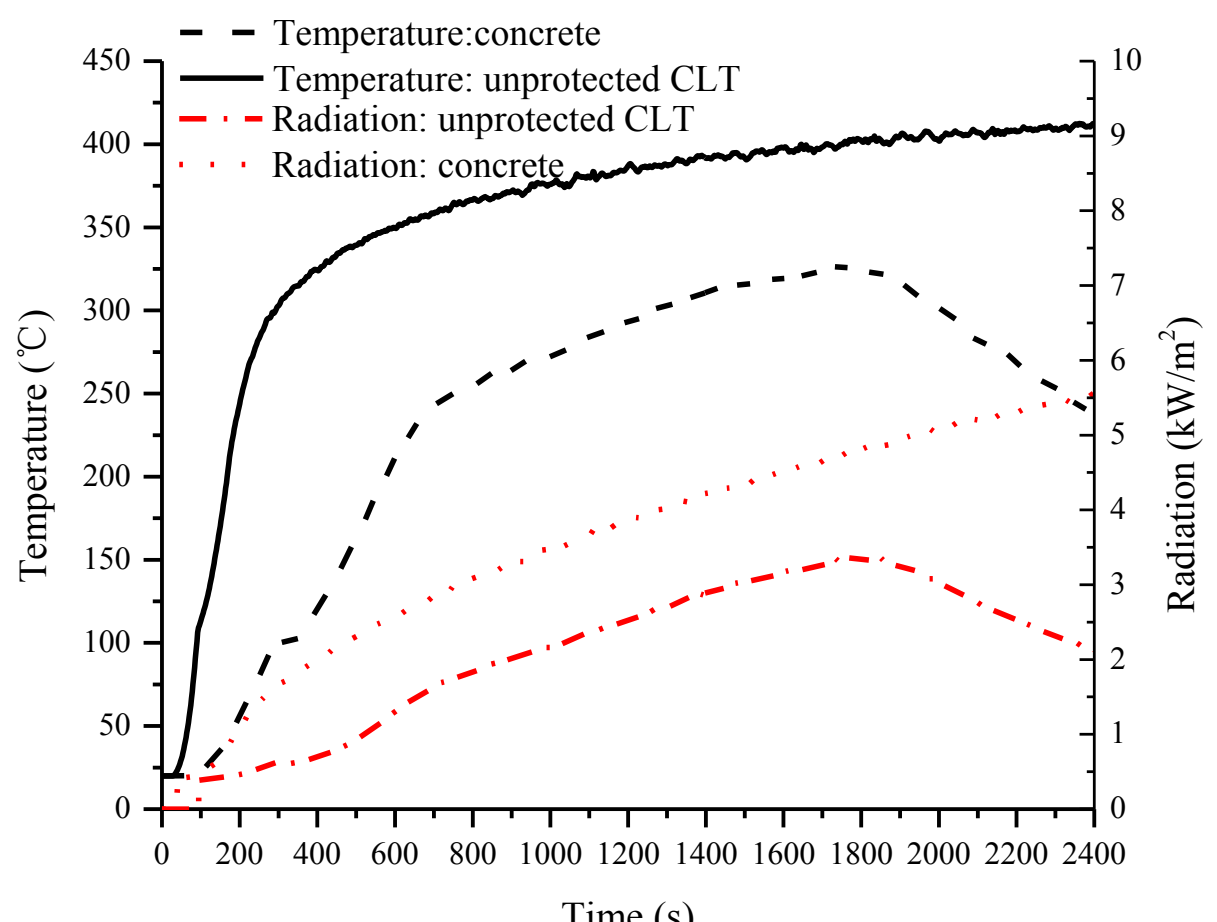

Time (s)

Figure 4.14 Upper layer temperature and radiation vs. time of scenarios No.16 in the corridor of the

\section{first floor}


Figure 4.13 shows the average percentages of occupants who haven't evacuated the building as a function of time in the absence of sprinklers and fire department. It can be found that occupants can quickly evacuate the building if the detector systems are available, as shown by the blue curve. Without detector systems, about $7 \%$ of the occupants are in the building in the unprotected CLT building by the end of the simulation. These occupants are considered to be trapped, dead or injured depending on the condition at their locations. The reason for this is that in the unprotected CLT building, the time to flashover is only about 145 seconds and during this very short period, fire and smoke spread to the adjacent corridor very quickly. As seen in Figure 4.14, in 145 seconds the smoke temperature on the first floor corridor reaches over $200{ }^{\circ} \mathrm{C}$. Thermal radiation flux exceeds the tenability limit of $2.5 \mathrm{~kW} / \mathrm{m}^{2}$ after $400 \mathrm{~s}$. While, in the concrete building, occupants on the first floor still have time to get out of the building before flashover. The building made of CLT or light-frame timber protected by gypsum boards with appropriate fire resistance rating have similar performance to the concrete building, which provides a relatively safe evacuation environment.

\subsubsection{Property Loss and Casualties}

The Fire Cost Expectation submodel of CUrisk can predict the total fire loss including indirect and direct losses for each scenario. The direct damages include damages to the building and fire protection systems, and damages to the building contents. In CUrisk, 
building contents are categorized into 11 categories based on the sensitivity to be damaged by high temperature, smoke, and water. These categories include books, electronic equipment, clothes, upholstered furniture, and so on. Damages to the building are based on cost data that are similar for all building types, due to lack of knowledge of costs of different building construction materials. It is also assumed that all buildings contain the same contents. The total cost for a 6 -storey building is $\$ 10787 \mathrm{k}$.

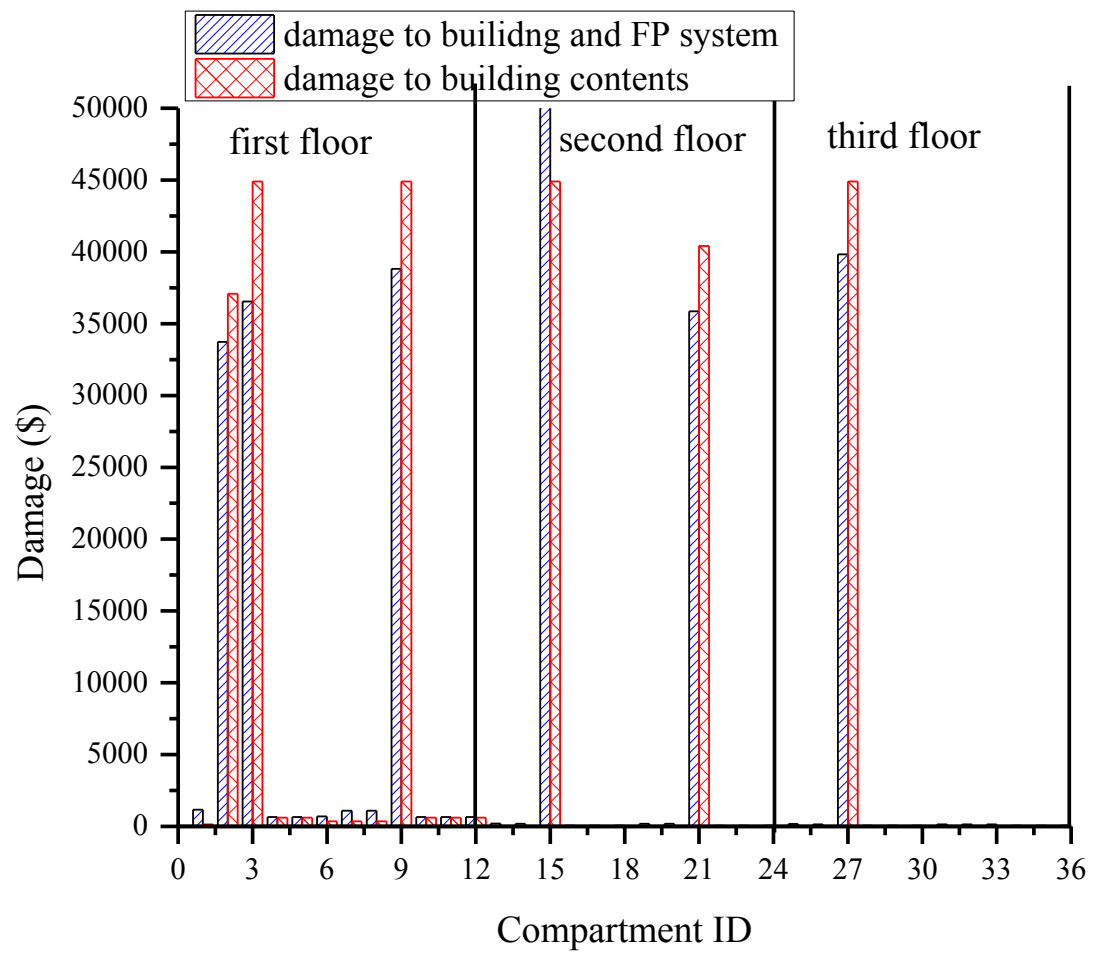

Figure 4.15 Damages to each compartment of the protected CLT building of scenario No.16

Figure 4.15 shows the direct damages to the compartments of the first three floors of the building. Damages to compartments over the third floor are very small. The majority of the damages occur in the compartments that are adjacent to the fire compartment, or right above it. The maximum damage to building contents is $\$ 44.9 \mathrm{k}$ in compartment 3 (the 
fire room), compartment 9 (facing) and compartments 15 and 27 (above). This is due to fire spread through openings (the door and broken window) to those compartments. The maximum damage in a compartment is about $\$ 50 \mathrm{k}$. This occurs in compartments 15 rather than the fire room because the size of the fire room is half the size of the other compartments. In summary, in the worst scenario, fire and smoke can spread to the third floor and cause great losses within the first $2400 \mathrm{~s}$.

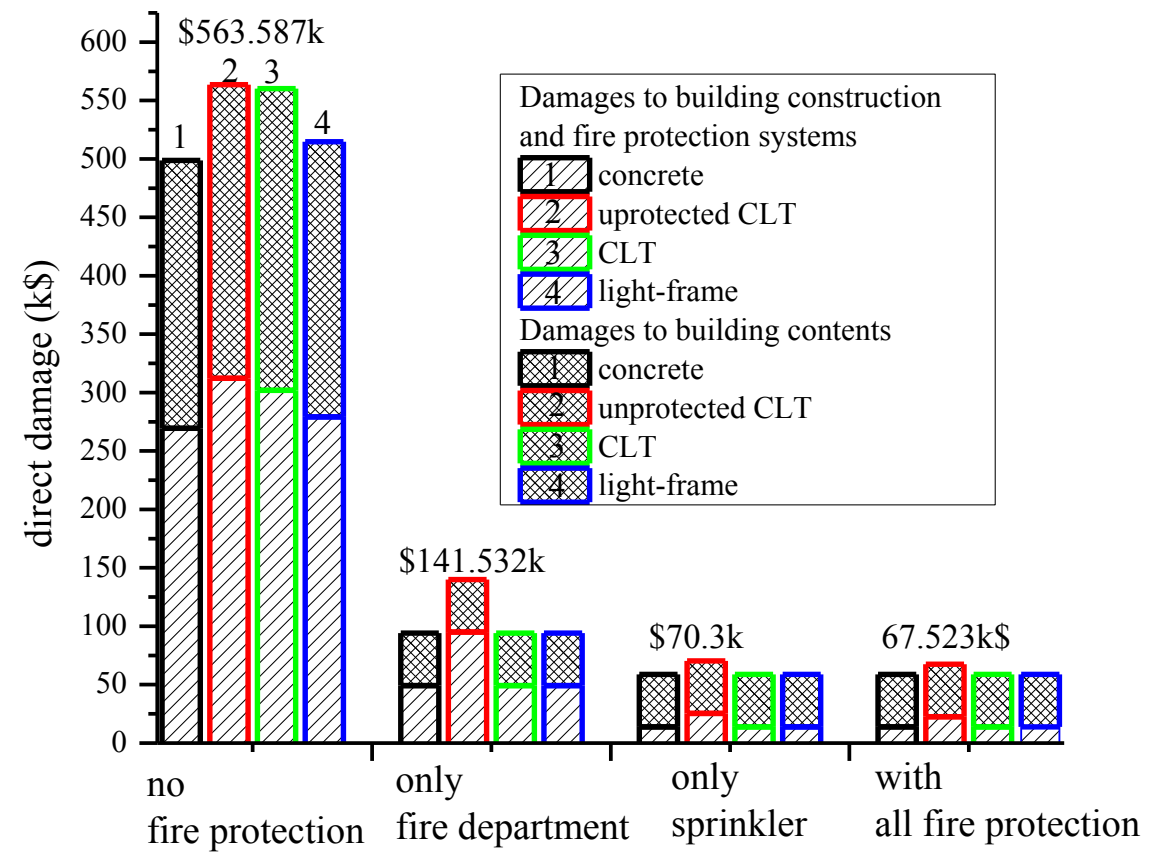

Figure 4.16 Direct damages to the four different buildings of four scenarios (No.9, No.12, No.14 and

No.16)

The total direct damages of the four types of buildings are compared using four different fire protections options. The four options include: 1) no fire protection; 2) only fire department; 3) only sprinklers; and 4) all fire protections (fire department, sprinklers and detectors). Figure 4.16 shows that the damages are minimized when sprinklers activate in 
options 3 and 4 . If only the fire department is available, the damages caused by fire in the unprotected CLT building are almost twice as that of options 3 and 4 but still much less than the option with no fire protection. Among the four building designs, the light-frame timber building has similar fire behaviour as the non-combustible building while the CLT structure suffers larger damages and the loss is $\$ 563.587 \mathrm{k}$ in the unprotected CLT building. 


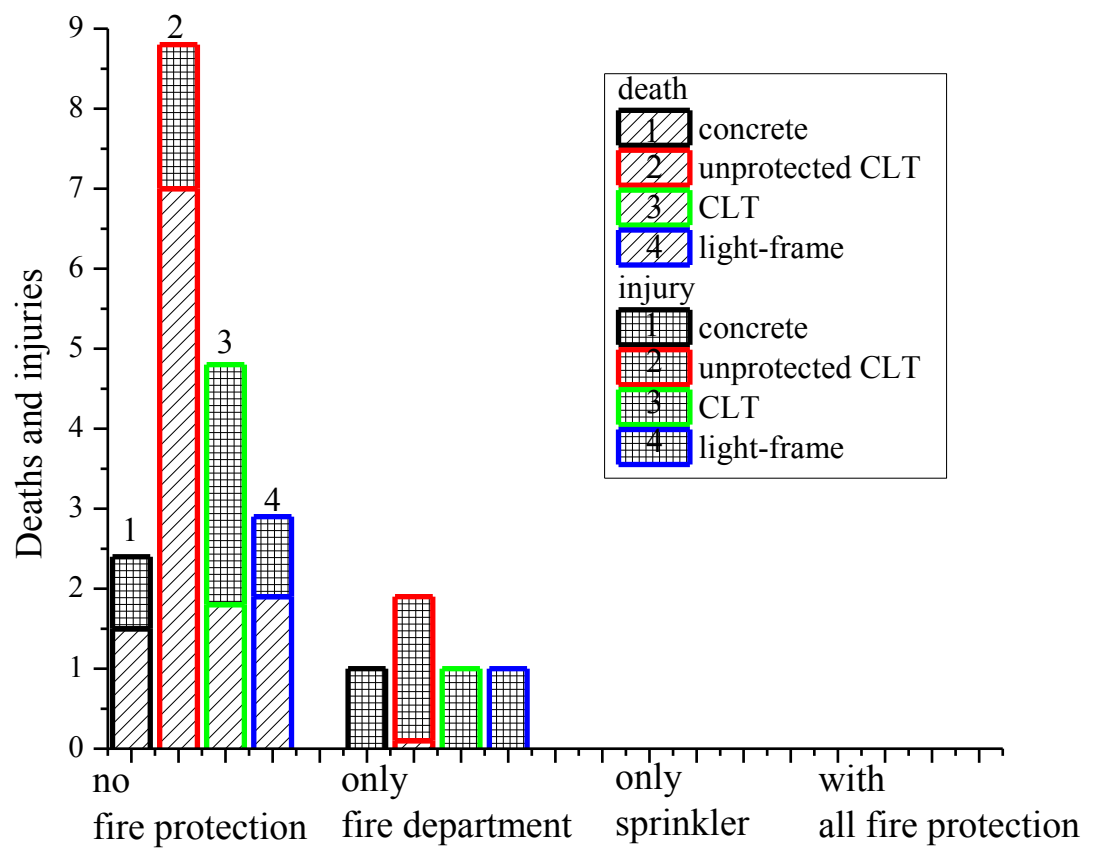

Figure 4.17 Deaths and injuries of four different buildings of four scenarios (No.9, No.12, No.14 and

No.16)

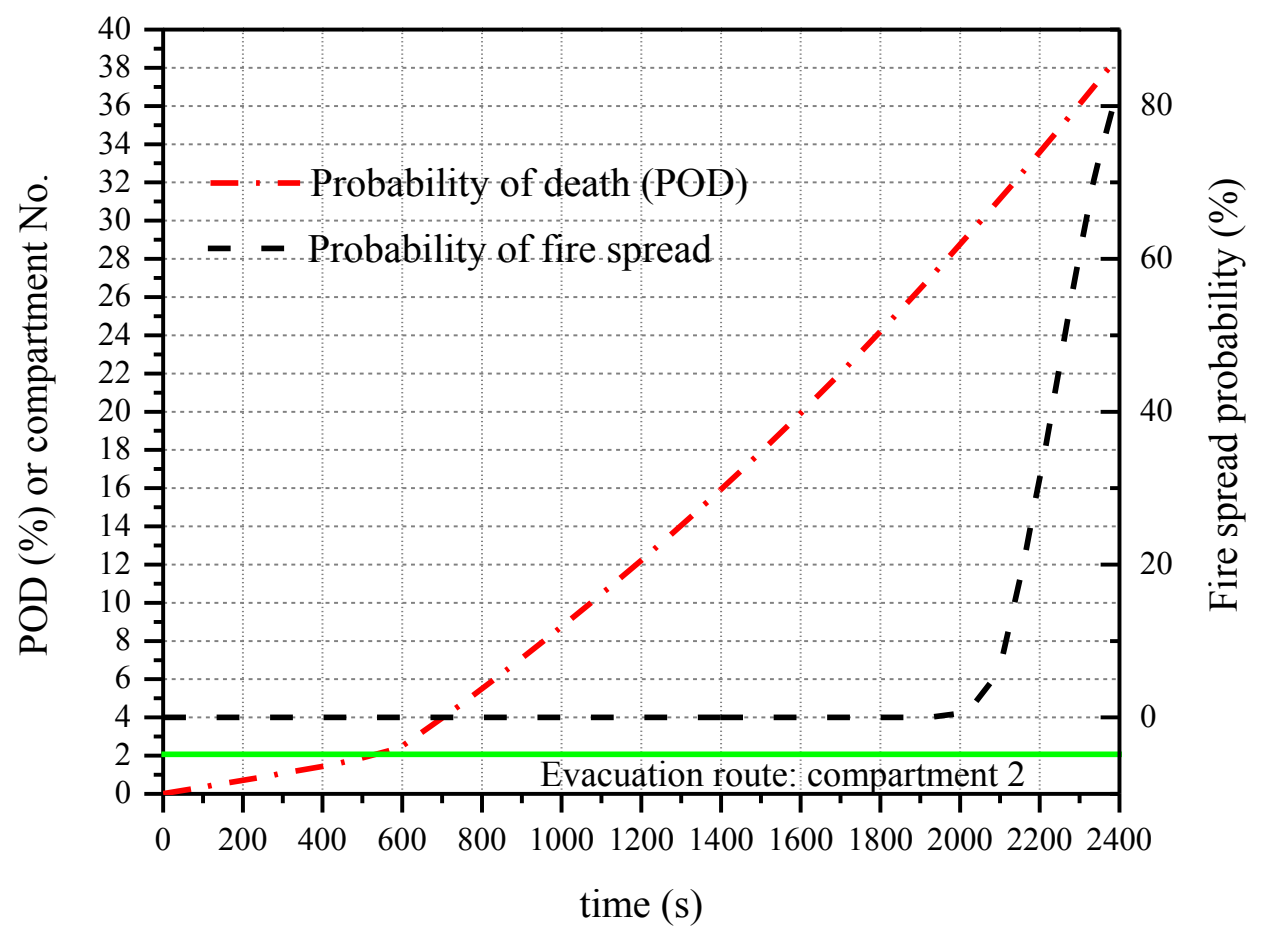


Figure 4.18 Probabilities of death and fire spread of scenario No.16 in the unprotected CLT building

The number of deaths and injuries for the four options are plotted in Figure 4.17. As shown in this graph, in option 1 without any fire protection systems has the highest deaths and injuries: 7 and 1.8 in the unprotected CLT building; 1.8 and 3 in the protected CLT building; 1.9 and 1 in the light-frame building; and 1.5 and 1 in the concrete building. The reasons for these serious casualties are the fire hazardous conditions and fire spread. As seen in Figure 4.15, fire can spread from the fire origin room to adjacent rooms, and to rooms directly above the fire room. An assumption is also made in the Occupant Evacuation submodel that occupants will stay in their current compartment if the temperature in the exit route is over $200{ }^{\circ} \mathrm{C}$. As an example consider occupant No.8 who located in the compartment No.2 near the fire room, Figure 4.18 shows the evacuation route (green line), the probability of death (black dash line) for this person and the probability of fire spread (red dash line). The left Y-axis includes both the POD and the compartment number and the right Y-axis is the probability of fire spread. The evacuation route indicates that this occupant is trapped in compartment No.2 because of the high temperature in the corridor (next node of his evacuation route). The probability of death increases gradually with time reaching $38 \%$ at the end, which is over the predefined injury threshold. And the probability of fire spread increases quickly after $2000 \mathrm{~s}$ and reaches $80 \%$. This high probability potentially leads to death. When sprinklers are installed in the building as options 3 and 4, almost no one is injured. When the fire 
department takes action in option 2, the casualties are minimized. But there are still about two injuries in the unprotected CLT building and one injury in the other buildings. The reason is that before the fire department arrives, evacuating occupants have already experienced severe fire conditions. Overall it can be concluded that, the unprotected CLT building fire is the most dangerous, and that the sprinkler system greatly reduces the occupant casualties.

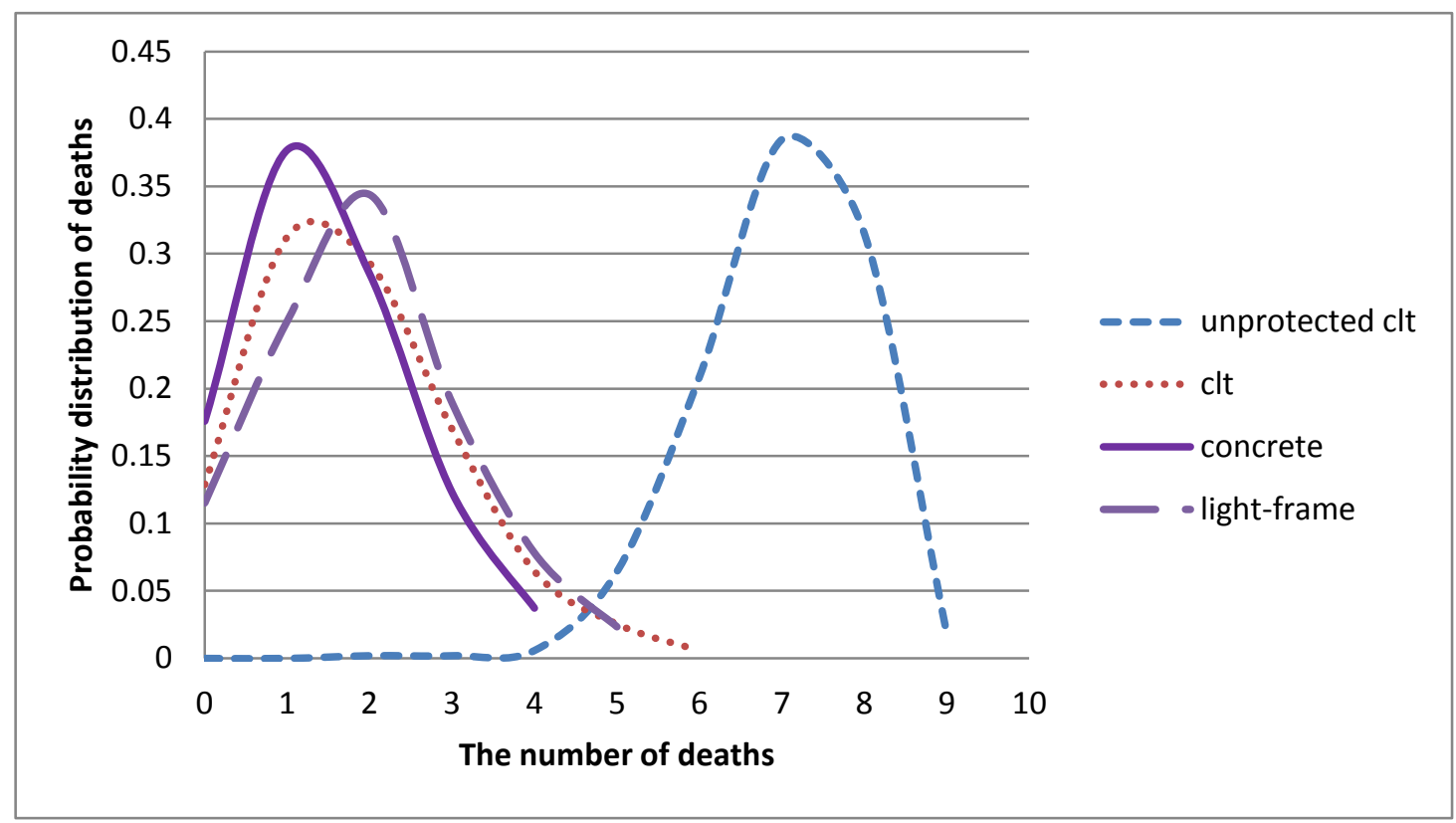

Figure 4.19 Probability distribution of deaths produced by Mont Carlo simulation for scenario No.16 


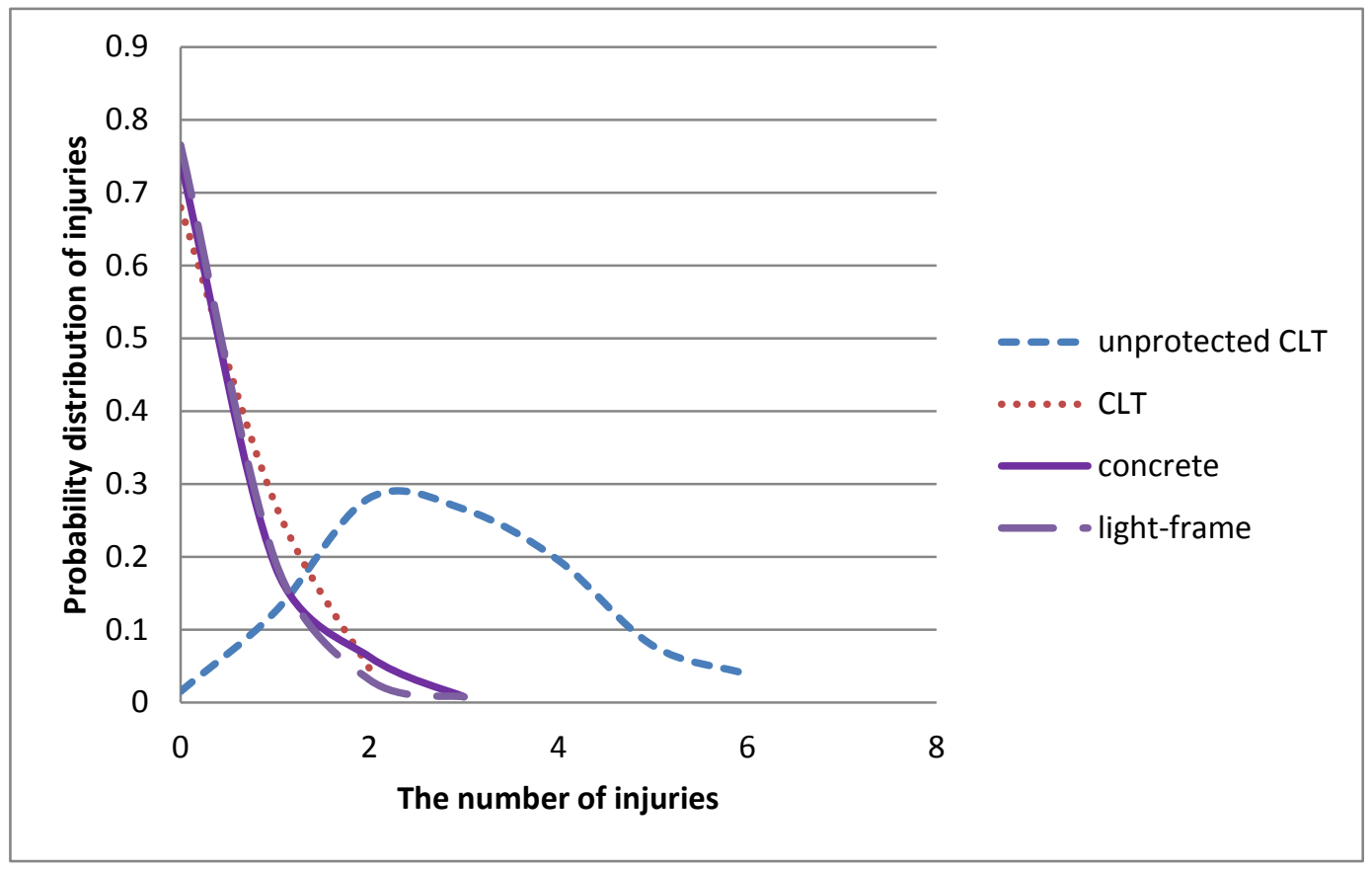

Figure 4.20 Probability distribution of injuries produced by Mont Carlo simulation of scenario No.12

As CUrisk is a probability model, it can calculate the probability distribution of casualties.

Figure 4.19 and Figure 4.20 show the probability distributions of the number of deaths of scenario No.16 and injuries of scenario No.12 in non-combustible and combustible buildings. It can be found that non-combustible, protected CLT and light-frame buildings perform similarly. For example, in the case without any fire protection systems scenario No.16, the number of deaths varies in a small range and the maximum probability corresponds to around 1.5 deaths. However, for the unprotected CLT building, the death number varies in the range from 4 to 9 and the maximum probability corresponds to about 7 deaths. In the case with only the fire department arrivals, nearly no death occurs in all buildings. The ranges of injuries are from 0 to 3 and 0 to 6 respectively, and the injuries with maximum probability for the unprotected building is approximately 2 
occupants.

\subsubsection{Effect of Building Height}

This section compares fire risk levels of 4-storey, 6-story and 12-storey buildings. The construction materials are taken as non-combustible and combustible. For the purpose of this analysis, the three types of buildings have the same floor area, the fire room has the same area and size, and same contents. The wall and floor assemblies have a one-hour fire resistance rating in the 4-storey and 6-storey buildings and a two-hour fire resistance rating in the 12-storey building. As the results of the 6-storey building have been discussed in section 4.4.1, this section will consider the following building design options.

Design Option 5: 4-storey non-combustible building (concrete);

Design Option 6: 4-storey CLT building without gypsum board protection;

Design Option 7: 4-storey CLT building with one layer of gypsum board protection (15 minutes fire resistance rating);

Design Option 8: 4-storey light-frame building with one layer of gypsum board protection (15 minutes fire resistance rating);

Design Option 9: 12-storey non-combustible building (concrete);

Design Option 10: 12-storey CLT building without gypsum board protection;

Design Option 11: 12-storey CLT building with one layer of gypsum board protection 
(15 minutes fire resistance rating);

Design Option 12: 12-storey light-frame building with one layer of gypsum board protection (15 minutes fire resistance rating).

\subsubsection{Fire Development and Smoke Spread}

Stair shafts are very important routes for occupants egress, fire fighting and rescue.

Smoke can spread through stair shafts to upper floors. This section presents results of smoke temperatures and $\mathrm{CO}$ concentrations in stair shafts of buildings with different heights.

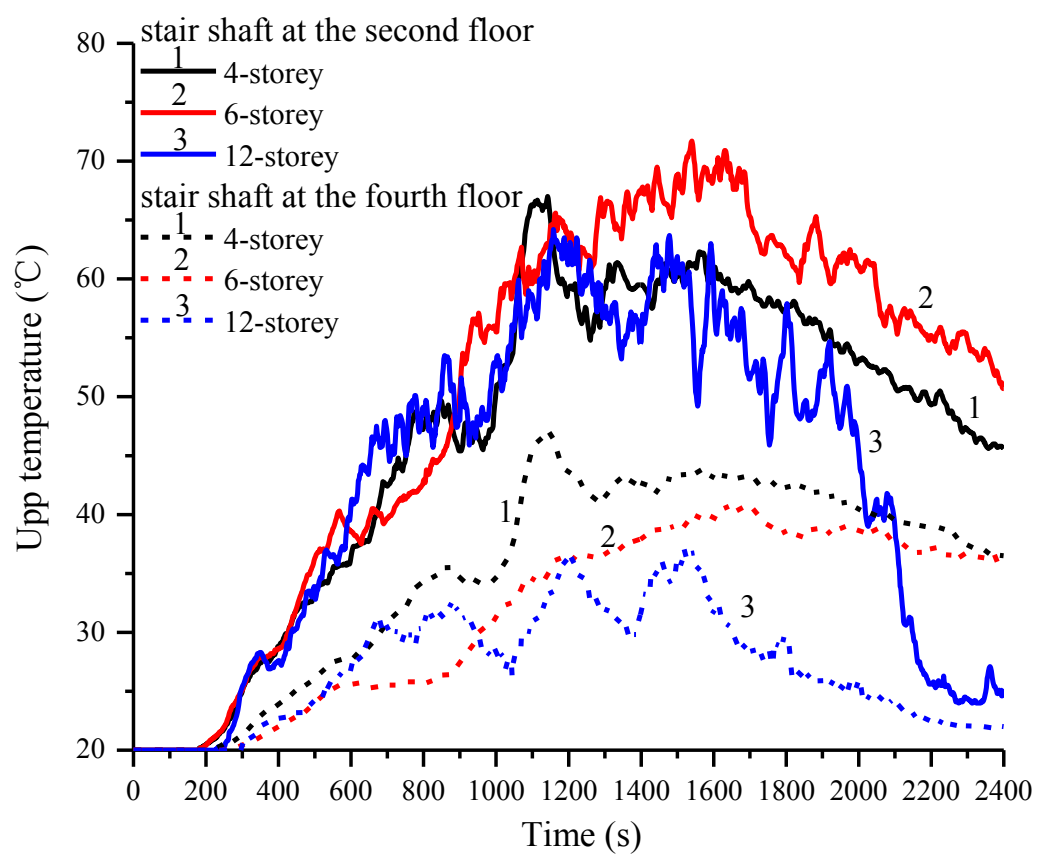

Figure 4.21 Upper layer temperatures in stair shafts of second and fourth floors vs. time of scenario

No.16 in light-frame timber buildings 


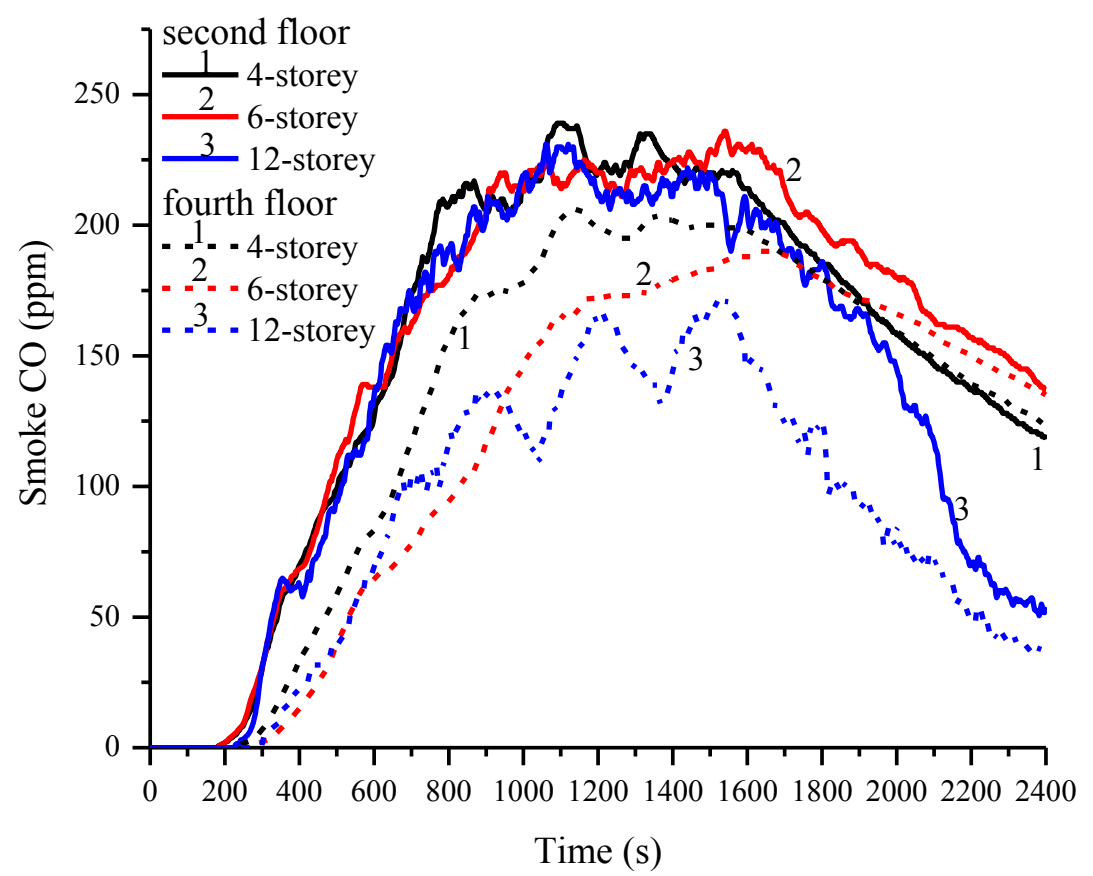

Figure 4.22 Smoke CO concentrations in stair shafts of second and fourth floors vs. time of scenario

\section{No.16 in light-frame timber buildings}

Figure 4.21 compares smoke temperatures in stair shafts at the second and fourth floors of light-frame timber buildings. The upper layer temperature in the stair shaft starts to grow at around $190 \mathrm{~s}$ and reach the maximum at about $1200 \mathrm{~s}$. The temperatures at the second floor stair shaft with different heights buildings have similar curves and similar peak values, approximately $70^{\circ} \mathrm{C}$. Whereas, the temperature at the fourth floor stair shaft of 4-storey building is always slightly higher than that of the 6-storey and 12-storey buildings. $\mathrm{CO}$ concentrations shown in Figure 4.22 have similar trends as the temperature in Figure 4.21. The maximum concentration at the second floor stair shaft is around 220 ppm in all three buildings while 4-storey building has the higher $\mathrm{CO}$ concentration at the fourth floor stair shaft. Compared to the 4-storey and 6-storey buildings, the temperature 
and smoke concentration decrease faster after $1200 \mathrm{~s}$ in the 12 -story building. This is due to dilution effects of air in buildings with different heights. After about $1400 \mathrm{~s}$ the decay phases occur in light-frame buildings due to the decrease in fuel.

\subsubsection{Occupants Response}

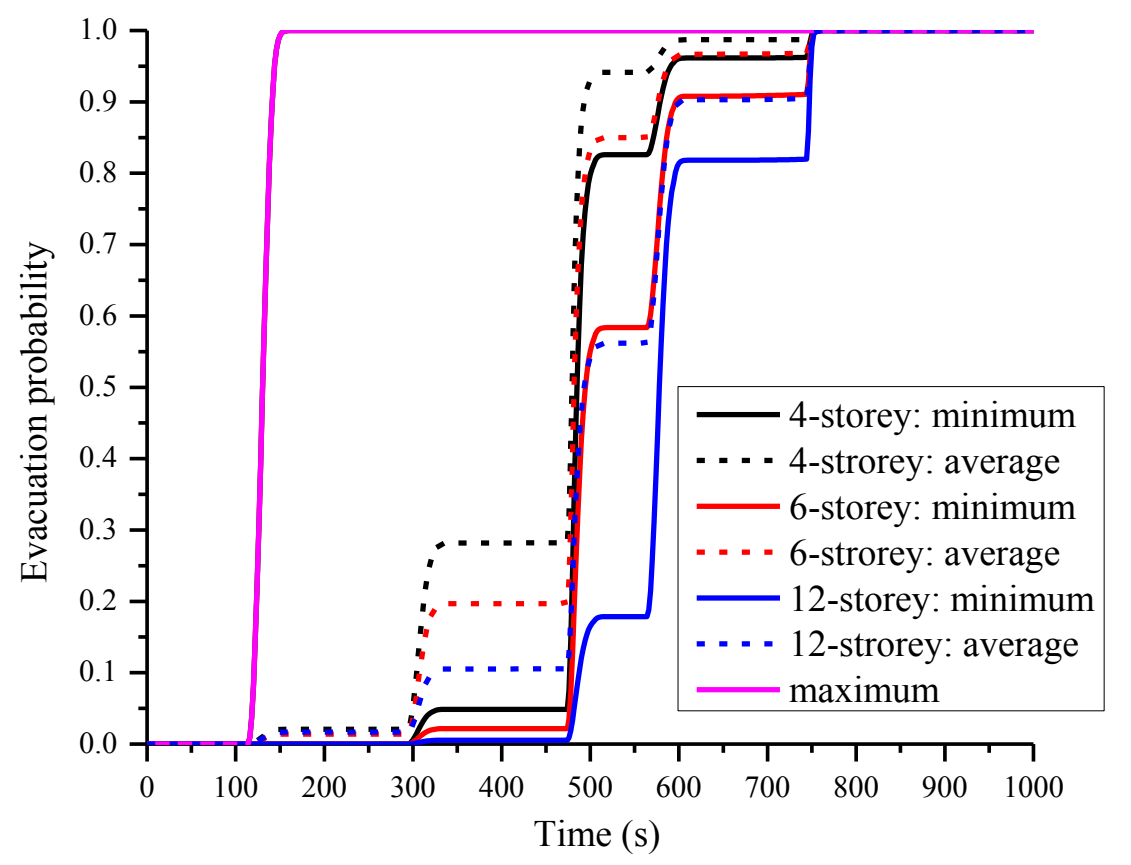

Figure 4.23 Probability of evacuation of scenario No.16 in light-frame buildings

Figure 4.23 shows the maximum, minimum and average evacuation probability curves of light-frame buildings for the scenario without any fire protection systems. As it can be seen from the figure, buildings with different heights have the same maximum response probability because the maximum probability corresponds to the fire room. The minimum and average response probabilities show similar trends, but occupants in the 4-storey building respond quicker. This is reasonable as the fire is located on the first floor 
therefore occupants located on the higher floors would take longer time to receive warnings.

\subsubsection{Property Losses and Casualties}

Direct damages to each compartment of 4-storey and 12-storey buildings in the scenario without any fire protection systems are shown in Error! Reference source not found. and Figure 4.25.

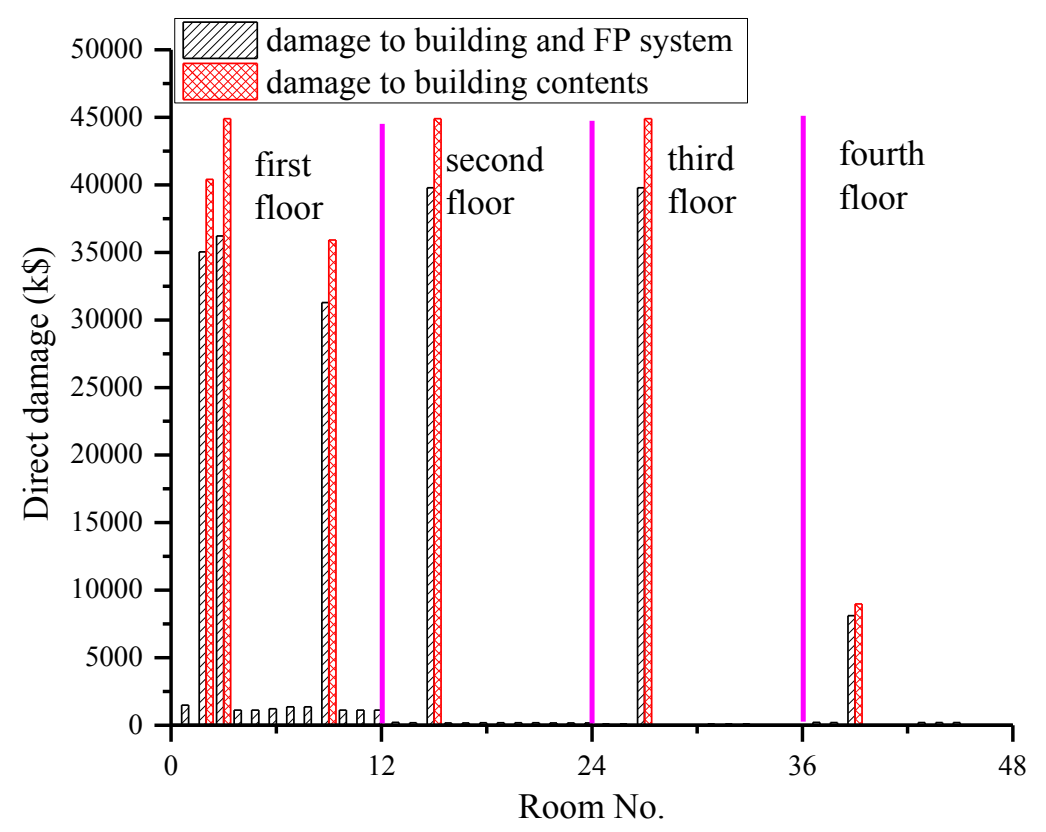

Figure 4.24 The direct damage to each compartment of the 4-storey light-frame building for scenario No.16 


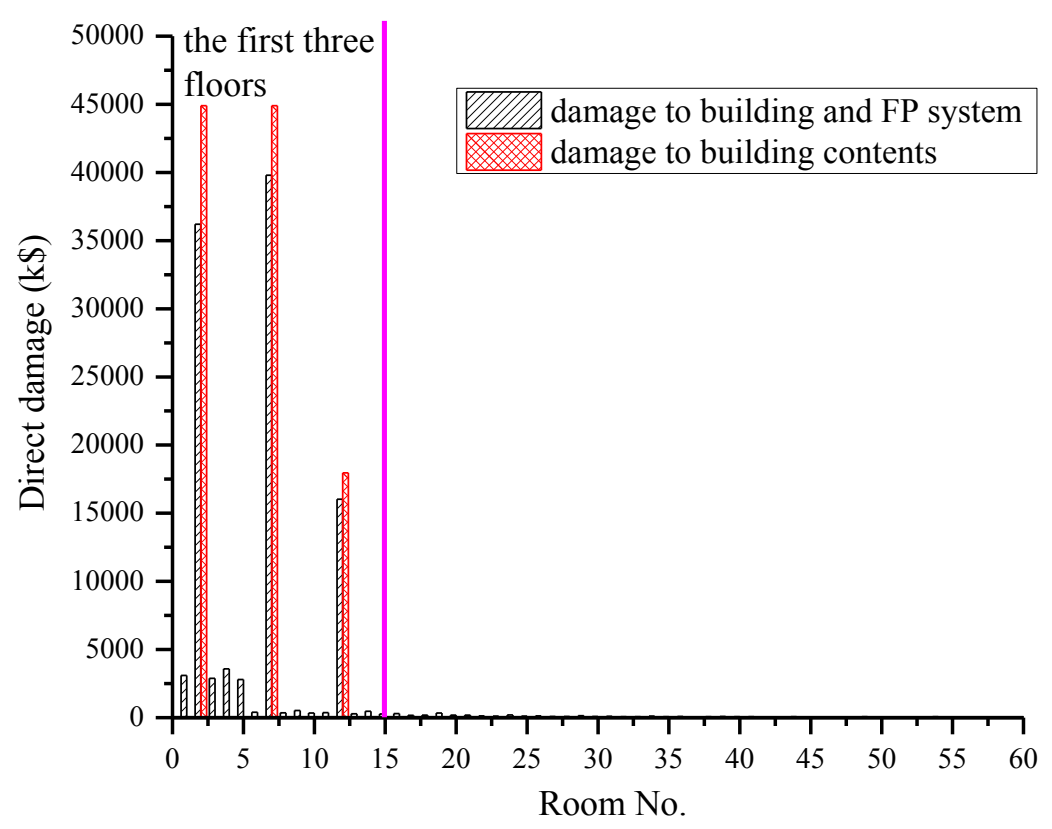

Figure 4.25 The direct damage to each compartment of the 12-storey light-frame building for scenario

\section{No.16}

According to these two figures, we can see that the loss distributions in the two buildings are different. In the 4-storey building, smoke can spread up to the fourth floor causing about $\$ 2000$ fire loss. While, in the 12 -storey the fire damage to the building only occurs in the first three floors and the damage to the adjacent compartment of the fire origin is very small. The fire loss distribution difference can be explained by the different probabilities of fire spread. In the 12-storey building, the wall and floor assemblies have a 2-hour fire resistance rating which is twice the fire resistance rating of the 4-storey building. The lower fire resistance rating would produce higher fire spread probabilities, hence higher damages. The damage to the building and fire protection system is lower in the fire room due to the small room size compared to the other compartments. In both 
buildings, the highest direct damages always occur in the fire room and the room directly up the fire room.

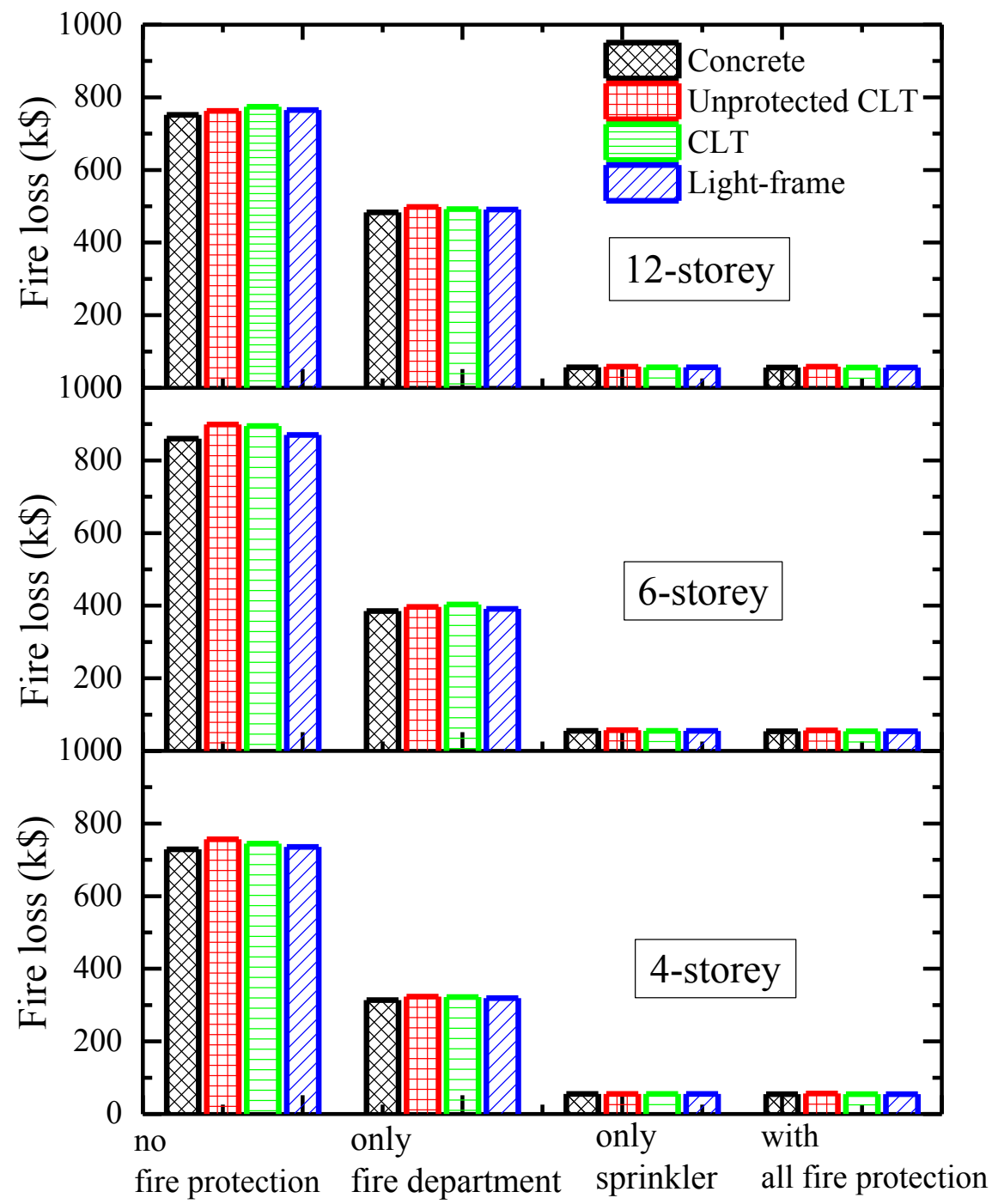

Figure 4.26 Fire losses of buildings with different heights

Figure 4.26 compares the total fire losses of four scenarios for the 4-storey, 6-storey and 12-storey buildings with different construction materials. It can be seen that the fire losses of the case with the fire department are half the losses without fire department; with sprinklers, the fire losses are greatly minimized. The fire losses in the combustible 
buildings are always slightly higher than those of the non-combustible buildings. The maximum fire loss occurs in the 6-storey building at around $\$ 850 \mathrm{k}$. The 4-storey and 12-storey buildings have similar losses at about $\$ 750 \mathrm{k}$. This is because of the different fire resistance ratings of the building components. The losses of the 6-storey buildings which have the same fire resistance as the 4-storey are higher. Increasing the fire resistance rating of components decreases building damage in the case of fire, even if the height of the building is increased, demonstrating the benefit of fire resistance in reducing fire losses.

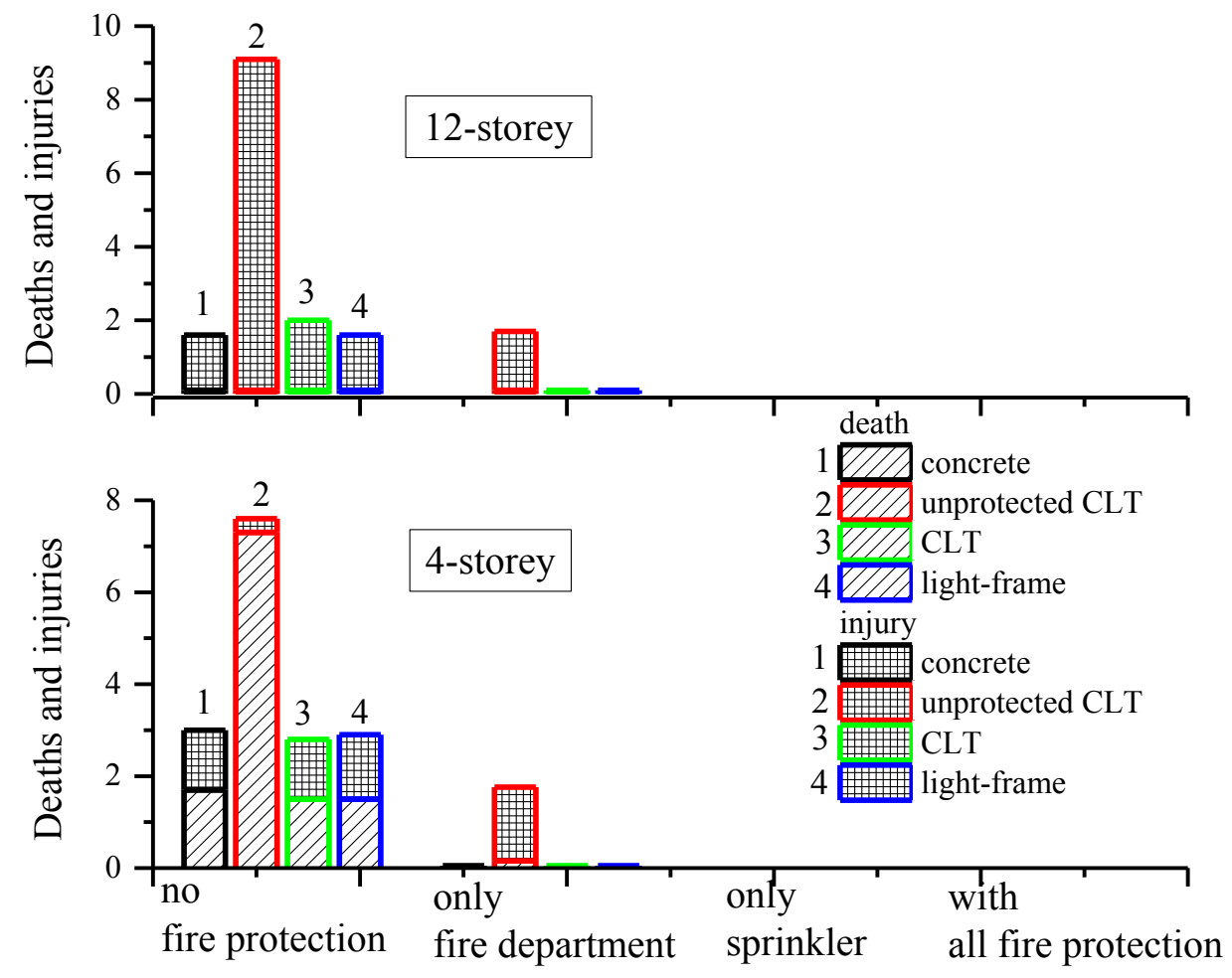

Figure 4.27 The number of deaths and injuries for four scenarios

Figure 4.27 as did in Figure 4.17 shows that sprinklers minimize the number of casualties.

Unprotected CLT buildings without fire protection systems have the highest number of 
casualties. There are some differences in the number of casualties between the 4-storey and 12-storey buildings for the scenario without any fire protection systems. For example, in the 12-storey buildings, almost nobody is killed, but about 9 occupants get injured in the unprotected CLT and 1.8 occupants get injured in the other buildings. In the 4 -storey buildings, both deaths and injuries occur: 7 occupants are killed and 0.3 occupants get injured in the unprotected CLT building; and about 1.8 deaths and 1.1 injuries in the other buildings. The main reason is fire spread. In the 12-storey building, no fire spread to adjacent compartments occurs during the 40 mins of simulation time because of the higher fire resistance rating of the wall and floor assemblies. There are however some occupants trapped in their original rooms due to the hazardous fire conditions in the corridor (the next evacuation route). Those occupants may face a risk of death due to the accumulated hot and toxic smoke if the fire department would not arrived at the fire scene after 40 mins. In the 4-storey building, the death number is similar to the 6-storey building (see Figure 4.17) because of the same fire resistance rating of the building components. The injury number is smaller due to the lower building height and the total number of occupants. The fire department arrival decreases the casualties in all buildings except for the unprotected CLT building. This is because the unprotected CLT fire grows faster and produces heavier smoke. Before the fire department arrival occupants already experienced severe fire conditions. This chart demonstrates that increasing the timber building height does not increase the life risk, if sufficient fire resistance rating is 
provided.

\subsubsection{Floor Areas}

This section compares the fire risk levels between 6-storey buildings with different floor areas. The floor area of the large building is twice that of the base area of $918 \mathrm{~m}^{2}$. As the building size increases, the building cost increases proportionally. For the purpose of this analysis, it is assumed that the fire room has the same area and size, and all the buildings have wall and floor assemblies with one hour fire resistance rating. As the base-size 6-storey building has been done in section 4.4.1, this section will consider the following building design options.

Design Option 13: large-size 6-storey non-combustible building (concrete);

Design Option 14: large-size 6-storey CLT building without gypsum board protection;

Design Option 15: large-size 6-storey CLT building with one layer of gypsum board protection (15mins fire resistance rating);

Design Option 16: large-size 6-storey light-frame building with one layer of gypsum board protection (15mins fire resistance rating).

\subsubsection{Fire Development and Smoke Spread}

Building corridor is the necessary path in fire evacuation. The smoke temperature and $\mathrm{CO}$ concentration in corridors with different floor areas and construction materials are 
compared Figure 4.28 and Figure 4.29.

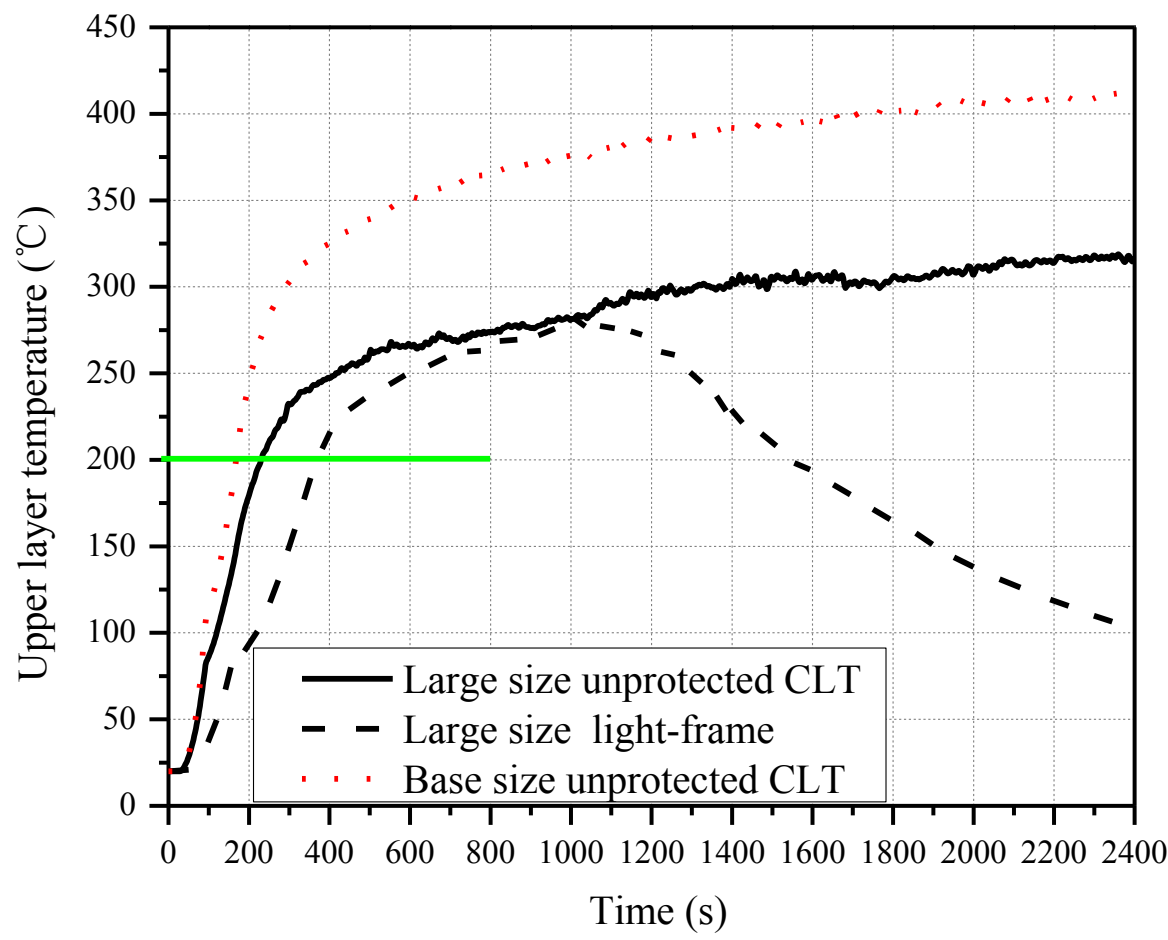

Figure 4.28 Upper layer temperatures in the $1^{\text {st }}$ corridor vs. time of scenarios No.16 in buildings with different floor areas and construction materials 


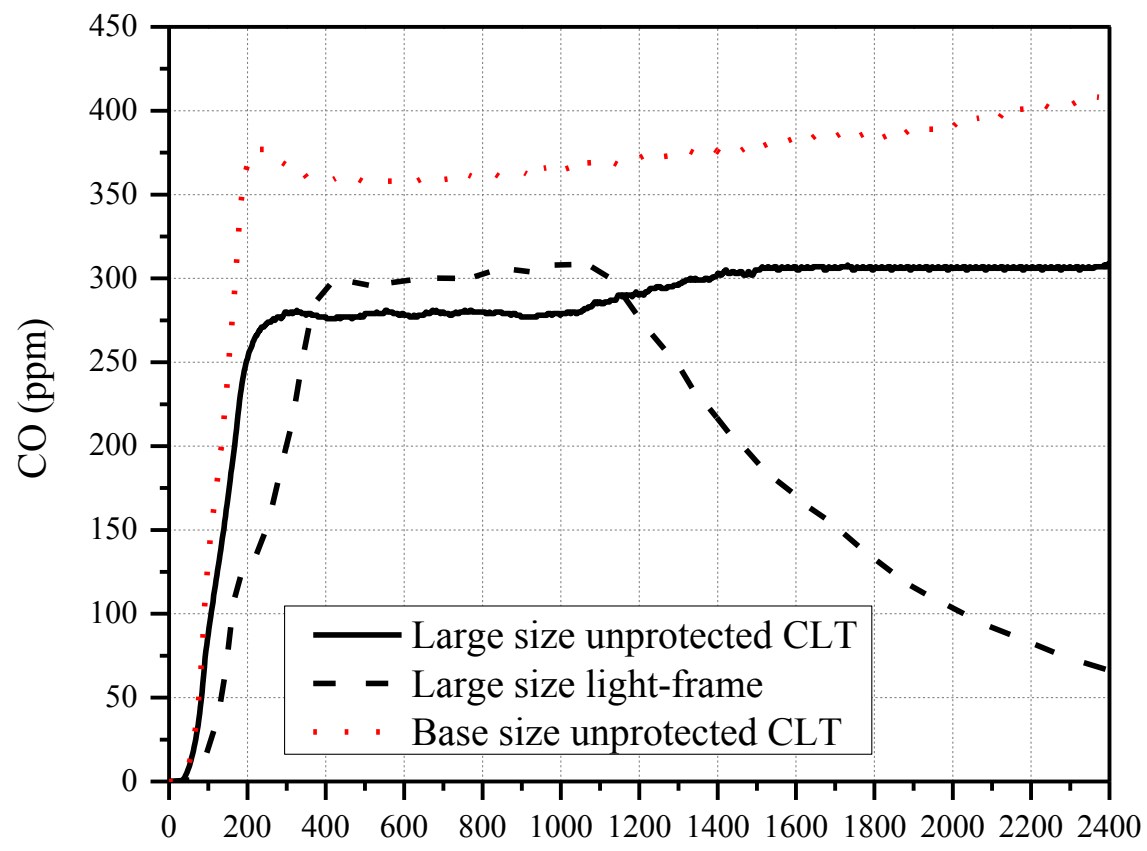

Time (s)

Figure 4.29 Upper CO concentrations in the $1^{\text {st }}$ corridor vs. time of scenarios No.16 in buildings with

different floor areas and construction materials

As we can see from Figure 4.28 and Figure 4.29, the upper layer temperature and smoke concentration in the first floor corridor of the unprotected CLT buildings increases faster than those of the light-frame buildings. As mentioned before, a smoke layer temperature of $200{ }^{\circ} \mathrm{C}$ is one of the acceptance criteria for evacuation. The times at which the temperature reaches $200{ }^{\circ} \mathrm{C}$ are around $150 \mathrm{~s}$ in the base CLT building, $240 \mathrm{~s}$ in the large CLT building and $350 \mathrm{~s}$ in the large light-frame building respectively. The peak temperature and $\mathrm{CO}$ in the base size building is about $160{ }^{\circ} \mathrm{C}$ and $60 \mathrm{ppm}$ higher than those in the large size building. This is expected as the increase of the building size can decrease smoke concentration and temperature in the corridor. The decay phase only 
occurs in the building made of light-frame timber due to the less contribution to the fire load compared to the unprotected CLT.

\subsubsection{Occupant Response and Evacuation}

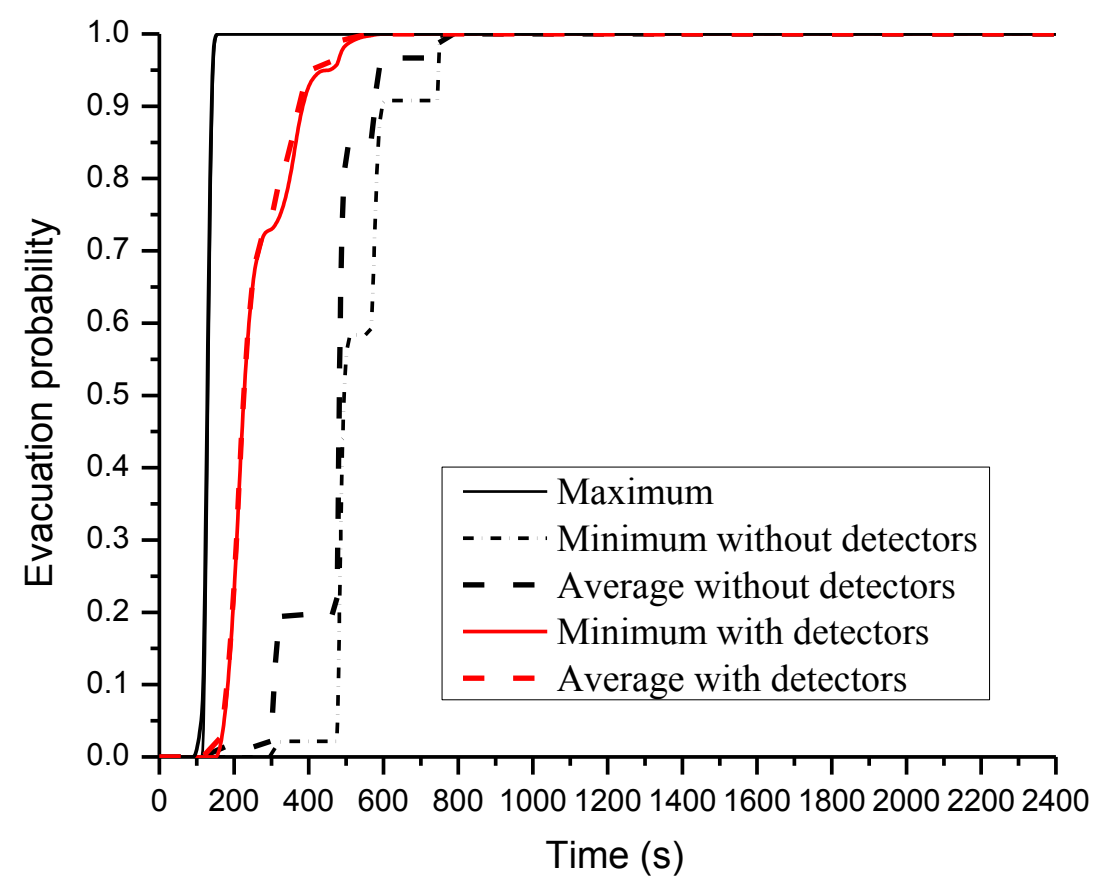

Figure 4.30 Probability of evacuation in large unprotected CLT buildings for scenarios No.15 and

\section{No.16}

Evacuation probabilities of two scenarios with or without detectors depicted in Figure 4.30 show that occupants react much faster if the detectors are installed. Occupants in the fire compartment have the maximum response probability. The average response probability for scenario No.15 with detector systems starts at about $100 \mathrm{~s}$ and increases steeply to the maximum of 0.99 at around 550 s. However, the average response 
probability for scenario No.16 reaches the peak at around $700 \mathrm{~s}$ due to the lack of detectors.

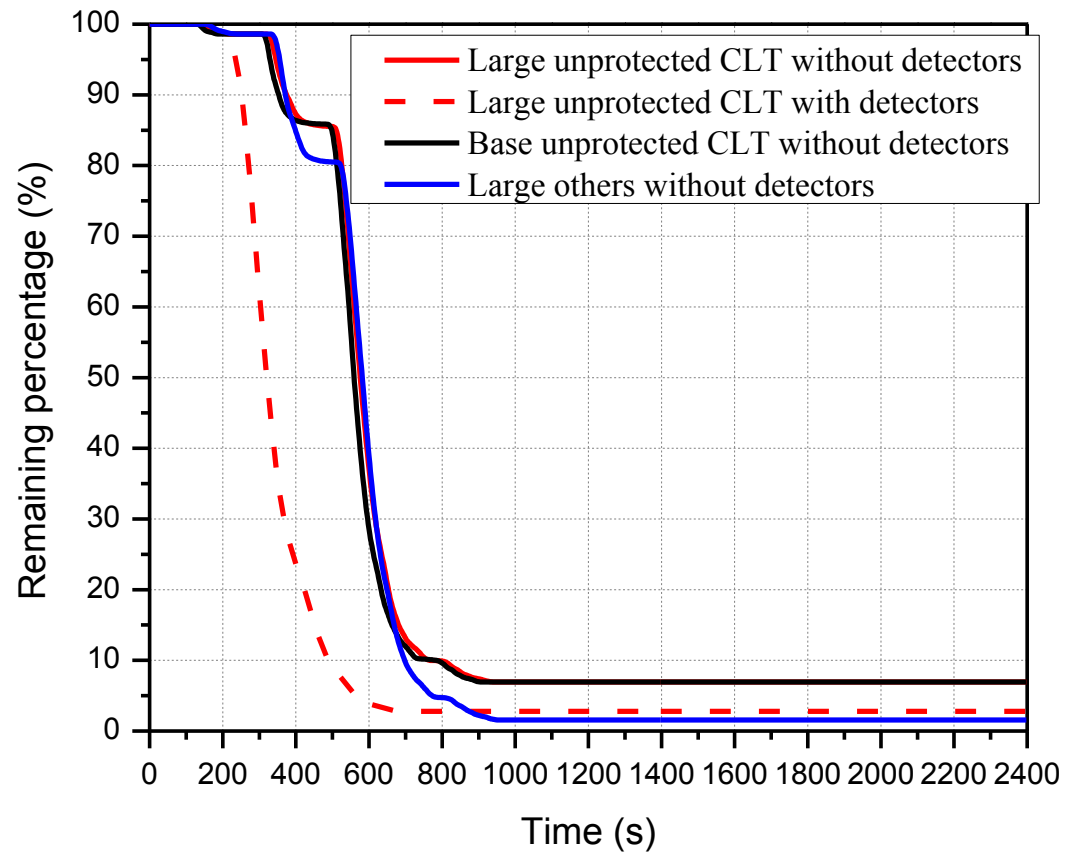

Figure 4.31 Remaining percentage in unprotected buildings for scenario No.15 and No.16

Figure 4.31 shows the percentage of occupants still in the CLT building during the evacuation process. It is apparent from the graph that detectors greatly reduce the evacuation time, and there is no obvious difference of the remaining percentages between large and base size unprotected CLT buildings. At $400 \mathrm{~s}$, almost $75 \%$ of occupants have evacuated the building when the detectors are installed. However, for the scenario without detectors, only $15 \%$ of occupants have evacuated by that time. Although the unprotected CLT building and other buildings have similar trends, at the end of the simulation a large number of occupants are trapped in the unprotected CLT building for 
scenario No.16, 4\% higher than that for No.15.

\subsubsection{Casualties}

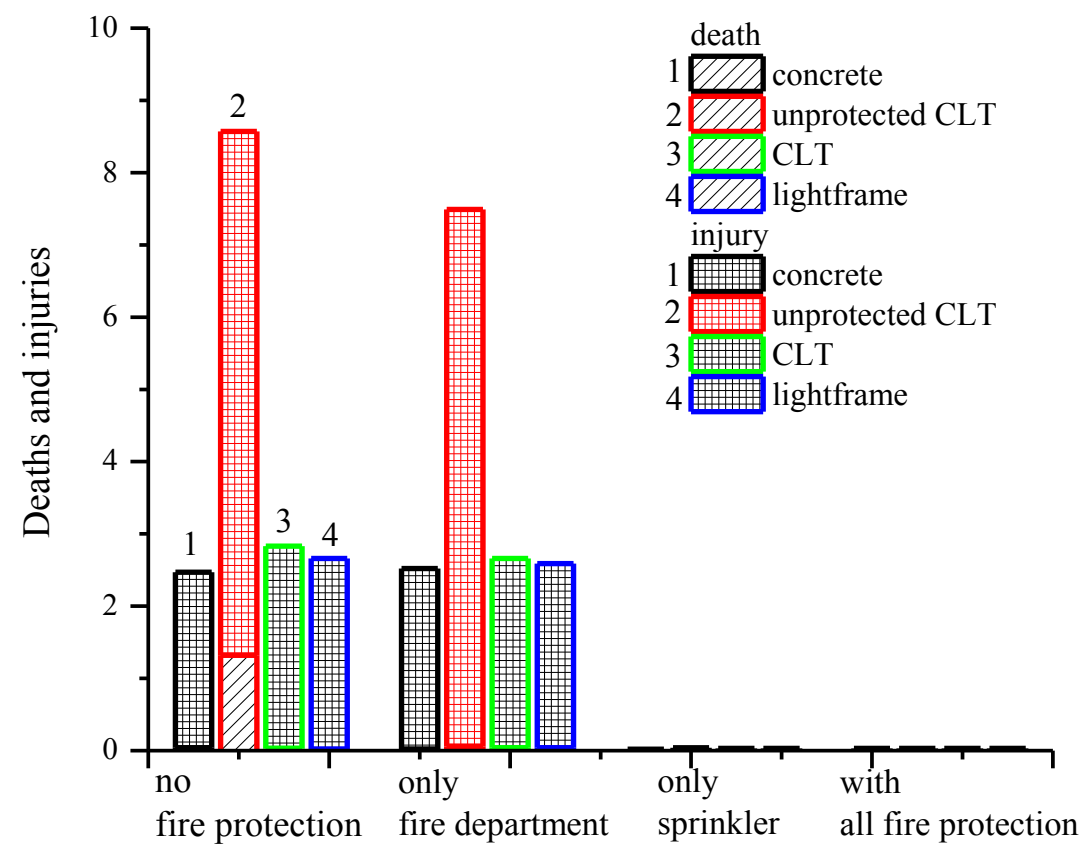

Figure 4.32 The number of deaths and injuries for the large 6-storey building in four scenarios

According to Figure 4.32, the casualties in the large-size buildings are different from those in base-size buildings (see Figure 4.17). The scenario without fire protection systems causes 1.3 deaths in the unprotected CLT building and no death in the other buildings which about 2.5 injuries. The main reason that leads to deaths and injuries for the large-size building is the hot and toxic gases in the corridor rather than fire spread. In this type of building, occupants are not trapped in their original compartments as the occupants in the base-size 6-storey building. As is reflected in Figure 4.28, the time to reach the critical temperature of $200{ }^{\circ} \mathrm{C}$ is delayed due to the increased building size and 
dilution of the smoke concentration which give occupants more time to escape from their original compartments. However, the doubled corridor length increases the travel distance for occupants. Figure 4.33 shows the POD and evacuation routes for occupants in room 2 and 7 of the concrete building. Their evacuation routes are room 2--corridor 75 --stair 86--outside, and room 7--corridor 75--stairs 86--outside respectively. The longer travel time in the corridor causes a quick increase of the POD to $48 \%$ for the occupant in room No.2 and to $45 \%$ for the occupant in room 7 .

The fire department arrival does not seem to decrease the number of casualties because by the time of fire department arrival, occupants have already evacuated to the hazardous corridor and face the high probability of death. Once POD exceeds the threshold for injuries, occupants are assumed to be injured. Nobody is killed as the concentration of hot and toxic gases is controlled after the fire department arrives. Sprinkler systems can control the fire earlier and provide a safer evacuation environment. 


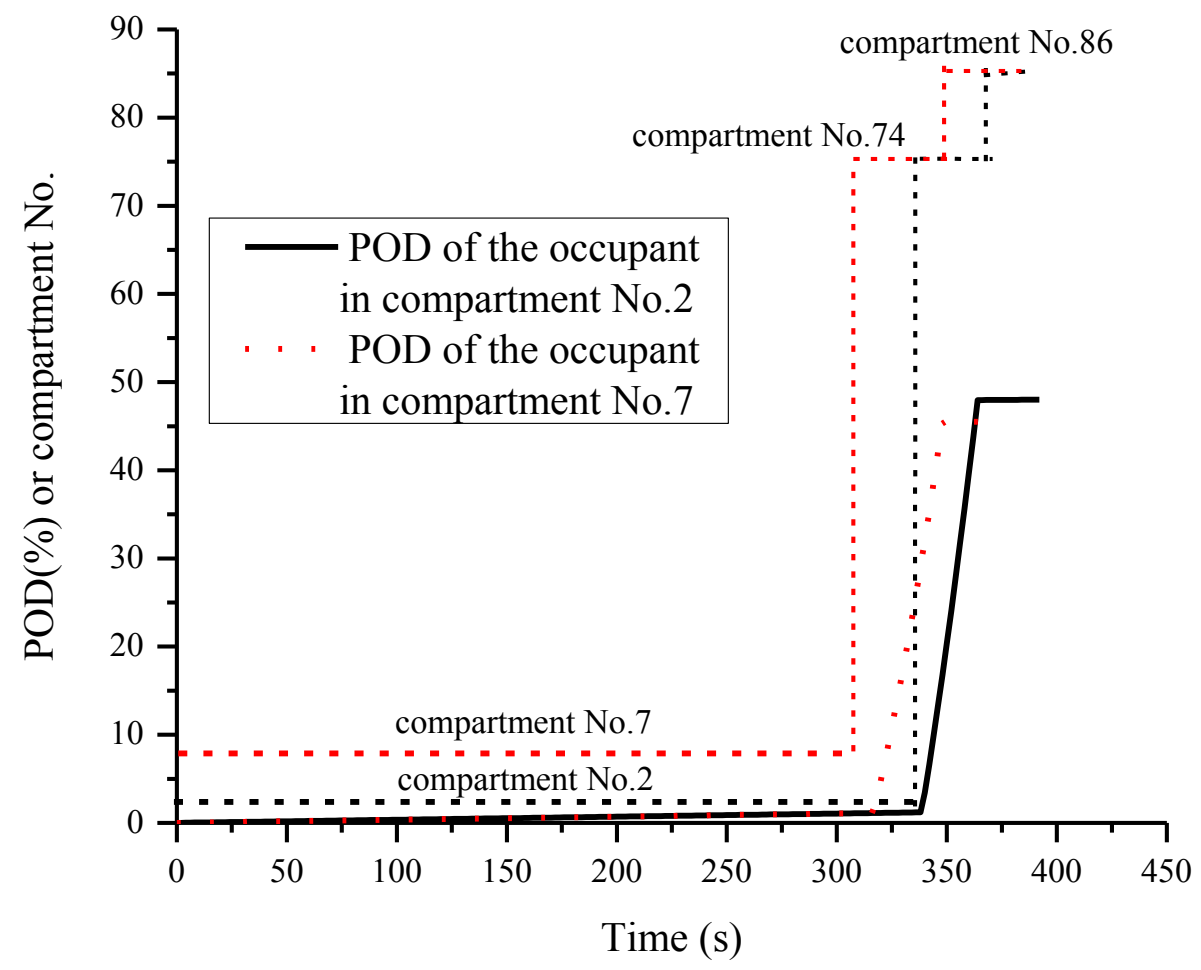

Figure 4.33 Probability of death and evacuation route for occupants

\subsection{Risk Analysis}

The risk to building occupants for all expected fire scenarios is calculated using equation

$$
R=\sum_{i=1}^{n}\left(P_{i} \times C_{i}\right)
$$

where, $\mathrm{n}$ is the total number of scenarios, $\mathrm{i}$ is the scenario counter, $P_{i}$ is the probability of scenario i, $C_{i}$ is the consequence of scenario i.

This equation produces the potential occupant life loss and potential economic loss per year. Calculation results are shown in Figure 4.34 and Figure 4.35 based on the sixteen 
scenarios for each design option.

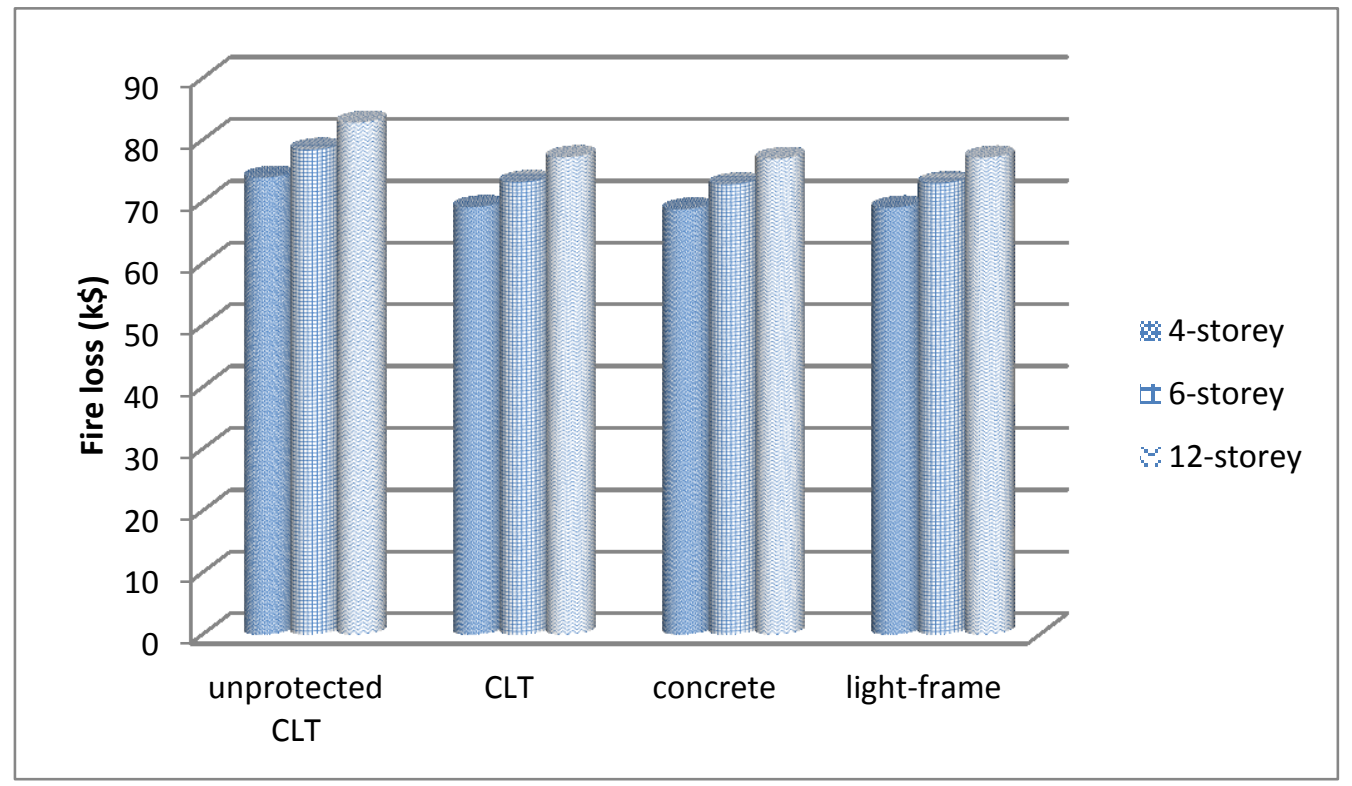

Figure 4.34 Expected fire losses in buildings with different heights and construction materials

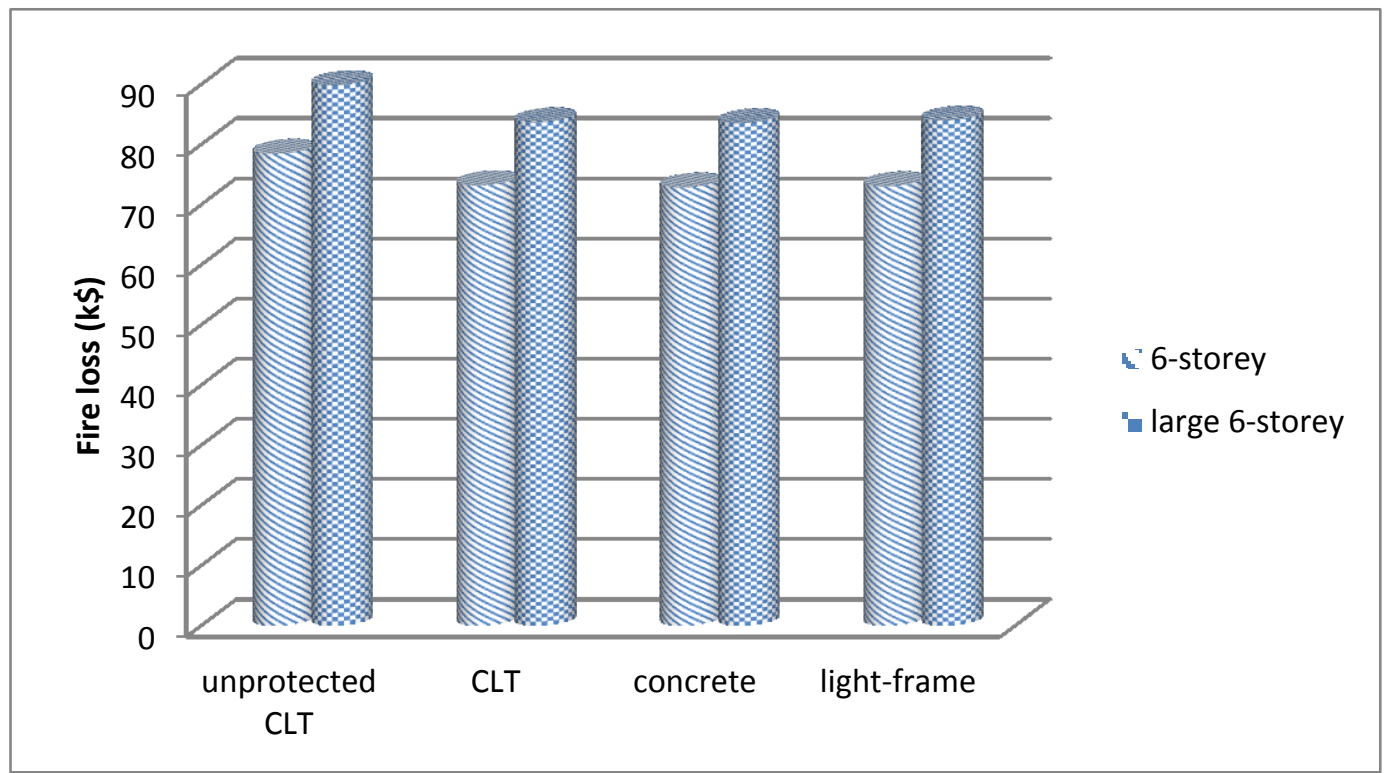

Figure 4.35 Expected fire losses in buildings with different floor sizes and construction materials

Figure 4.34 and Figure 4.35 show the risk of fire damages to the whole building when a fire occurs on the first floor. The results indicate that if the building is made of 
unprotected CLT, the expected losses are always larger. Taking the 6-storey building for example, the expected fire losses are calculated to be $\$ 78.4 \mathrm{k}, \$ 73.2 \mathrm{k}, \$ 72.8 \mathrm{k}$ and $\$ 73 \mathrm{k}$ respectively in concrete, unprotected CLT, CLT and light-frame constructions. This demonstrates that there is no difference in the risk of damages between non-combustible building and combustible buildings with gypsum board protection. When the building height increases to 12 storeys, the buildings pose a slightly greater risk than the 6-storey buildings and the difference is only around $\$ 4 \mathrm{k}$ indicating that a 12 -storey building with a 2 hour fire resistance rating performs the similar fire risk level as a 6-storey building with a 1 hour fire resistance rating. With the larger area, the expected fire losses increased by approximately $\$ 11 \mathrm{k}$ from those of the base-size 6-storey building. Considering the increased building costs, the expected fire damages do not rise greatly.

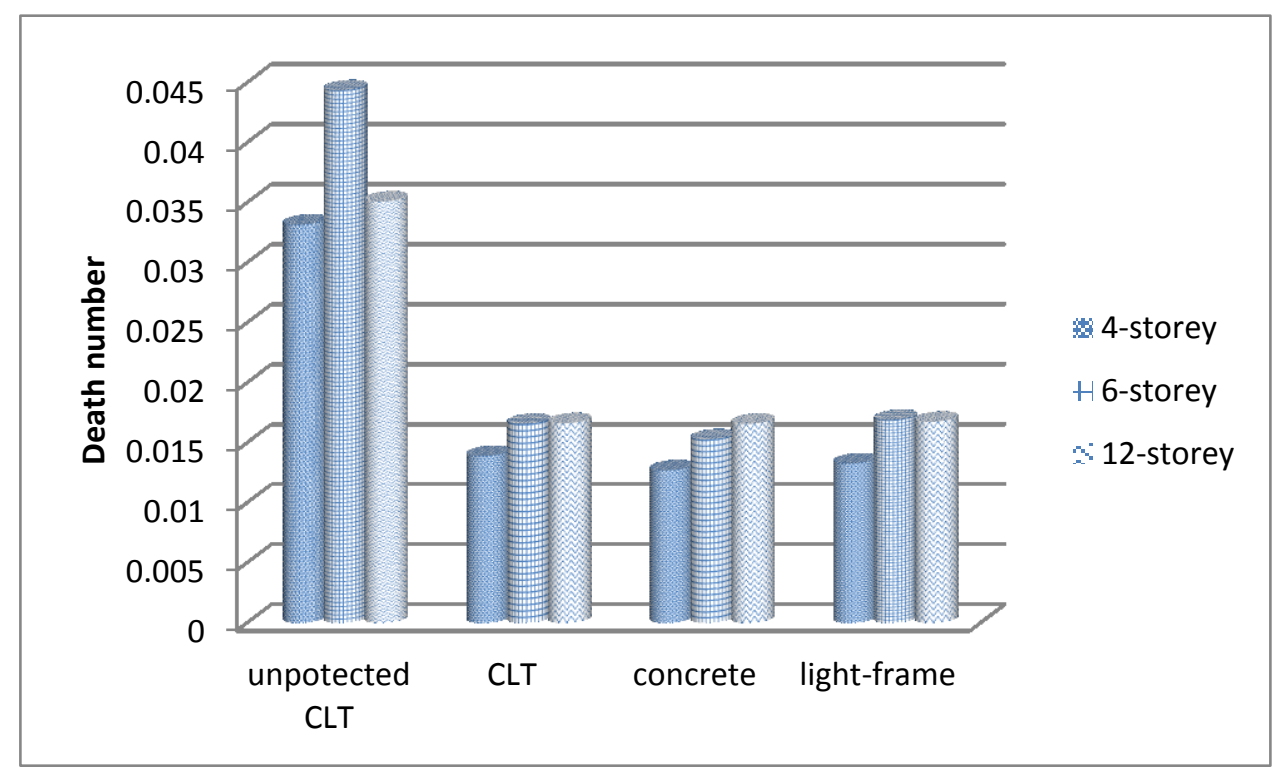

Figure 4.36 Expected number of deaths in buildings with different heights and construction materials 


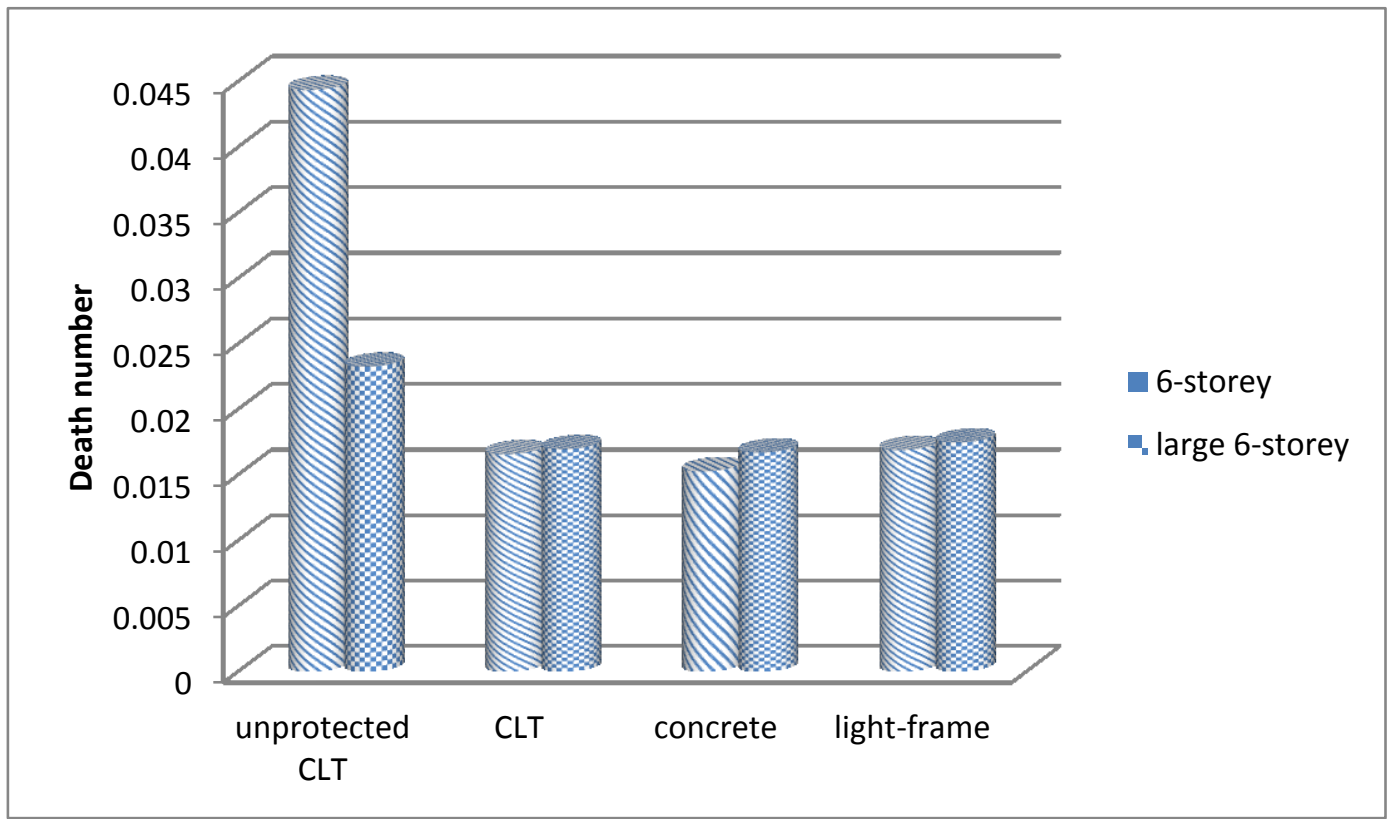

Figure 4.37 Expected number of deaths in buildings with different floor areas and construction

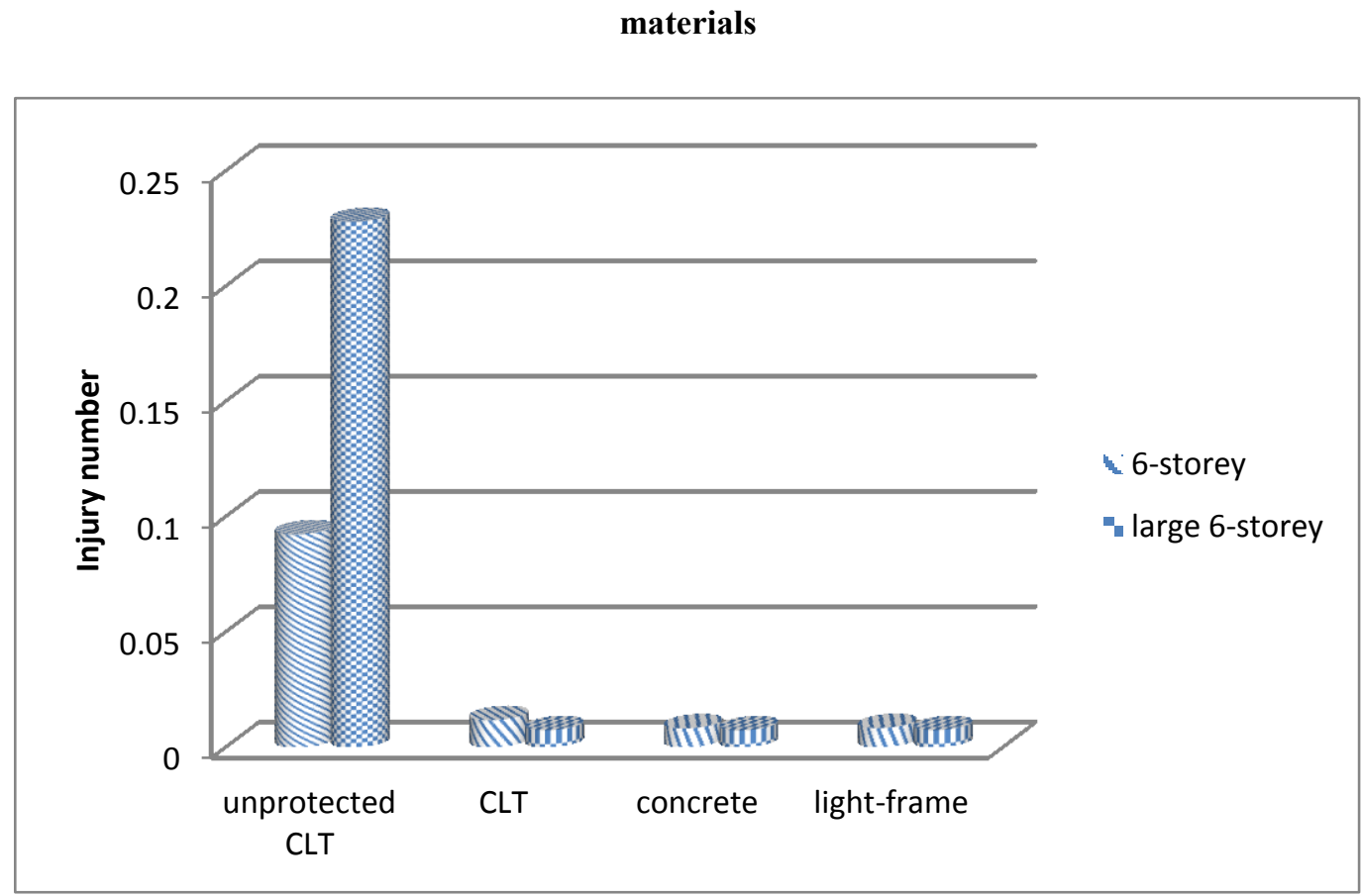

Figure 4.38 Expected number of injuries in buildings with different floor areas and construction

materials

Figure 4.36--Figure 4.38 show the expected number of death and injuries of the building 
based on all expected scenarios. Most casualties occur in the unprotected CLT buildings. When the combustible material is protected with gypsum boards, the expected number of deaths and injuries is very close to that of the non-combustible buildings. Increasing building heights and floor area does not increase the expected casualties. The reason is that the 12-storey building with a two hour fire resistance rating reduces the fire spread probability. Although the large size building reduces smoke concentration, the movement time is increased in the corridor causing an increase in expected casualties.

CUrisk calculates two risk parameters Excepted Risk to Life (ERL) and Fire Cost Expectation (FCE) to reflect risks to life safety and property damages.

ERL is the expected death frequency per year divided by the total population in the building, and it can be calculated using equation 4.3.

$$
E R L=\frac{F \sum_{i=1}^{n}\left(P_{i} \times N_{i}\right)}{P O P}
$$

where, $\mathrm{F}$ is the annual fire frequency for the building, $N_{i}$ is the number of death in scenario $i$, and POP is the number of occupants.

Similarly, the expected risk of injury (EROI) is calculated using equation 4.4.

$$
E R O I=\frac{F \sum_{i=1}^{n}\left(P_{i} \times M_{i}\right)}{P O P}
$$

where, $M_{i}$ is the number of injury in scenario $i$.

The Fire Cost Expectation (FCE) includes three parts: 1) fixed capital cost of the passive and active fire protection $\left.\left(\mathrm{COST}_{\text {Fixed }}\right) ; 2\right)$ the annual maintenance cost of the active fire protection systems $\left.\left(\mathrm{COST}_{\text {Maintain }}\right) ; 3\right)$ the expected annual fire losses as a result of all 
possible fire scenarios in the building $\left(\mathrm{COST}_{\mathrm{Loss}}\right)$. The expected annual fire loss is calculated using equation 4.5 .

$$
A F L=\operatorname{COST}_{\text {Loss }}=F \sum_{i=1}^{k} P_{i} E_{i}
$$

where, $E_{i}$ is the economic loss to the entire building in scenario $i$.

According to Ontario statistical data, the annual residential fire ignition frequency is 2.61 $\times 10^{-3}$ per unit [102]. Therefore, the annual fire frequency of the first floor which has 12 compartments is $3.132 \times 10^{-2}$. Table 4.6 and Table 4.7 list the Expected Risk to Life (ERL), and Expected Annual Fire Loss (AFL) for different design options.

Table 4.6 Values of ERL in different design options (person/year)

\begin{tabular}{|l|r|r|r|r|}
\hline & \multicolumn{1}{|l|}{ Concrete } & \multicolumn{2}{l|}{ Unprotected } & \multicolumn{2}{l|}{ CLT } & \\
\hline 4-storey & $1.4 \mathrm{E}-06$ & $3.6 \mathrm{E}-06$ & $1.5 \mathrm{E}-06$ & $1.4 \mathrm{E}-06$ \\
\hline 6-storey & $1.7 \mathrm{E}-06$ & $4.8 \mathrm{E}-06$ & $1.8 \mathrm{E}-06$ & $1.8 \mathrm{E}-06$ \\
\hline 12-storey & $9.0 \mathrm{E}-07$ & $1.9 \mathrm{E}-06$ & $9.0 \mathrm{E}-07$ & $9.0 \mathrm{E}-07$ \\
\hline 6-storey (large) & $1.8 \mathrm{E}-06$ & $2.5 \mathrm{E}-06$ & $1.8 \mathrm{E}-06$ & $1.9 \mathrm{E}-06$ \\
\hline
\end{tabular}

Table 4.7 Values of AFL in different design options (k\$)

\begin{tabular}{|l|l|l|l|l|}
\hline & Concrete & Unprotected & CLT & Light-frame \\
& CLT & & \\
\hline
\end{tabular}




\begin{tabular}{|l|r|r|r|r|}
\hline 4-storey & 2.1 & 2.3 & 2.2 & 2.2 \\
\hline 6-storey & 2.3 & 2.4 & 2.3 & 2.3 \\
\hline 12-storey & 2.4 & 2.6 & 2.4 & 2.4 \\
\hline 6-storey (large) & 2.6 & 2.8 & 2.6 & 2.6 \\
\hline
\end{tabular}

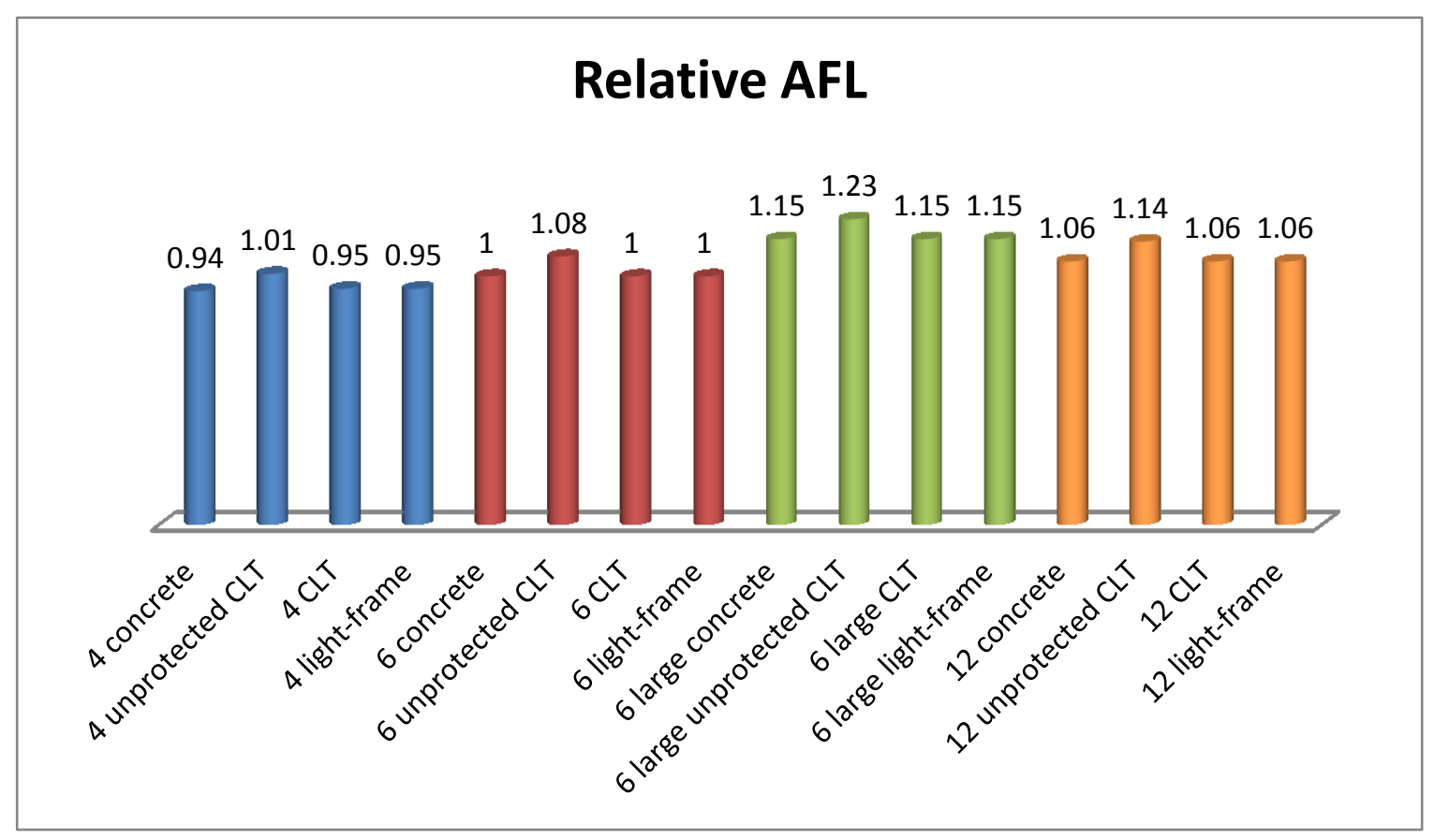

Figure 4.39 Relative FCE of sixteen building design options 


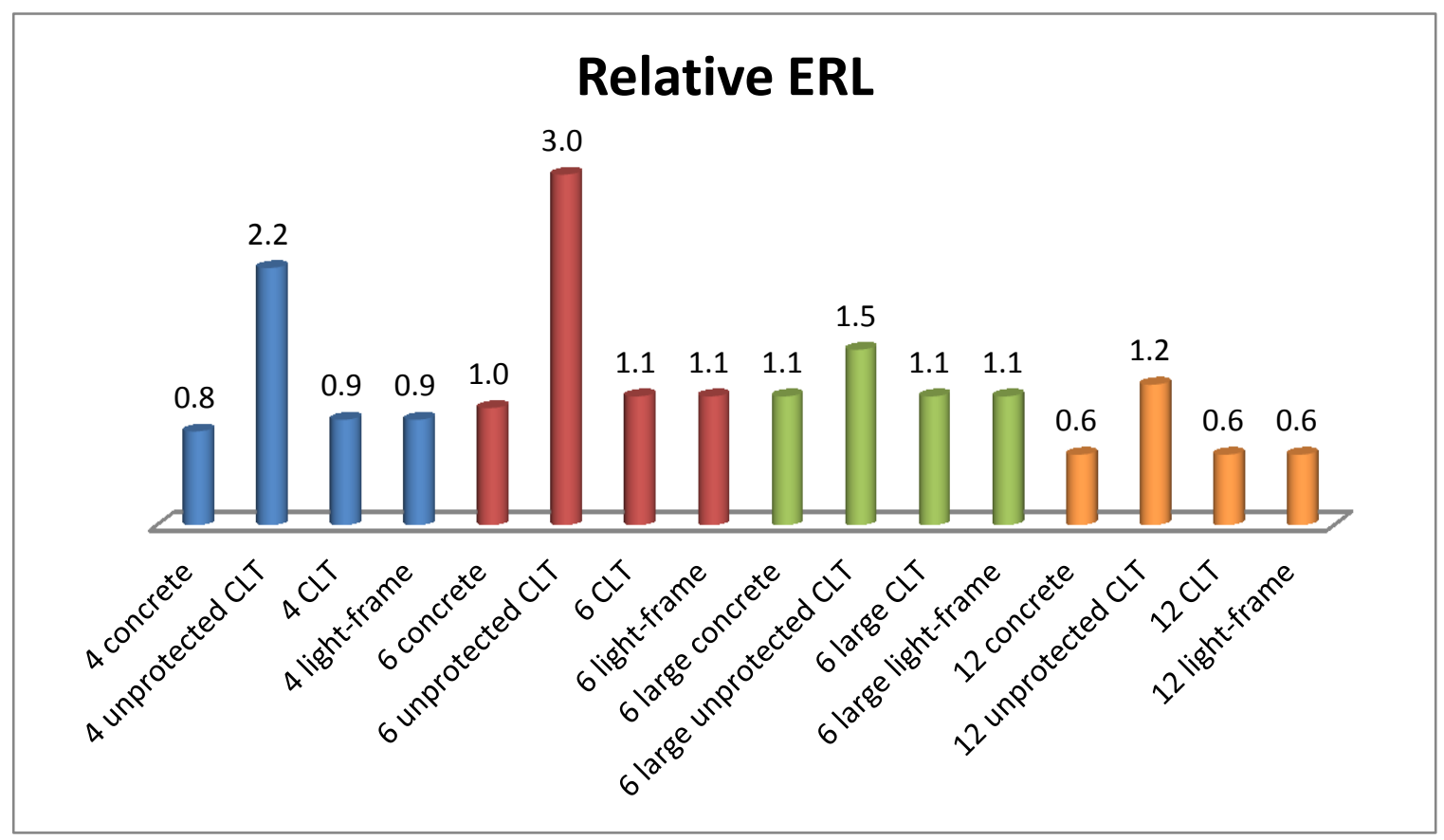

Figure 4.40 Relative ERL of sixteen building design options

Figure 4.39 and Figure 4.40 show the relative value of expected risk to life (ERL) and expected annual fire loss (AFL) of the sixteen proposed design options. This number is calculated by dividing them by the reference values of the 6-storey building made of concrete. These two figures provide an easy and intuitive way to present the risk levels in different design options.

The figures show that for any type of building designs unprotected CLT buildings have the highest expected annual fire loss (AFL) and expected risk to life (ERL), and that there is almost no difference between the values for non-combustible and combustible buildings with gypsum board protection. For example, the 4-storey unprotected CLT building has a higher relative ERL of 2.2 which is almost 2.5 times of that for the concrete and protected light-frame buildings. Increasing the floor area and building 
height results in a slight increase of the AFL, but does not increase the ERL. For example, the 12-storey protected combustible buildings have a relative AFL of 1.06 and a relative ERL of 0.6, and the large 6-storey protected combustible buildings have a relative AFL of 1.15 and a relative ERL of 1.1.

It should be noted that the assessment of the expected risk to life and property in the present case study is based on the present CUrisk model. CUrisk is undergoing further improvements, which may yield different results. Once completed more case studies will be conducted.

\subsection{Summary}

This chapter presented results of a case study using the fire risk analysis model CUrisk to predict the fire risk of sixteen design options incorporating different construction materials, building heights and floor areas.

The results show that unprotected CLT buildings have the most severe fires with longer fire duration and generate large quantities of combustion products. Non-combustible and combustible buildings with gypsum board protections perform similarly in terms of fire growth, time to flashover and duration of the fully developed phase. A faster decay phase is seen in the non-combustible building.

Active fire protection systems reduce significantly the fire risk in buildings. Detector systems including smoke and heat detectors and alarms provide a good performance by 
quickly identifying a developing fire and alerting occupants before extensive damage occurs. The fire department is also effective in controlling the fire and reducing fire losses and casualties in the building. Sprinkler systems have the best impact on fire risk. CUrisk is able to evaluate whether higher-rise and larger building would have the same fire risk as the 6-stroey building with one-hour fire resistance rating. Simulation results demonstrate that increasing the building height to 12 -storey does not increase risks and there is no increase in risk to life in a large-size 6-storey building. 


\section{Chapter: Conclusion}

\subsection{Conclusions}

As the interest in mid-rise wood-based buildings construction increased over the last few years, research on mid-rise building fire safety started to receive more and more attention. At Carleton University in Canada, a quantitative fire risk analysis computer model CUrisk is being developed to evaluate the fire performance of buildings. In this project, CUrisk has been applied to a series of case studies considering different building construction types, heights and floor areas. The main conclusions of this thesis are as follows.

1) Occupant Evacuation submodel comparison and application.

The CUrisk evacuation submodel is a probabilistic occupant evacuation model based on Monte Carlo methods. For model comparison, two other methods were selected: the Pathfinder evacuation model and SFPE analytical calculations. Case studies were performed by applying these methods to 6 scenarios, using a 4 -storey and a 6 -storey office building each with three different building areas. Results show that the total evacuation time produced by the CUrisk model for each scenario has a normal distribution with a small standard deviation. The mean values of the results do not differ significantly from the results of the other methods. The results showed that the main factor influencing evacuation times is the number of stairways rather than floor area. Increasing occupant load results in an increase of the evacuation time. 
2) Fire risk assessment in buildings of non-combustible frame and combustible construction.

The CUrisk model has the ability to perform risk analysis of non-combustible, light-frame timber, protected CLT and unprotected CLT buildings. The model results show that unprotected CLT structures contribute to fire duration and intensity. Non-combustible and protected combustible buildings perform similarly in terms of fire behavior such as growth, time to flashover and duration and the severity of the fully developed phase. A faster decay phase occurs in the non-combustible buildings. In general, fully-unprotected CLT building fires pose a significant risk to life and property. The predictions of CUrisk also demonstrate that active fire protection systems reduce fire risk in buildings. Sprinkler systems have the most impact on the fire safety minimizing the number of deaths and injuries and property damages. Detector systems are important in facilitating quick occupant evacuation.

3) Fire risk in higher-rise and larger buildings.

CUrisk was used to evaluate whether higher-rise and larger buildings would have the same fire risk as a 6-storey building with 1 hour fire resistance rating. Results demonstrated that increasing the building height to 12 storeys does not increase fire risks and that there is no substantial increase in fire risk in a larger size 6-storey building.

The study demonstrated that CUrisk can provide information on the consequences resulted from all possible fire scenarios in a building which can help engineers to 
evaluate building fire performance and design better solutions.

\subsection{Future Work}

Based on this thesis, some recommendations for future work are as follows.

1) Develop an integrated network evacuation model that integrates both fine and coarse methods. For example, some special structures like the fire floor can be divided into fine grids and other structures can be divided into coarse grids.

2) Consider occupants returning to their apartment if the exit route is dangerous in the Occupant Evacuation submodel. For example, in a fire evacuation occupants could go to upper floors or other safe compartments if the next evacuation route is blocked by the heavy smoke.

3) Use the CUrisk to model a mixed-construction building. For example, light-frame timber walls in conjunction with heavy timber floors.

4) Check the effects of fire loads, opening sizes, occupant response times, fire department response times and sprinklers response times (RTI) on the fire risk level.

5) Develop an interface for the input files of CUrisk. 


\section{Reference}

1. http://www.mcscs.jus.gov.on.ca/english/FireMarshal/MediaRelationsandResources/Fi reStatistics/OntarioFires/FireLossesCausesTrendsIssues/stats_causes.html

2. http:/globalnews.ca/news/1125586/death-toll-in-quebec-seniors-home-fire-raised-to$\underline{28 /}$

3. Leslie R.R.. "Fire Losses in Selected Property Classifications of Non-residential, Commercial and Residential Wood Buildings Part 1: Hotels/Motels and Care Homes for Aged". Fire and Materials, 2007, 31 (2), pp. 97-123.

4. Risk Guidance Note 37, "Fire Safety of Timber Frame Buildings". Mitsui Sumitomo Insurance Group.

5. Beck, V.R.. "Performance-based Fire Engineering Design and its Application in Australia," Fire Safety Science - Proceedings of the 5th International Symposium, International Association for Fire Safety Science, 1997, pp. 23.

6. Hadjisophocleous, G., Bénichou, N., Torvi, D.A., Reid, I.. "Evaluating Compliance of Performance-based Designs with Fire Safety Objectives", Proceedings of the 3rd International Conference on Performance-Based Codes and Fire Safety Design Methods, Lund, Sweden, , 2000, pp. 307.

7. Fraser-Mitchell, J.N.. "An Object-oriented Simulation (CRISP II) for Fire Risk Assessment", Fire Safety Science - Proceedings of the 4th International Symposium, International Association for Fire Safety Science, Ottawa, Canada, 1994, pp. 793-804.

8. Li, X., Zhang, X., Hadjisophocleous, G.. "Fire risk analysis of a 6-storey residential building using CUrisk". The $9^{\text {th }}$ Asia-Oceania Symposium on Fire Science and Technology. 2013, 62, pp.609-617.

9. Hadjisophocleous G., Fu, Z., Li, X.. Technical Report on CUrisk: A Fire Risk Analysis Model. Carleton University Internal Report, Ottawa, Canada. , 2011.

10. Bryan, J.N.. "Human Behaviour in Fire: The Development and Maturity of A Scholarly Study Area”. Fire and Materials, November 1999, 23 (6), pp. 249-253.

11. Wood P.G.. "The Behavior of People in Fires". Fire Research Note. 953. Fire Research Station: Borehamwood, 1972.

12. Sime, J.. "The concept of panic. Fires and Human Behaviour". Chichester, UK; John Wiley \& Sons. 1980, PP. 63-81.

13. Breaux, J., Canter, D., Sime, J.. "Psychological Aspects of Behaviour of People in Fire Situations". University of Surrey, Fire Research Unit, 1976.

14. Fruin, J.J.. "Pedestrian Planning Design”. New York: Metropolitan Association of Urban Designers and Environmental Planners, Inc., 1971.

15. Proulx, G. "Evacuation Time and Movement in Apartment Buildings". Fire Safety Journal, 1995, 24(3), pp. 229-246. 
16. Kuligowski, E.D., Peacock, R.D., Hoskins, B.L.. “A Review of Building Evacuation Models". Technical Note 1471. Fire Research Division Building and Fire Research Laboratory. National Institute of Standards and Technology (NIST). July 2005.

17. Gwynne, S., Galea, E.R., Owen, M., et al. "A Review of The Methodologies Used in The Computer Simulation of Evacuation from The Built Environment". Building and Environment, 1999, 34(6), pp.741-749.

18. Shi, L.*, Xie, Q.Y., Cheng, X.D., "Developing A Database for Emergency Evacuation Model”. Building and Environment, 2009, 44, pp.1724-1729.

19. Predtechenskii, V.M., Milinskii, A.I.. "Planning for Foot Traffic Flow in Buildings. Springfield". Virginia: U.S. Department of Commerce. 1978 (Original work published 1969)

20. Smith, R.A., "Density, Velocity and Flow Relationships for Closely Packed Crowds". Safety Science, 1995, 18, pp. 321-327.

21. Ando, K., Ota, H., Oki, T., "Forecasting The Flow of People”, (in Japanese), RRR, Railway Research Review, 1988, 45(8), PP.8-14.

22. Nelson, H.E., Mowrer, F.W.. "Emergency Movement". SFPE Handbook of Fire Protection Engineering. Quincy, Massachusetts; National Fire Protection Association. 2002, PP.367.

23. Proulx, G., Fahy, R.F.. "Account Analysis of WTC Survivors". Proceedings of the 3rd International Symposium on Human Behaviour in Fire, Belfast, UK. 2004, PP.203-214.

24. Qi, Z., H. B.M., L. DW., "Modeling and Simulation of Passenger Alighting and Boarding Movement in Beijing Metro Stations". Transportation Research Part C-Emerging Technologies, 2008, 16(5), pp. 635-649.

25. Cheung, C.Y. Lam, W.H.K., "Pedestrian Route Choices between Escalator and Stairway in Metro Stations". Journal of Transportation Engineering-Asce, 1998, 124(3): pp: 277-285.

26. Hokugo, A., Kubo, K., Murozaki, Y.. Experimental Study on Confluence of Two Foot Traffic Flows in Staircase. Journal of Architecture, Planning and Environmental Engineering, 1985. 358, pP. 37-43.

27. Yang L.Z.*, Rao, P., Zhu, K.J.. “Observation Study of Pedestrian Flow on Staircases with Different Dimensions under Normal and Emergency Conditions". Safety Science, 2012, 50, pp.1173-1179.

28. Takeichi, N., et al. "Characteristics of Merging Occupants in a Staircase". In Proceedings of the Eighth International Symposium on Fire Safety Science. 2005. China.

29. Nagatani, T., Nagai, R.. "Statistical Characteristics of Evacuation without Visibility in Random Walk Model". Physica a-Statistical Mechanics and Its Applications. Oct 2004, 341, pp.638-648. 
30. Isobe, M., Helbing, D., Nagatani, T.. "Experiment, Theory, and Simulation of the Evacuation of a Room without Visibility". Physical Review E. Jun 2004, 69(6), pp.066132-066140.

31. Nagai, R., Fukamachi, M., Nagatani, T.. "Evacuation of Crawlers and Walkers from Corridor through an Exit". Physica a-Statistical Mechanics and Its Applications. Jul 2006, 367, pp.449-460.

32. Kretz, T., Grunebohm, A., Kaufman, M., et al. "Experimental Study of Pedestrian Counterflow in a Corridor". Journal of Statistical Mechanics-Theory and Experiment. 2006, 10, PP. 10001.

33. Liu, S.B., Yang, L.Z., Fang, T., Li, J.. "Evacuation from a Classroom Considering the Occupant Density around Exits". Physica A: Statistical Mechanics and its Applications. 2009, 9(338), pp.1921-1928.

34. Shiwakoti, N., et al., "Enhancing the Safety of Pedestrians during Emergency Egress Can We Learn from Biological Entities?”. Transportation Research Record, 2009, (2137), pp. 31-37.

35. Schadschneider, A., Klingsch, W., et al., "Evacuation Dynamics: Empirical Results, Modeling and Applications". Encyclopedia of Complexity and Systems Science, Springer. 2009

36. Song, W.G., Zhang, J., Seyfried, A.. "Experimental Study of Pedestrian Flow in the Channel through Bottleneck". Pedestrian and Evacuation Dynamics. 2010, pp.455-463.

37. Helbing, D.. "Simulating Dynamical Features of Escape Panic". Nature, 2000, 407, pp. 487-490.

38. David, J.L., Helbing, D.. "Following the Crowd", Nature, 2000, 407, pp. 465-466.

39. Zhao, D.L, Yang L.Z, Li, J.. "Occupants' Behavior of Going with the Crowd Based on Cellular Automata Occupant Evacuation Model". Physica A: Statistical Mechanics and its Applications, 2008, 387(14), pp. 3708-3718.

40. Yang, L.Z., Zhao, D.L., Li, J., et al. "Simulation of the Kin Behavior in Building Occupant Evacuation Based on Cellular Automaton". Building and Environment, 2005, 40(3), pp. 411-415.

41. Ping, R., Yang, L.Z., "Analysis of Characteristics of Pedestrian Flow on Staircases during Fire". Journal of Applied Fire Science. Number, 2011-2012, Volume 21, pp. $123-142$.

42. Henderson, L.F.. "Sexual Differences in Human Crowd Motion". Nature, 1972, 240, PP.353.

43. Bryan, J. L.. "Behavioral Response to Fire and Smoke". SFPE Handbook of Fire Protection Engineering. Quincy, Massachusetts, National Fire Protection. Association. 2002, pp.315.

44. Zhao, C.M., Lo, S.M., Liu, M., et al. "A Post-fire Survey on the Pre-evacuation 
Human Behavior". Fire Technology, 2009, 45, pp.71-95.

45. Chu, G.Q.. "The Effect of Pre-movement Time and Occupant Density on Evacuation Time". Journal of Fire Sciences, May 2006, 3(24), pp.237-259.

46. Shen, T.S.. "Building Planning Evaluations for Emergency Evacuation". Phd thesis . April. 2003.

47. Proulx G. "Movement of People: The Evacuation Timing". SFPE Handbook of Fire Protection Engineering. Quincy, Massachusetts; National Fire Protection Association. 2002, PP.342.

48. Kisko, T.M., Francis, R.L.. "EVACNET+: A Computer Program to Determine Optical Evacuation Plans". Fire Safety Journal, 1985, 9, pp.211-220.

49. Shestopal, V.O, Grubits, S.J.. "Evacuation Model for Merging Traffic Flows In Multi-Room And Multi-Storey Buildings". In: Kashiwagi T, editor. Proceedings of the Fourth International Symposium on Fire Safety Science, 1994, pp.625-632.

50. Reiser, W.F.. "Simulating Human Behaviour in Emergency Situation". RINA, International Conference of Escape. Fire and Rescue, 19/20 Nov 1996.

51. Thompson, P., Marchant, E.. "A Computer Model for the Evacuation of Large Building Populations". Fire Safety Journal, 1995, 24, pp.131-148.

52. Owen, M., Galea, E.R., Lawrence, P.J., "The Exodus Evacuation Model Applied to Building Evacuation Scenarios". Journal of Fire Protection Engineering, 1996, 8(2), pp.65-86.

53. Bensilum, M., Purser, D.A.. "Gridflow: an Object-oriented Building Evacuation Model Combining Pre-movement and Movement Behaviours for Performance-based Design”. Fire Safety Science, 2003, 7, pp.941-952.

54. MacDonald, M.. "STEPS Simulation of Transient Evacuation and Pedestrian Movements User Manual". 2003.

55. Klupfel, H. Meyer, K.T.. "Characteristics of the PedGo Software for Crowd Movement and Egress Simulation". In 2nd International Conference in Pedestrian and Evacuation Dynamics. London, U.K.: University of Greenwich. 2003, pp. 331-340.

56. Lo, S.M., Fang, Z., Zhi, G.S.. "An Evacuation Model: the SGEpackage”. Fire Safety Journal, 2004, pp.169-190.

57. Ketchell, N., Cole, S. S., Webber, D. M.. "The EGRESS Code for Human Movement and Behaviour in Emergency Evacuation". In R.A.Smith \& J. F. Dickie, Engineering for Crowd Safety, London: Elsevier. 1994, pp. 361-370.

58. http://www.legion.com/

59. Deal, S.. "Technical Reference Guide for FPETool Version 3.2". (Rep. No. NISTIR 5486-1). Natl. Inst. Stand. Technol. 1995.

60. Lo, S.M. Fang, Z.. "A Spatial-Grid Evacuation Model for Buildings". Journal of Fire Sciences, 2000, 18, pp.376-394.

61. Helbing, D., Mulnár, P. "Social Force Model for Pedestrian Dynamics". Phys. Rev. E 51, 1995, pp.4282- 4286. 
62. Jin, T.. "Studies on Human Behavior and Tenability". In Fire Safety Science Proceedings of the Fifth International Symposium. 1997, pp. 3-21.

63. http://www1.toronto.ca/wps/portal/contentonly?vgnextoid $=7238036318061410 \mathrm{VgnV}$ CM10000071d60f89RCRD

64. http://www.woodworks.org/index.php?option=com content\&view $=$ article \&id $=148 \&$ $\underline{\text { Itemid }=222}$

65. The Standing Senate Committee on Agriculture and Forestry. "The Canadian Forest Sector: A Future Based On Innovation,” Evidence, 3rd Session, 40th Parliament. 2011.

66. Kruszelnicki, M.. "Rationalization of Life Safety-Code Requirements for Mid-RiseBuildings". Master thesis, Carleton University. April 5, 2011.

67. http://www.housing.gov.bc.ca/building/code questions/

68. City of Toronto. "Avenues \& Mid-Rise Buildings Study. Section 3: Performance Standards for Mid-Rise Buildings". May, 2010.

69. Ching, F.D., Winkel, S.R.. "Building Codes Illustrated: A Guide to Understanding the 2012 International Building Code", 4th Edition. Wiley, Jun 14, 2012.

70. National Building Code of Canada 2005. National Research Council Canada, Institute for Research in Construction Ottawa, On., 2005.

71. NFPA 101, Life Safety Code, National Fire Protection Association, Quincy, MA, 1994.

72. http://www.ehs.gatech.edu/fire/occupant load.pdf

73. Milke, J.A., Caro, T.C.. "A Survey of Occupant Load Factors in Contemporary Office Buildings". Journal of Fire Protection Engineering. January 1996, 8 (4), pp. 169-182.

74. Wong, L.T.. "Occupant Load Assessment for Old Rise Buildings". Architectural Science Review. 2003, 3(46), pp. 273-277.

75. Johnson, B.M., Pauls, J.. Report of a study carried out in conjunction with Canada national health and welfare as part of a pilot study on personnel movement in office buildings, National Research Council of Canada, division of building research, 1977.

76. ÖSTMAN, B.. "National Fire Regulations Limit the Use of Wood in Buildings". In Proceedings of WCTE 2004 Conference, Lahti, Finland, 2004.

77. Dientenburger, M.A., Grexa, O. White, R.H.. "Room-corner Tests of Wall Linings with 100/300 KW Burner". Proceedings of the 4th International Fire and Materials Conference, Washington, DC, 1995.

78. Note 4, Design for Fire Resistance. Civil and environmental engineering, Carleton Univeristy.2013.

79. Note 7, Fire Behavior of Materials. Civil and environmental engineering, Carleton Univeristy. 2013.

80. Geoff, T.. "Fire Safety Design of Multi-storey Timber Buildings". Journal of the New Zealand Timber Design Society. 2008, 2(16).

81. Lennon, T., Bullock, M.J., Enjily, V.. "The Fire Resistance of Medium-rise Timber 
Fame Buildings". In Proceeding of World Conference on Timber Engineering, Whistler, University of British Columbia, Canada, 2000.

82. Frangi, A., Fontana, M.. "Fire Performance of Timber Structures under Natural Fire Conditions". Fire Safety Science, 2005, 8, pp.279-290.

83. Thomas, G.C.. "The Feasibility of Multi-Storey Light Timber Frame Structures". University of Canterbury, Department of Civil Engineering Research Report 91-2, Christchurch, 1991.

84. Bénichou, N., Sultan, M.A.. "Fire Resistance Performance of Lightweight Wood-framed Assemblies". Fire Technology, 2000, 3(36), pp.184-219.

85. Gerard, R., Barber, D.. "Fire Safety Challenges Tall Wood Buildings". Fire Protection Research Foundation report. December, 2013.

86. Eurcodes 5: Design of Timber Structures, Part 1-2: Gereral-Structural Fire Design. EN 1995-1-2: 2004 (E).

87. Frangi, A., Fontana, M.. "Charring rates and temperature profiles of wood sections". Fire and materials. 2003, 2(27), pp. 91-102.

88. Collier, P.C.R.. "Charring Rates of Timber". BRANZ Study Report No.42 New Zealand: Building Research Association of New Zealand. 1992.

89. Frangi, A., Fontana, M., et al. "Fire Behaviour of Cross-Laminated Solid Timber Panels", Fire Safety Science, 2008, 9, pp. 1279-1290.

90. Nam, D., Hasemi,Y., Kagiya,K. Harada, T.. "Role of Initial Burning Objects in the Fire Growth in a Large Enclosure-Experiment for the Investigation of a Recent Timber Gymnasium Building Fire". Symposiums-International Association for Fire Safety Science. AOFST 6. 2004.

91. Feangi, A., Bochicchio, G., Ceccotti. A.. "Natural Full-Scale Fire Test on a 3 Storey XLam Timber Building". Proceedings of 10th World Conference on Timber Engineering, Miyazaki, Japan. 2008, pp.116.

92. Michael Mcmahom. Passive and Active Aspects of Fire Protection. New Straits Times (Malaysia), May 4, 2003, pp.5.

93. Zeeland, I.V., Hicks, S.. "Passive Fire Protection: Treatments and coatings can reduce surface flame spread or increase fire resistance, and add design flexibility in wood systems". Wood design and building, summer 2013, pp. 44-45.

94. Zhang, X., Li, X., Hadjisophocleous, G.. "A probabilistic occupant evacuation model for fire emergencies using Monte Carlo methods". Fire Safety Journal. Volume 58, May 2013, pp.15-24.

95. Thunderhead Engineering, Pathfinder: Technical Reference, Pathfinder 2012, Thunderhead Engineering, Manhattan, 2012.

96. Custrer, R.L.P., Meacham, B.J.. "Introduction to Performance-based Fire Safety". Society of fire protection engineers and national fire protection association. Quincy, MA, 1997. 
97. Xin, J., Huang C.H.. "Fire Risk Analysis of Residential Buildings based on Scenario Slusters and Its Application in Fire Risk Management”. Fire Safety Journal, 62. 2013, pp.72-78.

98. Life threat from fires - Guidance on the estimation of time available for escape using fire data. ISO 2001.

99. Bwalya, A.C., Sultan, M.A., Be'nichou, N.. "A Pilot Survey of Fire Loads in Canadian Homes". Research Report No 159. Institute for Research in Construction, National Research Council Canada, Ottawa, ON, Canada. 2004.

100.Bukowski, R.W.. "Estimates of the Operational Reliability of Fire Protection Systems", Journal of Fire Sciences, 24(3), 2006, pp.237-259.

101. U.S. Fire Administration/National Fire Date Center. "Structure Fire Response Times". Topical Fire Research Series, 6(7), 2006.

102.Gaskin, J., Yung, D... "Canadian and USA Fire Statistics for Use in the Risk-Cost Assessment Model". Institute for Research in Construction, Canada. 1993. 